LBNL-49095

\title{
Behavior of Capstone and Honeywell Microturbine Generators During Load Changes
}

\author{
Prepared By \\ Robert J. Yinger \\ Southern California Edison \\ Rosemead, California
}

July, 2001

The work described in this report was coordinated by the Consortium for Electric Reliability Technology Solutions, and funded by the Assistant Secretary of Energy Efficiency and Renewable Energy, Office of Power Technologies of the U.S. Department of Energy under Contract No. DE-AC03-76SF00098 and by the California Energy Commission, Public Interest Energy Research Program, under Work for Others Contract No. BG 99-396 (00). 


\begin{abstract}
This report describes test measurements of the behavior of two microturbine generators (MTGs) under transient conditions. The tests were conducted under three different operating conditions: grid-connect; stand-alone single MTG with load banks; and two MTGs running in parallel with load banks. Tests were conducted with both the Capstone 30-kW and Honeywell Parallon 75kW MTGs. All tests were conducted at the Southern California Edison /University of California, Irvine (UCI) test facility. In the grid- connected mode, several test runs were conducted with different set-point changes both up and down and a start up and shutdown were recorded for each MTG. For the stand-alone mode, load changes were initiated by changing load-bank values (both watts and VARs). For the parallel mode, tests involved changes in the load-bank settings as well as changes in the power set point of the MTG running in grid-connect mode. Detailed graphs of the test results are presented. It should be noted that these tests were done using a specific hardware and software. Use of different software and hardware could result in different performance characteristics for the same units.
\end{abstract}


Table of Contents

List of Tables

List of Figures 


\section{Introduction}

This report describes tests of the behavior of two microturbine generators (MTGs) under three different transient operating conditions: one MTG in "grid-connect" mode; one stand-alone MTG with load banks; and two MTGs running in parallel with load banks. Tests were conducted on both the Capstone 30-kW and Honeywell Parallon 75-kW MTGs.

For the grid-connect mode, several test runs were conducted with set-points changed up and down, and a start up and shutdown were recorded for each MTG. In the stand-alone mode, load changes were initiated by stepping load-bank values (both watts and VARs) up and down. For the parallel mode, tests involved stepping the load-bank settings up and down for the stand-alone unit as well as stepping the MTG running in grid-connect mode up and down.

The testing focused on the behavior of the MTGs during changes in load settings in both gridconnect and stand-alone modes. The tests also delineate the behavior of the MGTs' power electronics. Data from these tests can be used to evaluate the slow dynamic behavior of MTGs and to create models that could be used in studies of system simulations. These test results will be incorporated into current studies of distribution system impacts and of the microgrid concept.

MTG behavior was also assessed during start up and shutdown. Start-up and shutdown times could be of importance if MTGs units were used for grid support or in microgrids.

Parallel tests with two MTGs were performed to assess interactions between the units. One concern that has been expressed about the widespread use of MGTs is that these generators might have instabilities that would cause problems with neighboring units or other power electronic devices such as adjustable speed drives. Close observation of the operation of MTGs in parallel operation was intended to identify any such potential problems.

These tests were done using a specific hardware configuration and software version for each MTG available at the UCI test site. Use of different software and hardware could result in different performance characteristics for the same units. 


\section{Description of the Microturbine Tests}

\subsection{Test Site Description}

The testing was conducted at the Southern California Edison (SCE)/ University of California, Irvine (UCI) Test Facility. This outdoor site has four test bays with instrumentation for gas use and basic electrical monitoring. The site has a 100-psig natural gas supply (on-site gas compressor) and the ability to blend gas for lower Btu levels. In addition, heat dissipation facilities are available for testing of combined heat and power applications. The test facility is connected to the power grid a 480-VAC, three-phase, four-wire transformer rated at 400 amps. Because of this fairly stiff connection, voltage variations caused by the MTGs connected to the utility system are small or undetectable. The site is operated by two experienced part-time staff members who supervise routine testing and maintenance. Additional test equipment is available for special situations.

\subsection{MTG Descriptions}

The two MTGs that were tested are each composed of a high-speed microturbine with a permanent-magnet generator attached to the same shaft. The turbine uses a recuperator to help improve efficiency. Power is produced by the generator as high-frequency alternating current (AC). This variable-frequency AC is transformed to direct current (DC) and then converted to utility-grade $\mathrm{AC}$ by an inverter.

\subsubsection{The Capstone Micro Turbine}

The Capstone Micro Turbine Generator, Model 330, is composed of the following subassemblies: a fuel system; a turbogenerator; and a Digital Power Controller (DPC). It operates on high-pressure natural gas or low-pressure gas with optional gas compressor. The fuel control system for the high-pressure unit is based on a Smart Proportional Value (SPV). Fuel flow is controlled by the position of the SPV. Fuel flow for the low-pressure unit is controlled by a variable-speed gas compressor. The turbogenerator includes a compressor, recuperator, combustor, turbine, and generator. The rotating components are mounted on a single shaft supported by air bearings. The generator is cooled by the air flow into the microturbine. The output of the generator is variable-voltage, variable-frequency AC power. The shaft rotates at up to 96,000 RPM. During the microturbine's start up, the generator is used as the starter motor.

The DPC controls the microturbine operation and all power conversion functions. The DPC converts the variable-frequency power from the generator into grid-quality power (as defined by IEE 519) at 400-480 Volts, three-phase AC, 50/60 Hz). The variable-frequency power from the rotating generator is converted to constant-voltage DC that is then inverted to constant-frequency AC. During microturbine start up, the DPC operates as a variable-frequency drive supplying power to the turbine until sufficient power is available from the generator. Grid power is used to rotate the turbine during start-up and cool down. If the grid voltage and/or frequency fall outside a preset range, the turbine shuts down automatically. 
Microturbine Performance (High-pressure and low-pressure natural gas):

- Full Load Power

- Efficiency (LHV)

- Heat Rate (LHV)

Emissions (natural gas fuel):

- NOx

Other:

- Noise level

- Fuel flow (natural gas - HHV)

- Exhaust gas temperature

- Total exhaust energy

- Dimensions

- Weight

- Voltage
$30 \mathrm{~kW}$ (HP unit), $28 \mathrm{~kW}$ (LP unit) at ISO conditions, 59 degrees $\mathrm{F}$, sea level

$27 \%+/-2$ points (HP Unit), $26 \%+/-2$ points (LP Unit)

$12,600 \mathrm{Btu} / \mathrm{kWh}$ (HP Unit), 13,000 Btu/kWh (LP Unit)

$<9 \mathrm{ppmV} / 6.7 \mathrm{~g} / \mathrm{hr} / 0.0147 \mathrm{lb} / \mathrm{hr}$

65 dBA@10 meters

410,000 Btu/hr / 428,000 kj/hr

520 degrees $\mathrm{F} / 271$ degrees $\mathrm{C}$

$277,000 \mathrm{Btu} / \mathrm{hr} / 295,000 \mathrm{kj} / \mathrm{hr}$

(base@ 59 deg. F / 15 deg. C)

74.8" H x 28.1" W x 52.9" D

$1900 \mathrm{~mm} \mathrm{H} \mathrm{x} 714$ mm W x 1344 mm D

$1052 \mathrm{lbs} / 478 \mathrm{~kg}$

400 - 480 VAC, 3 phase, 4 wire wye or 3 wire wye,

ungrounded delta, $43 \mathrm{~A}$ max

The Capstone MTG is designed to operate at constant temperature for best efficiency and lowest emissions. The power output of the turbine is varied by changing the turbine speed. The ramping rate of the turbine is limited by flame stability in the combustor, according to Capstone engineers. The fastest possible start up from 0 to full load takes about 10 seconds. The current unit should be able to ramp from 0 to full load in about 30 seconds while in grid-connect mode and about 20 seconds while in stand-alone mode. Although the current unit cannot vary power factor while in grid-connect mode, new software available in 2001 will allow power factor adjustment. The current unit is not able to change from grid-connect to stand-alone mode without a complete shutdown. Work is being done to design the unit so it can make this transition without shutting down.

\subsubsection{The Honeywell Parallon Microturbine}

The Parallon microturbine operates much like the Capstone MTG. The Parallon's specifications include:

Microturbine Performance (with low-pressure natural gas):

- Full Load Power

- Efficiency (LHV)

Emissions (natural gas fuel):

- $\mathrm{NOx}\left(\right.$ at $15 \% \mathrm{O}_{2}$ )
$75 \mathrm{~kW}$ gross (not including the compressor load) at ISO conditions, 59 degrees F, sea level, +/- 0.75 PF

$27.5 \%$ not including gas compressor and transformer

$<50$ ppm full power 59 degrees $\mathrm{F}$, sea level 
Other:

- Noise level

- Fuel flow (natural gas)

- Cogeneration capacity

- Dimensions

- Weight

- Voltage
65 dBA@10 meters

$1000 \mathrm{f}^{3} / \mathrm{hr}$ or 9.5 Therms per hour

$90 \mathrm{~kW}$ thermal output (hot water), 338,000 Btu/hour

85 " H x 48" W x 92" D

$2163 \mathrm{~mm} \mathrm{H}$ x $1219 \mathrm{~mm} \mathrm{~W}$ x $2334 \mathrm{~mm} \mathrm{D}$

$2850 \mathrm{lbs} / 1295 \mathrm{~kg}$ without gas compressor

275 VAC, 3 phase, 3 wire ungrounded delta, other voltages/configurations available with transformer, $100 \mathrm{kVA}$ maximum, single phase operation must be balanced within $10 \%$

\subsection{Testing Chronology}

In June 1999, initial tests were conducted to characterize the operation of a 30-kW Capstone microturbine generator (with high-pressure gas feed) in grid-connect mode. Subsequent tests were run on the Honeywell Parallon 75-kW MTG. Table 1 shows the test dates and configurations.

Table 1. Test Dates and Configurations

\begin{tabular}{|l|c||}
\hline \multicolumn{1}{|c|}{ Test Configurations } & Date \\
\hline \hline Capstone 30 kW - Grid-connect mode & $6 / 22 / 1999$ \\
\hline Capstone 30 kW (Low-pressure Gas) - Grid-connect & $10 / 25 / 2000$ \\
\hline Honeywell Parallon 75 kW - Grid-connect & $12 / 20 / 2000$ \\
\hline Capstone 30 kW (Low-pressure Gas) - Stand-alone w/ Load banks & $3 / 20 / 2001$ \\
\hline Parallel Operation of Two Capstone 30 kW w/ Load Banks & $4 / 17 / 2001$ \\
\hline Honeywell Parallon 75 kW - Stand-alone w/ Load Banks & $5 / 2 / 2001$ \\
\hline Parallel Operation of Capstone 30 kW and Honeywell 75 kW w/ Load Banks & $6 / 20 / 2001$ \\
\hline \hline
\end{tabular}

\subsection{Data Collection}

Both microturbines can record operational parameters (temperatures, pressures, fuel usage, turbine RPM, internal voltages/currents, status, and many others). These data can be accessed with a computer or modem connected to an RS-232 port on the microturbine. To supplement these data, additional electrical instrumentation was installed for some of the tests.

\subsubsection{Capstone}

Data for the Capstone MTG were collected with a direct RS-232 connection from the MTG back panel plug to a laptop computer using Capstone's communications software. This software is a commercial package available from Capstone. The most rapid sampling permitted by the software was at two-second intervals. These data were recorded in the laptop's hard disk and then downloaded for analysis on Excel spreadsheet software. The cable required for this operation has nine-pin female connectors at both ends. See Table 2 for the pin connections. 
Table 2. Cable Pin Connections

\begin{tabular}{|l|c|c|c|c|c|c|c|c|c||}
\hline $\begin{array}{l}\text { Connector \#1 } \\
\text { Pin Number }\end{array}$ & 1 & 2 & 3 & 4 & 5 & 6 & 7 & 8 & 9 \\
\hline $\begin{array}{l}\text { Connector \#2 } \\
\text { Pin Number }\end{array}$ & 4 & 3 & 2 & $1 \& 6$ & 5 & 4 & 8 & 7 & NC \\
\hline
\end{tabular}

\subsubsection{Honeywell}

Data for the Honeywell MTG were collected through a direct RS-232 connection from the MTG front panel plug to a laptop computer using Honeywell ITGCMD software. The ITGCMD software is not a commercial package and is used mostly by Honeywell technicians for diagnostics and monitoring. This software allowed one-second interval samples of a large number of analog and status values that were stored on the laptop's hard disk. The recorded data files were downloaded from the laptop for analyses on Excel spreadsheet software. The cable required for this operation has a nine-pin female connector on one end and a nine- pin male connector on the other end. All connections are straight through (i.e. pins 2 to 2,3 to 3 , and so on).

\subsubsection{Amprobe DM-II}

The Amprobe DM-II is capable of recording electrical parameters down to one-second resolution for almost two hours. This instrument can be connected directly to a three-phase, four-wire, 480volt system. Current is measured through the use of clamp-on current transformers. Parameters are measured for each phase and in total and include voltage, current, real power, reactive power, and power factor. The data are recorded internally in the instrument and later downloaded to a computer through the RS-232 cable that is supplied. The data are in a form that can be input to an Excel spreadsheet for analysis. 


\section{Grid-Connect Testing}

\subsection{Test Setup}

For this set of tests, each microturbine was connected to the utility grid and operated in gridconnect mode. In this mode, a power set point is entered in the front panel of the MTG and the turbine generates only the selected amount of power regardless of the load on the system. A laptop computer, running the required software, was connected to the MTG, and data were recorded during the tests. The test setup is shown in Figure 1.

\section{Utility Grid}

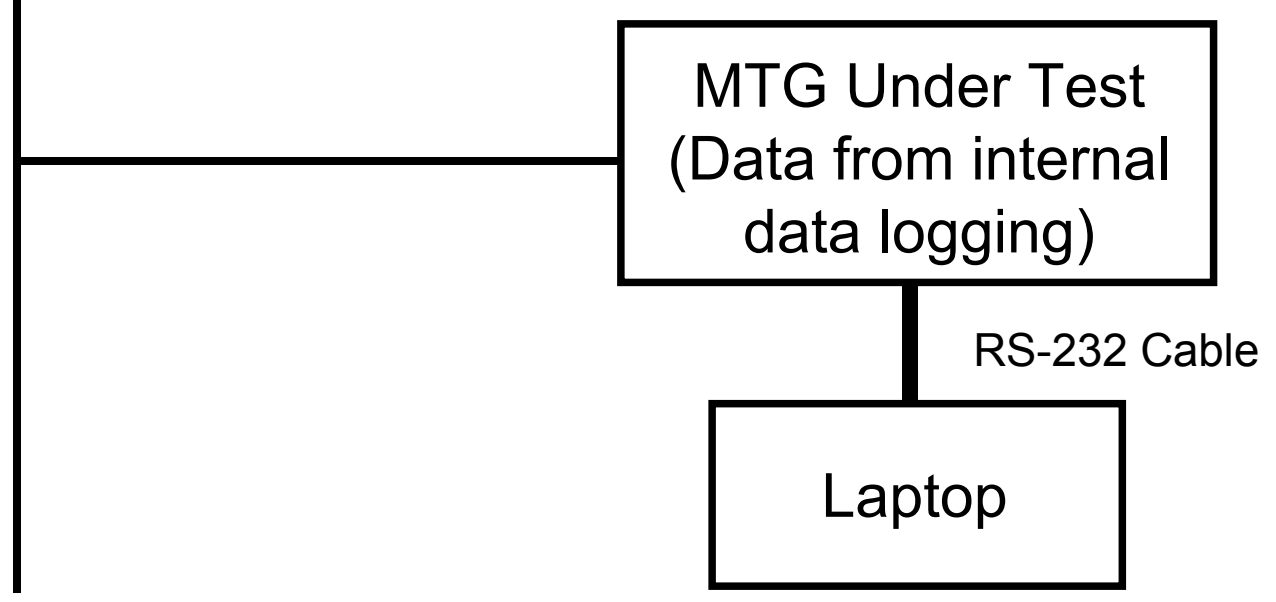

Figure 1. Grid-connect Test Setup

\subsection{Data Collection}

\subsubsection{Capstone}

For initial testing of the Capstone turbine in June 1999, a BMI 7100 took one-second snapshots of the MTG performance. Each snapshot was made up of 128 samples over one cycle. These snapshots were reduced through calculations to RMS values of voltage, current, and kVA. The results were plotted and analyzed for transition times. Also, at the beginning and end of each test, readings of turbine RPM, inverter current, inverter voltage, fuel-valve position, turbine exhaust temperature, inlet air temperature, and DC link voltage were manually recorded.

Data were recorded by the BMI 7100 and streamed to a laptop during the test. This data transfer caused problems during the tests; data were lost for tests 2, 3, 4, 7, 10, 15, and 16 .

After testing was completed, the raw data files were processed to retrieve the RMS voltages and currents for the graphs. Because the MTG was set to run at unity power factor, kVA and power 
were calculated as the product of currents and voltages. Each raw data file contained a series of high-speed samples of voltage and current taken every second during each test. These highspeed samples were reduced to an RMS number through use of Excel spreadsheets. The resulting RMS numbers were graphed for each test for which there were good data. This method of data collection proved to be both difficult and unreliable.

The second set of tests, conducted in October 2000, used Capstone software to connect directly to the MTG and collect all available internal data. This approach greatly simplified the data reduction phase of the testing. Data were communicated directly to the laptop and recorded in comma-delimited files. The fastest data-collection rate for this software package is two-second intervals. The only problem encountered was the software's tendency to occasionally record two entries with the same time stamp or to pause for a three-second interval rather than the two second interval that was intended. These problems are most likely caused by a slight difference in the microturbine and laptop clocks.

\subsubsection{Honeywell}

Data from the December 2000 tests of the Honeywell MTG were collected directly from the microturbine using Honeywell's ITGCMD software and an RS-232 connection. The fastest data sample rate that could be recorded with this software was one-second intervals. This rate was used in all the grid-connect tests. During the test setup, the option to record all internal data points was selected. The resulting file had too many columns to import properly into Excel, so each file had to be split into two parts and then imported. After columns were deleted that contained unused fields or data irrelevant to these tests, the two data sets were recombined in a single Excel spreadsheet, which was used for the final analyses. During later tests, care was taken to not include too many columns of data. Like the Capstone software, the Honeywell software occasionally recorded two entries with the same time stamp.

\subsection{Test Procedure}

Tests were conducted with several different steps up and down in decreasing in MTG output. The step change in MTG output was initiated by selecting the proper power level from the control panel on the front of the MTG. After each step change was entered on the front panel of the MTG, time was allowed for the power levels and temperatures to stabilize before the next step change was initialized. For the Capstone MTG, step tests were done for 18 percent, 36 percent, 54 percent, and 100 percent steps. For the Honeywell MTG, step tests were done for 20 percent 47-53 percent, and 100 percent steps. See the Analysis section below for more details. In addition to the step tests, a complete start-up and shutdown sequence was recorded for each MTG.

\subsection{Analysis}

\subsubsection{Capstone}

Two sets of tests were done for the Capstone MTG. The first set of tests was conducted on a high-pressure gas unit that could only operate in grid-connect mode. The second set of tests was 
conducted on a low-pressure gas unit that could operate in either grid-connect or stand-alone mode.

First Tests (June 22, 1999)

The results of measurements from the graphs for each test (Appendix A) are listed below. Because of normal variations in the output of the MTG and the way the power approached the final set point, it is difficult to get a completely accurate timing for each change. In Test \# 1, a loud pop was heard from the MTG, which appears to cause the data to be erroneous. Full power values vary with changing ambient air conditions.

The following table includes data for tests with increasing load:

Table 3 - Ramp-Up Tests

\begin{tabular}{||c||c|c|c|c|c||}
\hline \hline Test \# & Test Description & $\begin{array}{c}\text { Time for } \\
\text { Change } \\
(\mathrm{sec})\end{array}$ & $\begin{array}{c}\text { Load } \\
\text { Change } \\
(\mathrm{kW})\end{array}$ & $\begin{array}{c}\text { Transition } \\
\text { Time } \\
(\mathrm{sec} / \mathrm{kW})\end{array}$ & Comments \\
\hline \hline 5 & 5 to $10 \mathrm{~kW}$ & 12 & +5 & 2.4 & \\
\hline 6 & 10 to $15 \mathrm{~kW}$ & 15 & +5 & 3.0 & \\
\hline 8 & $20 \mathrm{~kW}$ to Full power & 11 & +3.8 & 2.9 & Full power $=23.8 \mathrm{~kW}$ \\
\hline
\end{tabular}

This table includes data from tests with decreasing load:

Table 4 - Ramp-Up Tests

\begin{tabular}{||c||l|c|c|c|l||}
\hline \hline Test \# & Test Description & $\begin{array}{c}\text { Time for } \\
\text { Change } \\
(\mathrm{sec})\end{array}$ & $\begin{array}{c}\text { Load } \\
\text { Change } \\
(\mathrm{kW})\end{array}$ & $\begin{array}{c}\text { Transition } \\
\text { Time } \\
(\mathrm{sec} / \mathrm{kW})\end{array}$ & \multicolumn{1}{||}{ Comments } \\
\hline \hline 1 & Full power to $20 \mathrm{~kW}$ & 26 & -2.8 & 9.3 & $\begin{array}{l}\text { Pop heard during this test } \\
\text { Full power }=22.8 \mathrm{~kW}\end{array}$ \\
\hline 11 & Full power to $20 \mathrm{~kW}$ & 13 & -4.8 & 2.7 & Full power $=24.8 \mathrm{~kW}$ \\
\hline 9 & Full power to $10 \mathrm{~kW}$ & 19 & -13.8 & 1.4 & Full power $=23.8 \mathrm{~kW}$ \\
\hline 17 & Full power to $0 \mathrm{~kW}$ & 30 & -24.9 & 1.2 & Full power $=24.9 \mathrm{~kW}$ \\
\hline 12 & 20 to $15 \mathrm{~kW}$ & 12 & -5 & 2.4 & \\
\hline 13 & 15 to $10 \mathrm{~kW}$ & 16 & -5 & 3.2 & \\
\hline 14 & 10 to $5 \mathrm{~kW}$ & 12 & -5 & 2.4 & \\
\hline
\end{tabular}

Second Tests (October 25, 2000)

During the second set of tests, there was some difficulty in running the turbine below $10 \mathrm{~kW}$, so some of the lower power output results may not be accurate. Also, because of the problems at low power, several turbine shutdowns and start ups were recorded. The low-power problem was not observed during the earlier testing done in 1999 and described above.

From the graphs of the MTG output (Appendix B), turbine ramping times were determined. These times are shown in Table 5 below. 
Table 4 - Ramp-Up Tests

\begin{tabular}{||c|c|c|c|c||}
\hline $\begin{array}{c}\text { Start Load } \\
(\mathbf{k W})\end{array}$ & End Load (kW) & $\begin{array}{c}\text { Percent } \\
\text { Change }\end{array}$ & $\begin{array}{c}\text { Time to Change } \\
\text { Load (sec) }\end{array}$ & $\begin{array}{c}\text { Transition Time } \\
(\mathbf{s e c} / \mathbf{k W})\end{array}$ \\
\hline \hline Full & 25 & 18 & 10 & 2 \\
\hline 25 & 20 & 18 & 12 & 2.4 \\
\hline 20 & 15 & 18 & 12 & 2.4 \\
\hline 15 & 10 & 18 & 22 & 4.4 \\
\hline 10 & 5 & 18 & 28 & 5.6 \\
\hline 5 & 0 & 18 & 36 & 7.2 \\
\hline 0 & 5 & 18 & 38 & 7.6 \\
\hline 5 & 10 & 18 & 22 & 5.4 \\
\hline 10 & 15 & 18 & 26 & 3.2 \\
\hline 15 & 20 & 18 & 18 & 2.8 \\
\hline 20 & 25 & 18 & 14 & 1.6 \\
\hline 25 & Full & 18 & 8 & 1.6 \\
\hline Full & 20 & 36 & 16 & 1.2 \\
\hline 20 & 10 & 36 & 12 & 4.4 \\
\hline 10 & 0 & 36 & 44 & 3.8 \\
\hline 0 & 10 & 36 & 38 & 4.2 \\
\hline 10 & 20 & 36 & 42 & 1.2 \\
\hline 20 & Full & 36 & 12 & 3.5 \\
\hline Full & 15 & 54 & 18 & 2.5 \\
\hline 15 & 0 & 54 & 52 & 1.1 \\
\hline 0 & 15 & 54 & 38 & 1.7 \\
\hline 15 & Full & 54 & 16 & 1.6 \\
\hline Full & 0 & 100 & 50 & \\
\hline 0 & Full & 100 & 49 & \\
\hline
\end{tabular}

As can be seen from the table, the ramp-up and ramp-down times are similar. Because of normal variations in the output of the MTG and the way the power approaches the final set point, it is difficult to get a completely accurate timing for each change. An examination of the data from earlier tests done in 1999 shows that the response of the newer unit is somewhat slower than the older unit. This is most noticeable when the MTG is operating at low power output. See the comparisons in Table 6 below. 
Table 6 - Differences Between the 1999 and 2000 Tests

\begin{tabular}{||c|c|c|c|c||}
\hline $\begin{array}{c}\text { Start Load } \\
(\mathbf{k W})\end{array}$ & End Load (kW) & $\begin{array}{c}\text { Time to Change } \\
\text { Load (sec) - Old } \\
\text { Unit }\end{array}$ & $\begin{array}{c}\text { Time to Change } \\
\text { Load (sec) - New } \\
\text { Unit }\end{array}$ & $\begin{array}{c}\text { Difference } \\
\text { (New - Old) }\end{array}$ \\
\hline \hline 5 & 10 & 12 & 22 & 10 \\
\hline 10 & 15 & 15 & 26 & 11 \\
\hline 20 & Full & 11 & 12 & 1 \\
\hline Full & 20 & 13 & 16 & 3 \\
\hline 20 & 15 & 12 & 12 & 0 \\
\hline 15 & 10 & 16 & 22 & 6 \\
\hline 10 & 5 & 12 & 28 & 16 \\
\hline Full & 0 & 30 & 50 & 20 \\
\hline
\end{tabular}

During a step down in the MTG power output, several characteristics were seen. First, when the power reduction command was entered, there was a small rise in the MTG output power (1 to 2 $\mathrm{kW}$ ) as turbine speed smoothly decreased. As the MTG reached the new power level, turbine speed stabilized at a lower level. There was also a very small momentary rise (1 to 2 volts) in the DC Bus voltage, after which the voltage returned to 760 volts DC. The turbine exit temperature decreased slightly when the MTG output was at higher levels ( $15 \mathrm{~kW}$ to full power), probably because of an increase in turbine air flow. By contrast, the turbine exit temperature began a steady rise following the step-down in power at lower levels $(<10 \mathrm{~kW})$. This rise was on the order of 50 degrees $\mathrm{C}$.

During a step up in the MTG power output, the turbine shaft speed increased quickly and peaked when power reached the new setting. As turbine speed increased, DC link voltages increased from 1 to $3 \mathrm{VDC}$; these values then settled back to 760 volts. Turbine exit temperature dropped when the step change was entered and then settled at a lower temperature than before the step. When the new operating level was established, the turbine stabilized at a higher speed, and turbine exhaust temperature settled at about 600 degrees $\mathrm{C}$. The only exception to this pattern was when the turbine was operating at power levels lower than $10 \mathrm{~kW}$; under these conditions, the turbine exit temperature climbed to as high as 700 degrees $\mathrm{C}$.

During all of the ramping tests, line voltages, current injected into each phase, and per-phase power were recorded. In all cases the currents and powers were well balanced. Phase voltages were also well balanced, typically differing by less than 2 volts. This behavior is as expected because the inverter operates as a current source while the MTG is in grid-connect mode.

Several MTG shutdown sequences were captured because of the tripping of the MTG at low power level. The complete shutdown sequence from the time the turbine was tripped to turbine stop was 10 minutes and 37 seconds. The majority of this time was spent in the cool-down state. during which the turbine was driven at 45,000 RPM for almost 10 minutes. The timing and sequence of the shutdown are shown in Table 7 below. 
Table 7 - Shutdown Sequence for Capstone 28-kW MTG

\begin{tabular}{||c|c|l||}
\hline MTG State & $\begin{array}{c}\text { Time of Transition } \\
\text { to Next State }\end{array}$ & \multicolumn{1}{||}{ Events } \\
\hline \hline Unit on & $14: 46: 09$ & Unit running \\
\hline Trip & $14: 46: 15$ & Unit trip, start power ramp-down \\
\hline Fuel off & $14: 46: 30$ & Shut off fuel to MTG, complete power ramp-down \\
\hline Cool down & $14: 56: 21$ & Cool down unit at 45,000 RPM \\
\hline Spin down & $14: 56: 35$ & Turbine spins down to stop \\
\hline Turn off & $14: 56: 46$ & Power to DC link and AC input off \\
\hline Unit off & & Unit stopped \\
\hline
\end{tabular}

MTG start up was captured with data taken at two-second intervals. The complete start sequence from front panel initiation to full power output was two minutes and four seconds. Because the MTG had only been shut down a short time (about two minutes), the warm-up period might have been shorter than it would have been if the unit was cold at the start. The timing and sequence of the start are shown in Table 8 below.

Table 8 - Start-up Sequence for Capstone 28-kW MTG

\begin{tabular}{||l|c|l||}
\hline MTG State & $\begin{array}{c}\text { Time of Transition } \\
\text { to Next State }\end{array}$ & \multicolumn{1}{||}{ Events } \\
\hline \hline Unit off & $14: 58: 12$ & Unit stopped \\
\hline Spin unit & $14: 58: 15$ & Power to DC link, spin turbine to 25,000 RPM \\
\hline Wait & $14: 58: 36$ & Stabilize MTG \\
\hline Fuel on & $14: 58: 47$ & Turn on fuel and ignite, ramp to 45,000 RPM \\
\hline Warm up & $14: 59: 40$ & Warm up MTG \\
\hline Ramp & $15: 00: 16$ & Ramp up power to full power \\
\hline Unit on & & Unit running \\
\hline
\end{tabular}

\subsubsection{Honeywell}

From the graphs of the MTG output (Appendix C), turbine ramping times were determined. These times are shown in Table 9 below. 
Table 9 - Ramping Times for Honeywell 75-kW MTG

\begin{tabular}{||c|c|c|c|c||}
\hline $\begin{array}{c}\text { Start Load } \\
(\mathbf{k W})\end{array}$ & $\begin{array}{c}\text { End Load } \\
(\mathbf{k W})\end{array}$ & $\begin{array}{c}\text { Percent } \\
\text { Change }\end{array}$ & $\begin{array}{c}\text { Time to Change } \\
\text { Load (sec) }\end{array}$ & $\begin{array}{c}\text { Transition Time } \\
(\mathbf{s e c} / \mathbf{k W})\end{array}$ \\
\hline \hline 75 & 60 & 20 & 14 & 0.93 \\
\hline 60 & 45 & 20 & 16 & 1.07 \\
\hline 45 & 30 & 20 & 11 & 0.73 \\
\hline 30 & 15 & 20 & 13 & 0.87 \\
\hline 15 & 0 & 20 & 14 & 0.93 \\
\hline 0 & 15 & 20 & 17 & 1.13 \\
\hline 15 & 30 & 20 & 19 & 1.27 \\
\hline 30 & 45 & 20 & 18 & 1.20 \\
\hline 45 & 60 & 20 & 17 & 1.13 \\
\hline 60 & 75 & 20 & 17 & 1.13 \\
\hline 75 & 40 & 47 & 33 & 0.94 \\
\hline 40 & 0 & 53 & 36 & 0.90 \\
\hline 0 & 40 & 53 & 39 & 0.98 \\
\hline 40 & 75 & 47 & 36 & 1.03 \\
\hline 75 & 0 & 100 & 64 & 0.85 \\
\hline 0 & 75 & 100 & 149 & 0.99 \\
\hline 75 & 0 & 100 & 67 & 1.89 \\
\hline 0 & 75 & 100 & 142 & \\
\hline
\end{tabular}

As can be seen in the table, ramp-up times are typically longer than the ramp-down times by several seconds. This is probably because of limitations on the increase in turbine exit temperature. This effect is most pronounced in the ramping tests between 0 and 10 but also shows up in the tests with 20- and 47-53-percent step changes. Another characteristic, which can be seen in the curves for the 0 - to $75-\mathrm{kW}$ ramp test, is that the output power increase flattens out for several seconds before ramping to full power. Initially this effect appeared to be caused by limits on turbine exit temperature, but closer examination of the charts shows that the turbine exit temperature goes even higher after the output power reaches $75 \mathrm{~kW}$. The limiting factor seems to be turbine speed and DC link voltage. Both of these parameters reach peak values at the same time that the output power reaches a plateau. Then, as output power continues to rise, both turbine speed and DC link voltage decrease until a stable operating point is reached. Another important feature seen in the ramping charts is the zigzag pattern of the turbine speed and DC link voltage at low and zero power. This is caused by air being bypassed in the turbine for cooling (which was accompanied by a distinctive sound from the MTG).

During a step down in MTG power output, several characteristics could be seen. First, when the power reduction command was entered, there was an immediate rise in the DC link voltage (15 to 20 volts), followed shortly by a rise in the turbine shaft speed (1,000 to 1,500 RPM). The turbine exit temperature also decreased because of increased air flow and decreased fuel input. As the MTG reached the new power level, turbine speed stabilized at a lower level, as did turbine exit temperature. The DC link voltage reduced to about 500 volts and went no lower. 
During a step up in the MTG power output, a slightly different set of circumstances prevailed. When the output increase command was entered, the turbine shaft speed and DC link voltage both increased quickly and peaked when power reached the new setting. DC link voltages increased from 30 to $50 \mathrm{VDC}$ as turbine speed increased from 3,000 to 13,000 RPM. When the new operating level was established, the turbine speed and DC link voltage levels decreased to steady-state levels for that power output. The only exception to this pattern was when the turbine speed reached its maximum point as discussed above.

During all of the ramping tests, the current injected into each phase was recorded as equal in magnitude. This is as expected because the inverter operates in current source mode while the MTG is in grid-connect mode. The voltages in all three phases were also recorded as exactly equal. Those measurements are questionable. A note in the software documentation indicates that the current and voltage values are estimates, so there is insufficient information to verify these values.

An MTG shutdown sequence was captured with data taken at one-second intervals. The complete shutdown sequence from the time the key was turned off to turbine stop was about eight minutes. The data recorded did not include the first few seconds of the shutdown sequence because the record function was not activated in time. The timing and sequence of the shutdown are shown in Table 10 below.

Table 10 - Shutdown Sequence for Honeywell MTG

\begin{tabular}{||c|c|l||}
\hline $\begin{array}{c}\text { MTG } \\
\text { State }\end{array}$ & $\begin{array}{c}\text { Time of } \\
\text { Transition to } \\
\text { Next State }\end{array}$ & \\
\hline \hline & xxxxx & Shutdown initiated \\
\hline 8 & $14: 09: 19$ & Power is ramped down from $75 \mathrm{~kW}$ to about 1 kW \\
\hline 8 & $14: 11: 13$ & Turbine and recuperator are cooled while grid connected \\
\hline 9 & $14: 15: 20$ & Fuel is shut off; cool down sequence; and turbine slows to a stop \\
\hline 9 & $14: 16: 20$ & MTG controls shutdown \\
\hline 0 & & MTG off \\
\hline
\end{tabular}

An MTG start up was captured with data taken at one-second intervals. The complete start sequence from key turn to full power output was six minutes and 21 seconds. Because the MTG had only been shut down a short time (about five minutes), the warm-up period might have been shorter than it would have been if the unit had been completely cold at the start. The timing and sequence of the start are shown in Table 11 below. 
Table 11 - Start-up Sequence for Honeywell MTG

\begin{tabular}{||c|c|l||}
\hline $\begin{array}{c}\text { MTG } \\
\text { State }\end{array}$ & $\begin{array}{c}\text { Time of } \\
\text { Transition to } \\
\text { Next State }\end{array}$ & \\
\hline \hline 0 & $14: 21: 15$ & MTG off \\
\hline 1 & $14: 22: 33$ & Self test, purge, and charge DC link \\
\hline 2 & $14: 22: 44$ & Spin turbine to about 35,000 RPM \\
\hline 3 & $14: 22: 54$ & Turn on fuel, ignite combustor, and spin turbine to 50,000 RPM \\
\hline 4 & $14: 24: 04$ & Warm up MTG \\
\hline 5 & $14: 27: 36$ & Put MTG on line and ramp up to 75 kW \\
\hline Full & & MTG reaches full power \\
Power & & \\
\hline
\end{tabular}

\subsection{Observations/Conclusions}

Both microturbines were able to operate in grid-connect mode and follow the load changes input on the front panels as long as load settings were maintained within the specifications for the MTG.

\subsubsection{Capstone}

Based on the tests conducted for the Capstone MTG, we highlight the following observations and conclusions:

- The transition times during power increase and decrease were similar but much faster when the MTG power output was above $10 \mathrm{~kW}$.

- At higher load settings, step changes were accomplished at a rate of 1.2 to 3.6 seconds per $\mathrm{kW}$. At the lower load settings, the step changes moved at 4.4 to 7.6 seconds per $\mathrm{kW}$ during the second set of tests of this microturbine. This slower response at low loads is a result of unstable operation of the MTG at power levels below $10 \mathrm{~kW}$. This behavior was not observed in the original turbine tested in 1999.

- Most of the transition times measured in the October 2000 tests are somewhat slower than those measured for the unit tested in 1999.

This microturbine, as it was configured for this test, would not be able to react to quick load changes in the electrical system as would be required in a microgrid. It appears to be designed to generate at a specific set point with infrequent changes. Control changes could be made so that this unit could react more quickly; the range of allowed turbine ramping rates could be increased, or stored energy could be placed at the DC link portion of the power conversion equipment. Tests of a modified turbine would be useful to prove that these two possibilities are viable. This microturbine is also unsuitable for microgrid operation because it uses a line commutated inverter. This inverter means that the unit cannot control voltage or run in an isolated fashion without some other source of voltage and frequency control.

\subsubsection{Honeywell}


Based on the tests conducted on the Honeywell MTG, we highlight the following observations and conclusions:

- The transition times during power decrease were about 0.9 to 1 second per $\mathrm{kW}$ with the transition times during power increase being slightly slower (about 1.1 to 1.2 seconds per $\mathrm{kW})$.

- When the MTG was ramped from 0 to $75 \mathrm{~kW}$ the rate was about two seconds per $\mathrm{kW}$. This slower transition is a result of power increases leveling off at about $68 \mathrm{~kW}$ for several seconds while the turbine speed decreased before ramping resumed.

- The MTG operation was stable at all load levels. 


\section{Stand-alone Testing}

\subsection{Test Setup}

The second set of tests of the Capstone and Honeywell microturbines was designed to record the behavior of each MTG operated in stand-alone mode connected to load banks. These tests used Four Avtron load banks were used; two had a capacity of $55.5 \mathrm{~kW}$ each and the other two had a capacity of $40.5 \mathrm{kVAR}$ reactive load each. Approximately 60 feet of cable joined the turbines and load banks (30 feet of \#6 and 30 feet of 2/0). For these tests, data from the MTGs' internal monitoring were collected with a laptop computer running the required software. In addition, electrical data were collected at the load banks with the Amprobe data logger. The test setup is shown in Figure 2 below.

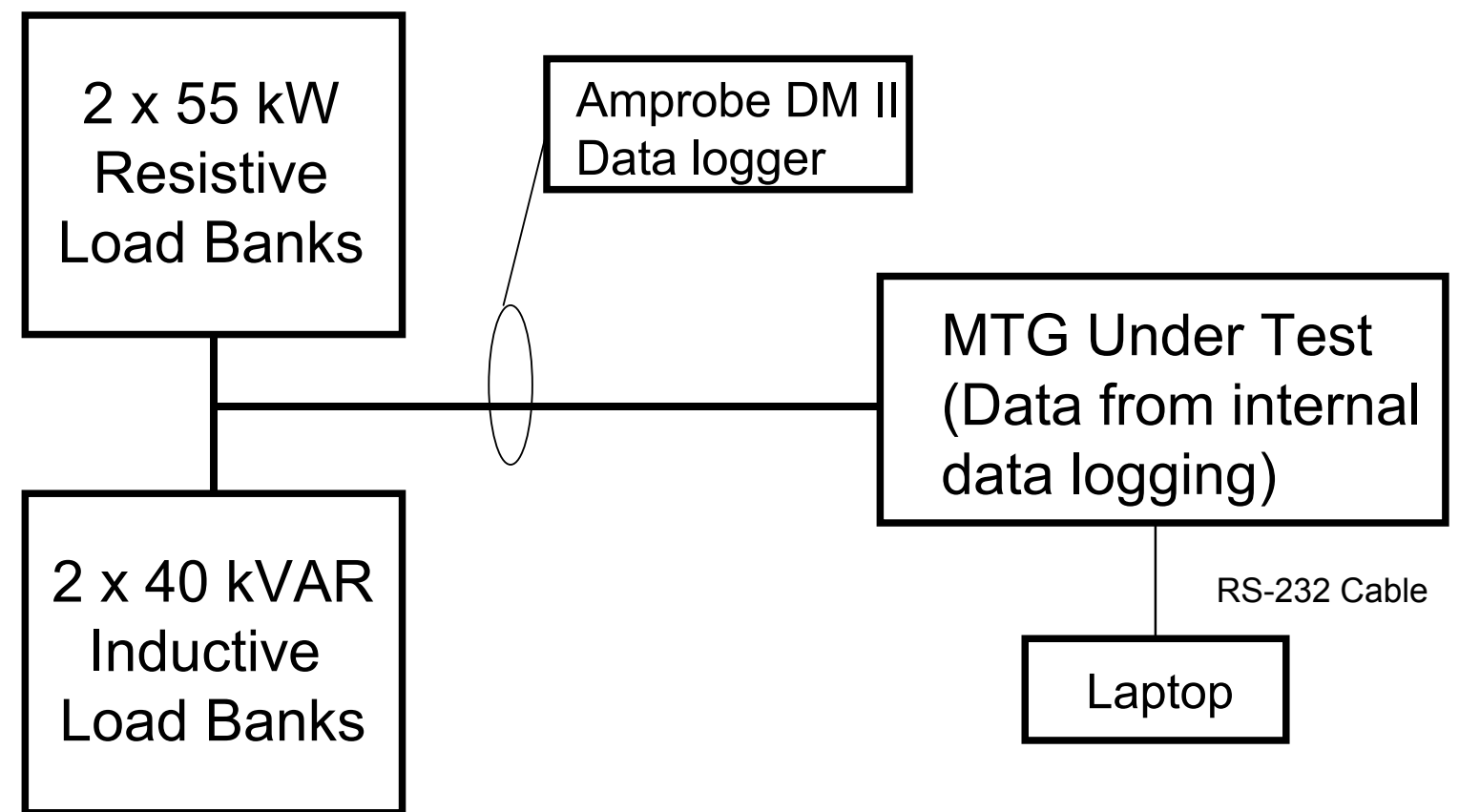

Figure 2 - Stand-alone Test Setup

\subsection{Data Collection}

As in the earlier grid-connect tests, data were collected directly from the MTG (data at onesecond intervals for the Honeywell MTG and at two-second intervals for the Capstone MTG) during the test. The MTG software occasionally output two data records with the same time stamp, as had happened in earlier tests. In addition, a second set of measurements (one-second intervals) was recorded at the load banks with an Amprobe DM-II data logger and recorder (which uses clamp-on current transformers and direct input of the 480 -volt signal). 


\subsection{Test Procedure}

The MTG under test was started and kilowatt load was applied by the load bank. Step changes in kilowatt and kVAR load were then made. Tests were conducted for both increases and decreases in load. The step sizes of the load changes were varied to determine the effects of increasing and decreasing load. During these tests, all available parameters were recorded from the MTGs. All electrical parameters (both single-phase and three-phase) were recorded at the load banks by the Amprobe.

\subsection{Analysis}

The first step in the analysis was to match the data set taken by the Amprobe data logger with the data set collected directly from the MTG. For the Capstone MTG, each data point in the twosecond-interval data file was doubled, creating a data set that could be combined with the Amprobe one-second-interval data. The Honeywell data set had been recorded at one-second intervals, so it could be directly combined with the Amprobe data. Duplicate data records were also removed from the Honeywell and Capstone files. Because the clocks of the MTG and Amprobe instruments were not synchronized, the two data sets needed to be lined according to time. Once the data set had been cleaned up, graphs of the results could be prepared.

Both turbines tested are capable of starting from their own internal batteries with no outside power required. Once started, the turbines are capable of supplying loads that have both real and reactive power requirements. The following table lists the rated capabilities of each microturbine based on available literature and conversations with each manufacturer.

Table 12 - MTGs' Electrical Capabilities

\begin{tabular}{|c|c|c|}
\hline & Capstone 330 & Honeywell Parallon 75 \\
\hline Rated Power Output & $30 \mathrm{~kW}, 3$ phase, 4 wire wye & $75 \mathrm{~kW}, 3$ phase, 3 wire delta \\
\hline Terminal Voltage (L-L) & $150-480 \mathrm{VAC}$ & $\begin{array}{l}275 \text { VAC; other voltages available } \\
\text { with transformer including } 480 \\
\text { VAC L-L }\end{array}$ \\
\hline $\begin{array}{l}\text { Maximum steady-state } \\
\text { current }\end{array}$ & $\begin{array}{l}46 \mathrm{~A} / \text { phase (including neutral), } \\
38 \mathrm{kVA}\end{array}$ & $\begin{array}{l}200 \mathrm{~A} / \text { phase at } 275 \mathrm{VAC} \mathrm{L}-\mathrm{L}, \\
100 \mathrm{kVA} \\
120 \mathrm{~A} / \mathrm{ph} \text { ase at } 480 \mathrm{VAC} \mathrm{L}-\mathrm{L}, \\
100 \mathrm{kVA} \text { (with transformer) }\end{array}$ \\
\hline Peak current & $\begin{array}{l}76 \text { A peak or } 54 \text { A RMS/phase } \\
\text { for } 10 \text { seconds }\end{array}$ & $\mathrm{N} / \mathrm{A}$ \\
\hline If overloaded: & $\begin{array}{l}\text { Trip turbine if cannot achieve } \\
\text { nominal voltage after set } \\
\text { timeout period }\end{array}$ & $\begin{array}{l}\text { Reduces terminal voltage to limit } \\
\text { current. If current limits still } \\
\text { exceeded, unit trips }\end{array}$ \\
\hline Power factor capability & $\begin{array}{l}\text { Any power factor as long as } \\
\text { current stays within limits }\end{array}$ & $\begin{array}{l}\text { Any power factor as long as } \\
\text { current stays within limits }\end{array}$ \\
\hline Unbalance load ability & $\begin{array}{l}\text { Any unbalance as long as } \\
\text { current stays within limits }\end{array}$ & Up to $10 \%$ of system capacity \\
\hline
\end{tabular}


Both MTGs can ramp voltage up to start a large load if necessary. The manufacturers recommend the use of soft-start devices for large motors to avoid large inrush currents during starting.

\subsubsection{Capstone}

Analysis of the graphs of the Capstone Model 330 microturbine (Appendix D) shows that this device can respond to load changes as rapidly as the monitoring equipment could measure (onesecond data sampling intervals). In the stand-alone mode, the turbine relies on its internal battery to handle quick increases or decreases in demand. The turbine then ramps to the new power level during the next few seconds. Tables 13 and 14 show the times required for the turbine to ramp to the new power output level during different step changes in load at the load banks. There were only minor changes in the turbine speed during reactive power load changes.

Table 13 - Capstone Ramp-Down Time

\begin{tabular}{||c|c|c|c||}
\hline Start Load (kW) & End Load (kW) & $\begin{array}{c}\text { Time to Change Load } \\
(\mathbf{s e c})\end{array}$ & $\begin{array}{c}\text { Transition Time } \\
(\mathbf{s e c} / \mathbf{k W})\end{array}$ \\
\hline \hline 24 & 20 & 5 & 1.3 \\
\hline 20 & 16 & 4 & 1.0 \\
\hline 16 & 12 & 6 & 1.5 \\
\hline 12 & 8 & 9 & 2.3 \\
\hline 8 & 4 & 14 & 3.5 \\
\hline 4 & 2 & 11 & 5.5 \\
\hline 24 & 12 & 5 & 0.4 \\
\hline 12 & 0 & 22 & 1.8 \\
\hline 24 & 0 & 26 & 1.1 \\
\hline
\end{tabular}

Table 14 - Capstone Ramp-Up Time

\begin{tabular}{||c|c|c|c||}
\hline Start Load (kW) & End Load (kW) & $\begin{array}{c}\text { Time to Change } \\
\text { Load (sec) }\end{array}$ & $\begin{array}{c}\text { Transition Time } \\
\text { (sec/kW) }\end{array}$ \\
\hline \hline 2 & 8 & 11 & 1.8 \\
\hline 8 & 16 & 4 & 0.5 \\
\hline 16 & 24 & 4 & 0.5 \\
\hline 0 & 24 & 10 & 0.4 \\
\hline 0 & 24 & 13 & 0.5 \\
\hline
\end{tabular}

During a step down in MTG real power output, several characteristics were noted. First, when the load bank power was reduced, turbine shaft speed dropped smoothly to its new operating point. The turbine exit temperature spiked for a few seconds, but it then returned to normal for the new operating point. The DC bus voltage rose to 785-800 VDC but then returned to the normal operating point of $745 \mathrm{VDC}$. The only exception to this pattern was when the turbine output power was very low or zero. In those cases, the DC voltage stayed near 785 VDC. 
During steps up in the MTG real power output, turbine speed also ramped up smoothly to the new operating point. There were only small changes in turbine exit temperature (mostly decreases) and then temperature returned to the normal operating point. The DC bus voltage dropped and then recovered to a point between 760 and 785 degrees $C$. Changes both up and down in the VAR load at the load banks had only minor effects on turbine shaft speed and turbine exit temperature. There was also no discernable pattern to the changes in the DC bus voltage; its level fluctuated between 740 and 785 VDC.

MTG power output drifted up as the VAR load was increased. This appears to be caused by losses in the inductive load banks and in the cabling. The microturbine's internal monitoring indicated that all the load increase -- about 200 watts -- took place on A-phase while the other phases remained the same. At the load banks, the increase was about equal for all three phases. The change was about 400 watts for each phase for a total of about 1,200 watts. It is not clear what is led to this discrepancy in the observed values, but the Amprobe measurements appear to be more reliable.

Observation of the voltage at the load banks during the tests showed a small sensitivity to real load level. The voltage decreased two to three VAC during changes from zero to full load. There was a larger change in load bank voltage during changes in reactive load. A drop of about give VAC was observed when a 16-kVAR load was placed on the MTG. This voltage regulation level showed a less than two percent deviation from the nominal voltage of $277 \mathrm{VAC}$.

Neutral current level increased as real and reactive loads increased. Measured at the load bank, neutral current exhibited an oscillatory characteristic with a period of 10 to 13 seconds. At no load, the current stayed close to $2 \mathrm{~A}$. When the load was at $24 \mathrm{~kW}$ and $18 \mathrm{kVAR}$, the neutral current ranged from 1.1 to $4 \mathrm{~A}$. These numbers did not agree with the neutral current values reported by the MTG internal monitoring, which ranged in value from 0 to 1,200 amps. These values did not appear to be valid and were not used in this analysis.

The 24-kW step on one of the load banks turned out to be unbalanced in load. The C phase was one $\mathrm{kW}$ lower than the other two phases. This is equivalent to about an eight percent unbalance in that phase as compared to the other phases. This introduced load imbalance on the MTG did not cause any noticeable voltage difference between the $\mathrm{C}$ phase and the other two phases.

In the stand-alone mode, the MTG is started and cooled down after shutdown using the internal battery connected to the DC bus to drive the generator as a motor. Graphs showing a shutdown and hot restart are included in Appendix D.

\subsubsection{Honeywell}

Analysis of the graphs of the Honeywell Parallon 75 micro turbine (Appendix E) shows it is capable of responding to load changes as rapidly as the monitoring equipment could measure (one-second data sampling intervals). This unit runs the microturbine at full speed at all times while in stand-alone operation. Instead of using the battery to handle quick changes in load, Honeywell uses the high turbine rotational speed and fast fuel control to manage load changes. During most load changes, a shaft speed increase or decrease from 65,000 RPM was observed. 
After a few seconds, the shaft speed returned to 65,000 RPM. Tables 15 and 16 show the times for the turbine shaft to recover nominal speed during load step changes up and down. The load levels shown in the tables are measured at the load banks. The turbine indicated output was three to five $\mathrm{kW}$ larger because of transformer losses and the load of the gas compressor.

Table 15 - Honeywell Ramp-Down Time

\begin{tabular}{||c|c|c|c||}
\hline Start Load (kW) & End Load (kW) & $\begin{array}{c}\text { Time to Change } \\
\text { Load (sec) }\end{array}$ & $\begin{array}{c}\text { Recovery Time } \\
\text { (sec/kW) }\end{array}$ \\
\hline \hline 66 & 54 & 11 & 0.92 \\
\hline 54 & 48 & 9 & 1.5 \\
\hline 48 & 24 & 11 & 0.46 \\
\hline 24 & 0 & 9 & 0.38 \\
\hline
\end{tabular}

Table 16 - Honeywell Ramp-Up Time

\begin{tabular}{||c|c|c|c||}
\hline \hline Start Load (kW) & End Load (kW) & $\begin{array}{c}\text { Time to Change } \\
\text { Load (sec) }\end{array}$ & $\begin{array}{c}\text { Recovery Time } \\
\text { (sec/kW) }\end{array}$ \\
\hline \hline 0 & 24 & 15 & 0.63 \\
\hline 24 & 48 & 30 & 1.25 \\
\hline 48 & 54 & 21 & 3.5 \\
\hline 54 & 60 & 27 & 4.5 \\
\hline 60 & 62 & 12 & 6 \\
\hline 62 & 64 & 25 & 12.5 \\
\hline 64 & 66 & 48 & 24 \\
\hline
\end{tabular}

As can be noted from Table 15, the turbine is capable of ramping down to lower load levels quite quickly. There is an approximately 600-RPM spike in the turbine during a reduction in real load at the load bank. The RPM returns to normal in about 10 seconds. The turbine exit temperature goes from a high of 1,090 deg $\mathrm{C}$ down to $680 \mathrm{deg} \mathrm{C}$ as the load is reduced from $66 \mathrm{~kW}$ to zero. The DC link voltage rises as the real power load goes down, increasing from $528 \mathrm{VDC}$ to a high of $630 \mathrm{VDC}$.

The MTG ramp up is quite different. At lower loads, the turbine accepts the load with little problem. However, as the load gets closer to the unit's rated load, it must be added in smaller and smaller increments to avoid tripping the MTG. Table 16 shows that the recovery time per $\mathrm{kW}$ increased dramatically as power output approached full load. No attempt was made to apply full load from the no-load setting because the MTG would likely have tripped. An attempt was made to apply a four-kW incremental load at the $60-\mathrm{kW}$ load level, but the incremental load added was quickly removed to avoid possible tripping of the turbine. A review of the data suggests that the turbine would not have tripped in this particular case. During load increases, the turbine exit temperature increased from 670 to $1,022 \mathrm{deg}$ C. At the same time, the DC bus voltage decreased from $630 \mathrm{VDC}$ at no load to $528 \mathrm{VDC}$ at full load. 
One observation about the voltage at the load banks is that phase $\mathrm{C}$ runs at least five VAC above the other phases at all times. This voltage difference exists at full load as well as no load, so it does not appear to be the result of a load imbalance. There appears to be an inverter voltage imbalance, gas compressor load imbalance, or an imbalance induced by the transformer. Looking at the two remaining phases, we see that, with no load on the MTG, the voltage at the load bank runs about $282 \mathrm{VAC}$. At full load ( $66 \mathrm{~kW}$ and $51 \mathrm{kVAR}$ at the load bank), the voltage is reduced to $273 \mathrm{VAC}$. This voltage swing is about nine volts or about three percent of the nominal voltage of 277 VAC. Voltage oscillates at all times by about one volt, peak to peak, with a period of seven to nine seconds. At zero load this oscillation increases in magnitude up to eight volts.

To further investigate the voltage imbalance observed at the load banks, an additional set of measurements was taken at the output terminals of the MTG before power went through the delta/wye transformer (Appendix F). The Amprobe data logger is designed to take delta measurements using the two-wattmeter method and records three line-to-line voltages but only two line currents (phases A and C). There are also only total values -- no per-phase watt/VAR readings available -- in this mode. On the Honeywell MTG, the line-to-line voltage is supposed to be $275 \mathrm{VAC}$. Records from these tests indicate that the voltage stays in a fairly narrow range of $274 \mathrm{VAC}$ to $277 \mathrm{VAC}$ with only a slight reduction as load increases. However, the two line currents that were measured showed a substantial imbalance. At $70 \mathrm{~kW}$ and $40 \mathrm{kVAR}$, the line currents were 144 amps (phase A) and 166 amps (phase C). At lighter loads, the difference was smaller. In an attempt to determine whether the imbalance is a result of an imbalance in the load banks, the 24-kW load bank setting known to have an imbalance and another setting without an imbalance were tested. In the $24-\mathrm{kW}$ position with an imbalance (phases A \& B -- $8 \mathrm{~kW}$; phase $\mathrm{C}--7 \mathrm{~kW}$ ), the line currents were $49 \mathrm{~A}$ for phase $\mathrm{A}$ and $52 \mathrm{amps}$ for phase $\mathrm{C}$. When the balanced load of $24 \mathrm{~kW}$ was used, the differences in currents were actually greater with phase A amps at 48 and phase $\mathrm{C}$ amps at 54. This suggests that the imbalance observed in the voltages at the load bank was caused by something other than load imbalance.

Neutral current is only present when there is an imbalance at the load bank. At full load, the neutral current increased to about two volts. It oscillated slowly -- a period of about 25 seconds.

In stand-alone mode, the MTG is started and cooled down after shutdown using the internal battery connected to the DC bus to drive the generator as a motor. Graphs showing a shutdown are included in Appendix E.

\subsection{Observations/Conclusions}

Both microturbines were able to track the load bank requirements as long as load settings were maintained within the specifications for each MTG.

\subsubsection{Capstone}

Based on the tests conducted, we highlight the following conclusions and observations:

- Microturbine output responded immediately to changes in the load bank settings (faster than the one-second time resolution of the Amprobe measuring equipment). 
- The initial load change was supplied/absorbed by the onboard battery. The microturbine was ramped up/down as quickly as possible to the new load level. The ramp up rate was observed to be about 10 seconds for 0 to $24 \mathrm{~kW}$ (as compared to 50 seconds when the unit was in grid-parallel mode). The ramp down rate was about 26 seconds for 24 to 0 $\mathrm{kW}$ (as compared to 50 seconds when the unit was in grid-parallel mode).

- Neutral current as measured by the Amprobe indicated a slow oscillation (10- to 13second periods) with an average value of two to 2.5 amps. The magnitude of the oscillation depended on load and ranged from zero to three amps peak to peak.

- The DC bus voltage generally varied from 745 to 785 volts during the load change tests. The DC bus voltage remained essentially constant (at 760 VDC) when the turbine was in grid-parallel mode.

- Power output of the microturbine drifted up as the VAR load increased.

- Even with an eight percent load imbalance in one of the phases, there was little change in the balance of the three-phase voltages.

\subsubsection{Honeywell}

The following conclusions and observations are based on the tests conducted:

- The microturbine output responded immediately to changes in the load bank settings (faster than the one-second time resolution of the Amprobe measuring equipment).

- The turbine does not seem to use its battery to track load changes. When the unite is in stand-alone mode, the turbine shaft speed is always 65,000 RPM. When the load changes, fuel flow is quickly changed. This mode of operation makes the MTG very sensitive to load changes especially when it is operating at higher power levels.

- Neutral current as measured by the Amprobe data indicated a slow oscillation (with a period of about 25 seconds) with an average value of two amps. The magnitude of the oscillation depended on load and ranged from zero to 0.5 amps peak to peak.

- The DC bus voltage generally varied from 528 to 630 volts during the load change tests. The DC bus voltage also varied while the unit was operating in grid-parallel mode but by a smaller amount.

- There was at least a five-volt imbalance in the three-phase voltages at the load banks. Phase $\mathrm{C}$ voltage was always higher than the other two. Load imbalance caused by the load banks does not seem to affect the output voltage levels.

- Measurements at the output terminals of the MTG (275 VAC delta line-to-line) showed balanced line-to-line voltages at all load values. Line currents were unbalanced at most loads with the greatest imbalance at the highest load. At $70 \mathrm{~kW}$ and $40 \mathrm{kVAR}$, the line currents were 144 amps (phase A) and 166 amps (phase C). 


\subsection{Parallel Testing}

\section{$\underline{5.1 \text { Test Setup }}$}

The third set of tests of the two microturbines was designed to record the behavior of two MTGs operating in parallel connected to load banks. For these tests, there were four Avtron load banks, two with a capacity of $55.5 \mathrm{~kW}$ and the other two with a capacity of $40.5-\mathrm{kVAR}$ reactive load. There were approximately 60 feet of cable between each turbine and the load banks ( 30 feet of \#6 and 30 feet of 2/0). In these tests, one MTG was operated in stand-alone mode and the second MTG was operated in grid-connect mode. This arrangement was necessary because safety protocols do not allow connection of the second MTG in stand-alone mode to the "grid" established by the first MTG. Data were collected from the internal MTG monitoring (for the stand-alone MTG) by a laptop computer running the required software. In addition, electrical data were collected at the load banks with the Amprobe data logger. The test setup is shown in Figure 3 below.

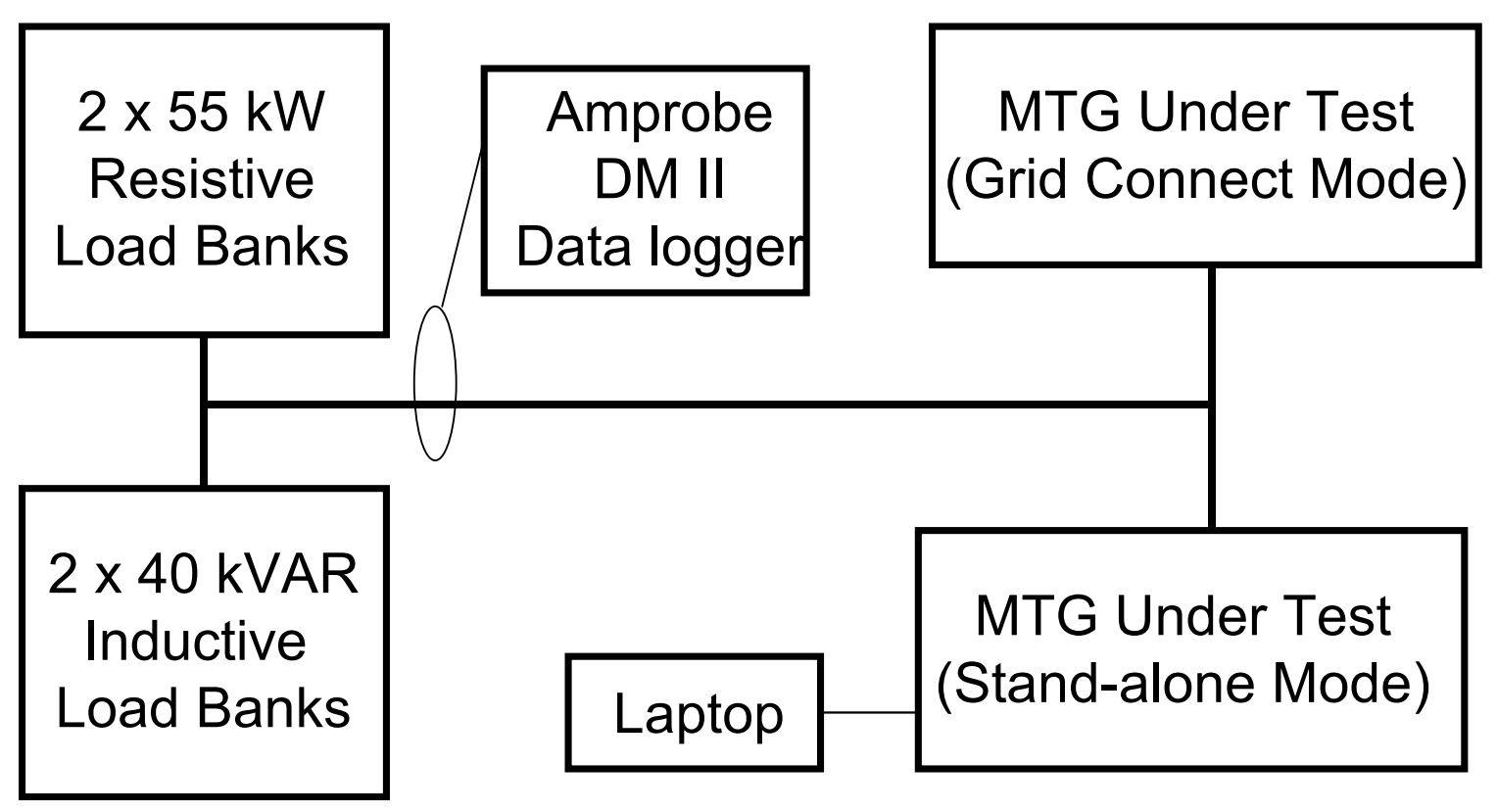

Figure 3 - Parallel Test Setup

\section{$\underline{5.2 \text { Data Collection }}$}

As in the earlier grid-connect tests, data were collected directly from the stand-alone MTG (at one-second intervals for the Honeywell and two-second data intervals for the Capstone MTG). As in previous tests, the MTG software occasionally produced two data records with the same time stamp. In addition, a second set of measurements (at one-second intervals) was taken at the load banks with the Amprobe DM-II data logger and recorder (using clamp-on current transformers and direct input of the 480 -volt signal). The second MTG that was operating in 
grid-connect mode was not monitored by laptop, but its power output values were known because they were input from the MTG front panel.

\section{$\underline{5.3 \text { Test Procedure }}$}

The stand-alone MTG being tested was first started and kilowatt load was applied by the load bank. Once this MTG was stabilized, the second MTG was started in grid-connect mode. Starting power was drawn from the stand-alone MTG. Tests were conducted with various combinations of load bank settings and grid-connect MTG power settings for both increases in load and decreases in load. The step size of the load changes was varied to determine the effect on both turbines of increasing or decreasing load. All available parameters were recorded from the stand-alone MTG. All electrical parameters (both single-phase and three-phase) were recorded at the load banks with the Amprobe logger. The shutdown process involved first reducing the power of the grid-connect MTG to zero, followed by the cool-down sequence. Once this MTG was off, the stand-alone MTG was shut down.

\section{$\underline{5.4 \text { Analysis }}$}

The first step in the analysis was to match the data set taken by the Amprobe data logger with the data set collected directly from the stand-alone MTG. For the Capstone MTG, each data point in the two-second interval data file was doubled, creating a data set that could be combined with the Amprobe one-second-interval data. The Honeywell data set had been collected at one-second intervals, so it could be combined directly with the Amprobe data. Duplicate data records were removed from the Honeywell and Capstone files. Because the MTG and Amprobe clocks were not synchronized, the two data sets needed to be lined up by time. Once the stand-alone MTG and Amprobe data were combined in one spreadsheet, the data for the grid-connect MTG were calculated from the difference between the load bank readings and stand-alone MTG output. Once this cleaned-up data set was obtained, graphs of the results could be prepared.

During both sets of tests (Capstone - Capstone, Honeywell - Capstone) the MTGs showed the same slow dynamic characteristics as they exhibited during the grid-connect and stand-alone testing done earlier. The focus of these tests was to see whether there were any measurable interactions between the MTGs. The primary indicators observed were the power output and the voltage stability. Any other unusual behavior was noted.

\subsubsection{Capstone - Capstone Parallel Tests}

Analysis of the graphs of the Capstone - Capstone parallel tests (Appendix G) showed no unusual behavior. The initial start up and taking of load for the stand-alone Capstone (LP) MTG were identical to what was described for the stand-alone testing discussed earlier. The load banks were set to $24 \mathrm{~kW}$; the stand-alone unit picked up the load, and turbine speed stabilized as in previous stand-alone tests. Once the first MTG was on line, the second Capstone turbine (HP) was started in grid-connect mode. Power to start the grid-connect MTG was drawn from the stand-alone turbine, and an increase in the power of the stand-alone MTG was observed. There was no noticeable voltage variation during this process. Once the grid-connect turbine was 
warmed up, it ramped to the $10-\mathrm{kW}$ set point. This ramping rate was the same as was observed for the turbine when it was tested in grid-connect mode. At the same time, the stand-alone turbine power ramped down to $14 \mathrm{~kW}$ from the initial $24 \mathrm{~kW}$. There was an initial voltage drop of almost seven volts ( 277 to $270 \mathrm{VAC}$ ), but the voltage recovered to the previous level in 20 seconds as turbine ramping was completed. A similar voltage dip was observed when the gridconnect MTG was ramped from $10 \mathrm{~kW}$ to $20 \mathrm{~kW}$. A voltage rise from $277 \mathrm{VAC}$ to $283 \mathrm{VAC}$ followed by a voltage drop to $273 \mathrm{VAC}$ were observed when the grid-connected MTG's set point was reduced from $20 \mathrm{~kW}$ to $10 \mathrm{~kW}$. The voltage returned to $277 \mathrm{VAC}$ when the grid-connect MTG reached $10 \mathrm{~kW}$. There were also other spikes and dips in voltage during changes in load bank power levels. These only lasted one or two seconds and may indicate some high-speed voltage fluctuations that are not captured by the data collected at one-second intervals. There were only small voltage changes when inductive loads were applied or removed.

During most of the test period, there was a load imbalance introduced by the load banks. The 24- $\mathrm{kW}$ step of one of the load banks had a one-kW unbalance (legs A and B with eight $\mathrm{kW}$ and leg $\mathrm{C}$ with seven $\mathrm{kW}$ ). This load imbalance seems to induce some neutral current (about two amps). When the load on the MTG pair was balanced, there was still some neutral current, but levels were less than one amp. There was no noticeable voltage imbalance caused by the load imbalance.

Both MTGs had to be kept within their operating ranges throughout the testing. When changes were made in the load bank loads, the step size had to be small enough to avoid MTG overload at the test ambient temperatures. In addition, load was kept above eight $\mathrm{kW}$ to avoid the combustion instabilities previously observed in the test turbines. In one case the stand-alone turbine load was allowed to drop to six $\mathrm{kW}$ for a long enough period that the unit tripped. When this turbine tripped, voltage and frequency control was lost. The grid-connect turbine also tripped immediately in response to loss of grid power. Although this test was not intentional, it showed that the anti-islanding protection worked as planned.

\subsubsection{Honeywell - Capstone Parallel Tests}

Analysis of the graphs from the Honeywell - Capstone parallel tests (Appendix H) showed the behavior of the turbines in parallel closely resembled the operation of each separately. The Honeywell MTG was started, and load was applied by the load banks. This loading was done in stages to avoid tripping the unit. When the load bank settings were at $50-\mathrm{kW}$ real power, the Capstone MTG was started in grid-connect mode. The Honeywell MTG supplied the starting power for the Capstone unit. The Capstone unit then ramped to $10 \mathrm{~kW}$ with an equivalent decrease in the power supplied by the Honeywell unit. Similar behavior was noted when the Capstone MTG was ramped to $20 \mathrm{~kW}$. Load bank reactive power was then ramped up and down again. The Capstone real power was ramped down in two steps and the unit was shut down and allowed to complete a cool-down cycle before the Honeywell MTG was shut down.

A voltage imbalance of at least five volts on phase $\mathrm{C}$ was noticed in the earlier stand-alone tests of the Honeywell MTG. This same imbalance was present in these tests. As a whole, the voltage did not change greatly during real load changes by either the load banks or the gridconnect MTG. There was a drop of about four volts (280 VAC to 276 VAC) when the reactive 
load was increased from zero to $24 \mathrm{kVAR}$. There were no observable voltage spikes during any of the load changes.

Neutral current exhibited an up and down pattern that went from a maximum of 1.5 amps to zero. The current would rise from one amp to $1.5 \mathrm{amps}$ and then drop back down to one amp. Then it would drop to zero and stay there for several seconds. This pattern would repeat every 25 to 60 seconds. During the ramping of the reactive load from zero to $12 \mathrm{kVAR}$, a spike in the neutral current to 2.5 amps was observed. A small increase in voltage imbalance can be observed in the measurements of the individual phase-to-neutral voltages for this event.

During this test it was important not to exceed the output capabilities of either MTG. In addition, load increases for the Honeywell MTG needed to be introduced in small enough increments to avoid tripping the unit.

\section{$\underline{5.5 \text { Observations/ Conclusions }}$}

\subsubsection{Capstone - Capstone Parallel Tests}

The following are the observations and major conclusions from this test:

- In general, there were no unusual interactions between the two MTGs under testing.

- The behavior of each MTG (grid-connect and stand-alone) was similar to the behavior that each MTG exhibited when tested separately.

- There were some noticeable voltage fluctuations when the grid-connect MTG was ramped up and down (four to seven VAC).

- There was an indication of voltage spikes and dips that were probably not captured completely by the Amprobe one-second-interval data.

- Load imbalance did not seem to cause any noticeable voltage imbalance, but it did cause neutral current to flow.

- The grid-connect MTG tripped in response to loss of grid power when the stand-alone MTG tripped.

\subsubsection{Honeywell - Capstone Parallel Tests}

The following are the observations and major conclusions of this test:

- There were no unusual interactions between the two MTGs being tested.

- The behavior of each MTG (grid-connect and stand-alone) was similar to the behavior that each MTG exhibited when tested separately.

- The C-phase voltage at the load banks was five to seven VAC higher than the other two phases throughout the test.

- Voltage level remained fairly constant throughout the test with some voltage sag caused by increasing the reactive load. 


\subsection{Conclusions}

Testing was conducted on three microturbines (two Capstone model 330s (LP and HP) and one Honeywell Parallon $75 \mathrm{~kW}$ ). These tests recorded the behavior of the units operating in gridconnect, stand-alone, and parallel modes. Data were collected from MTG internal monitoring and by an Amprobe DMII data logger with one-second time resolution for all electrical parameters.

\subsection{Grid-connect Tests}

In the grid-connect tests, both MTGs tested were able to ramp power up and down as commanded by changes in their power set points. Although the ramping times for the two MTGs are similar at higher load set points, the Capstone MTG generally responded more slowly at load set points lower than $10 \mathrm{~kW}$. This was a result of the rough operation of the Capstone unit at these lower load set points. The one case where the Honeywell responded more slowly was during ramping from 0 to $75 \mathrm{~kW}$. During this ramping sequence, the turbine paused in the ramp up at about $68 \mathrm{~kW}$ and then continued to full power. This hesitation seemed to be caused by turbine speed reaching maximum value and DC link voltage reaching a limit. When viewed by ramping time per $\mathrm{kW}$, the Capstone ramped at a slower rate than the Honeywell. This is mainly a result in the differences in the maximum output of the turbines $(28 \mathrm{~kW}$ vs. $75 \mathrm{~kW})$ and the that fact that the units have similar ramping times.

Both machines have similar shutdown times (eight to 10 minutes). The turbine cool-down sequences occupied most of these time periods. The start-up sequence for the Capstone MTG (two minutes) was significantly faster than that for the Honeywell ( more than six minutes). This difference was mostly in the time to ramp the MTG from 0 to full power.

The DC link voltage of the Capstone MTG was held very close to 760 VDC during changes in load; the Honeywell MTG allowed the voltage to change over a range of 500 to $550 \mathrm{VDC}$. The turbine speeds of both units varied with the power output; the Capstone unit ranged from 45,000 to 96,000 RPM. The Honeywell unit had a smaller range, from 52,000 to 65,000 RPM.

Measurements of the output of the Capstone MTG showed that the current was balanced for all three legs regardless of the load and of a slight system voltage imbalance. The measurements for the Honeywell MTG showed similar results although the values displayed were noted as being averages.

\subsection{Stand-alone Tests}

Both MTGs were able to operate in stand-alone mode, setting voltage and frequency while isolated from the grid and connected to load banks. Changes in load bank settings were immediately satisfied by the MTGs being tested as long as load settings were maintained within each unit's specifications. The Capstone MTG used an onboard battery to supply the energy necessary for the load changes while the turbine ramped to the new load level. The ramp-up rate was observed to be about 10 seconds for 0 to $24 \mathrm{~kW}$ (as compared to 50 seconds when the unit was in grid-parallel mode). The ramp-down rate was about 26 seconds for 24 to $0 \mathrm{~kW}$ (as 
compared to 50 seconds when the unit was in grid-parallel mode). This mode of operation made the MTG very forgiving when load changes were introduced. By contrast, the Honeywell MTG ran its turbine at full speed and counted on quick changes in fuel supply to adjust power output. This mode of operation made the MTG very sensitive to fast load changes, especially when it was operating at higher power levels. Some fast storage would make this MTG less sensitive to load changes.

During the Capstone tests, even with an imbalance of eight percent in one of the load phases, there was little change in the balance of the three-phase voltages. For the Honeywell tests, there was a consistent five-volt unbalance in the three-phase voltages at the load banks. Phase C voltage was always higher than the other two. Load imbalance caused by the load banks does not seem to affect output voltage levels. Measurements at the output terminals of the MTG (275 VAC delta line-to-line) showed balanced line-to-line voltages at all load values. Line currents were unbalanced at most loads with the greatest imbalance at the highest load. At $70 \mathrm{~kW}$ and 40 kVAR, the line currents were 144 amps (phase A) and 166 amps (phase C).

The DC bus voltage on the Capstone MTG varied between 745 and 785 VDC for the range of loads used in the testing. This was in contrast to what was observed during the grid-connect tests when the DC bus voltage remained essentially constant at 760 VDC. The Honeywell DC bus voltage generally varied from 528 to 630 volts during the load change tests. This voltage also varied while operating in grid-parallel mode, but by a smaller amount.

During the stand-alone tests with both machines, there were neutral current values at the load banks. With the Capstone MTG, the current generally had an average value of two to 2.5 amps with a 10- to 13-second period oscillation with a peak-to-peak magnitude of zero to three volts. The Honeywell also had a current average of about two amps with an oscillation period of 25 seconds and a peak-to-peak magnitude ranging from zero to $0.5 \mathrm{amps}$.

\subsection{Parallel Tests}

No unusual interactions were observed for either the Capstone-Capstone or HoneywellCapstone MTG pairs operated with load banks. In each of these pairs of MTGs, one MTG was operated in stand-alone mode, establishing voltage and frequency as well as ramping with load changes. The second MTG was operated in grid-connect mode at a specific set point using the first MTG as the "grid." The behavior of each MTG while in parallel mode was similar to the behavior of each when tested separately in either grid-connect or stand-alone mode. During the Capstone-Capstone tests, the MTG that was establishing the "grid" tripped, which caused the MTG operating in grid-connect mode to detect loss of the "grid" and immediately also trip. This is the appropriate behavior for a grid-connect device.

The Capstone MTG, while operating as the "grid" in the Capstone-Capstone test, showed fourto seven- VAC voltage variations while load was ramped from minimum to maximum. There were also indications of voltage spikes and dips that were probably not captured completely by the one-second-interval data. Load imbalance did not seem to cause any noticeable voltage imbalance but did cause some neutral current to flow. During the tests in which the Honeywell MTG was operating as the "grid," there was a consistent voltage imbalance at the load banks. 
The C-phase voltage was five to seven VAC higher than that of the other two phases throughout the test. This behavior is similar to what was observed in the stand-alone testing. If we ignore the voltage imbalance, we see that voltage levels remained fairly constant throughout the test with some voltage sag caused by increasing the reactive load

\subsection{Suggested Future Work}

To simulate the potential use of MTGs in a microgrid, additional parallel testing is recommended. The tests should be set up with impedance between the MTGs to simulate the operation of a MTG and load in one building with another MTG and load in a second, nearby building. It would also be valuable to use the load-following mode of operation to control the output of the grid-connect MTG rather than having it run at fixed set points as was done in the parallel tests described here.

The harmonic content of both voltage and current should be measured to see how it varies with load and connection arrangement (grid-connect, stand-alone, or parallel). MTGs could interact with each other or other power electronic devices through voltage harmonics.

Testing done so far shows that there can be significant differences between MTGs. Testing of additional MTGs would be useful to determine the extent of the variations among units. 
Appendix A

Capstone High Pressure Grid-connect Tests

6/22/1999 


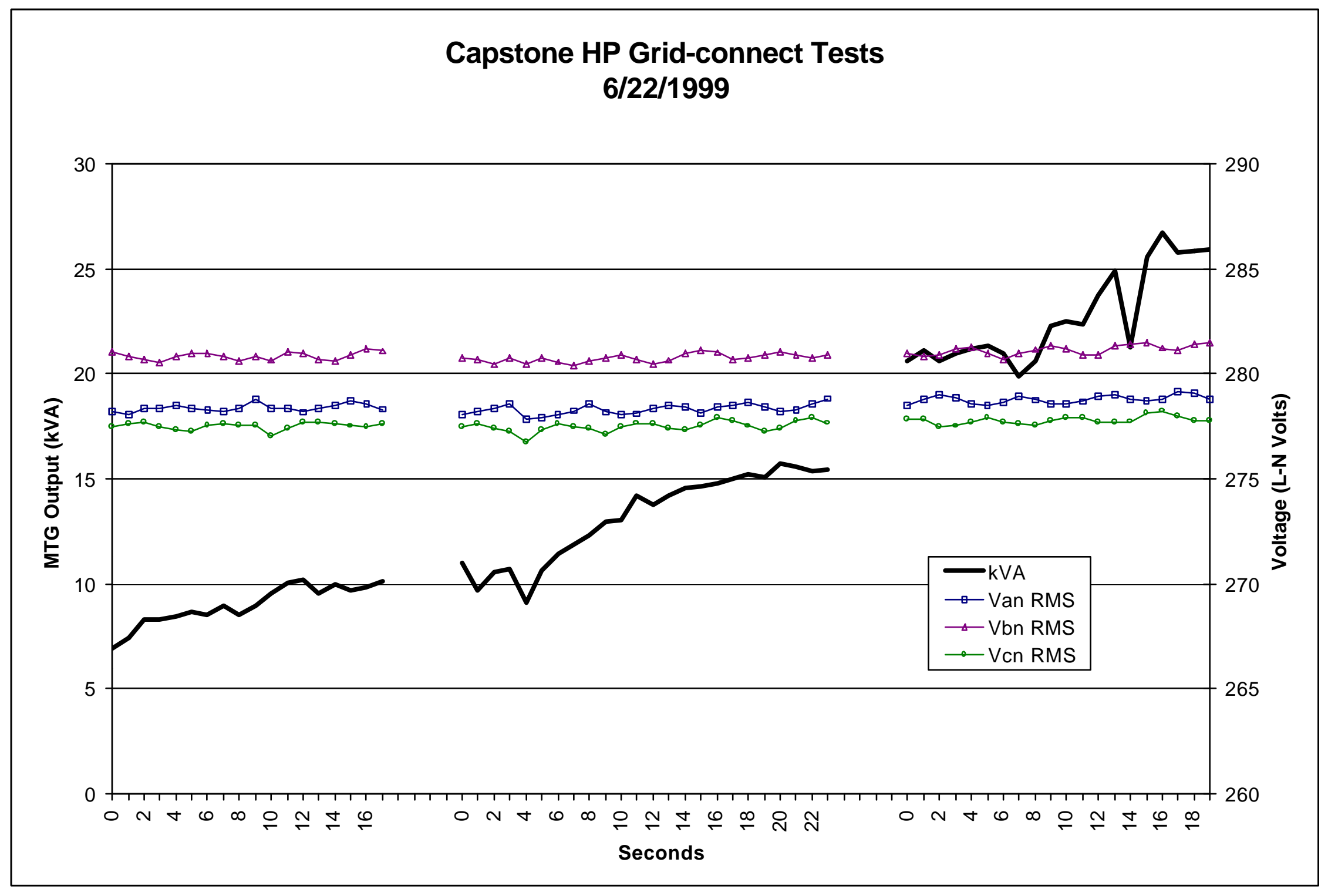

Figure A-1: Ramp Up Tests 


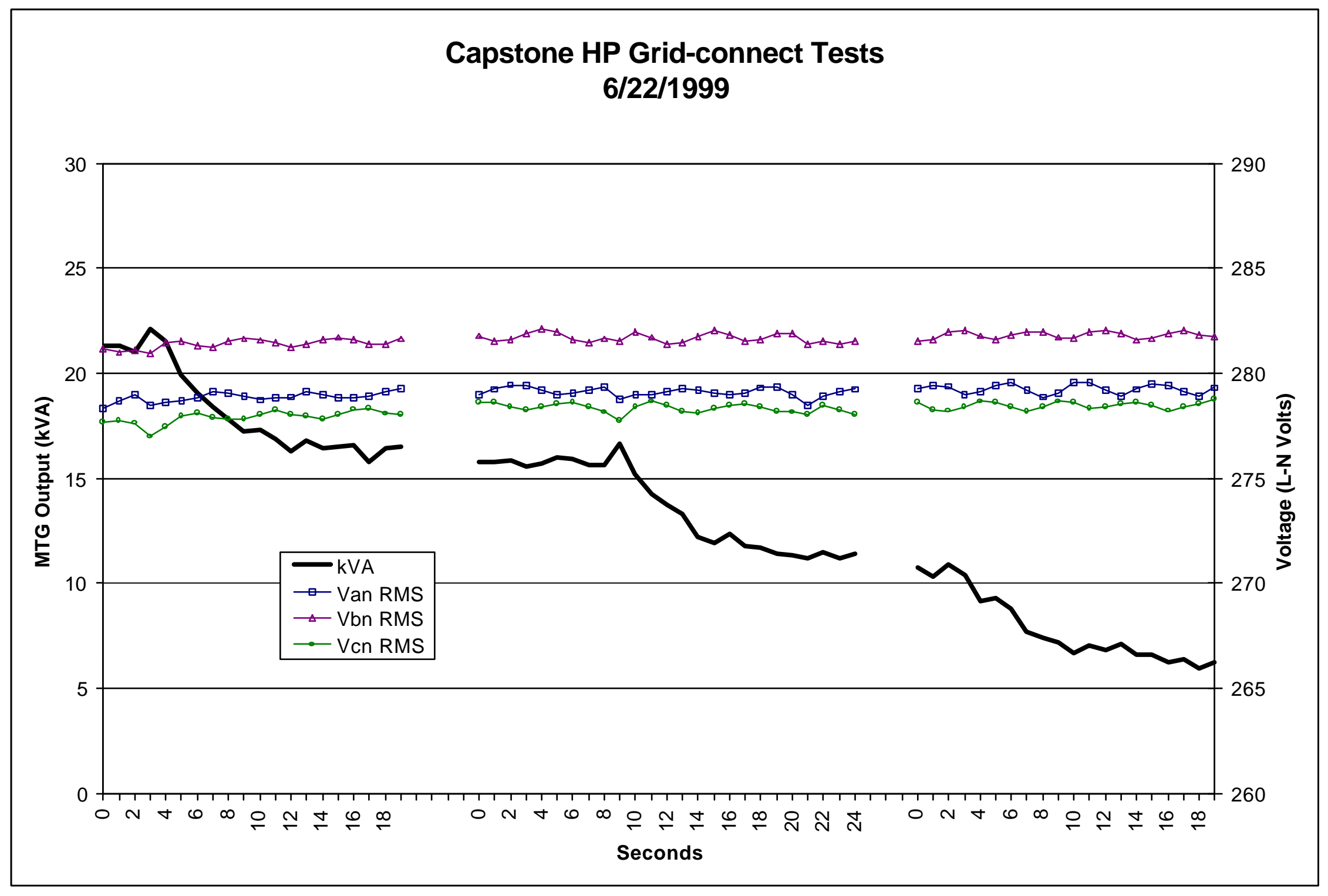

Figure A-2: Ramp Down Tests 


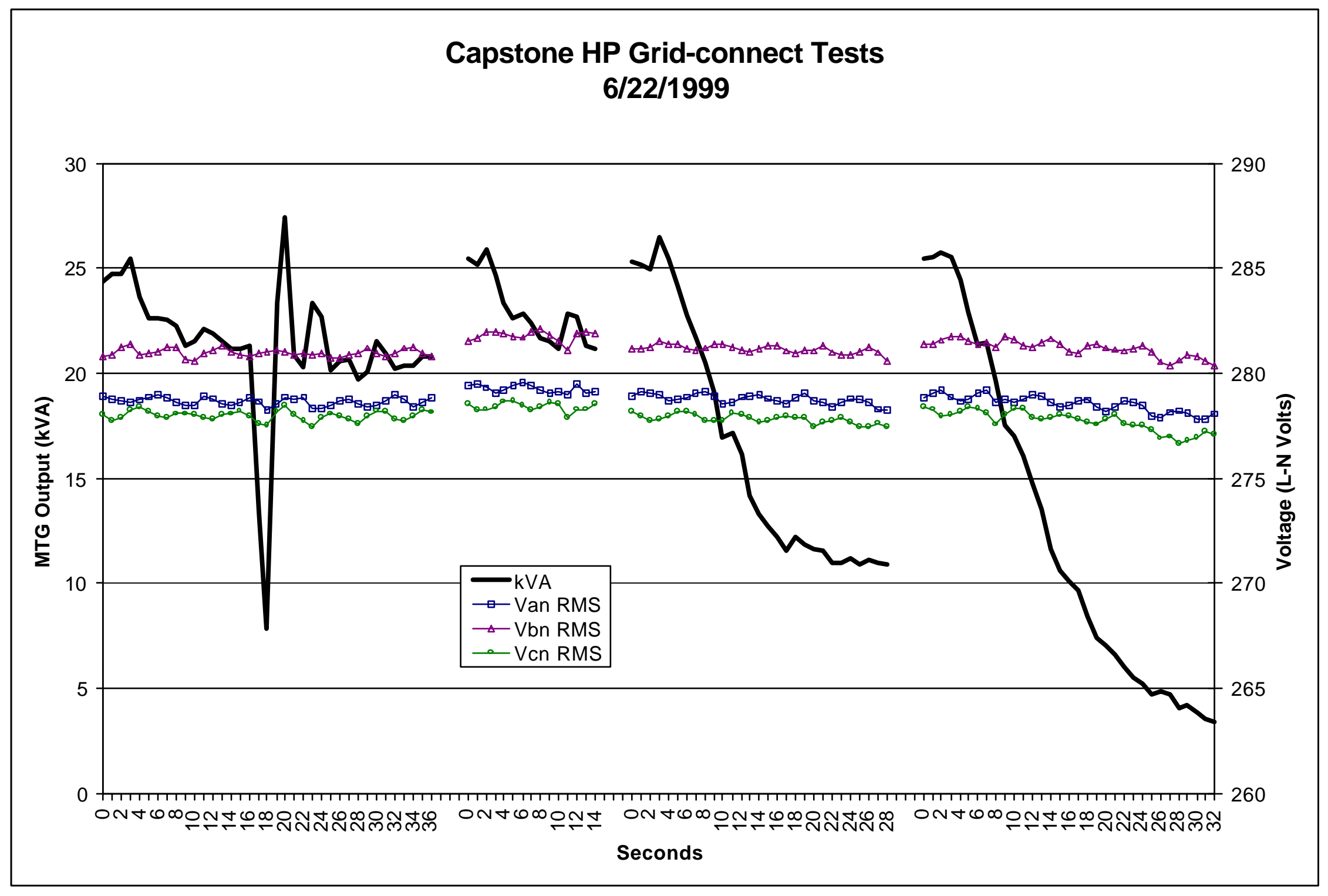

Figure A-3: Ramp Down from Full Load Tests 


\section{Appendix B}

Capstone Low Pressure Grid-connect Tests

10/25/2000 


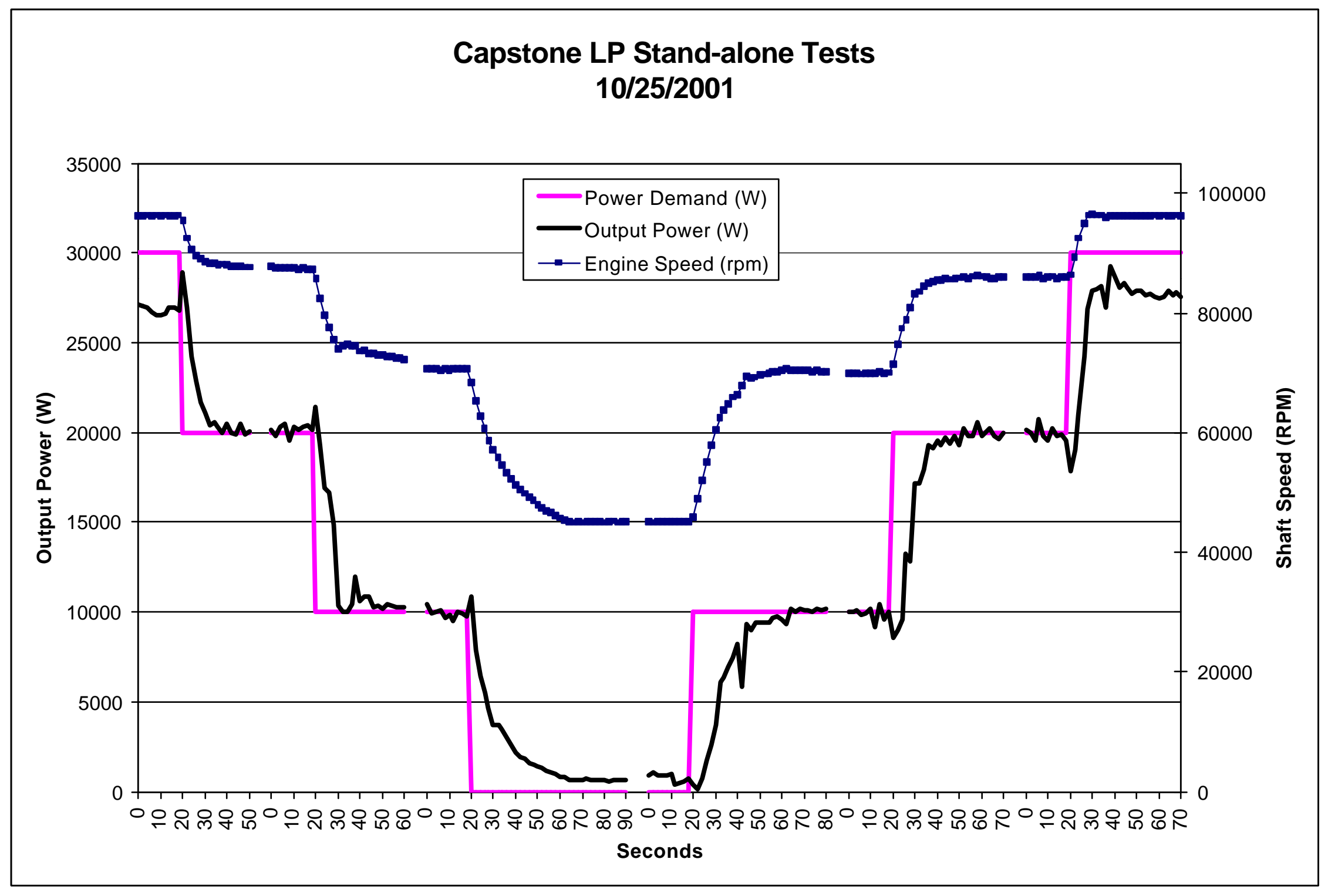

Figure B-1: Power and Shaft Speed - 10 kW Steps 


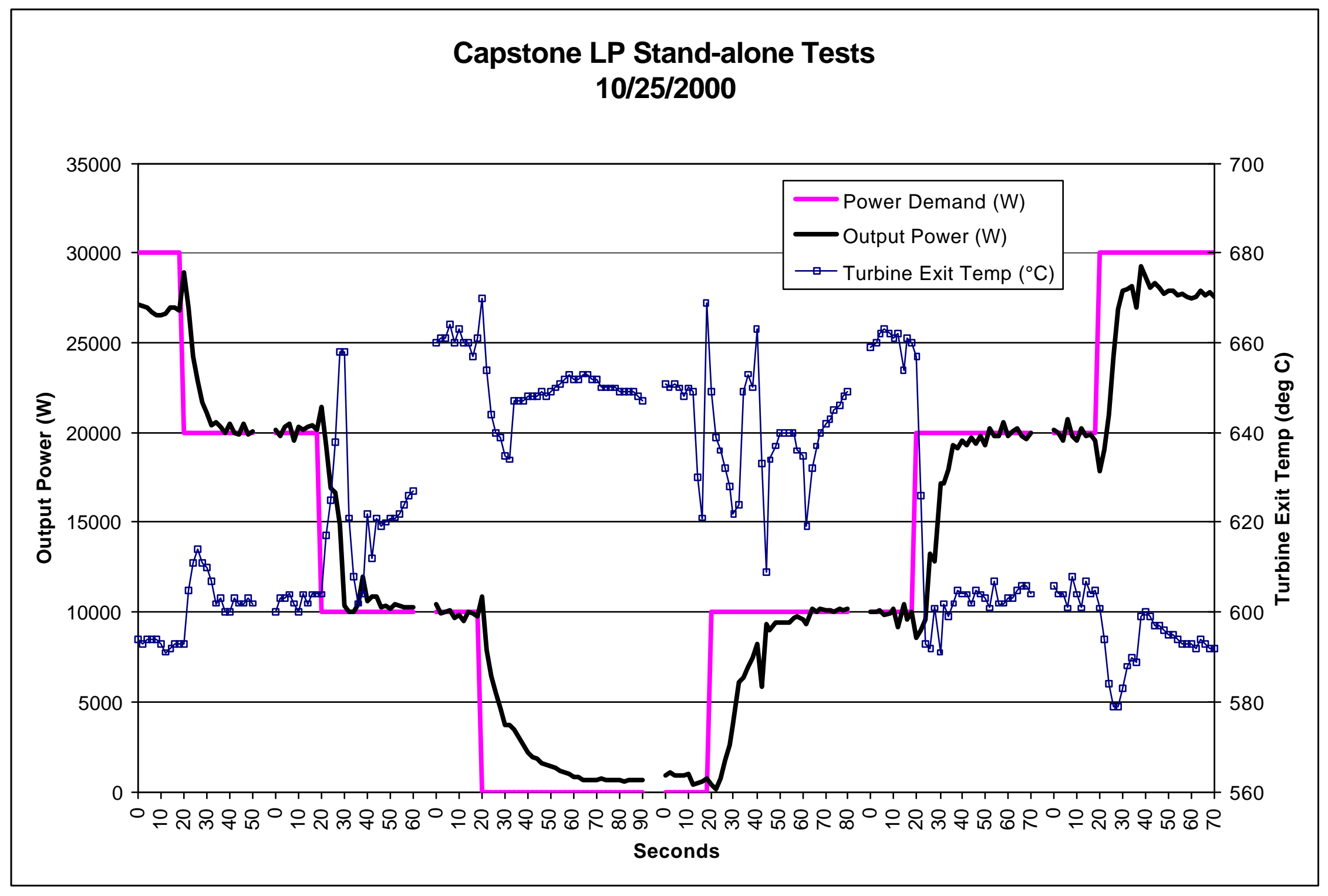

Figure B-2: Power and Turbine Exit Temperature - $10 \mathrm{~kW}$ Steps 


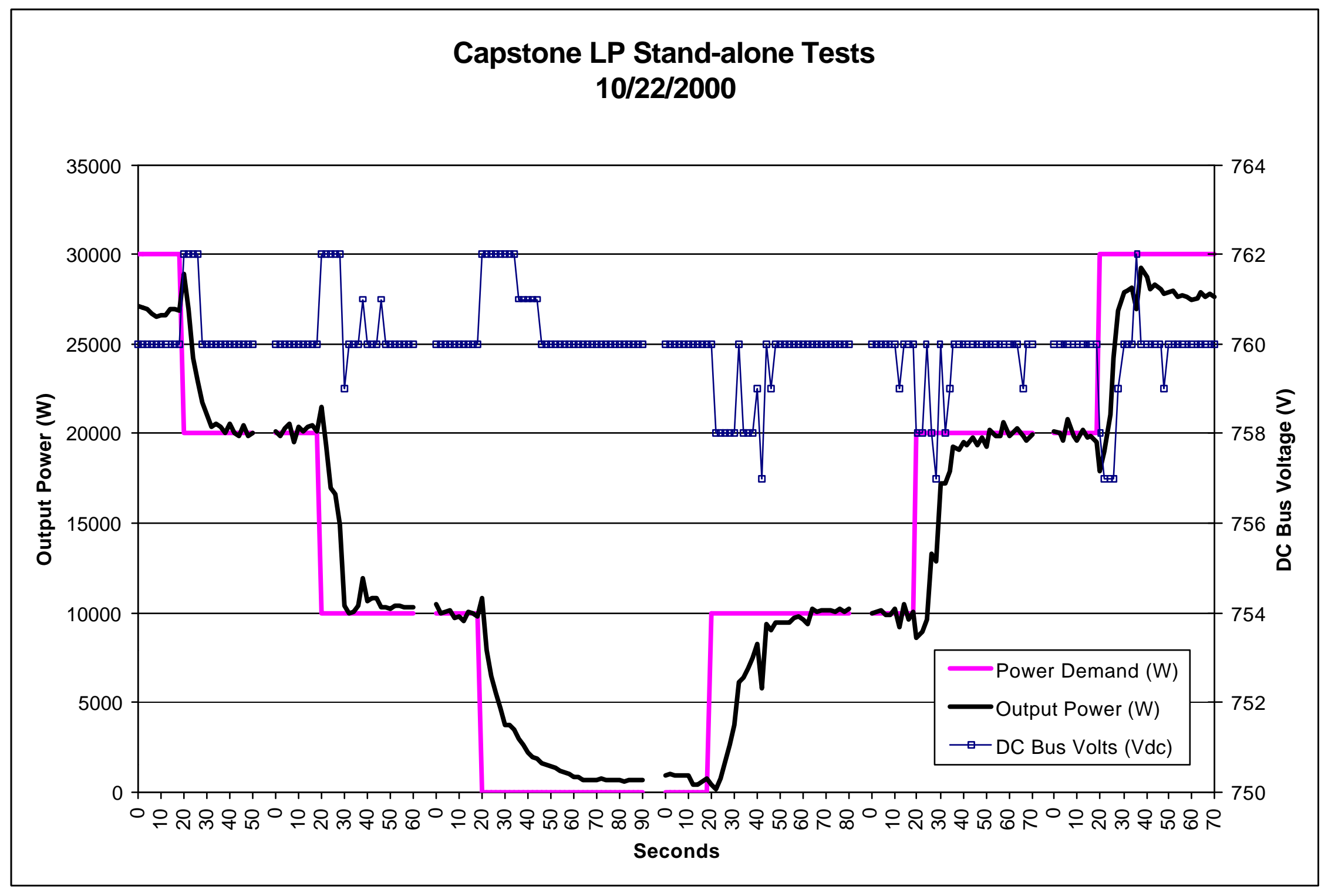

Figure B-3: Power and DC Bus Voltage - 10 kW Steps 


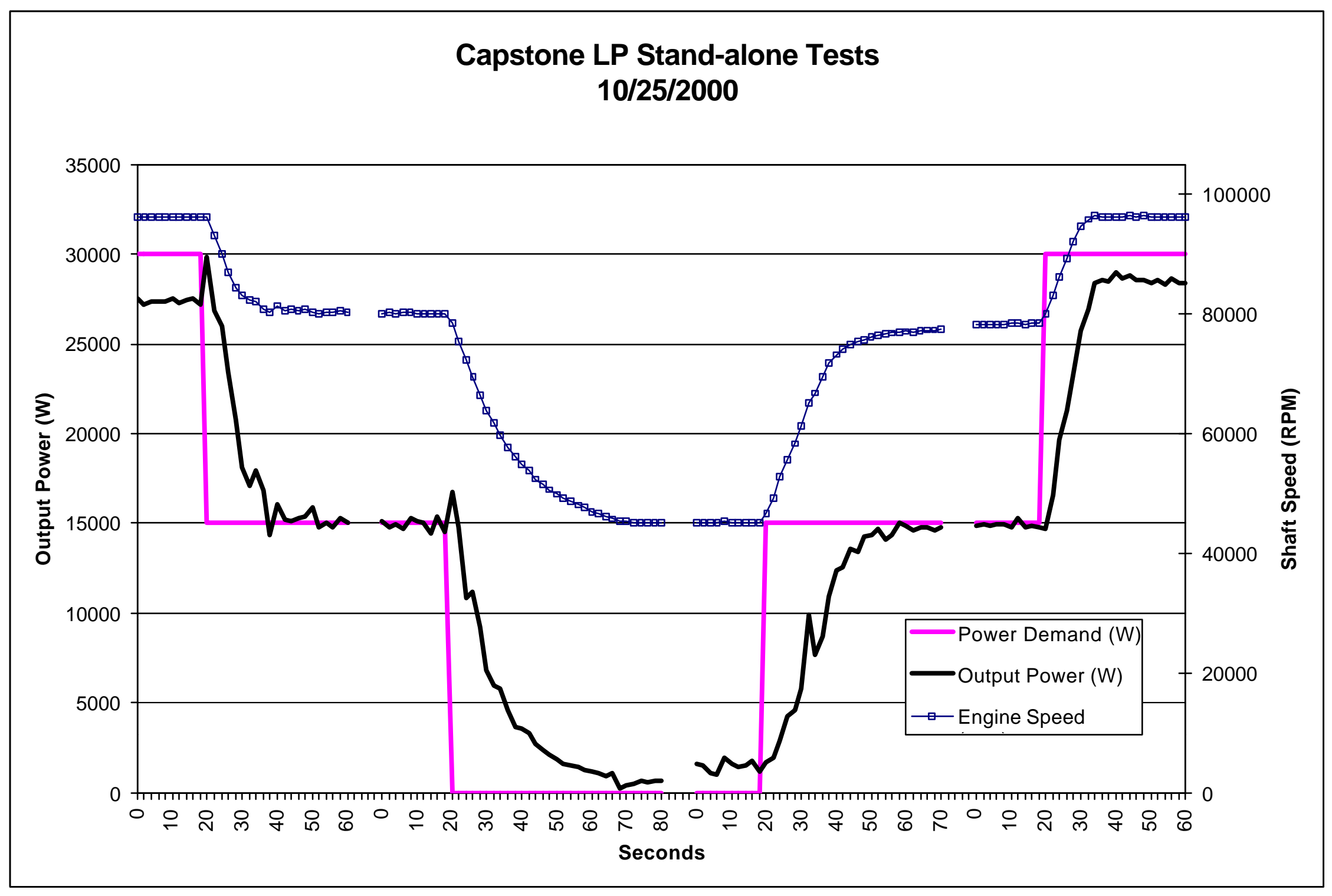

Figure B-4: Power and Shaft Speed - 15 kW Tests 


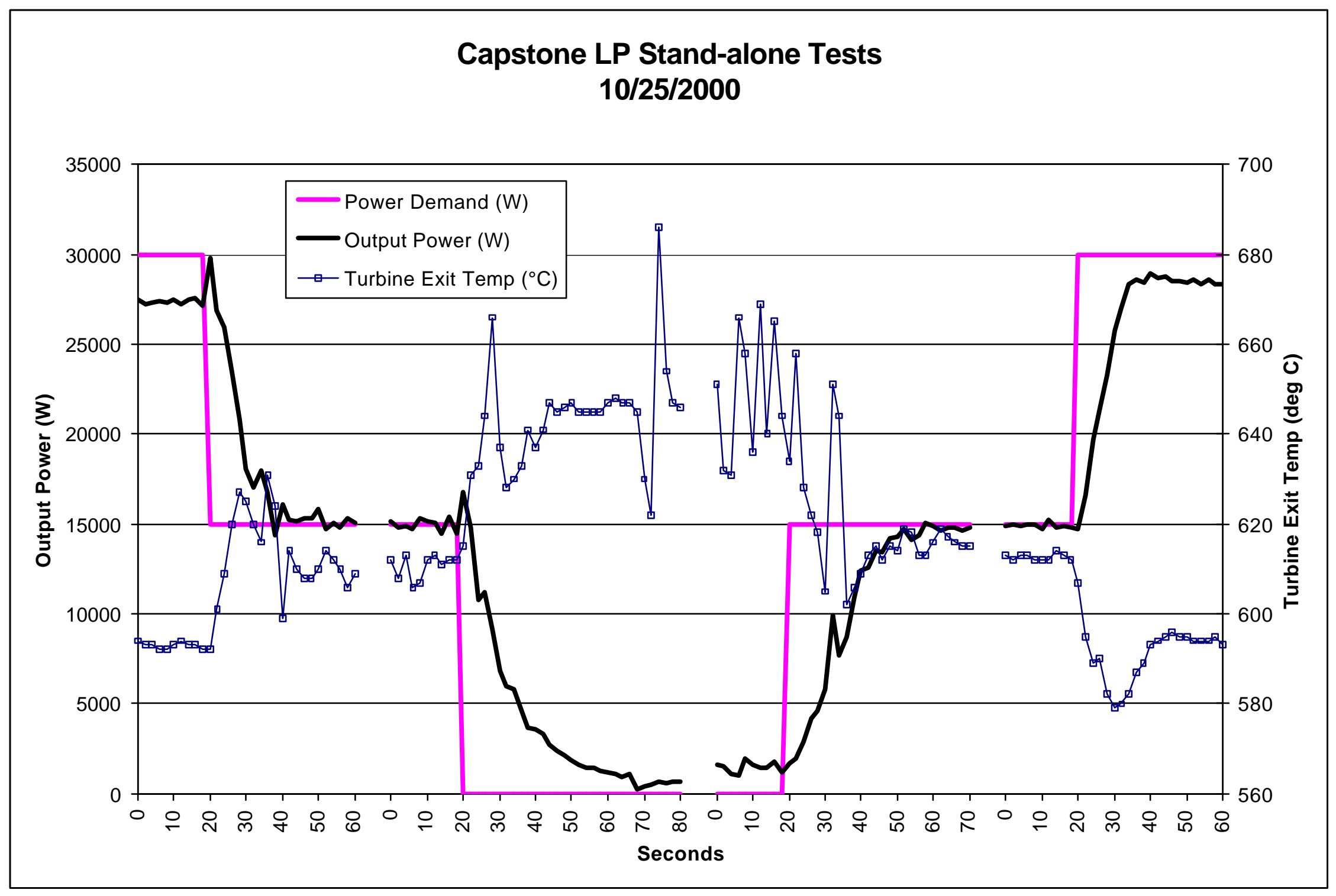

Figure B-5: Power and Turbine Exit Temperature - 15 kW Steps 


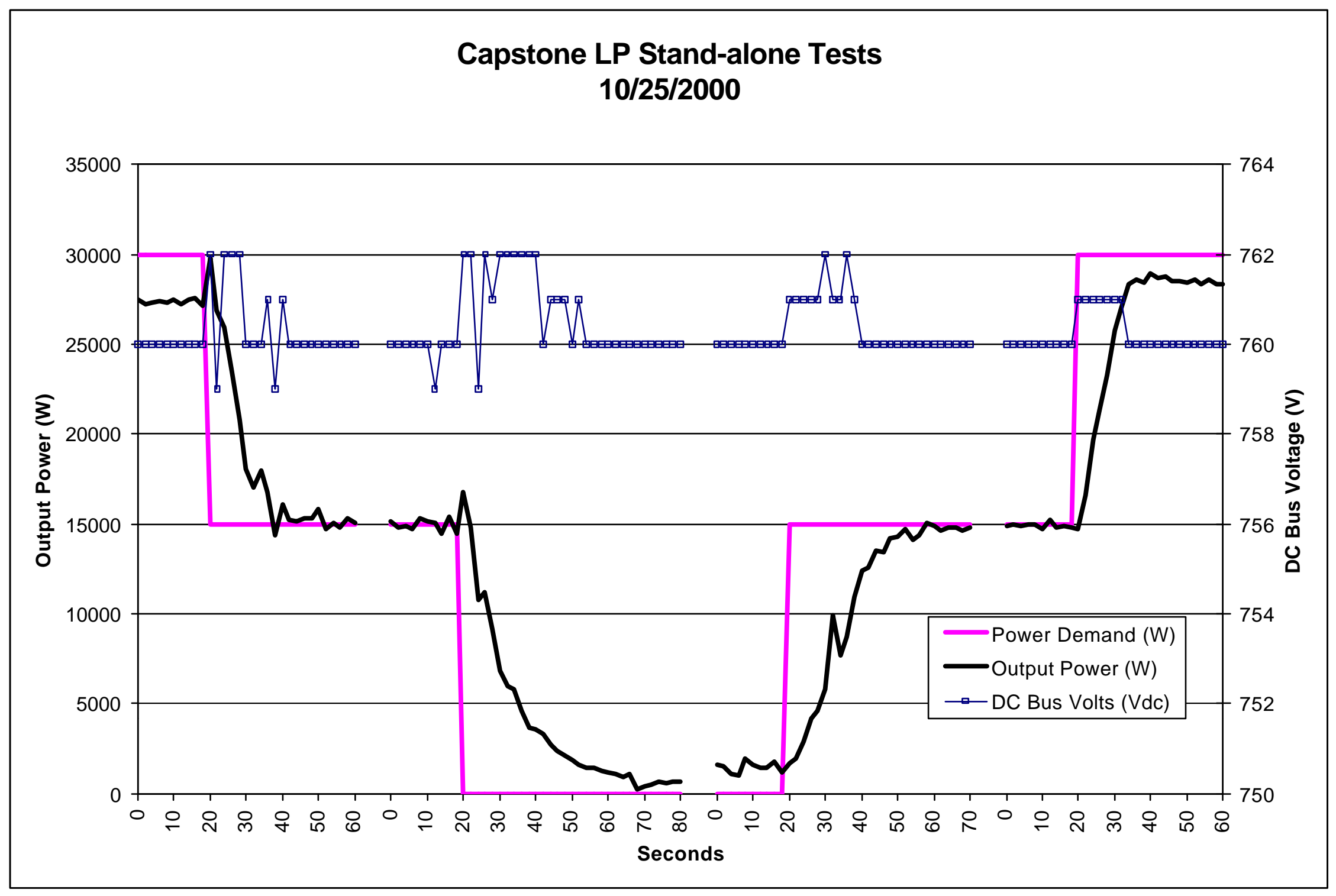

Figure B-6: Power and DC Bus Voltage - 15 kW Steps 


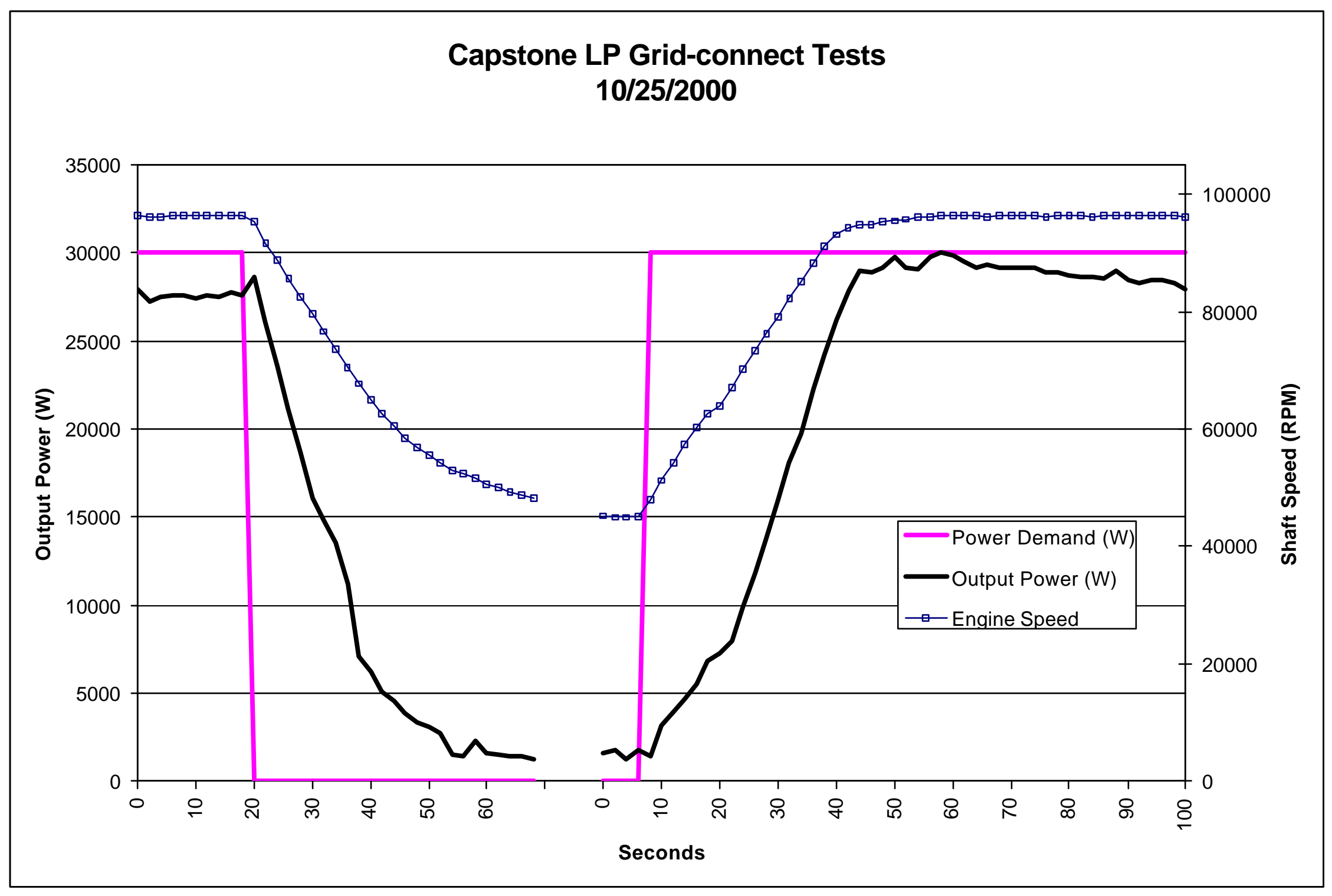

Figure B-7: Power and Shaft Speed - Full Load Steps 


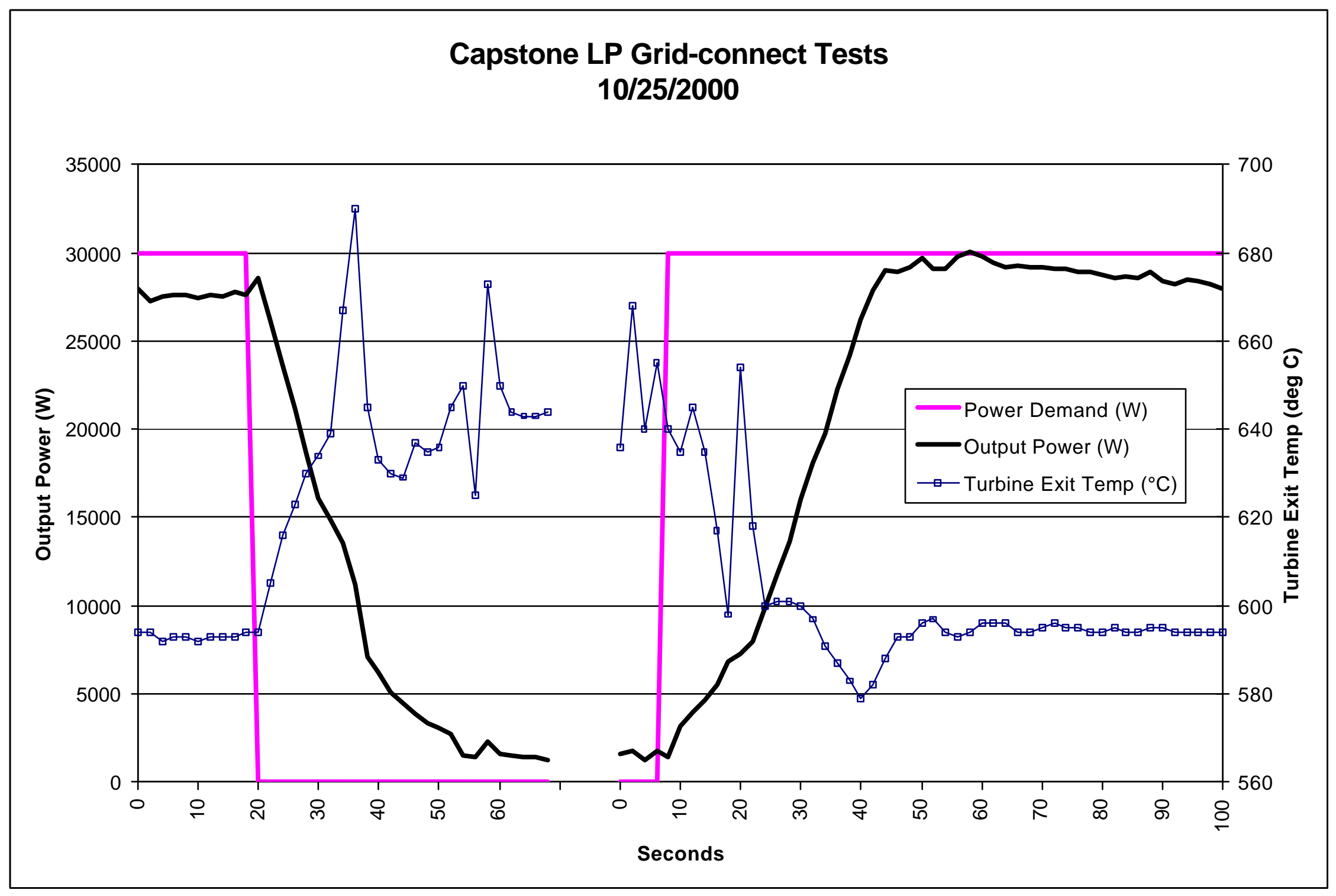

Figure B-8: Power and Turbine Exit Temperature - Full Load Steps 


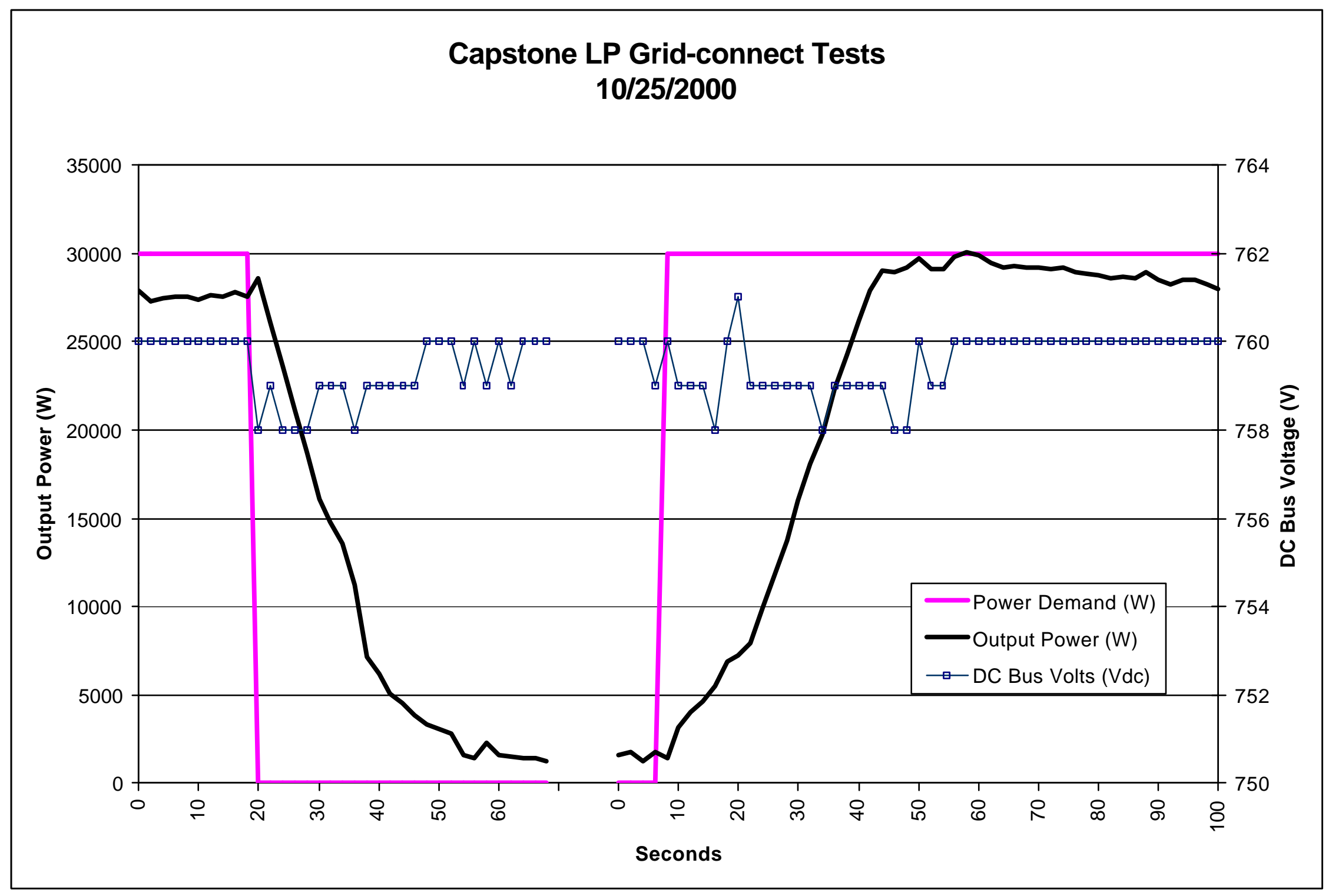

Figure B-9: Power and DC Bus Voltage - Full Power Steps 


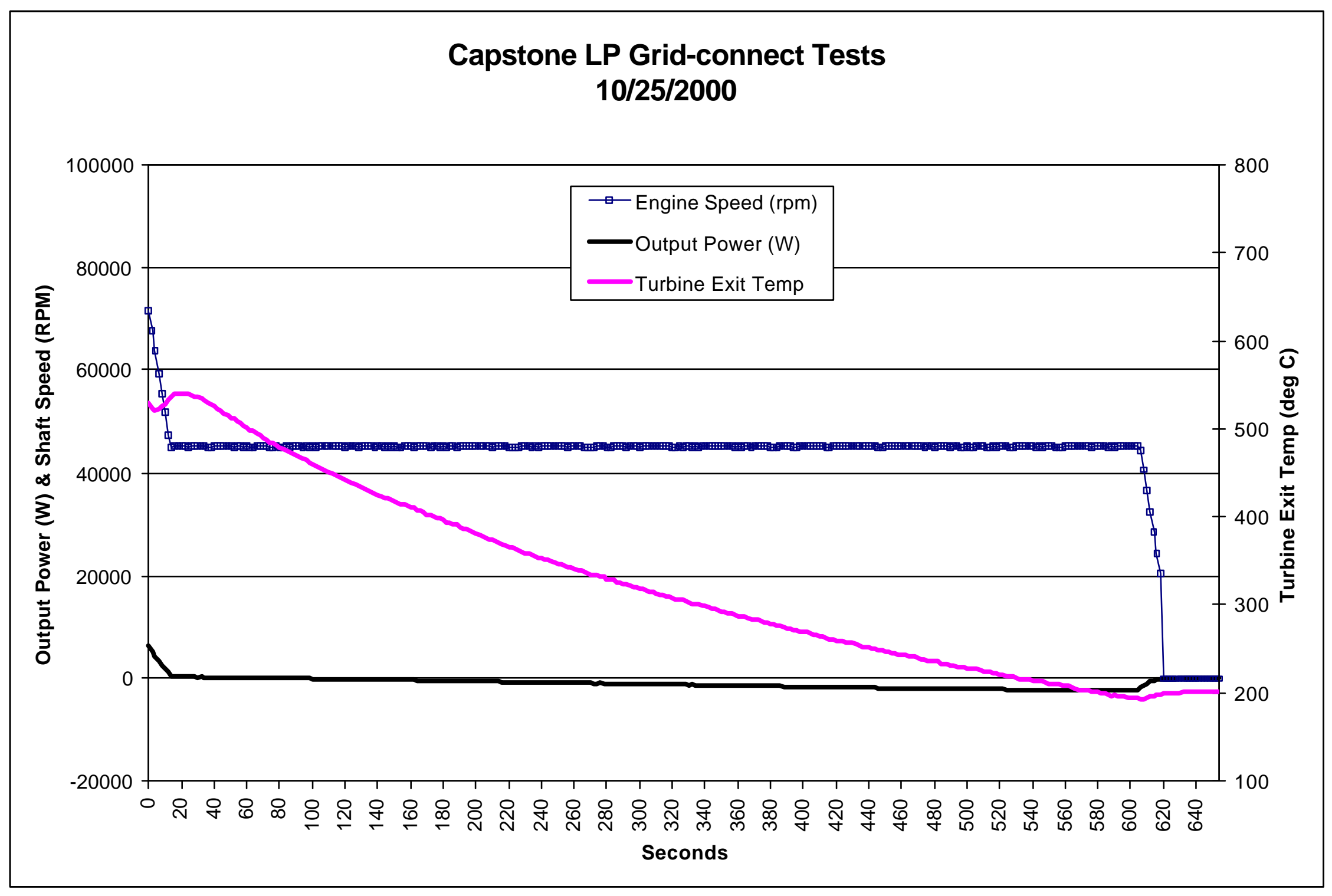

Figure B-10: Power, Shaft Speed and Turbine Exit Temperature During MTG Shutdown 


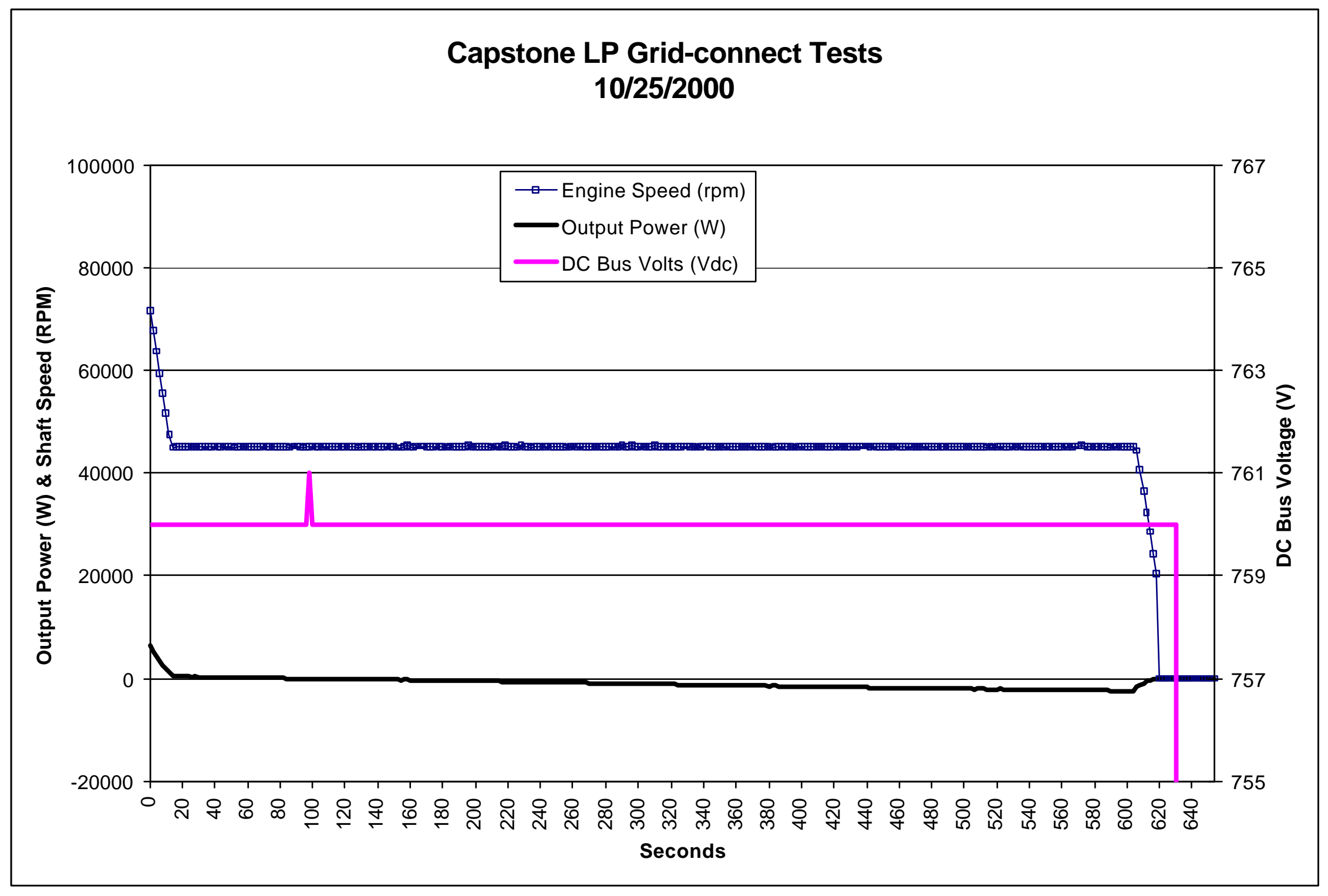

Figure B-11: Power, Shaft Speed and DC Bus Voltage During MTG Shutdown 


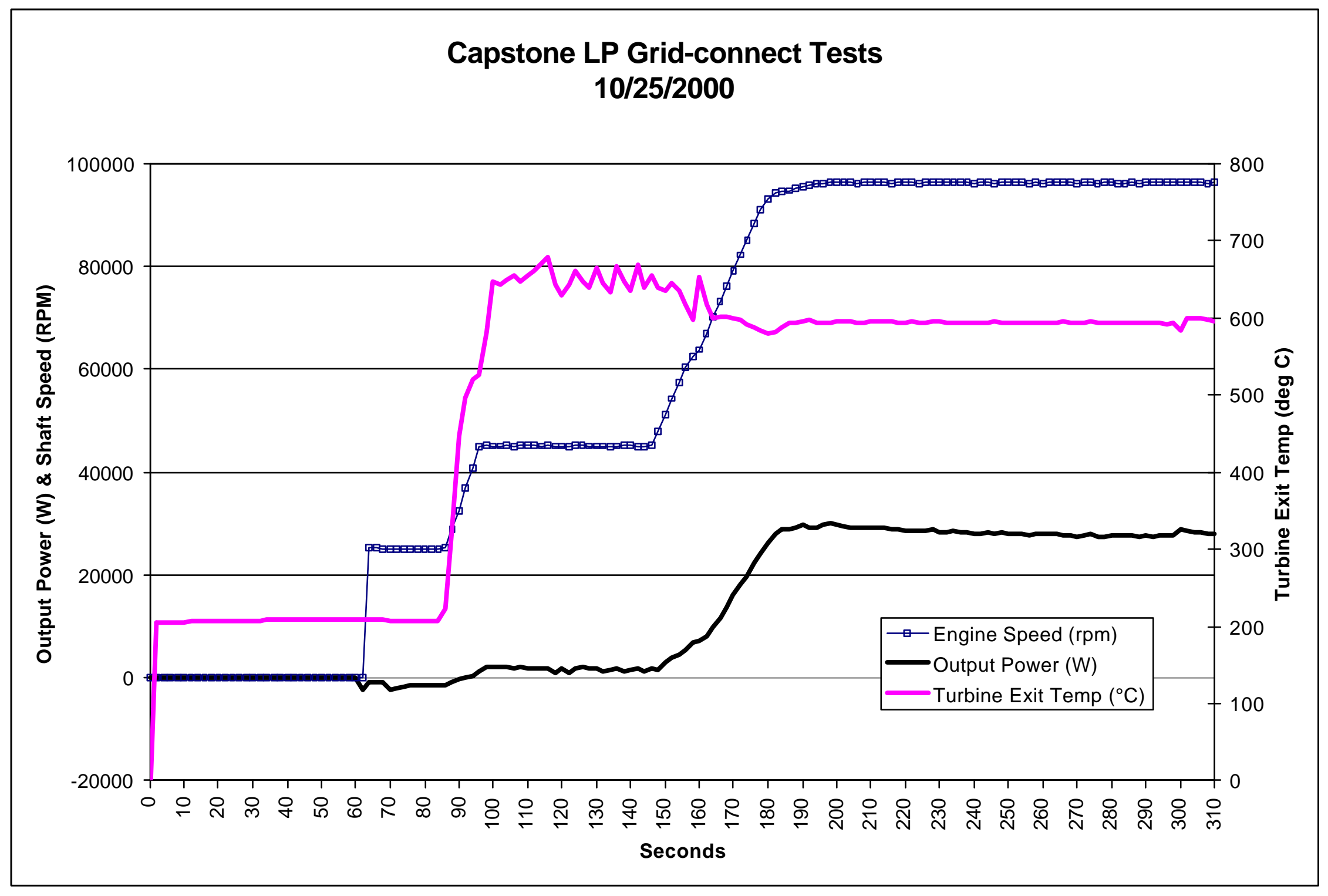

Figure B-12: Power, Shaft Speed and Turbine Exit Temperature During MTG Start 


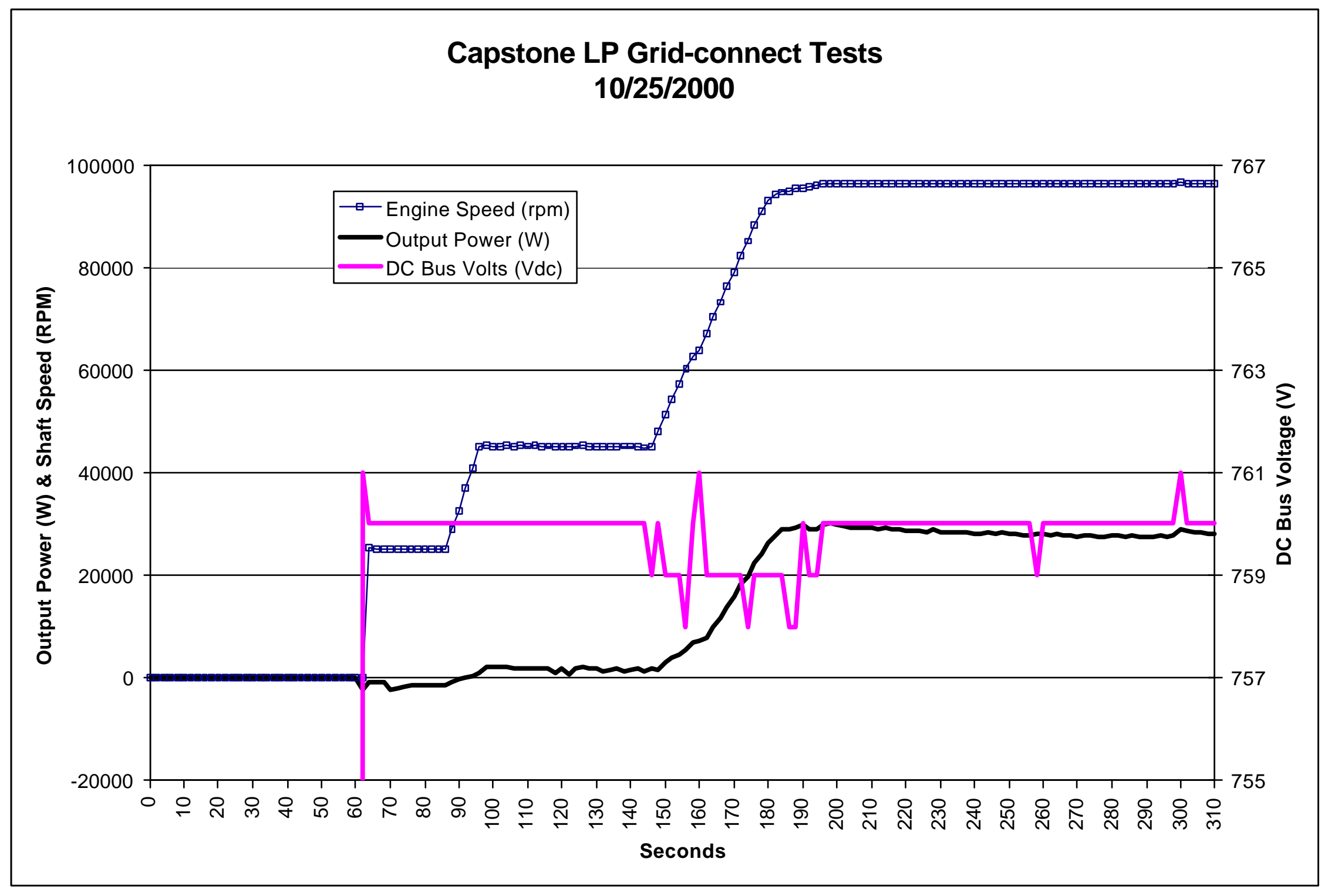

Figure B-13: Power, Shaft Speed and DC Bus Voltage During MTG Start 


\section{Appendix C}

\section{Honeywell Parallon Grid-connect Tests}

12/20/2000 


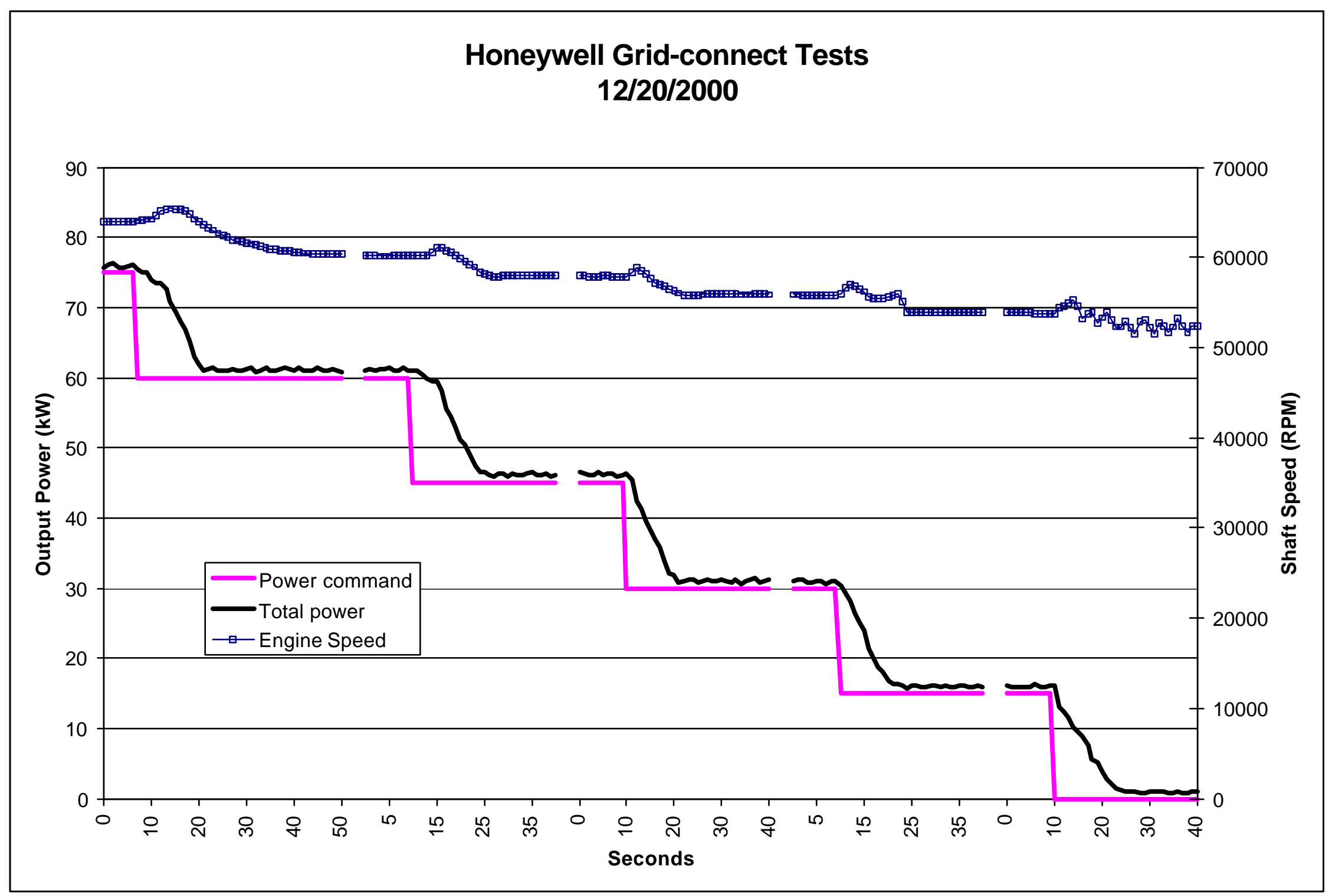

Figure C-1: Ramp Down Tests - Power and Shaft Speed - 15 kW Steps 


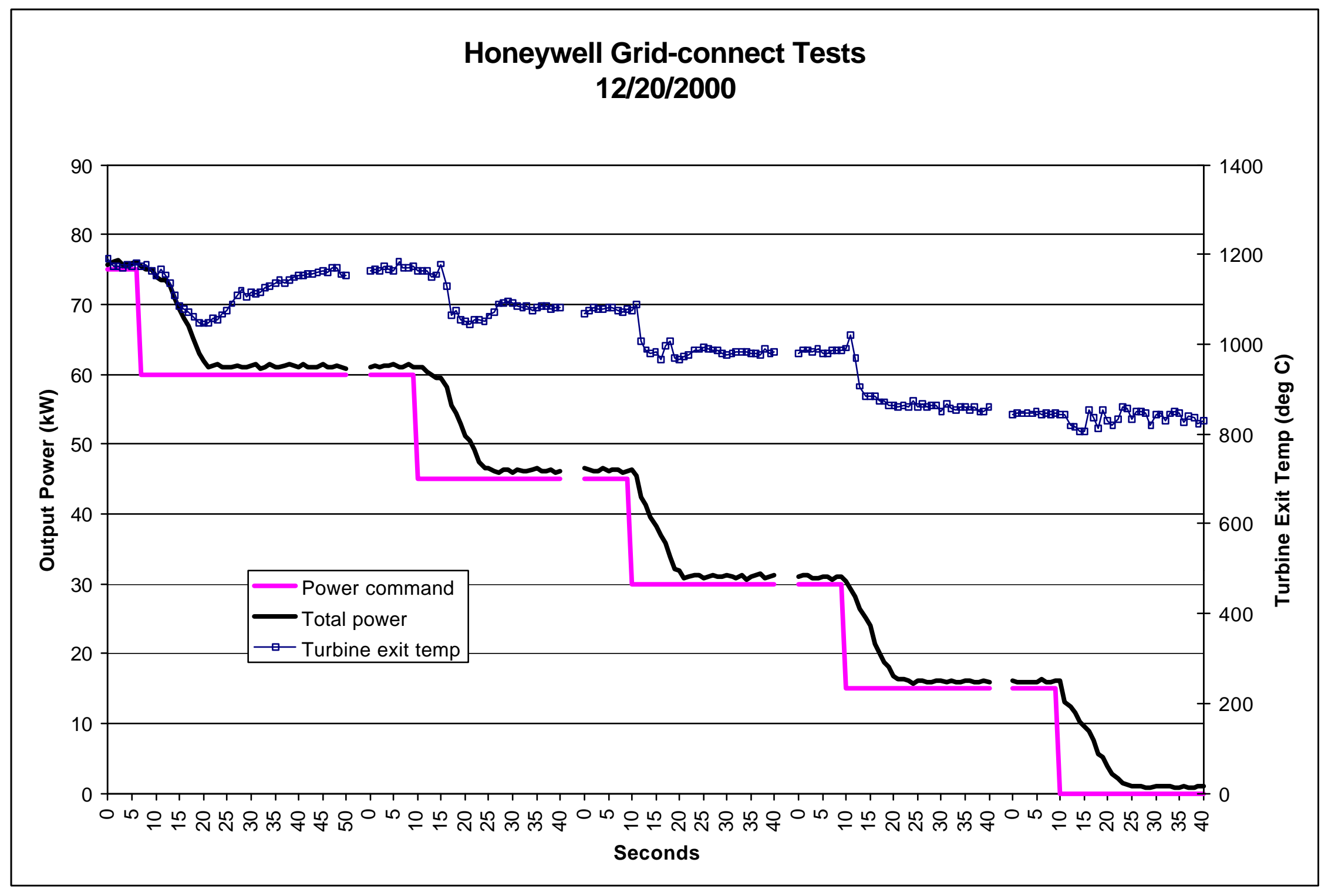

Figure C-2: Ramp Down Tests - Power and Turbine Exit Temperature - 15 kW Steps 


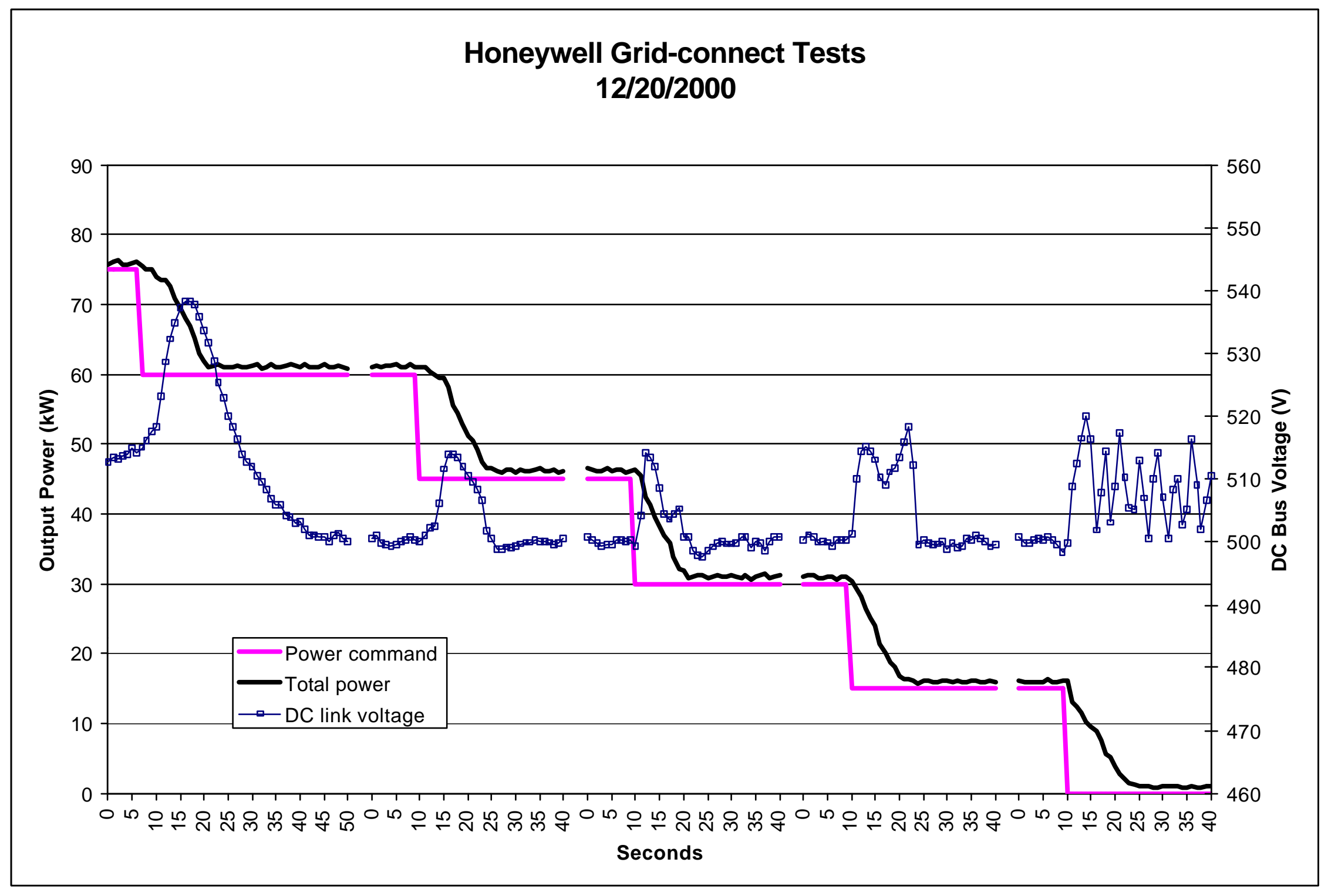

Figure C-3: Ramp Down Tests - Power and DC Bus Voltage - 15 kW Steps 


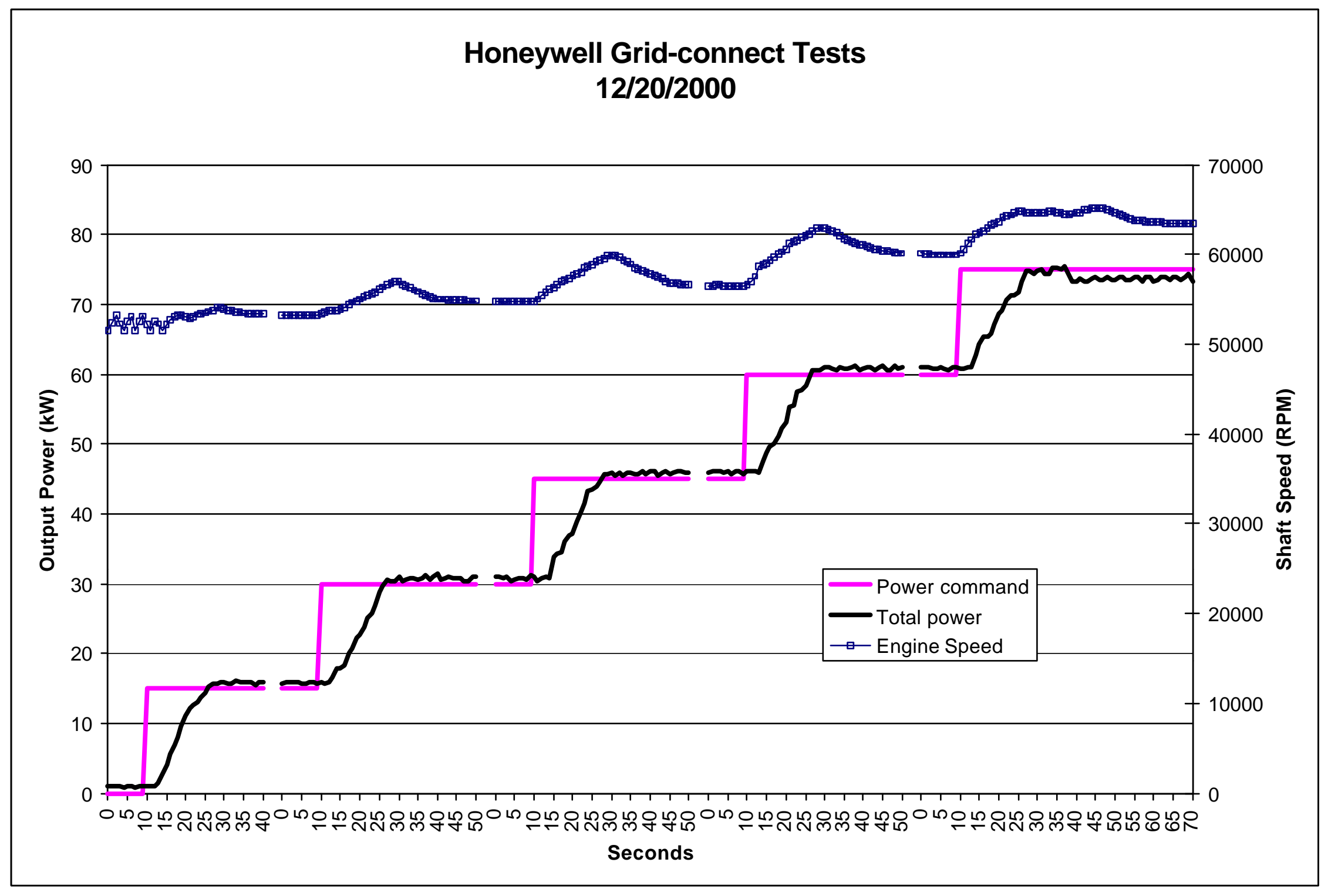

Figure C-4: Ramp Up Tests - Power and Shaft Speed - 15 kW Steps 


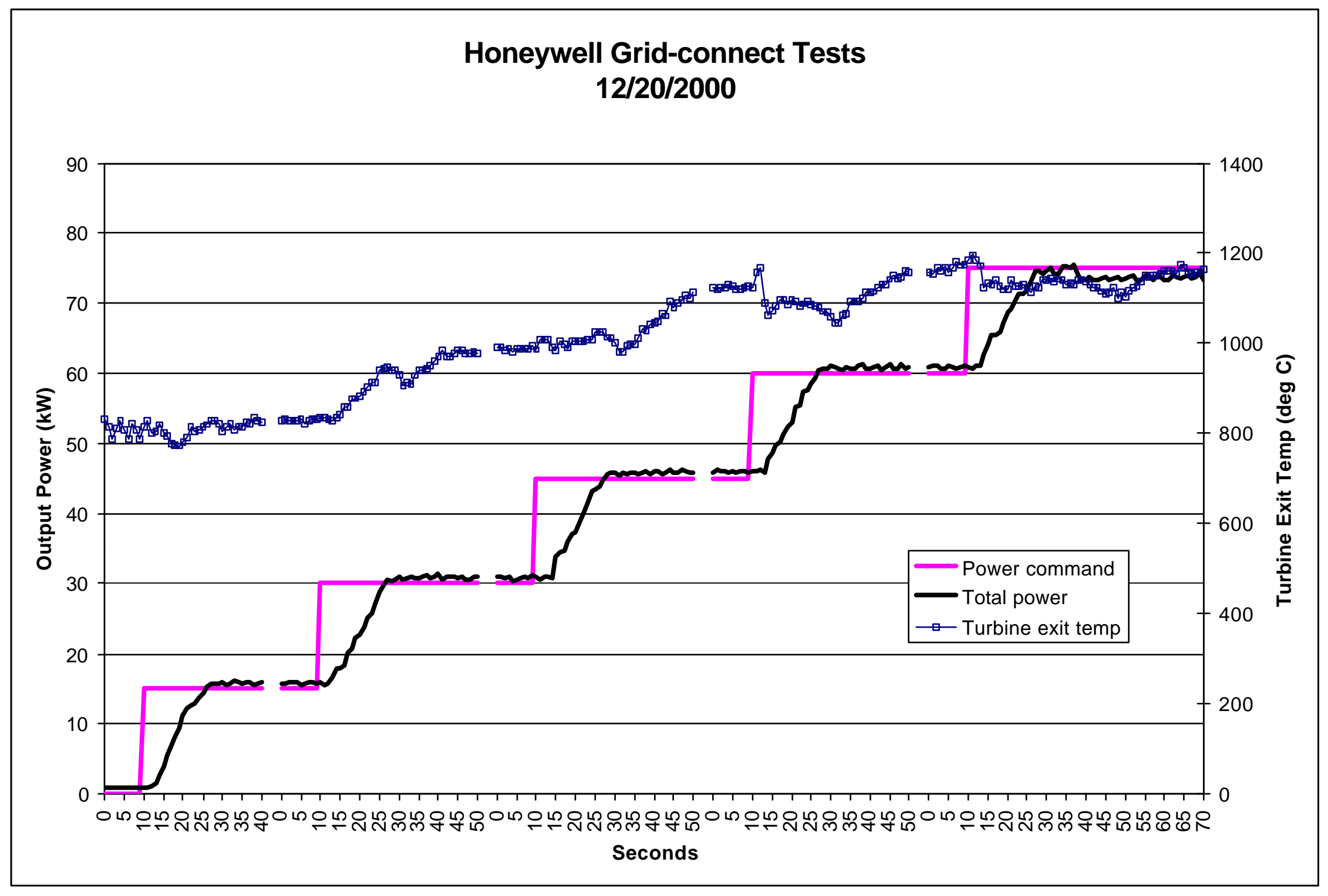

Figure C-5: Ramp Up Tests - Power and Turbine Exit Temperature - 15 kW Steps 


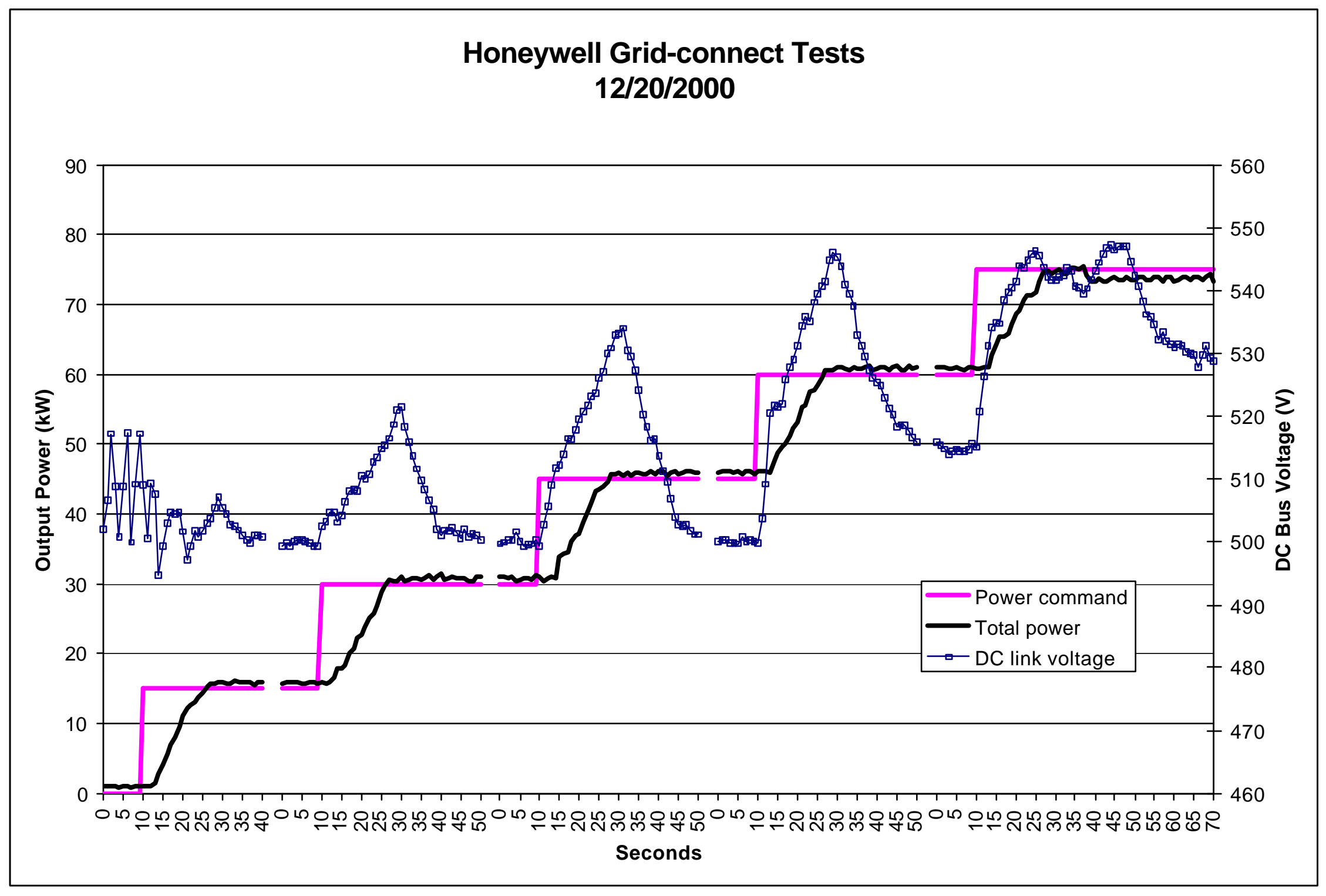

Figure C-6: Ramp Up Tests - Power and DC Bus Voltage - 15 kW Steps 


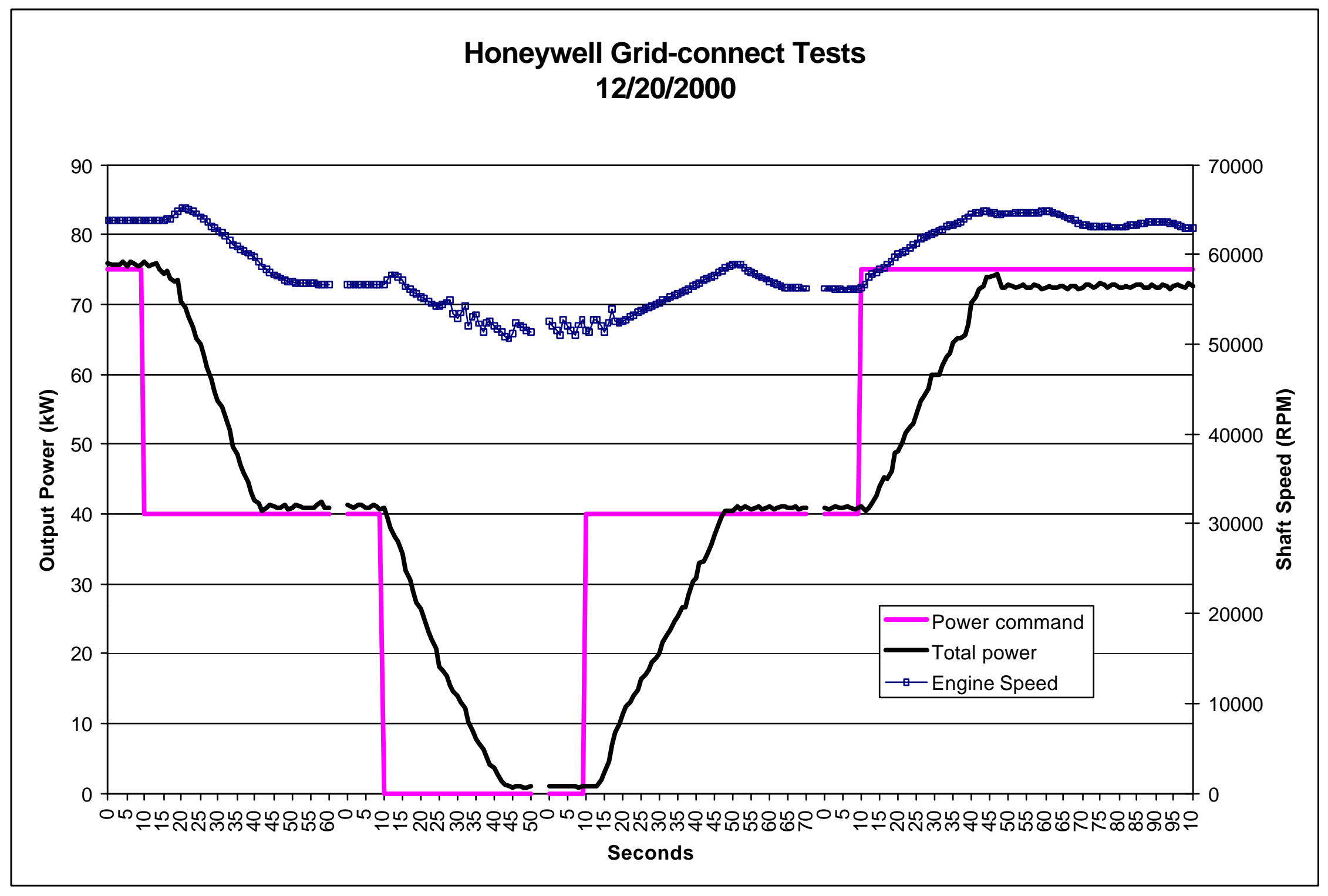

Figure C-7: Ramp Tests - Power and Shaft Speed - 40/35 kW Steps 


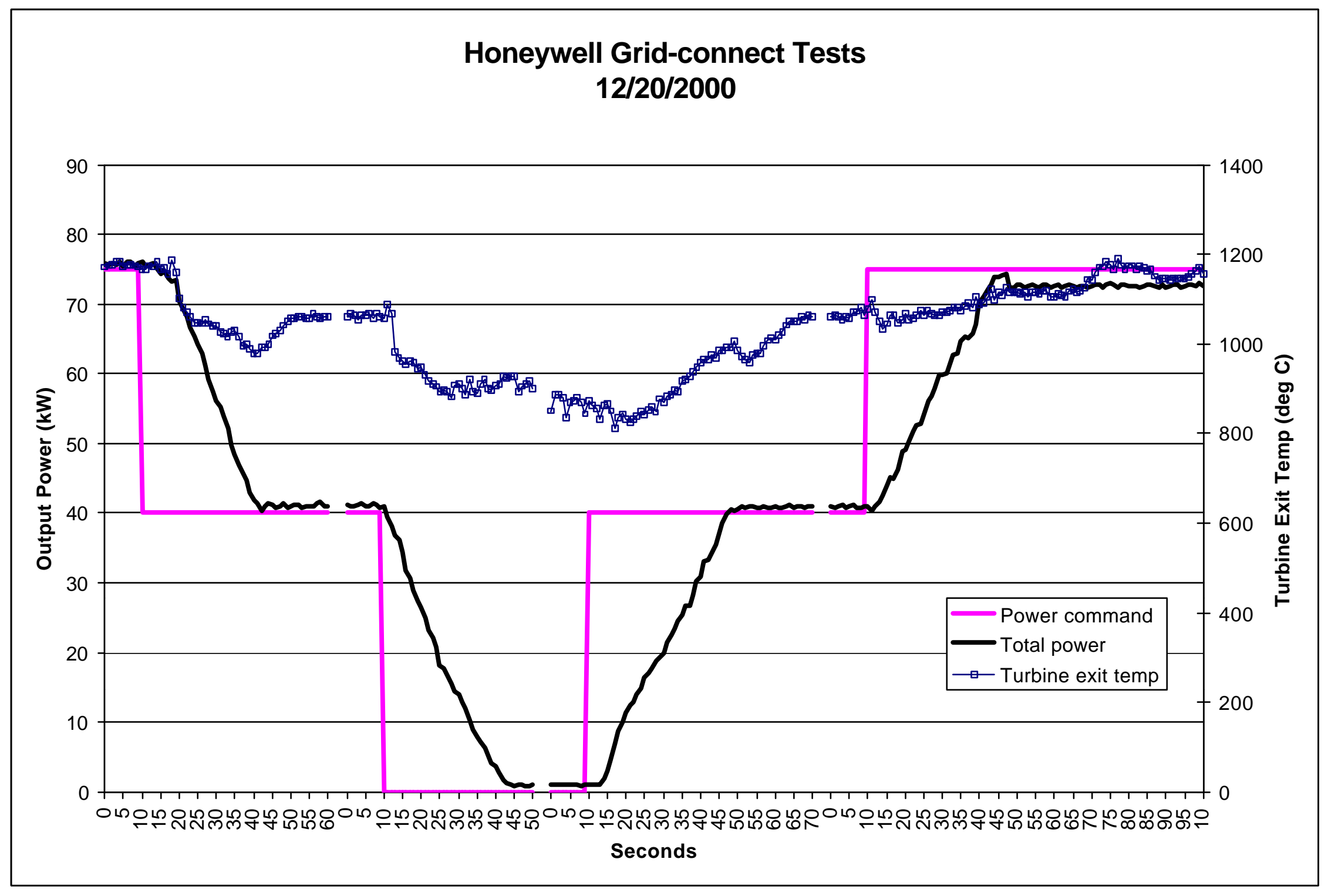

Figure C-8: Ramp Tests - Power and Turbine Exit Temperature - 40/35 kW Tests 


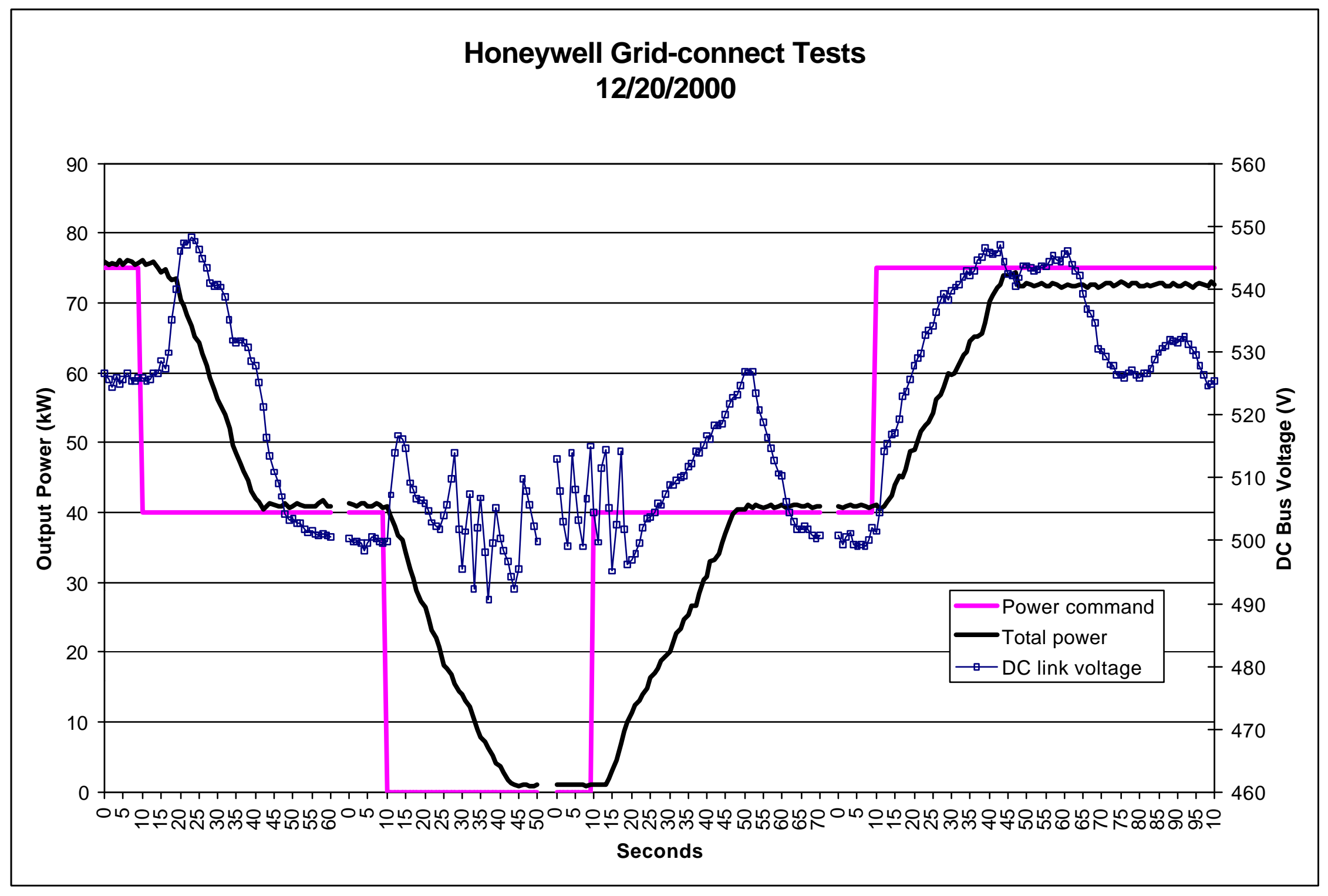

Figure C-9: Ramp Tests - Power and DC Bus Voltage - 40/35 kW Tests 


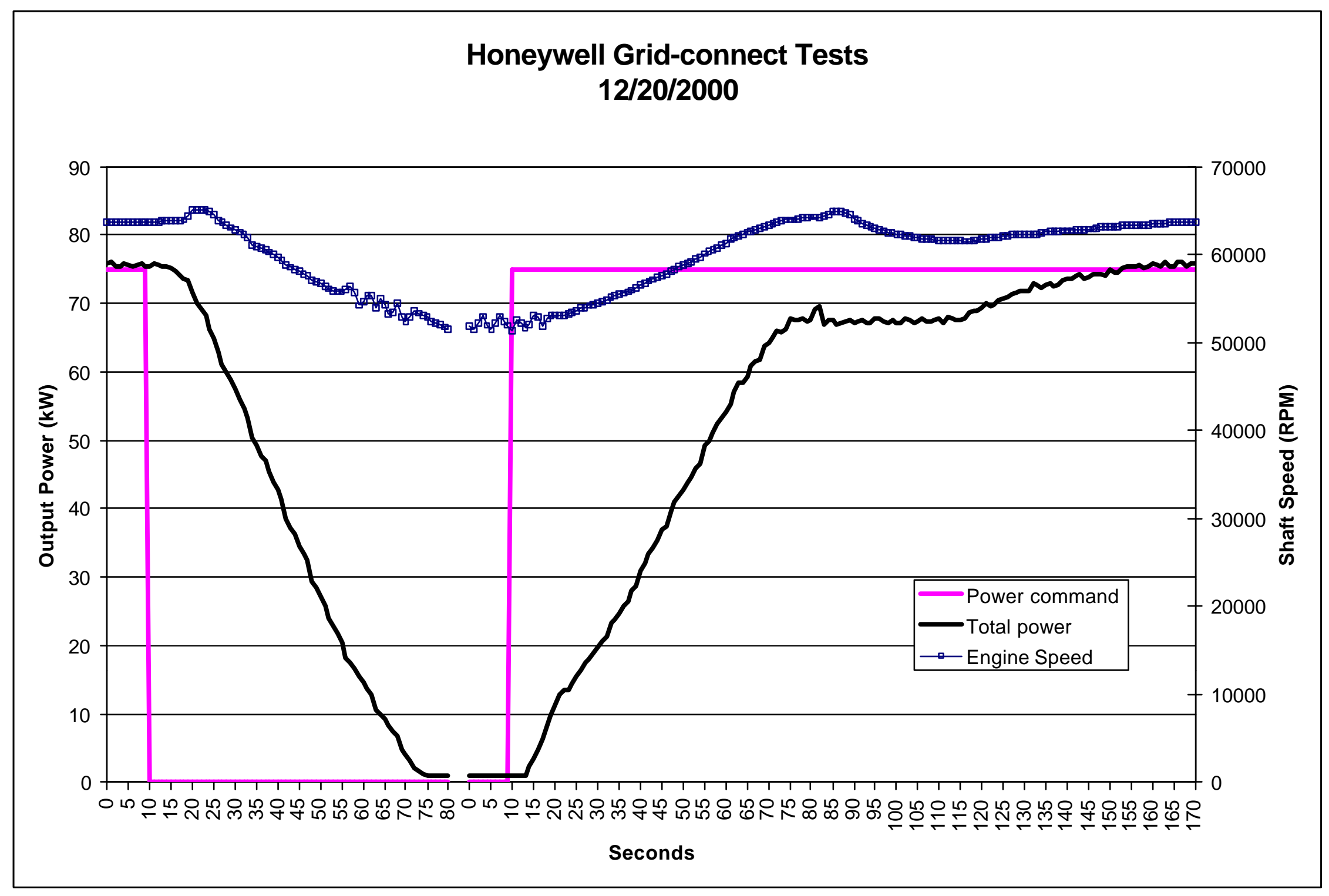

Figure C-10: Ramp Tests - Power and Shaft Speed - Full Load Steps 


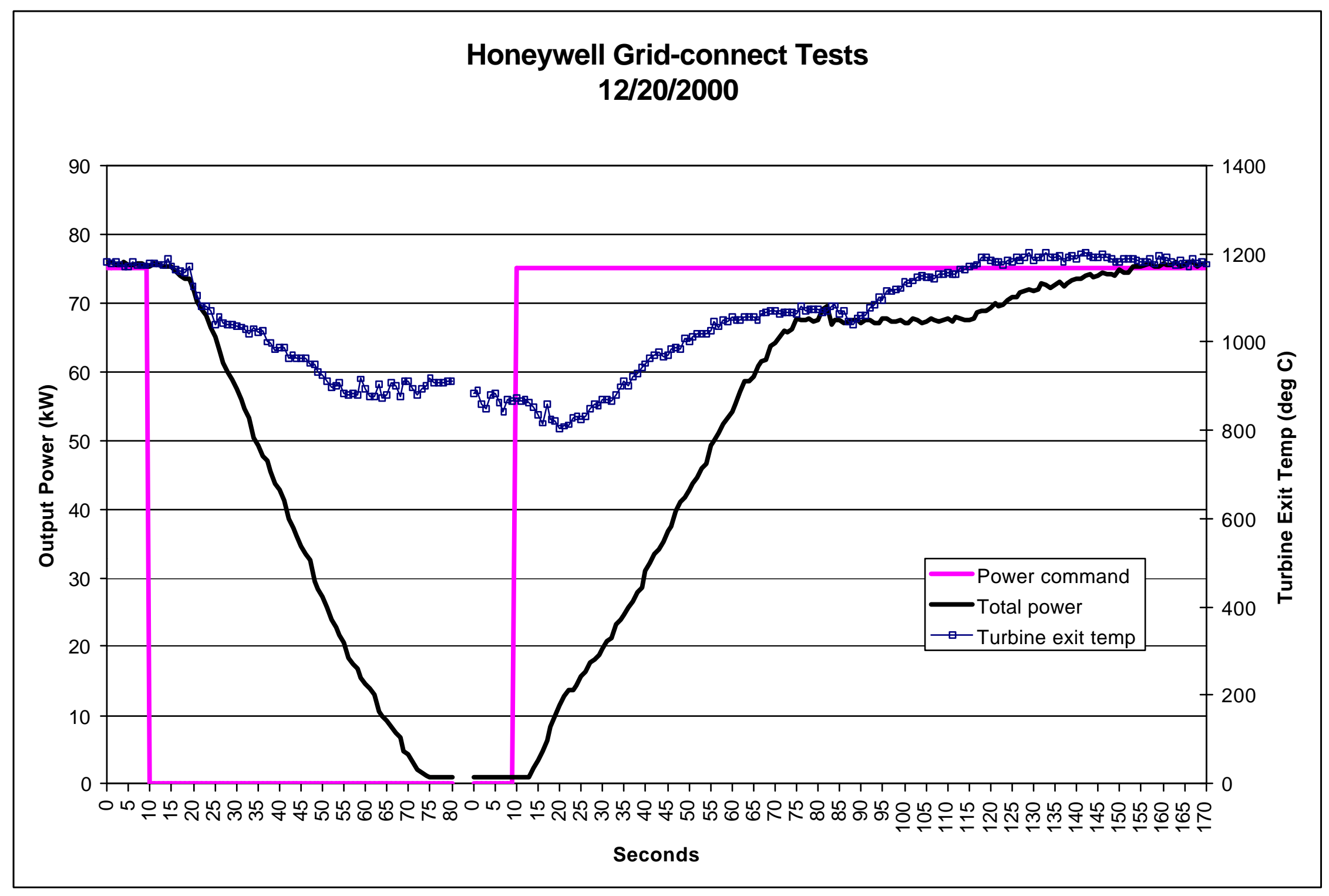

Figure C-11: Ramp Tests - Power and Turbine Exit Temperature - Full Load Steps 


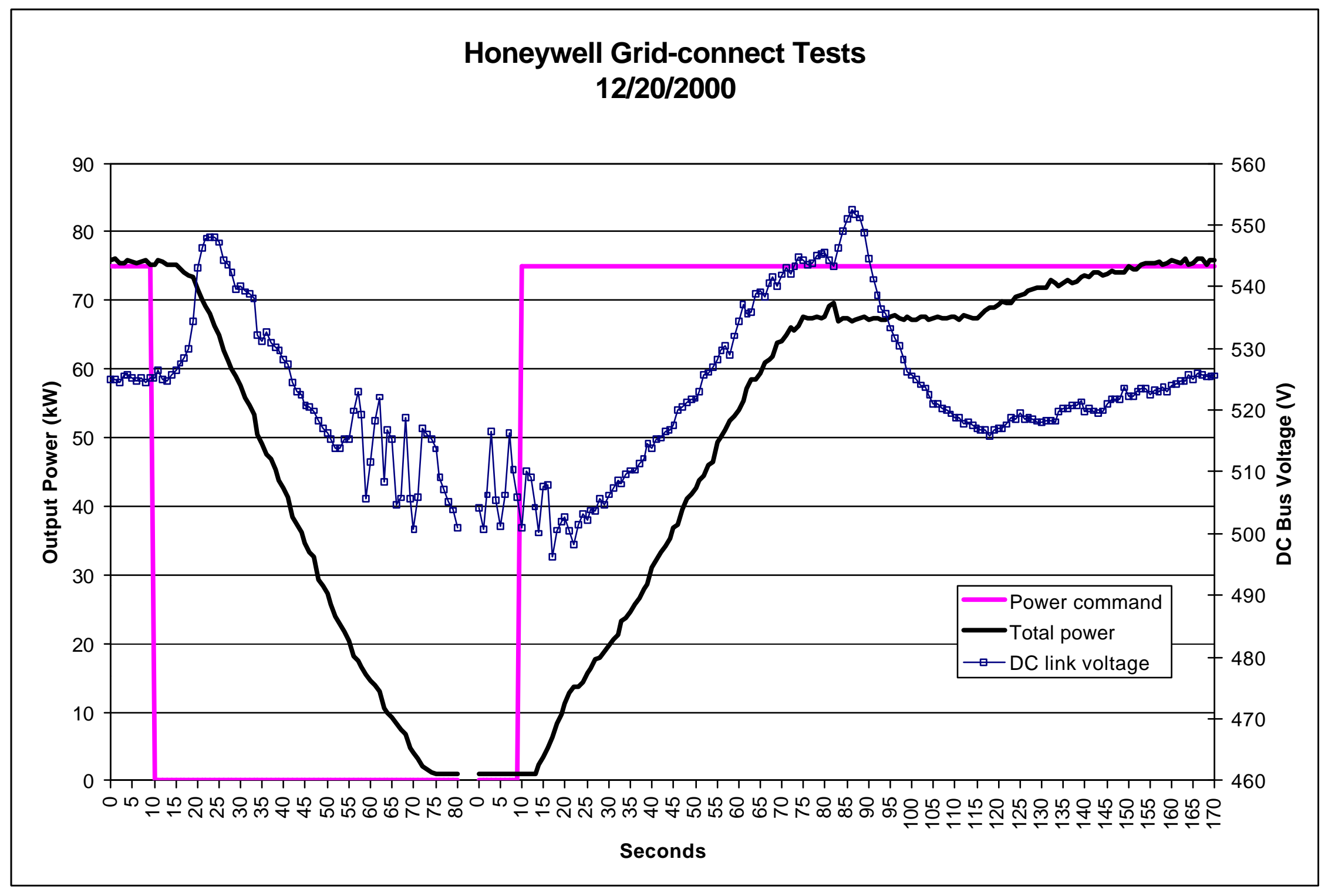

Figure C-12: Ramp Tests - Power and DC Bus Voltage - Full Load Tests 


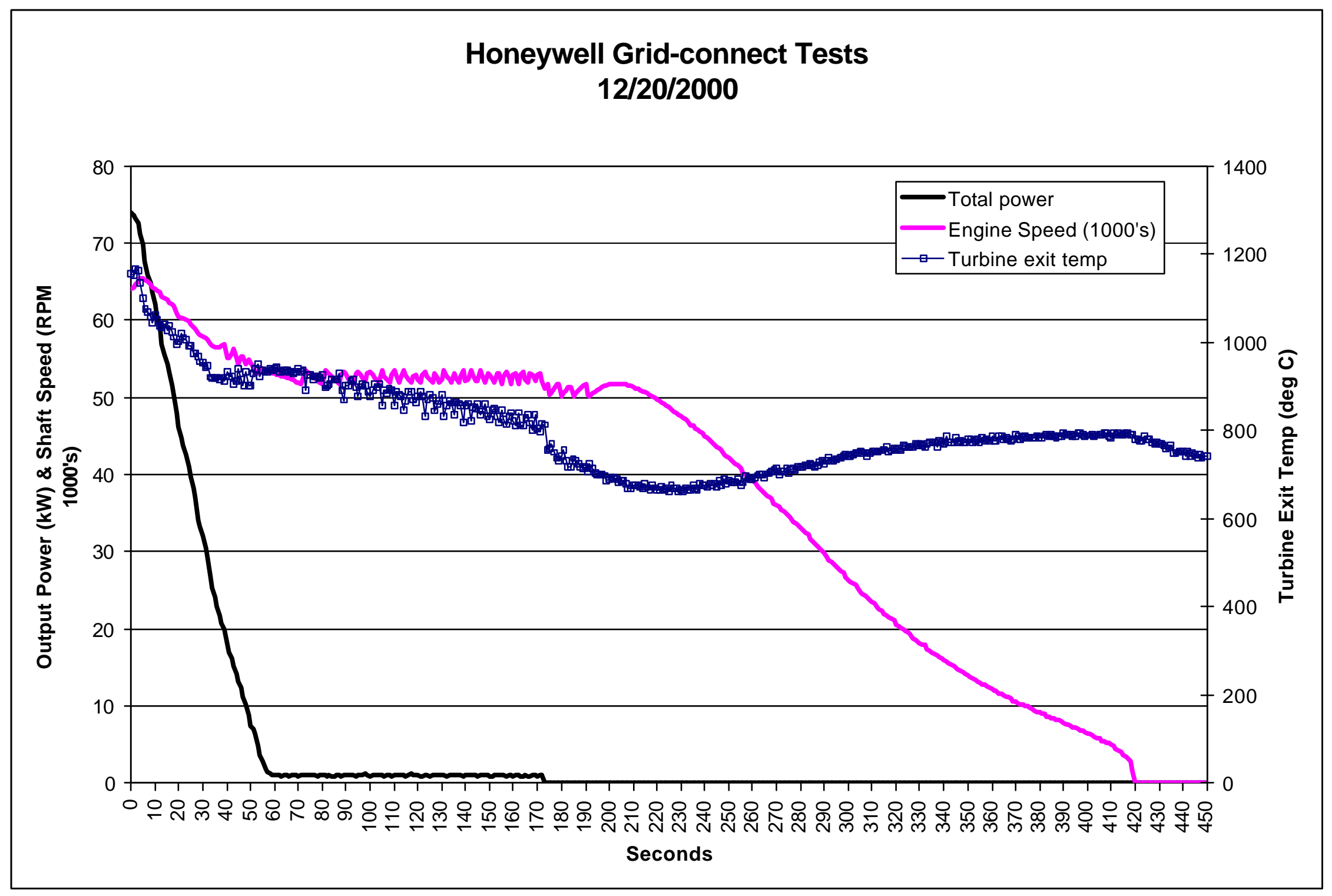

Figure C-13: Power, Shaft Speed and Turbine Exit Temperature During MTG Shutdown 


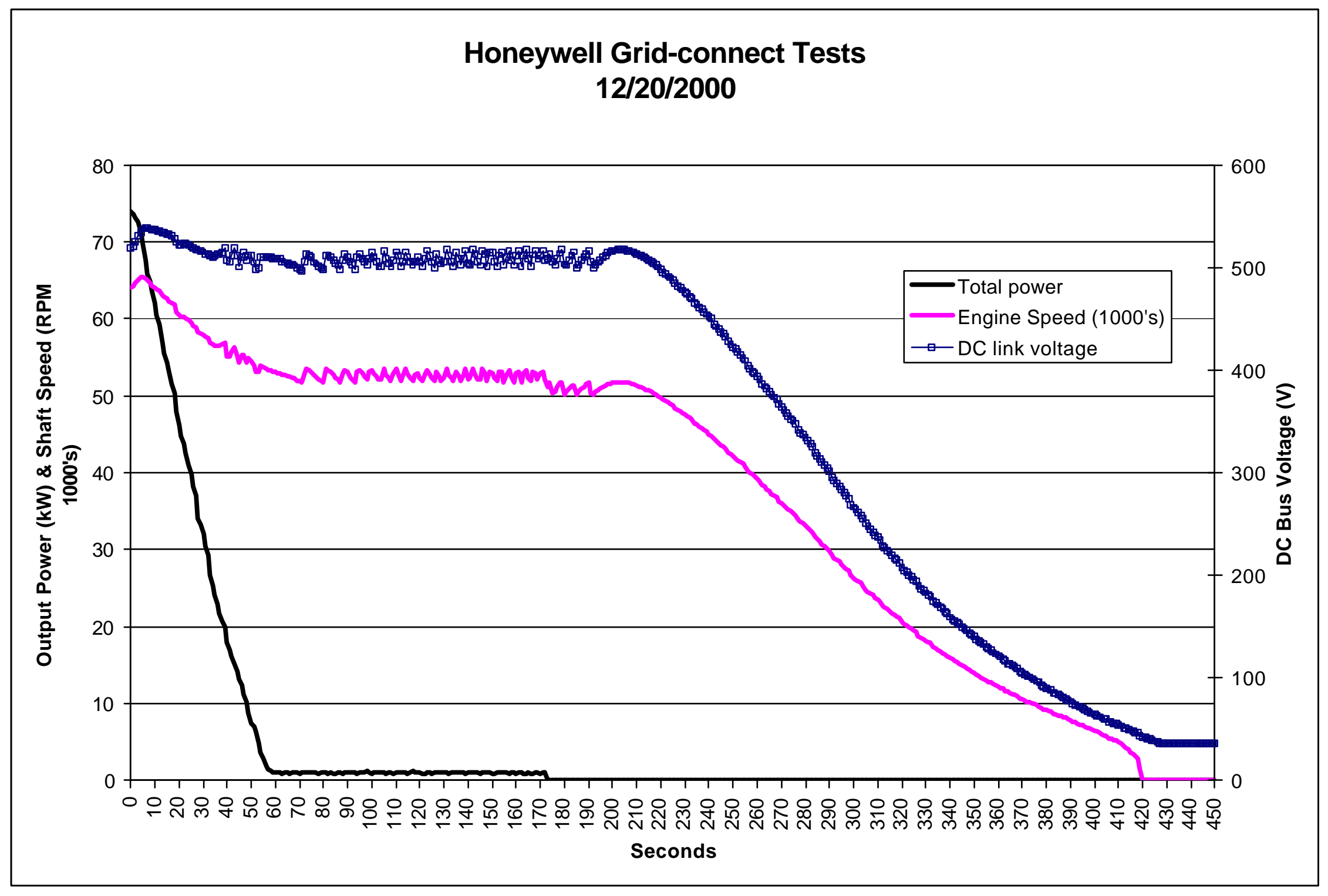

Figure C-14: Power, Shaft Speed and DC Bus Voltage During MTG Shutdown 


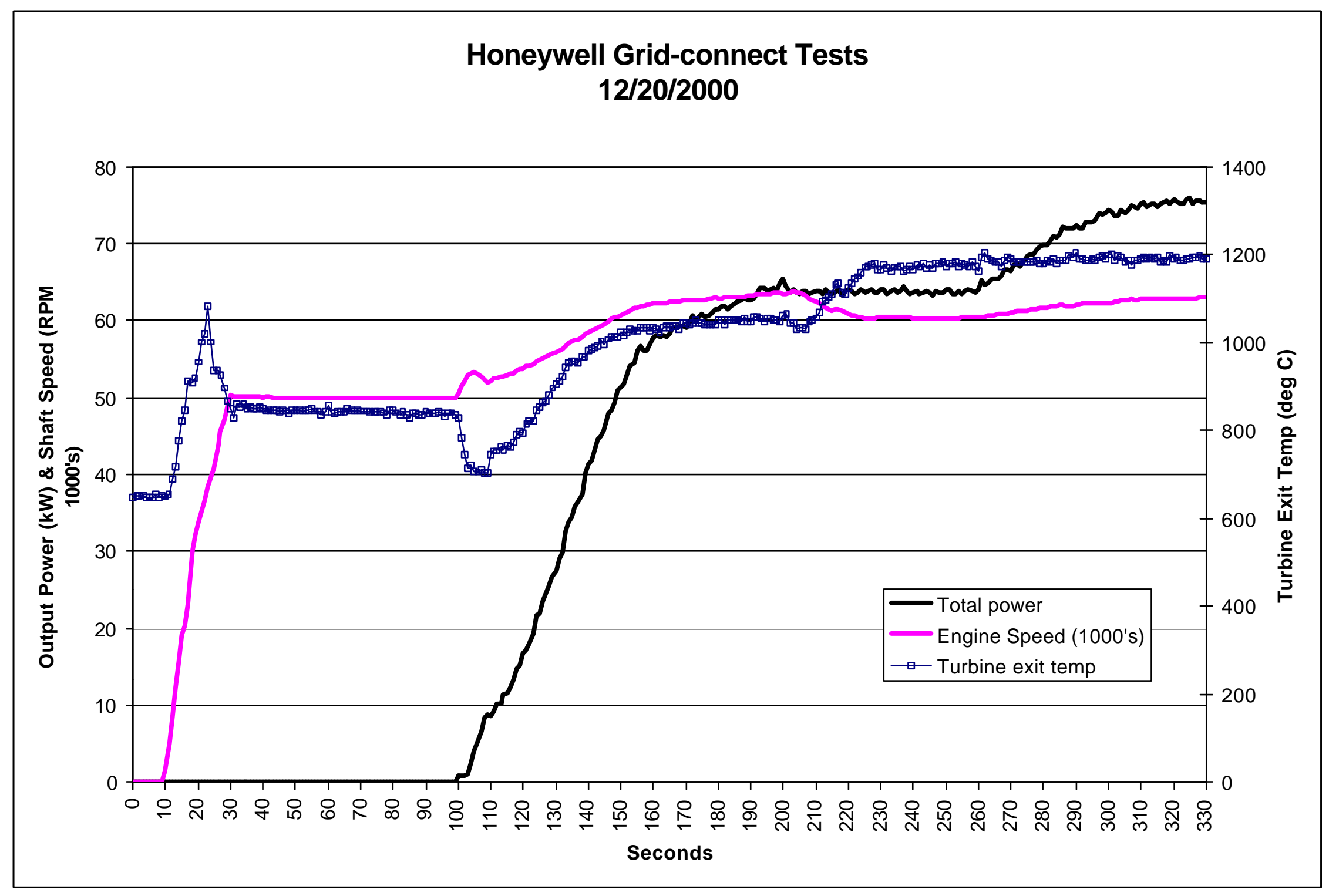

Figure C-15: Power, Shaft Speed and Turbine Exit Temperature During MTG Start 


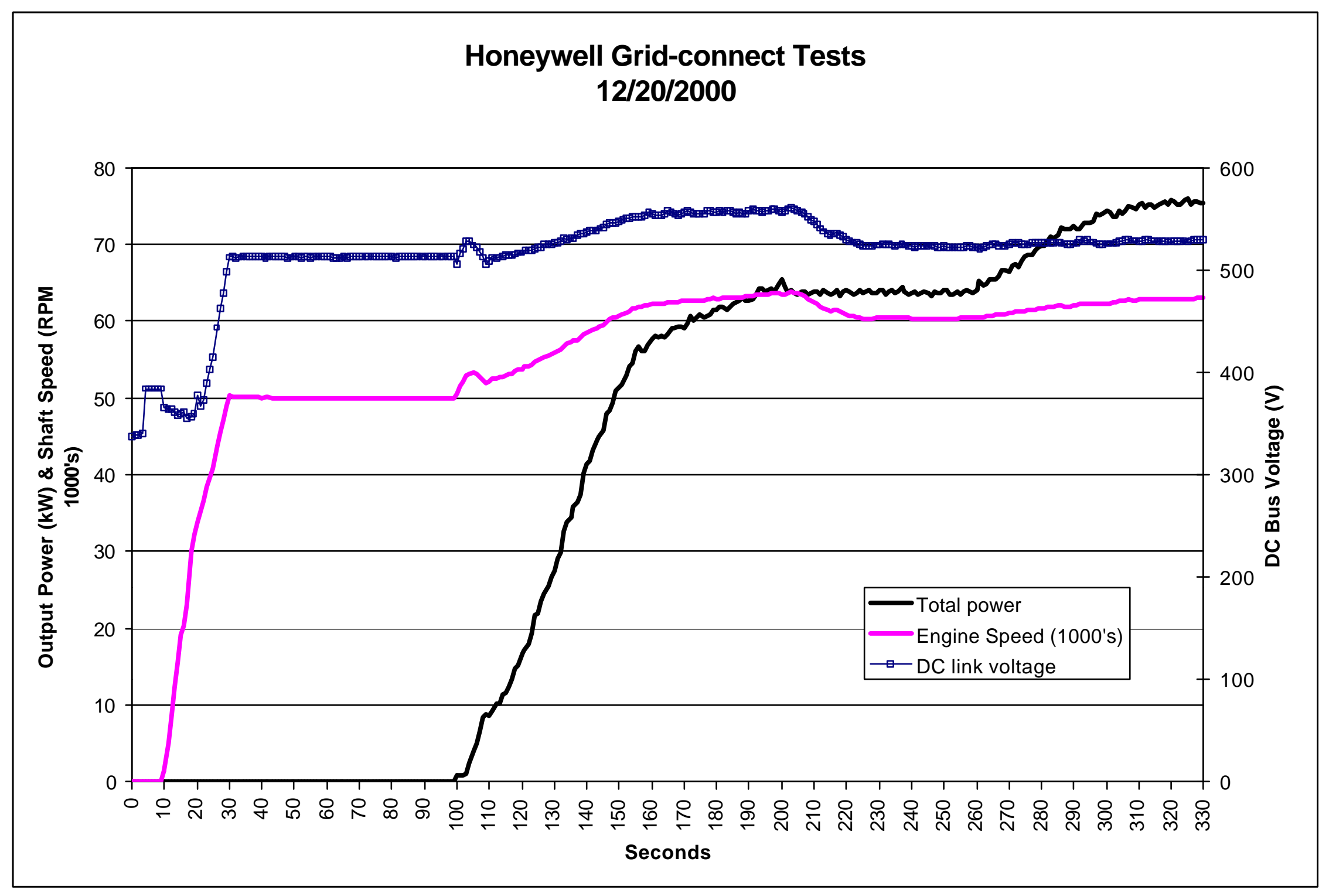

Figure C-16: Power, Shaft Speed and Turbine Exit Temperature During MTG Start 


\section{Appendix D}

Capstone LP Stand-alone Tests 3/20/2001 


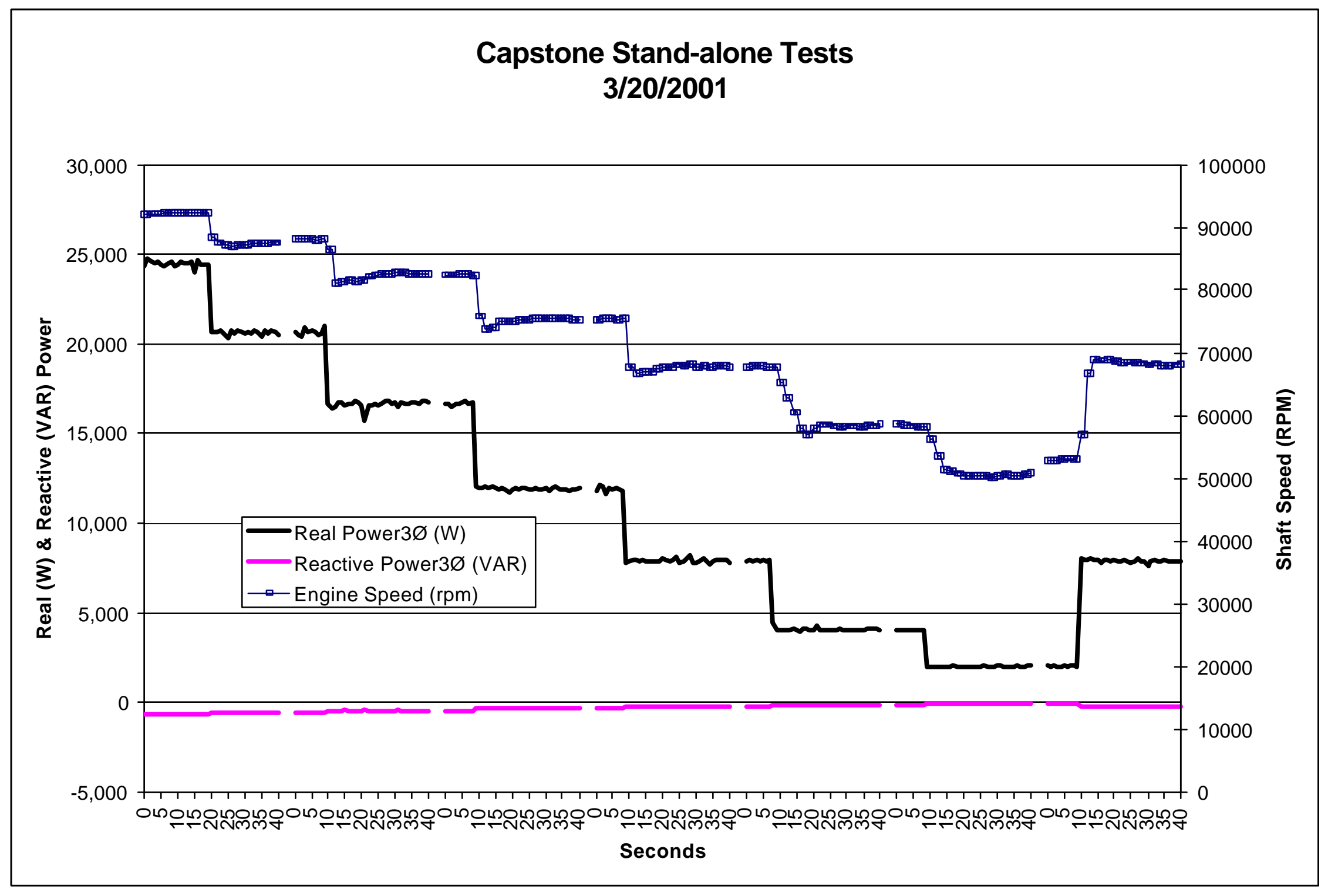

Figure D-1: Ramp Tests - Power and Shaft Speed - 4 kW Steps 


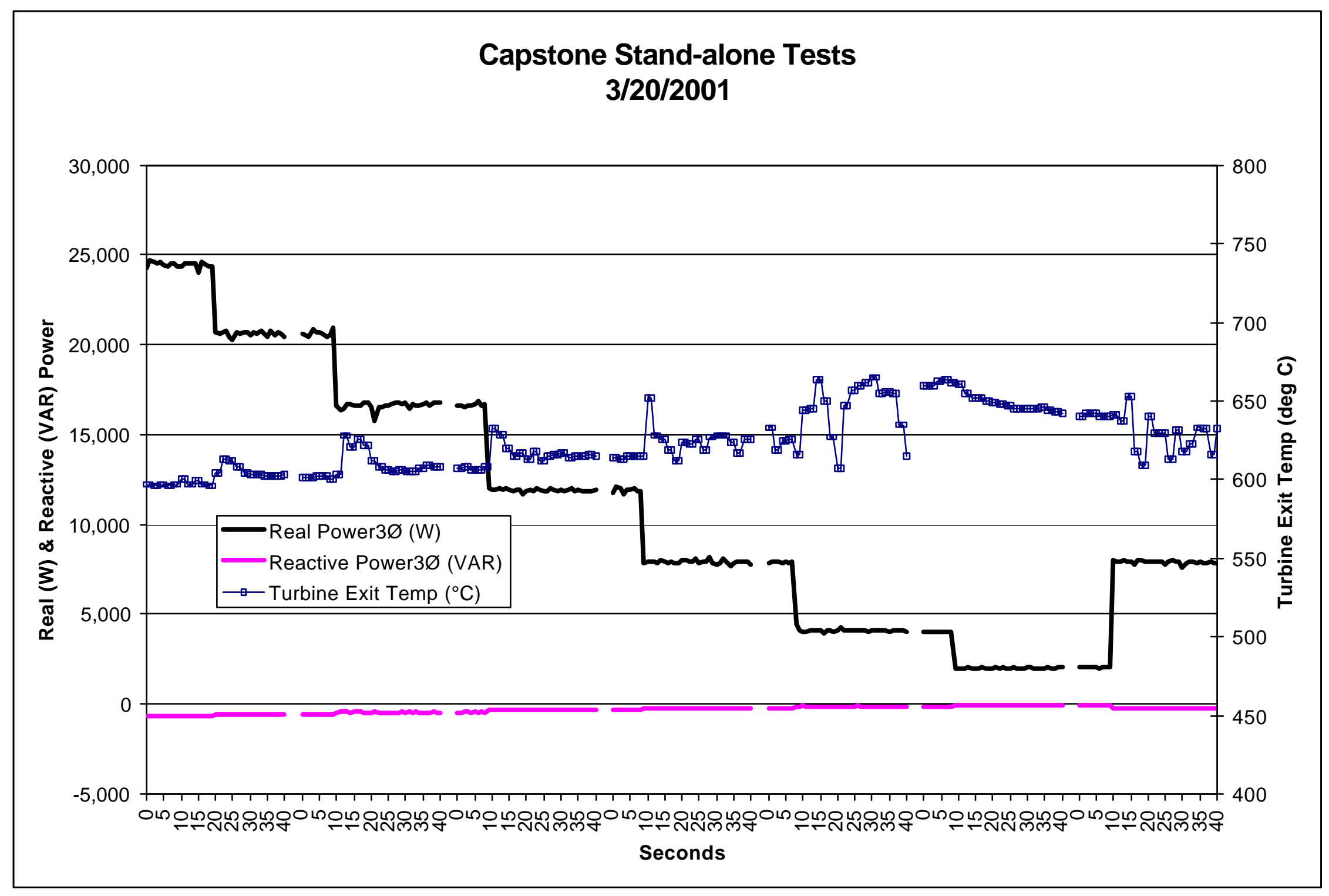

Figure D-2: Ramp Tests - Power and Turbine Exit Temperature - 4 kW Steps 


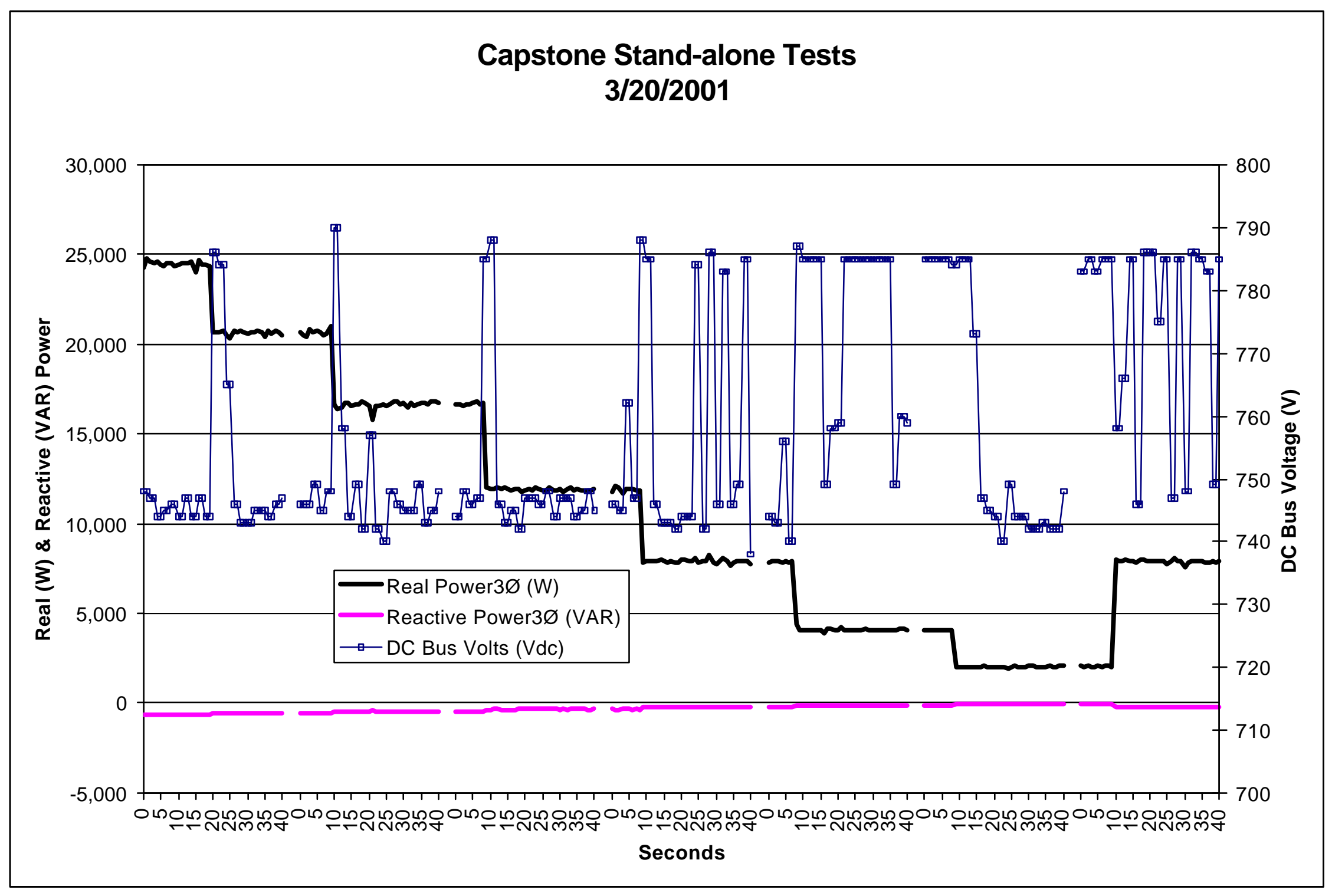

Figure D-3: Ramp Tests - Power and DC Bus Voltage - 4 kW Steps 


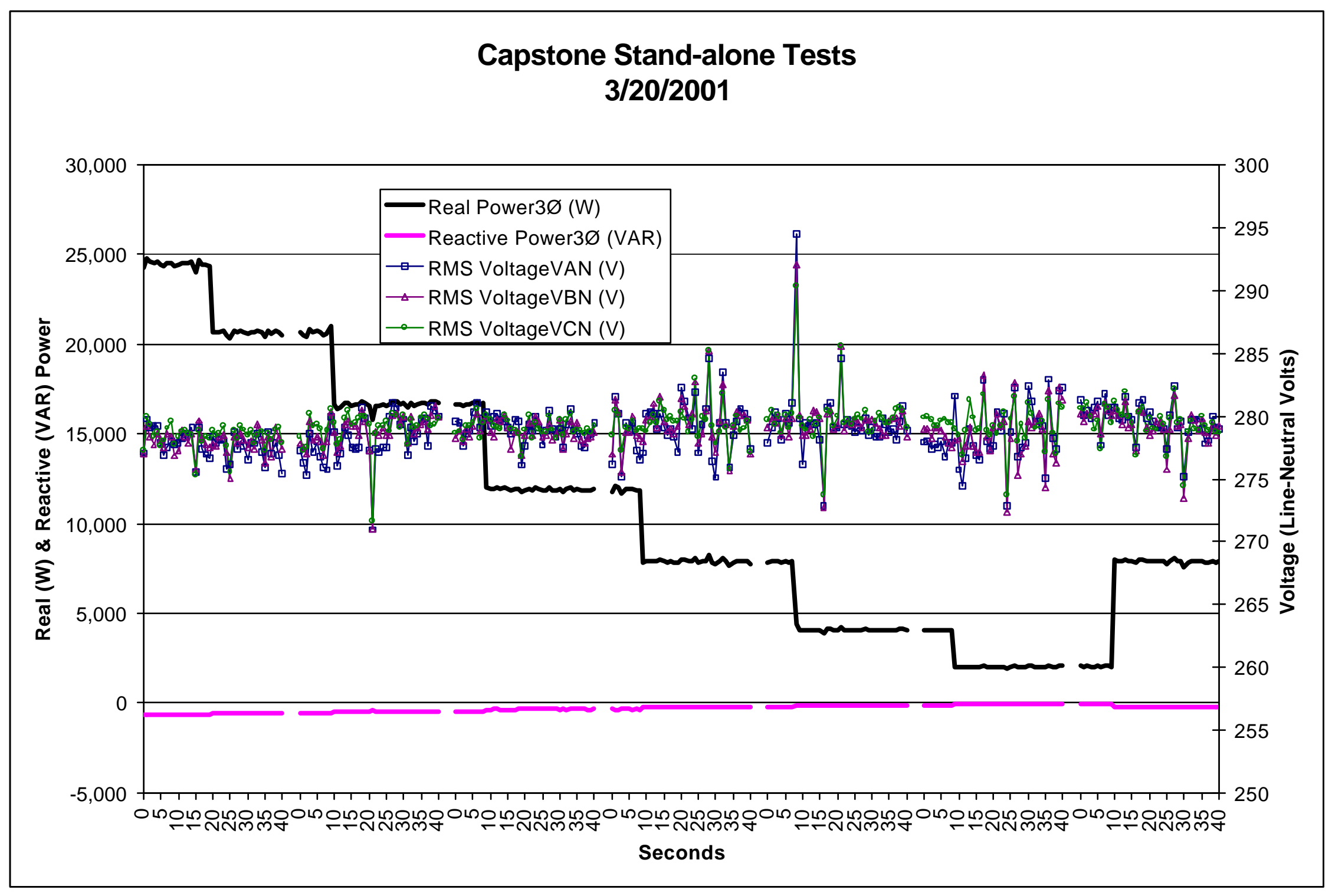

Figure D-4: Ramp Tests - Power and Line-Neutral Voltage - 4 kW Steps 


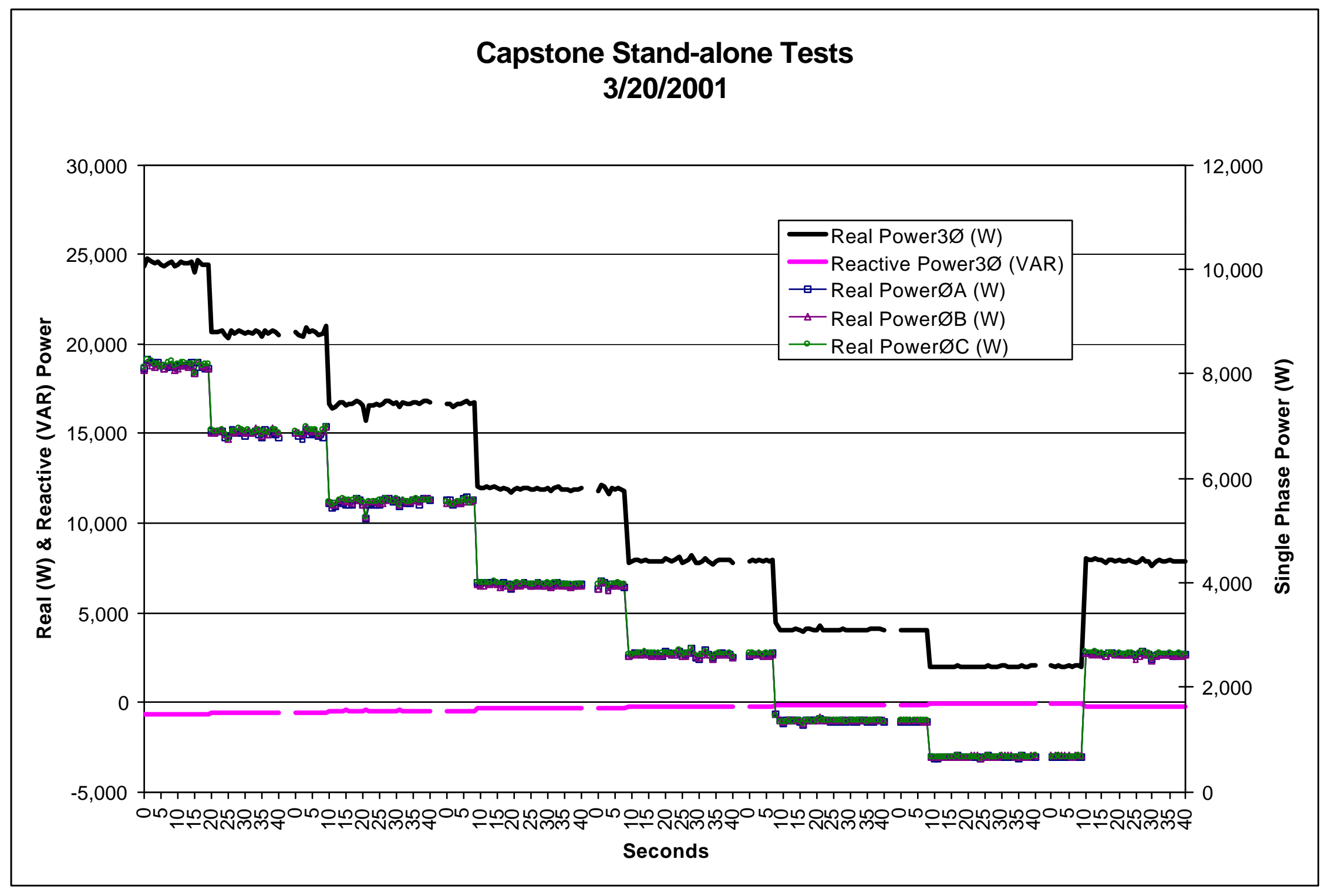

Figure D-5: Ramp Tests - Power and Single Phase Power - 4 kW Steps 


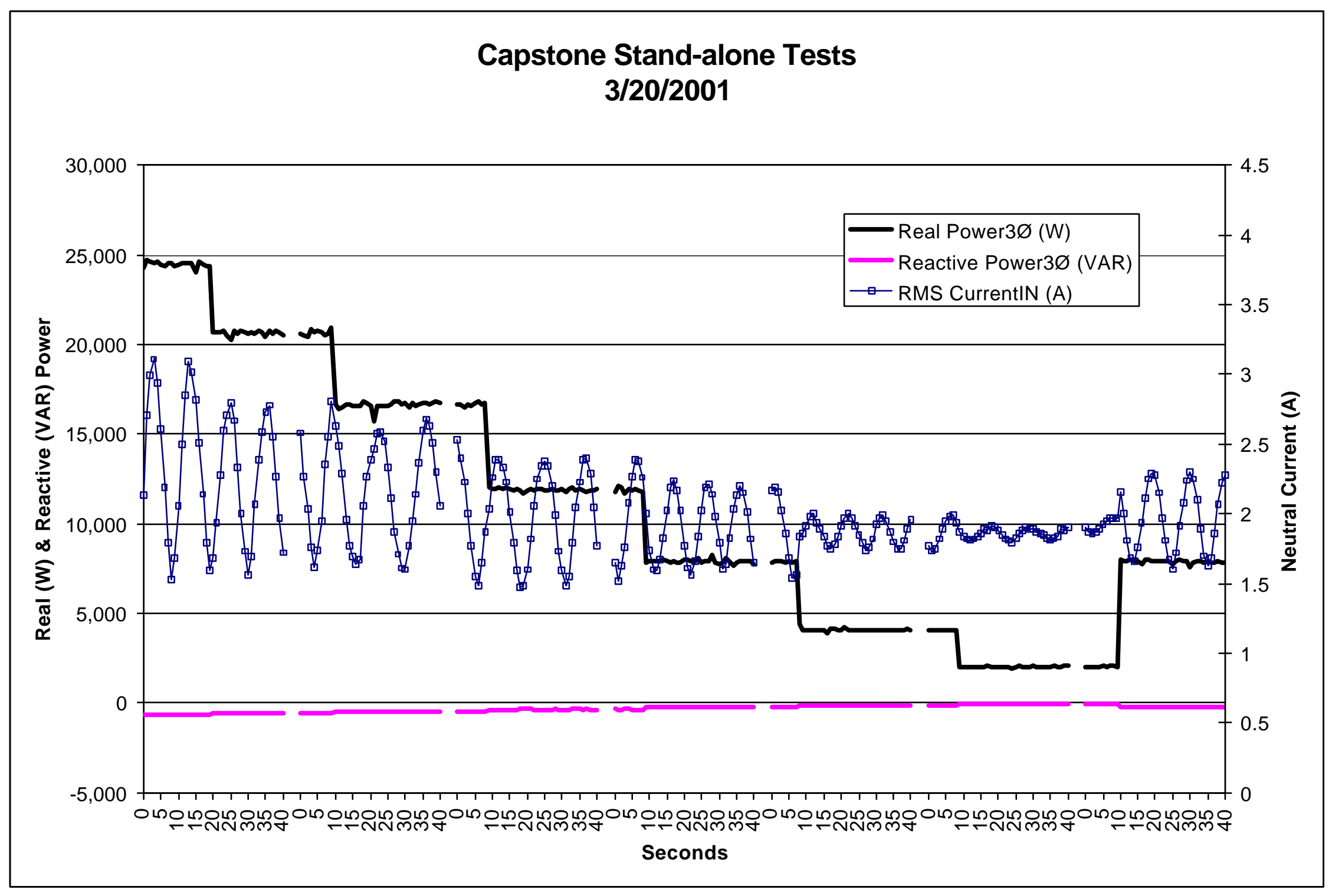

Figure D-6: Ramp Tests - Power and Neutral Current - 4 kW Steps 


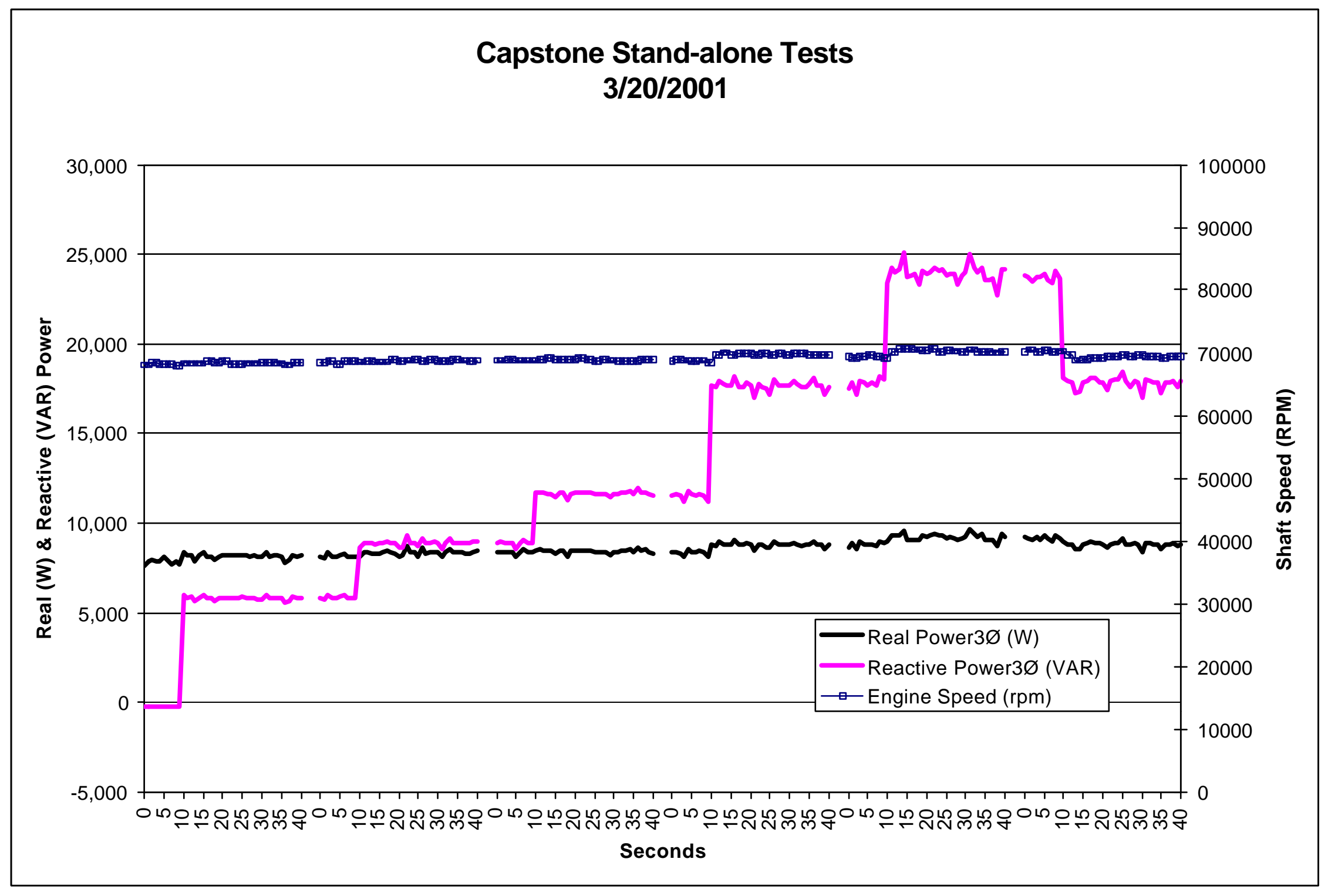

Figure D-7: Ramp Tests - Power and Shaft Speed - 3/6 kVAR Steps 


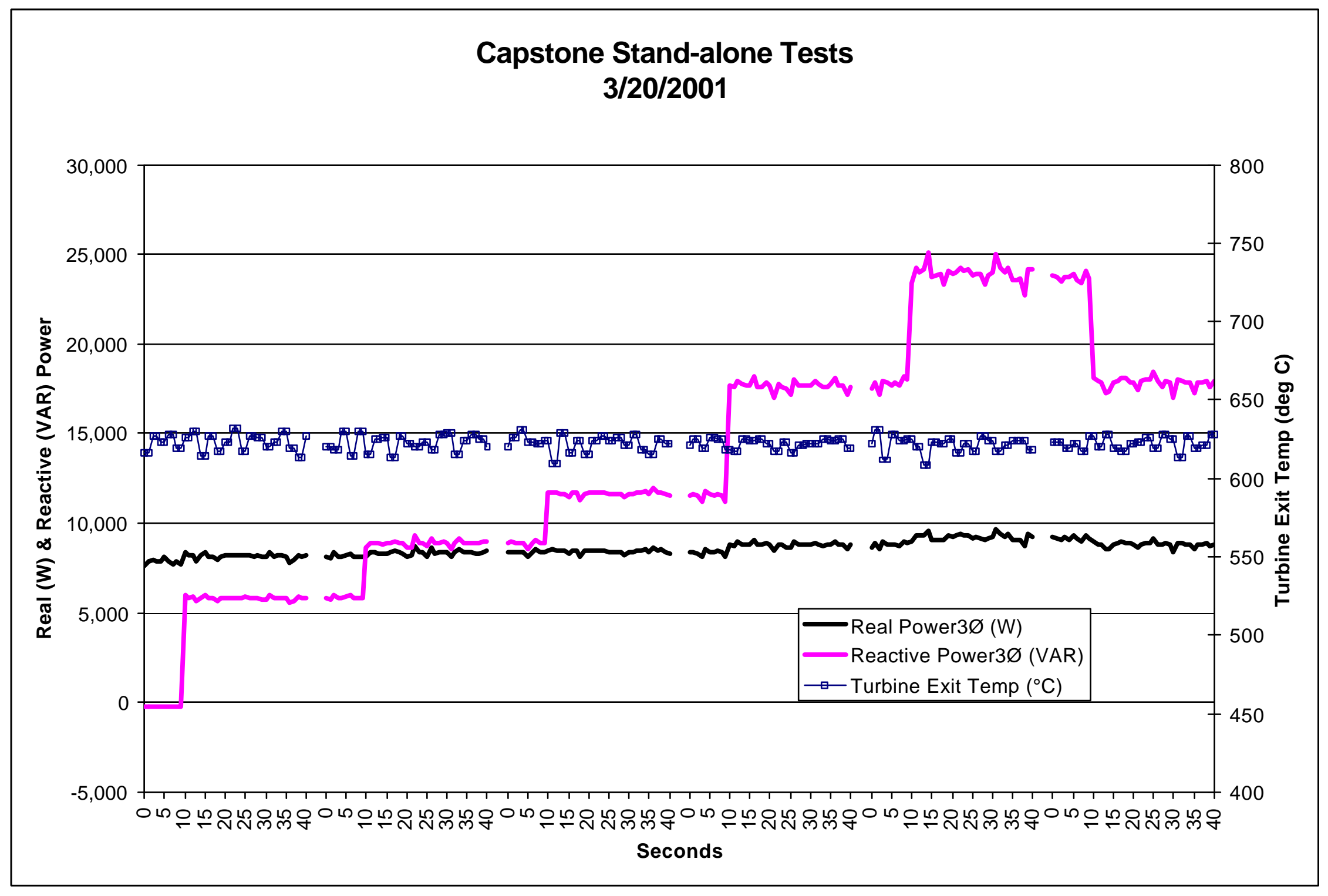

Figure D-8: Ramp Tests - Power and Turbine Exit Temperature - 3/6 kVAR Tests 


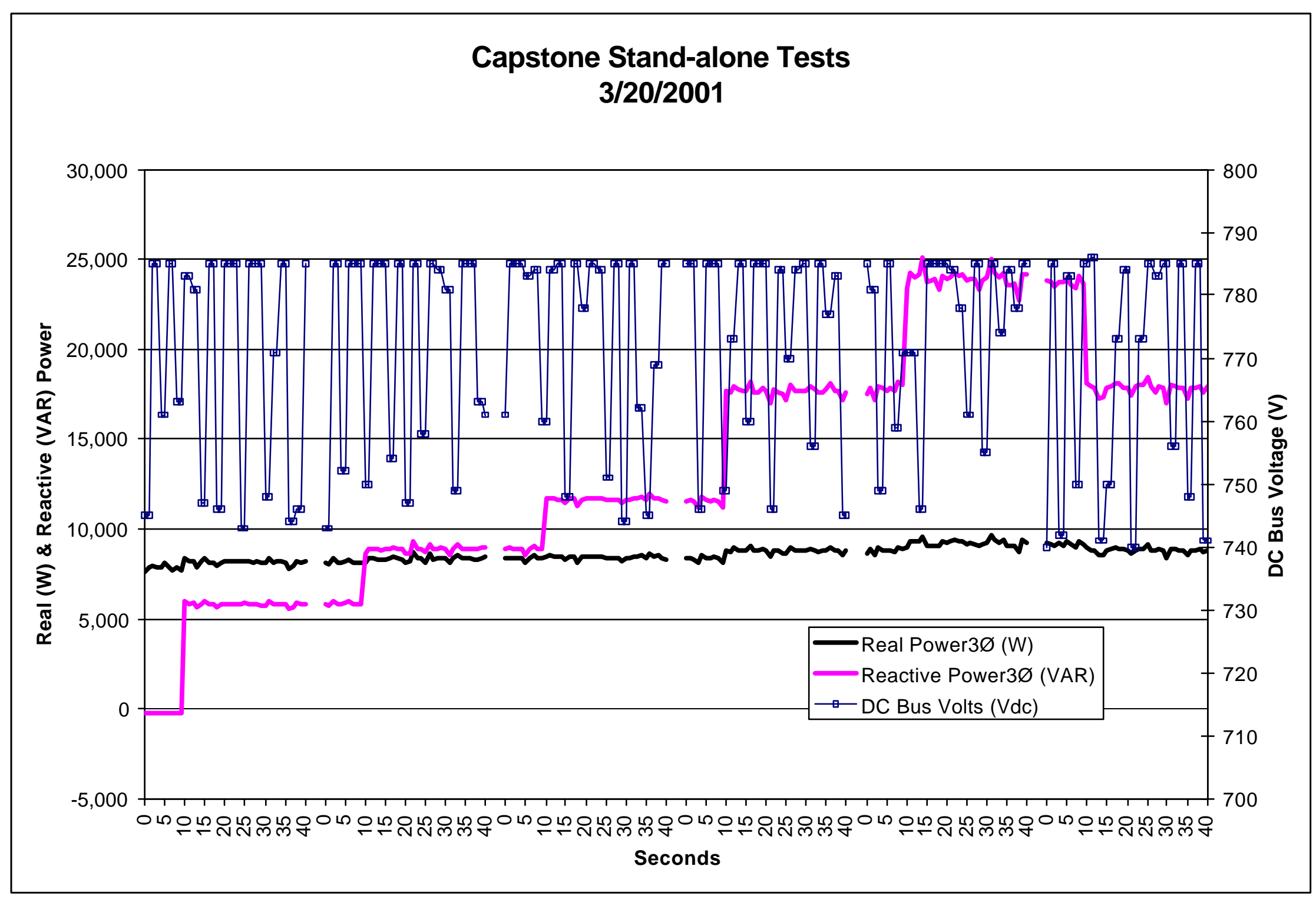

Figure D-9: Ramp Tests - Power and DC Bus Voltage - 3/6 kVAR Tests 


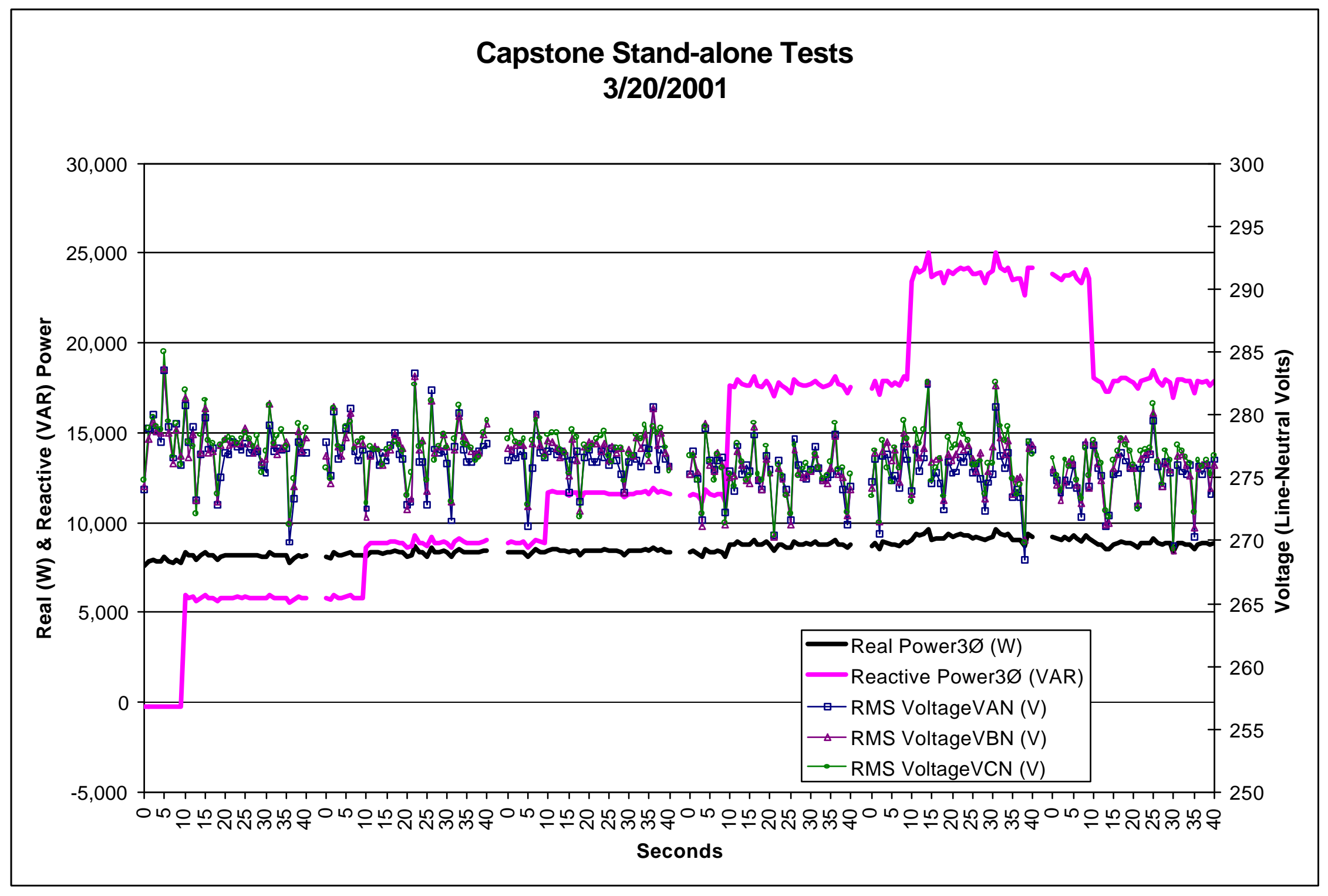

Figure D-10: Ramp Tests - Power and Line-Neutral Voltage - 3/6 kVAR Steps 


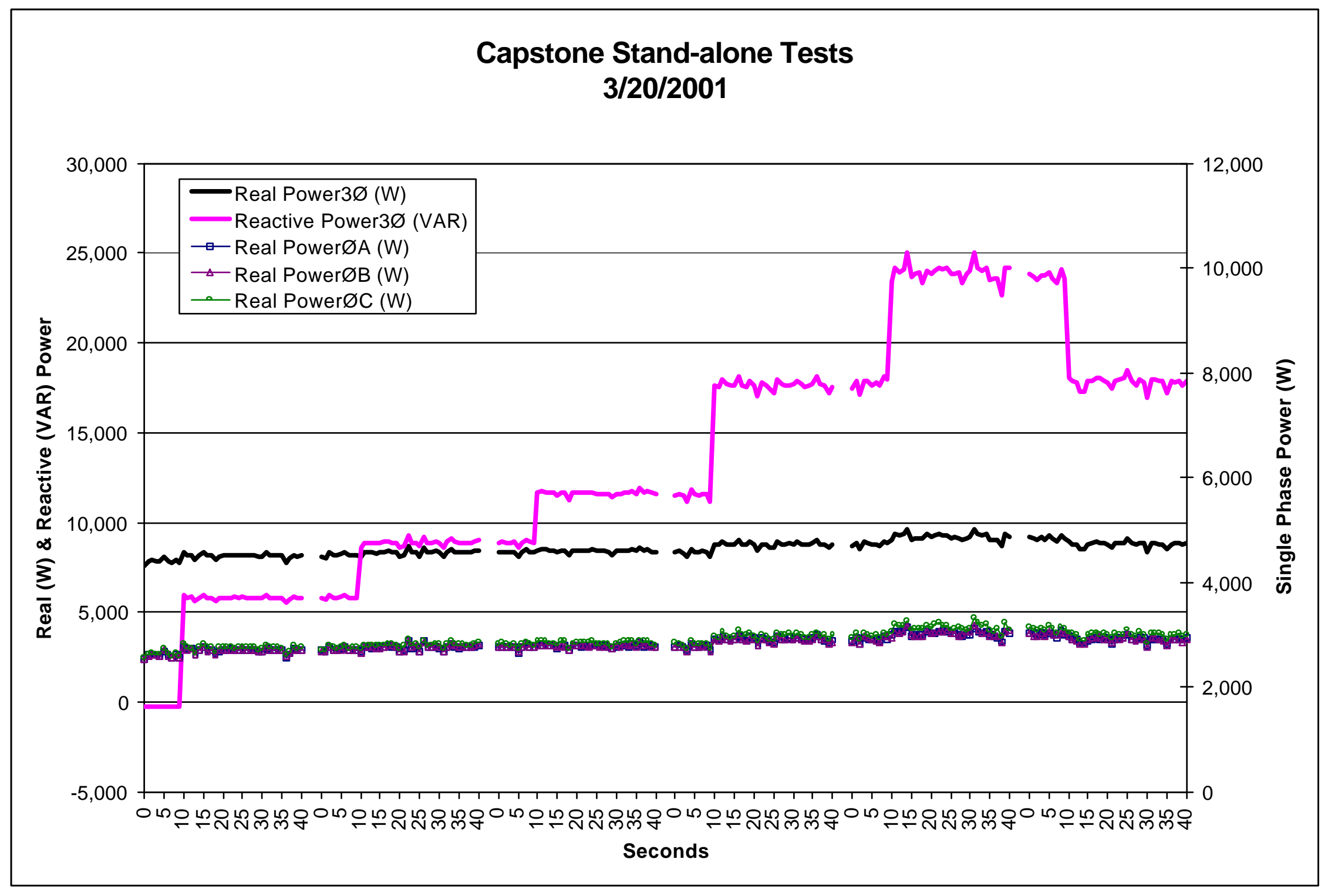

Figure D-11: Ramp Tests - Power and Single Phase Power - 3/6 kVAR Steps 


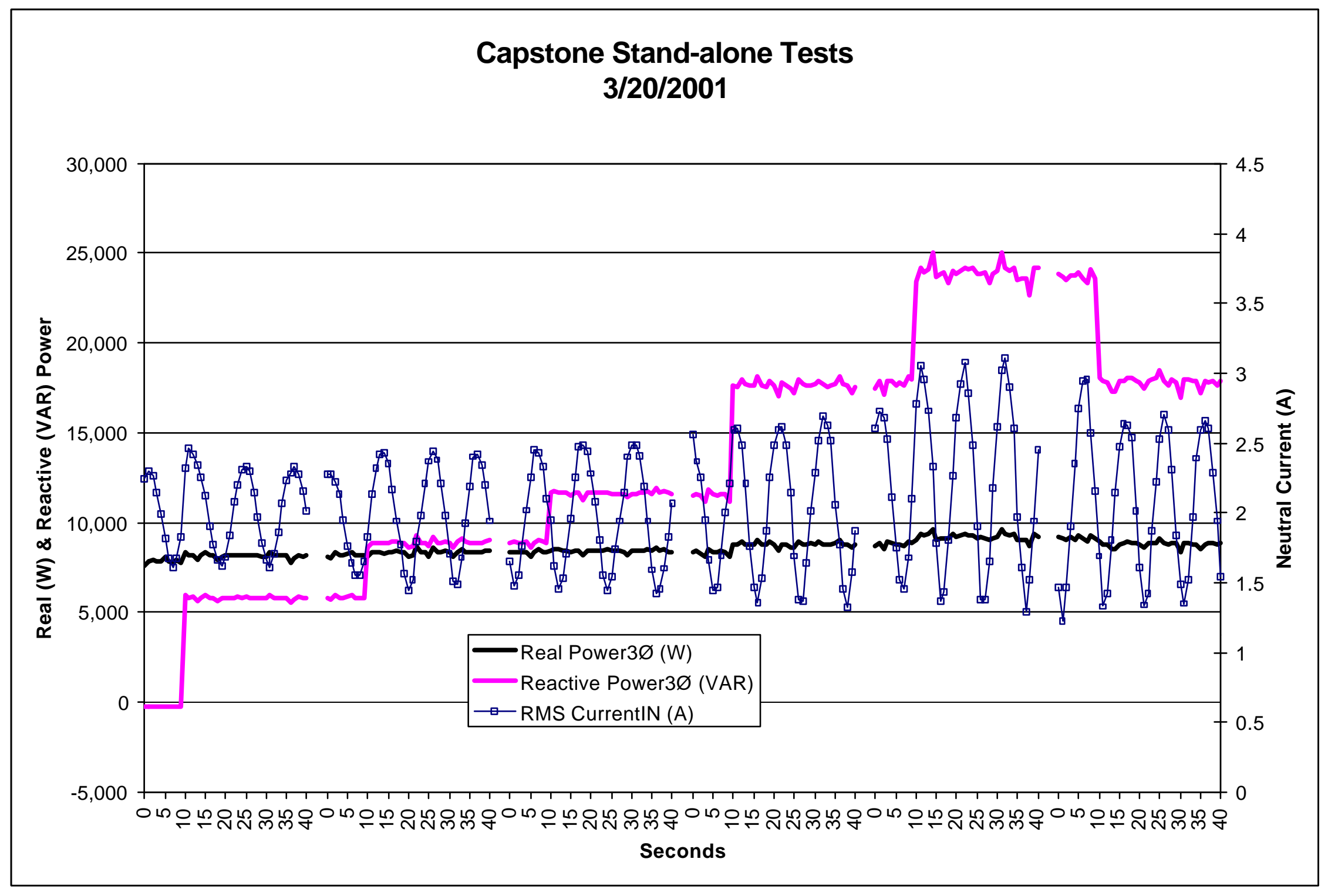

Figure D-12: Ramp Tests - Power and Neutral Current - 3/6 kVAR Tests 


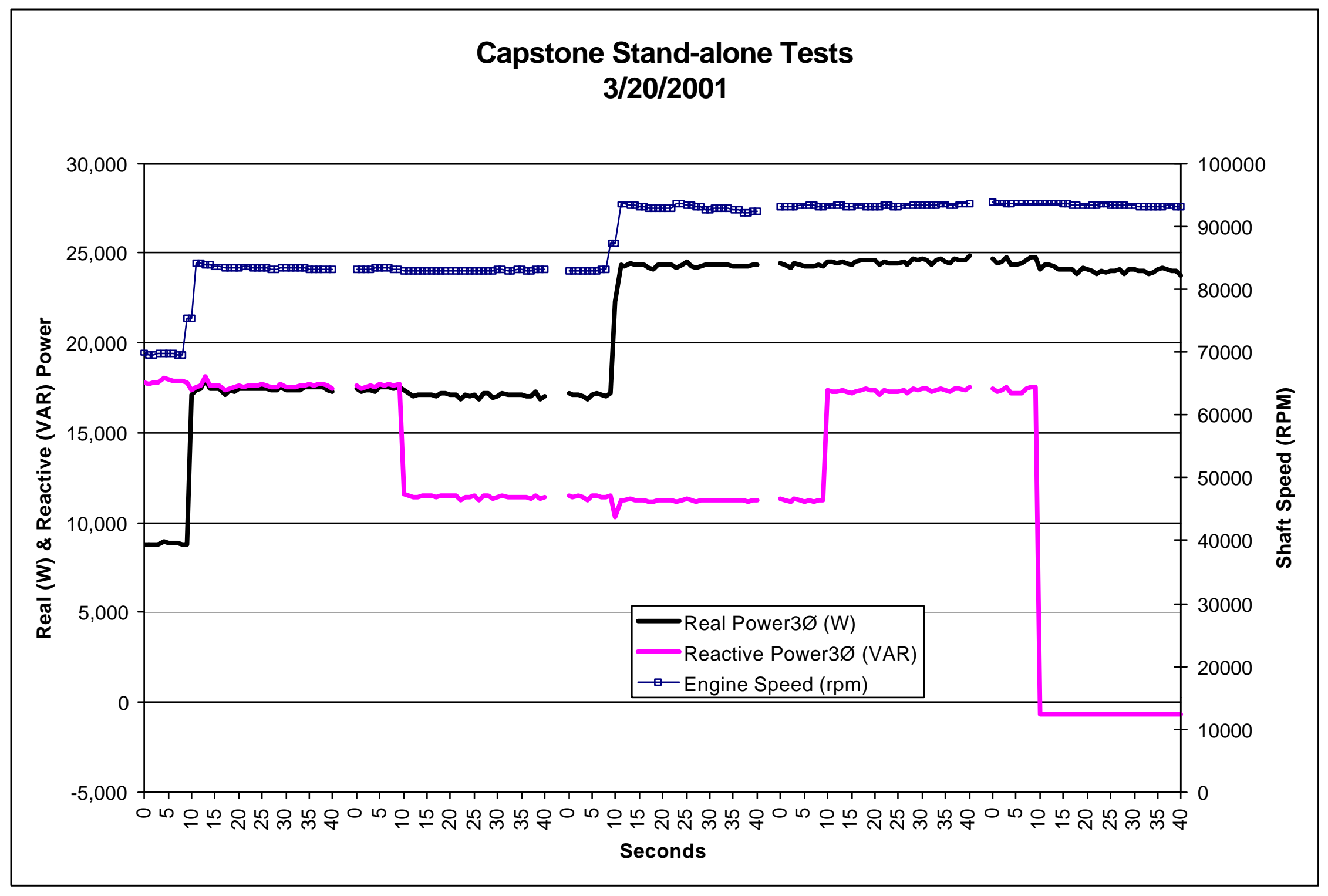

Figure D-13: Ramp Tests - Power and Shaft Speed - 8 kW and 6/18 kVAR Steps 


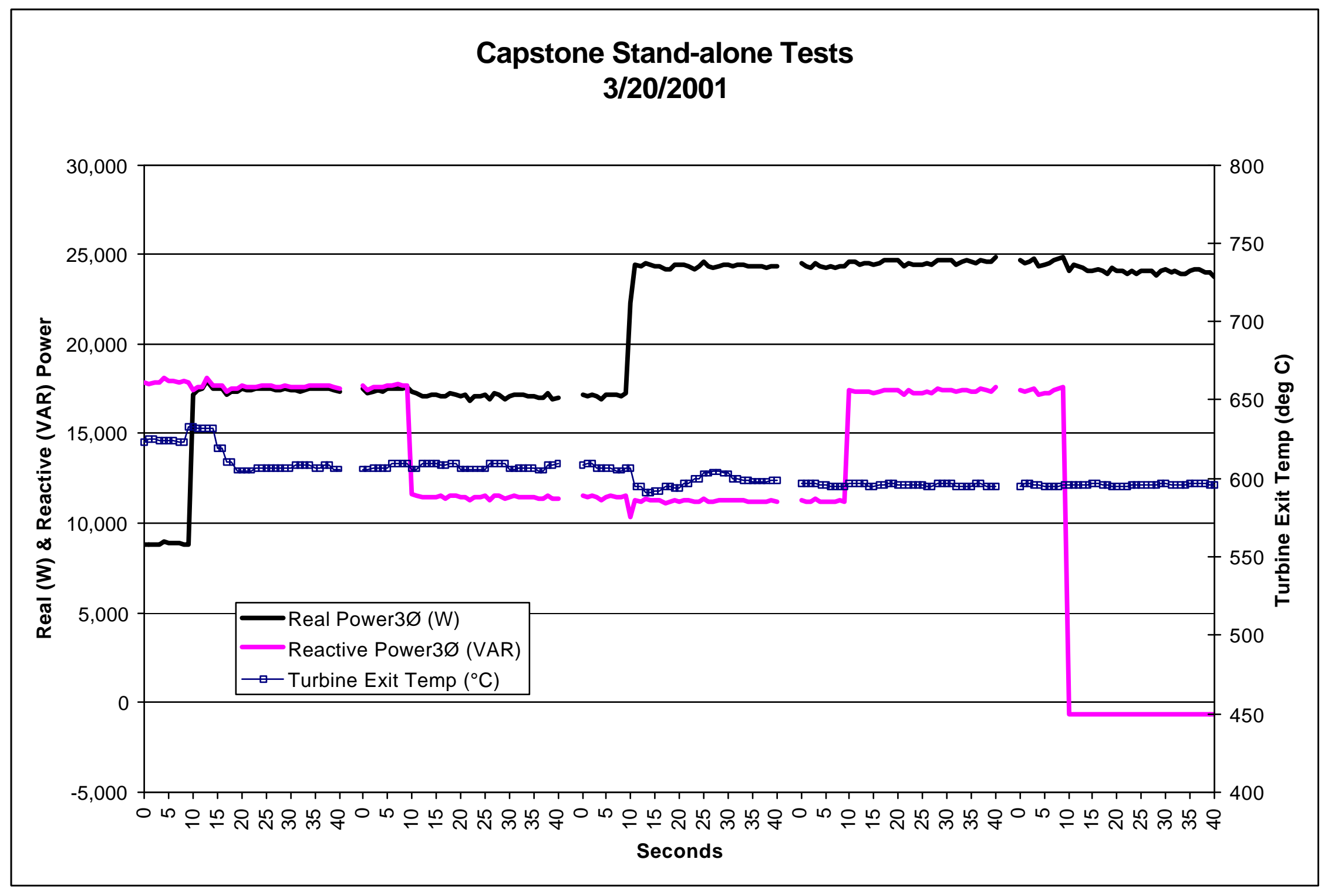

Figure D-14: Ramp Tests - Power and Turbine Exit Temperature - 8 kW and 6/18 kVAR Steps 


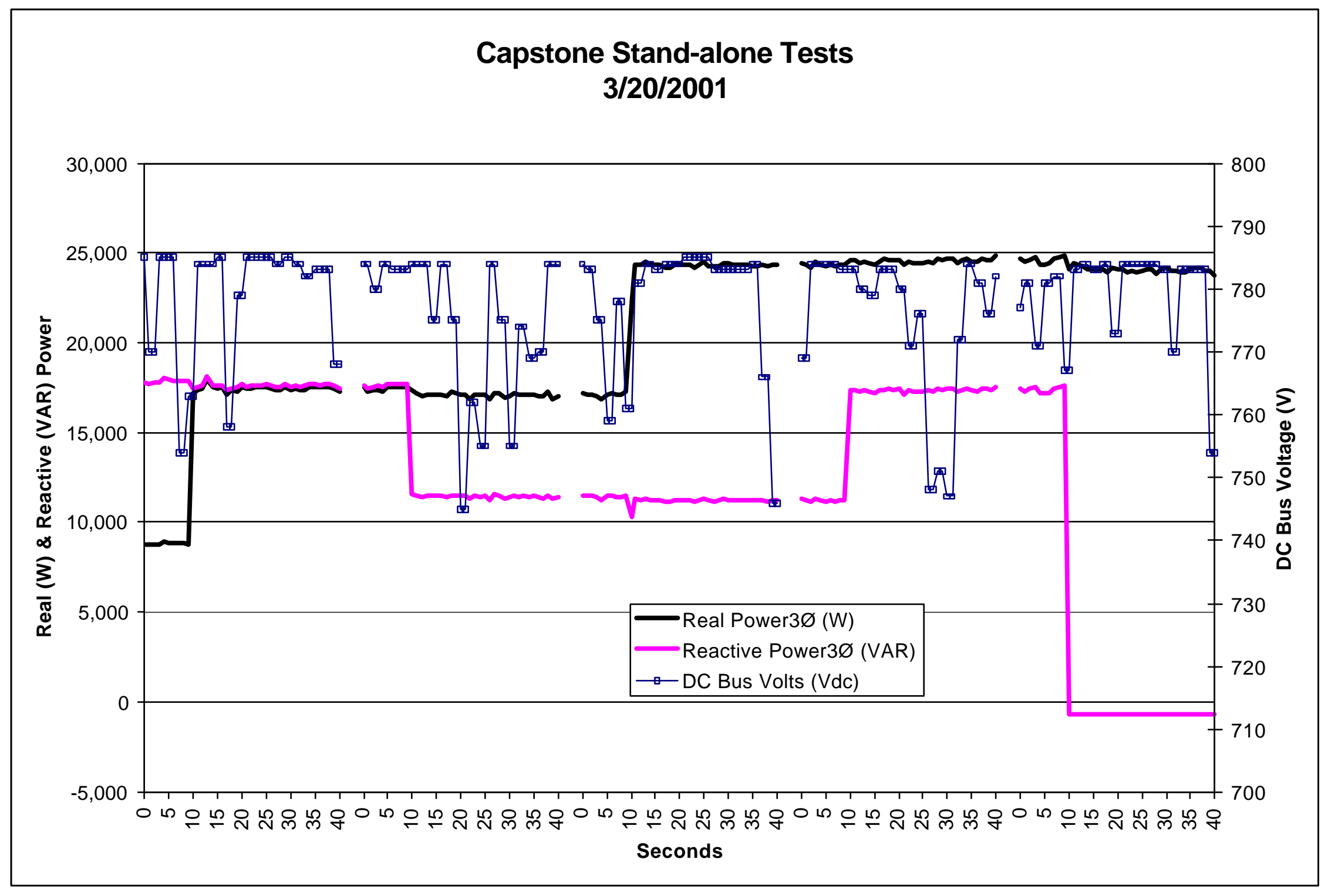

Figure D-15: Ramp Tests - Power and DC Bus Voltage -8 kW and 6/18 kVAR Steps 


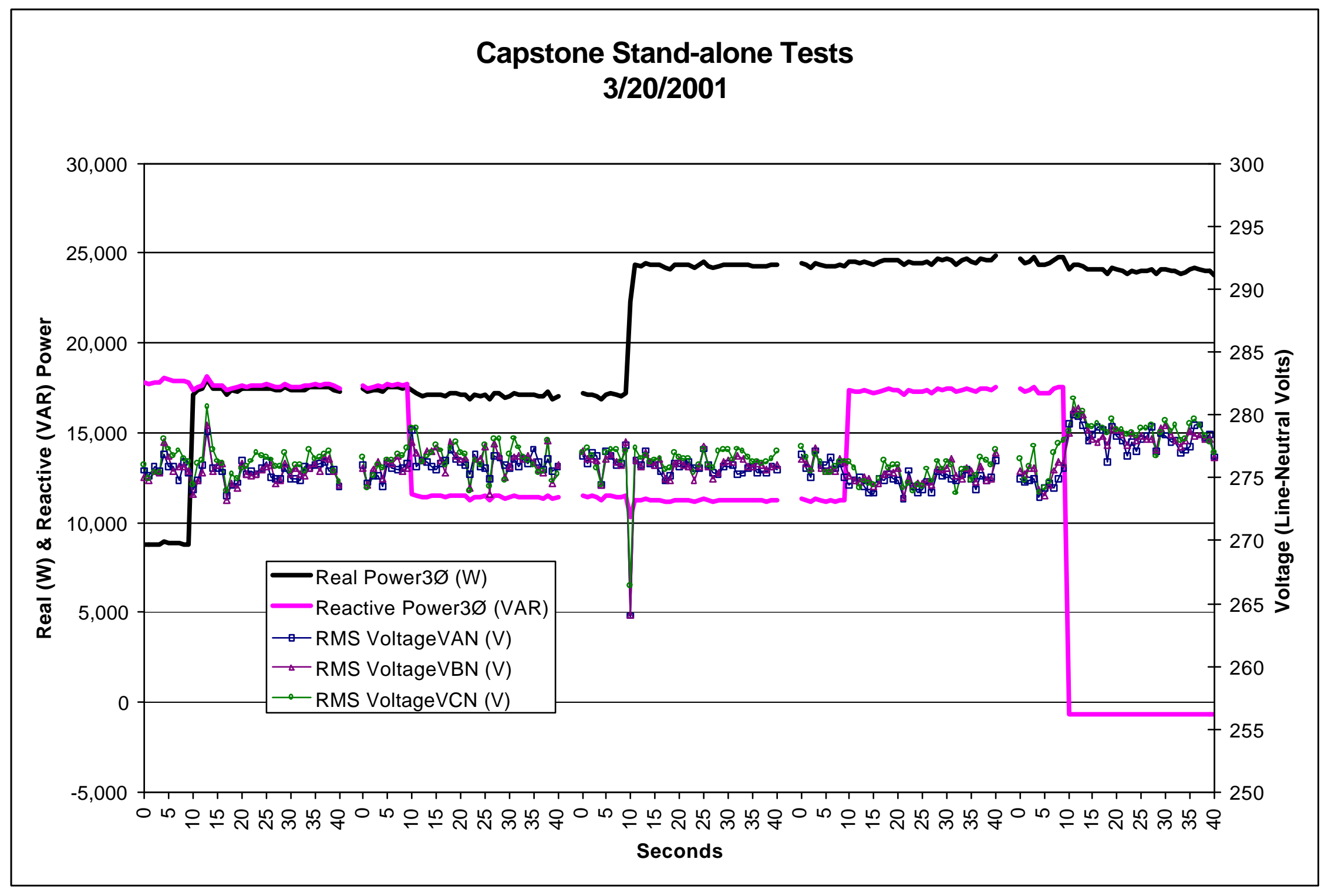

Figure D-16: Ramp Tests - Power and Line-Neutral Voltage $-8 \mathrm{~kW}$ and 6/18 kVAR Steps 


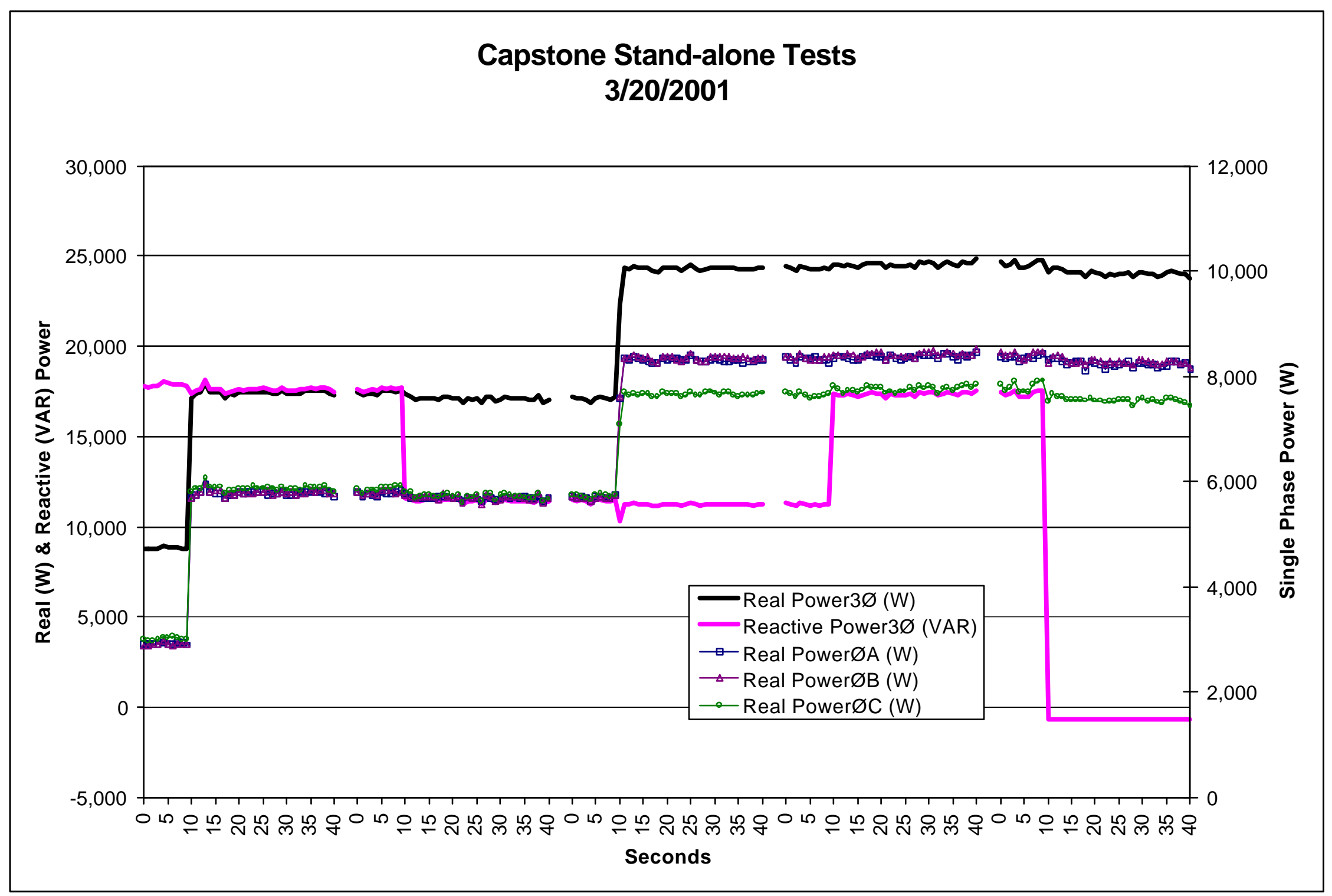

Figure D-17: Ramp Tests - Power and Single Phase Power - 8 kW and 6/18 kVAR Steps 


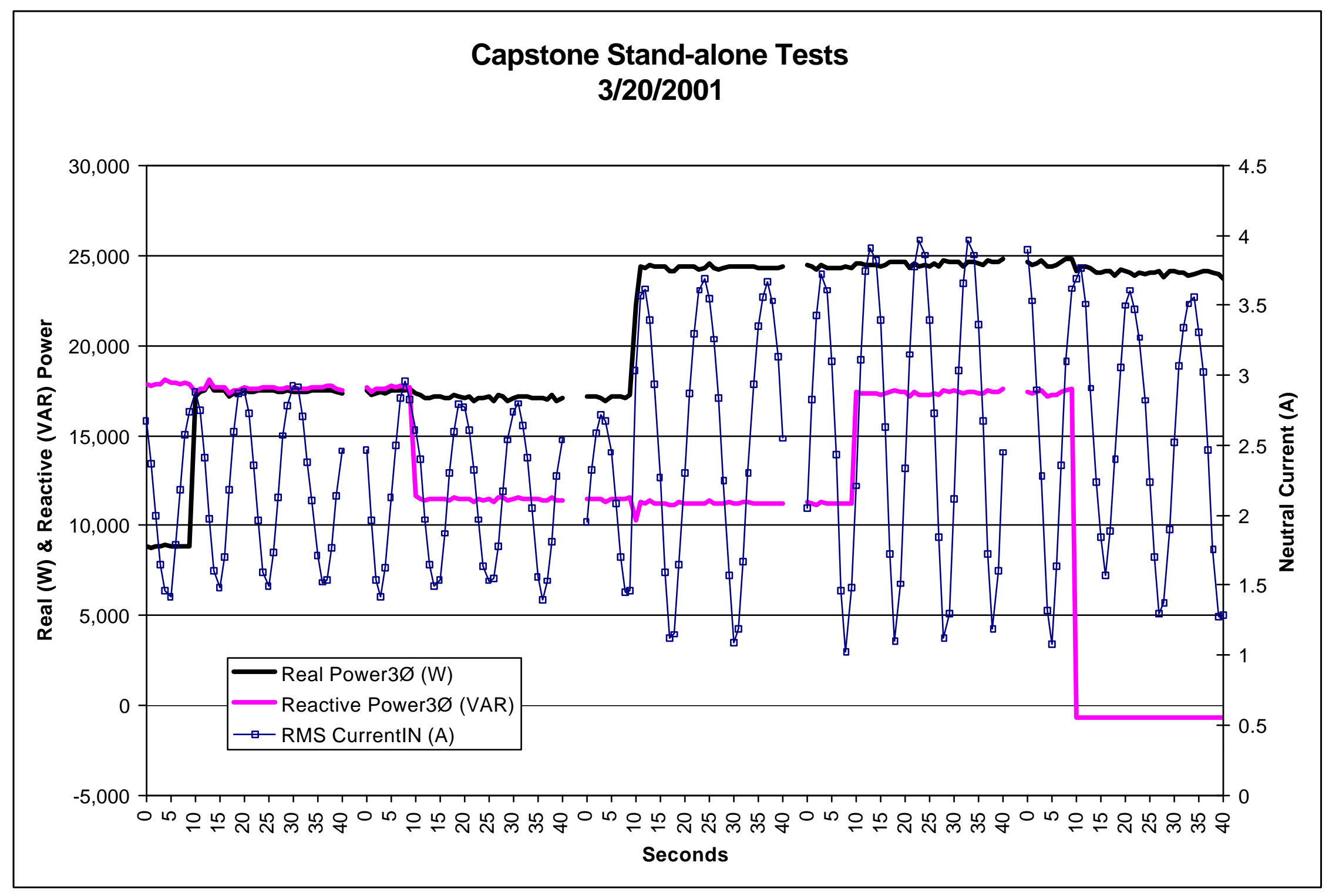

Figure D-18: Ramp Tests - Power and Neutral Current - 8 kW and 6/18 kVAR Steps 


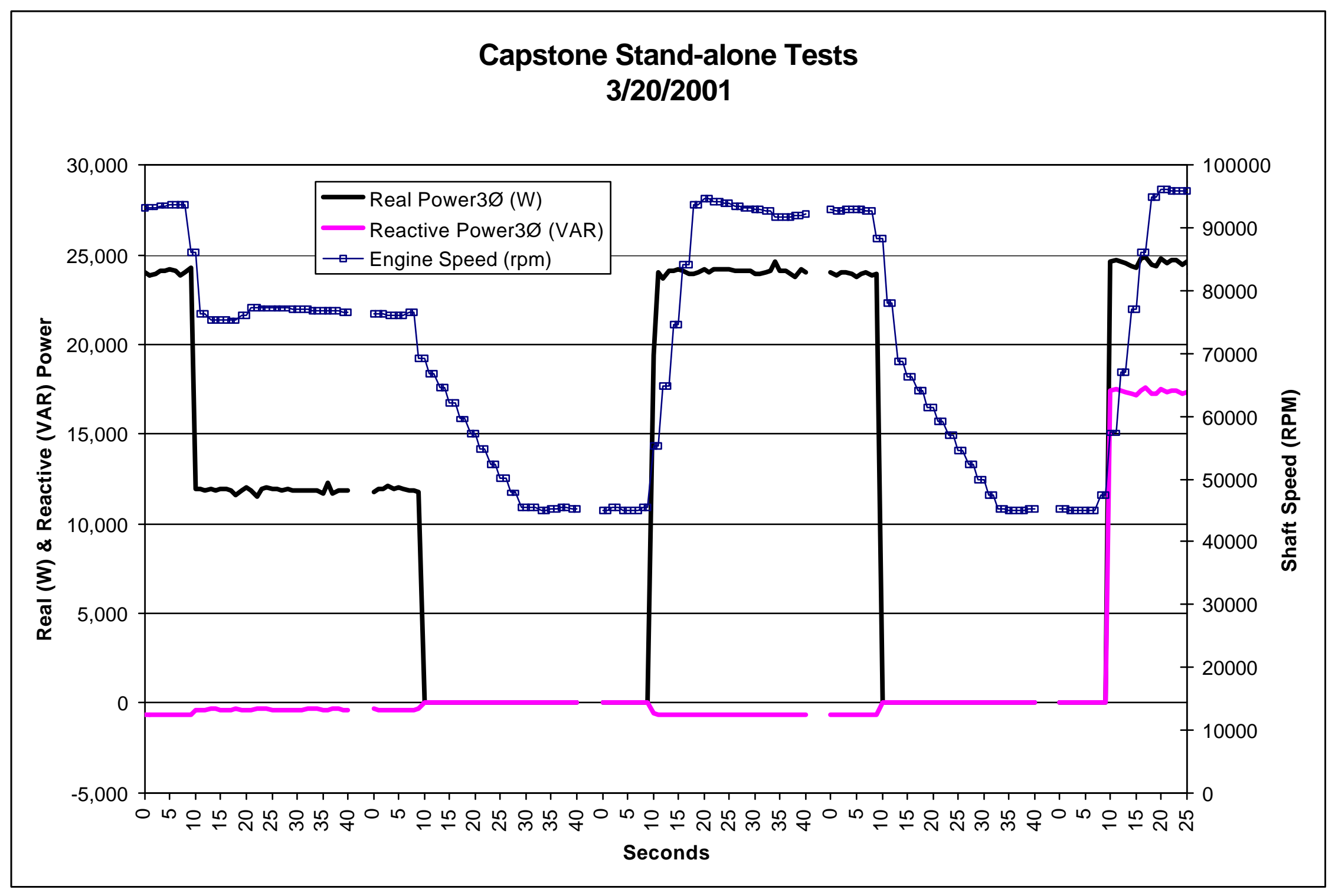

Figure D-19: Ramp Tests - Power and Shaft Speed - 12/24 kW and 18 kVAR Power Steps 


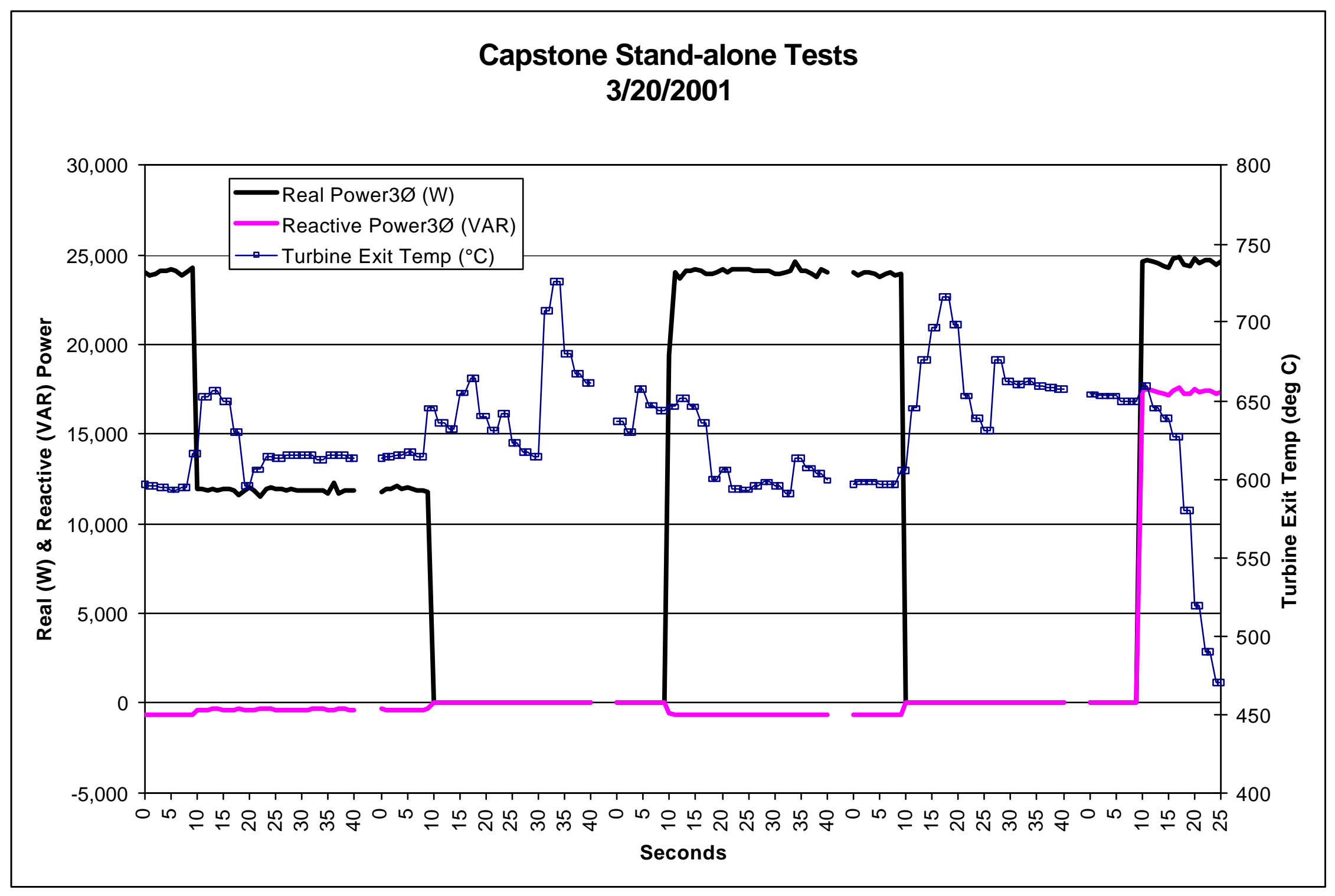

Figure D-20: Ramp Tests - Power and Turbine Exit Temperature - 12/24 kW and 18 kVAR Power Steps 


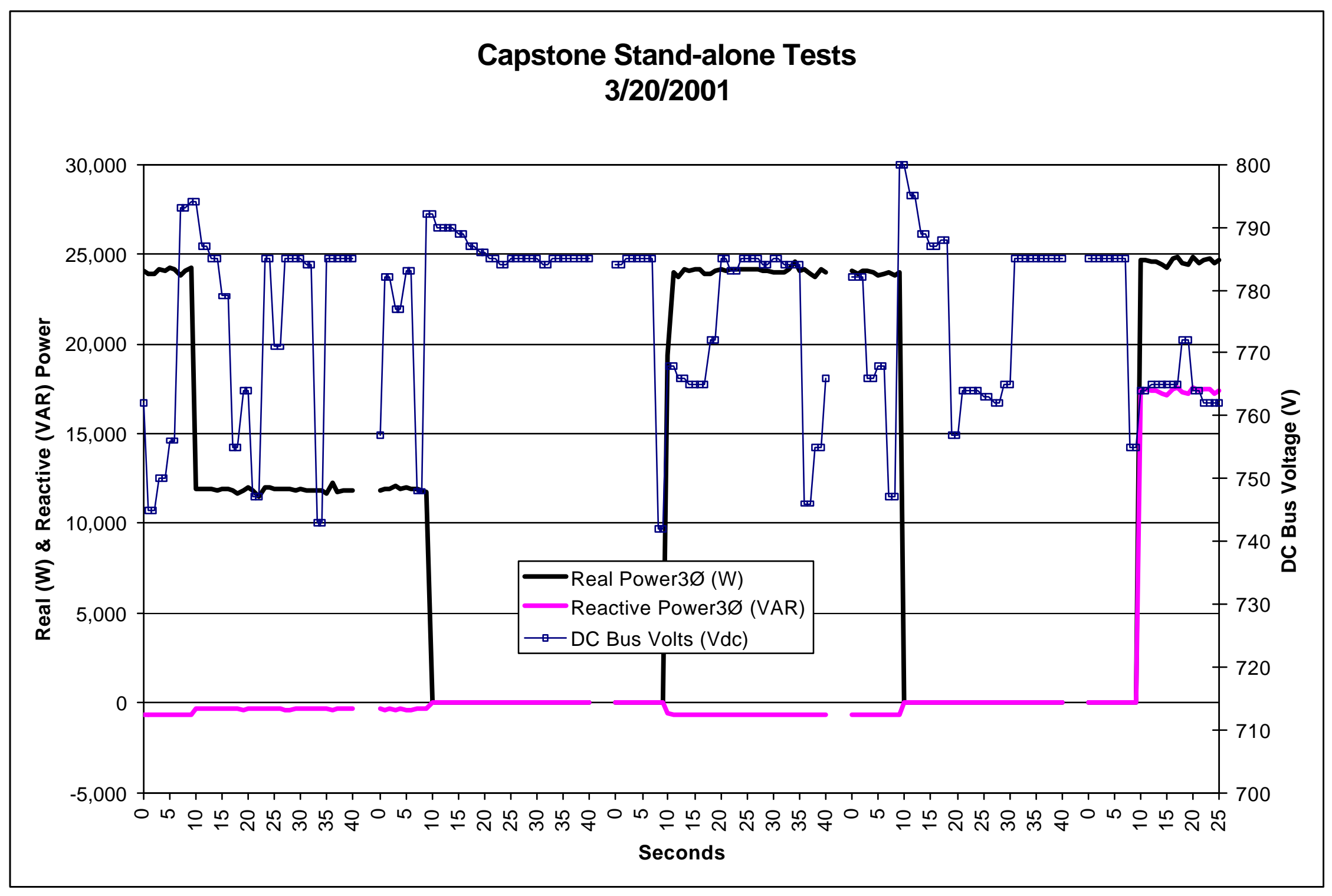

Figure D-21: Ramp Tests - Power and DC Bus Voltage - 12/24 kW and 18 kVAR Power Steps 


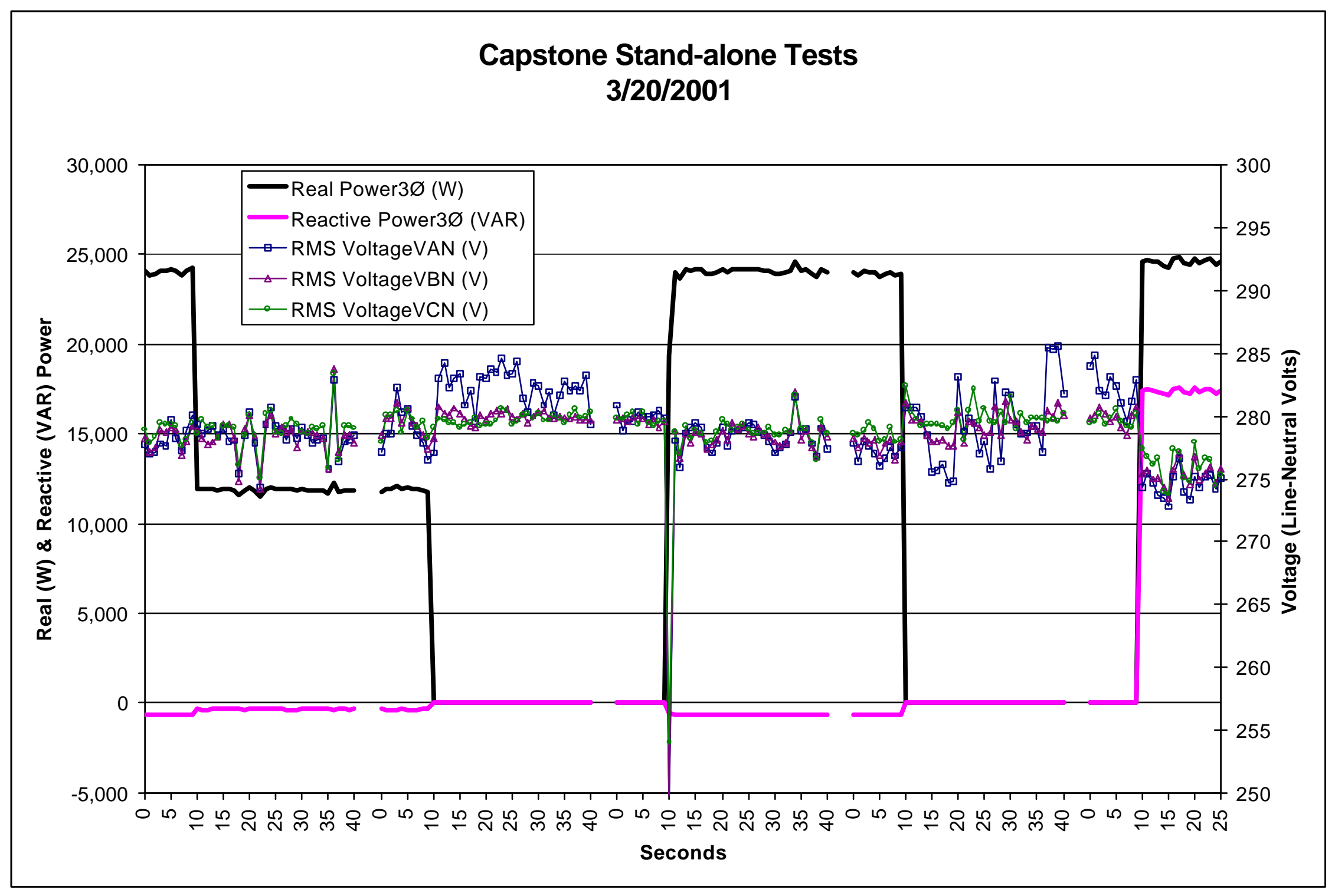

Figure D-22: Ramp Tests - Power and Line-Neutral Voltage - 12/24 kW and 18 kVAR Power Steps 


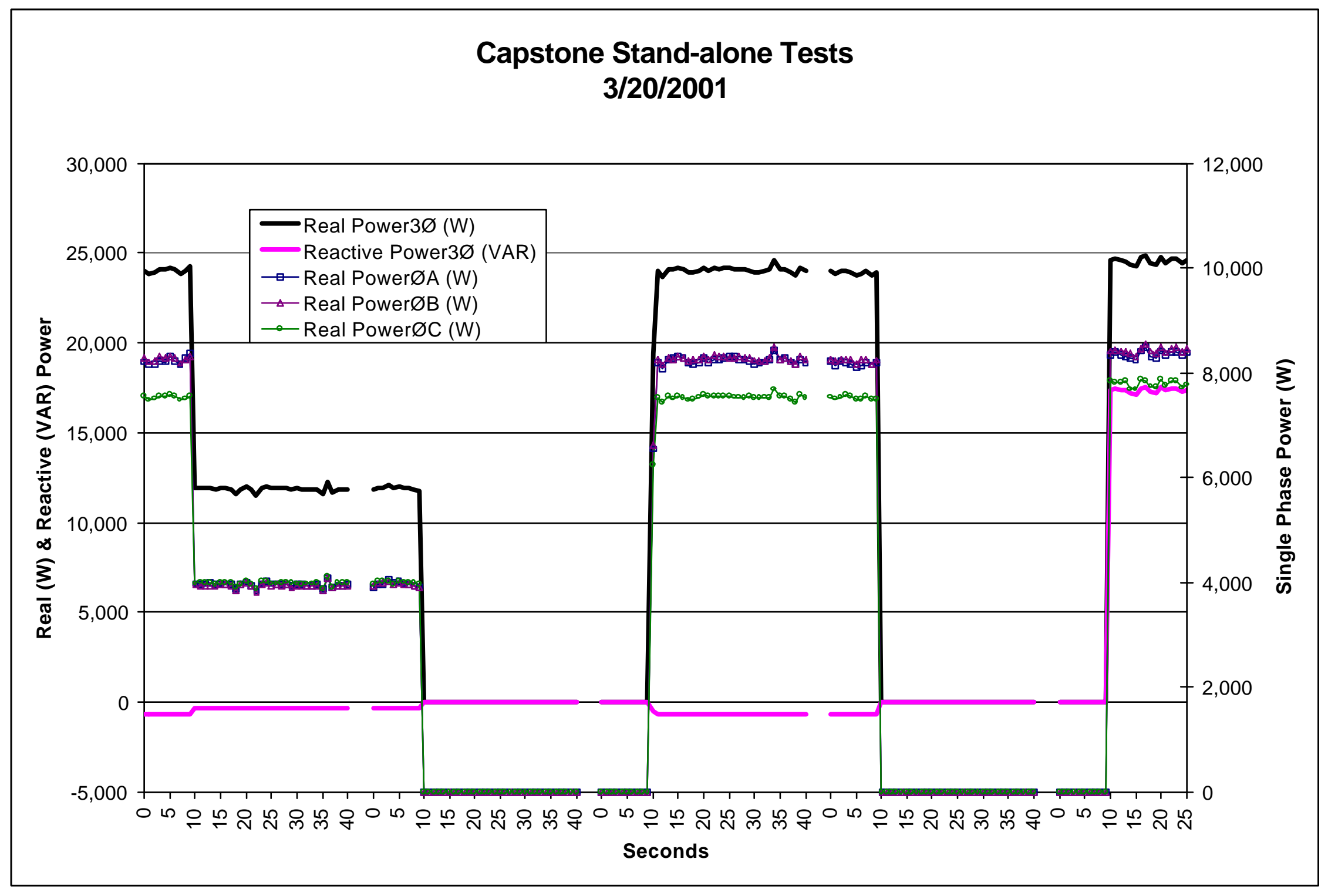

Figure D-23: Ramp Tests - Power and Single Phase Power - 12/24 kW and 18 kVAR Power Steps 


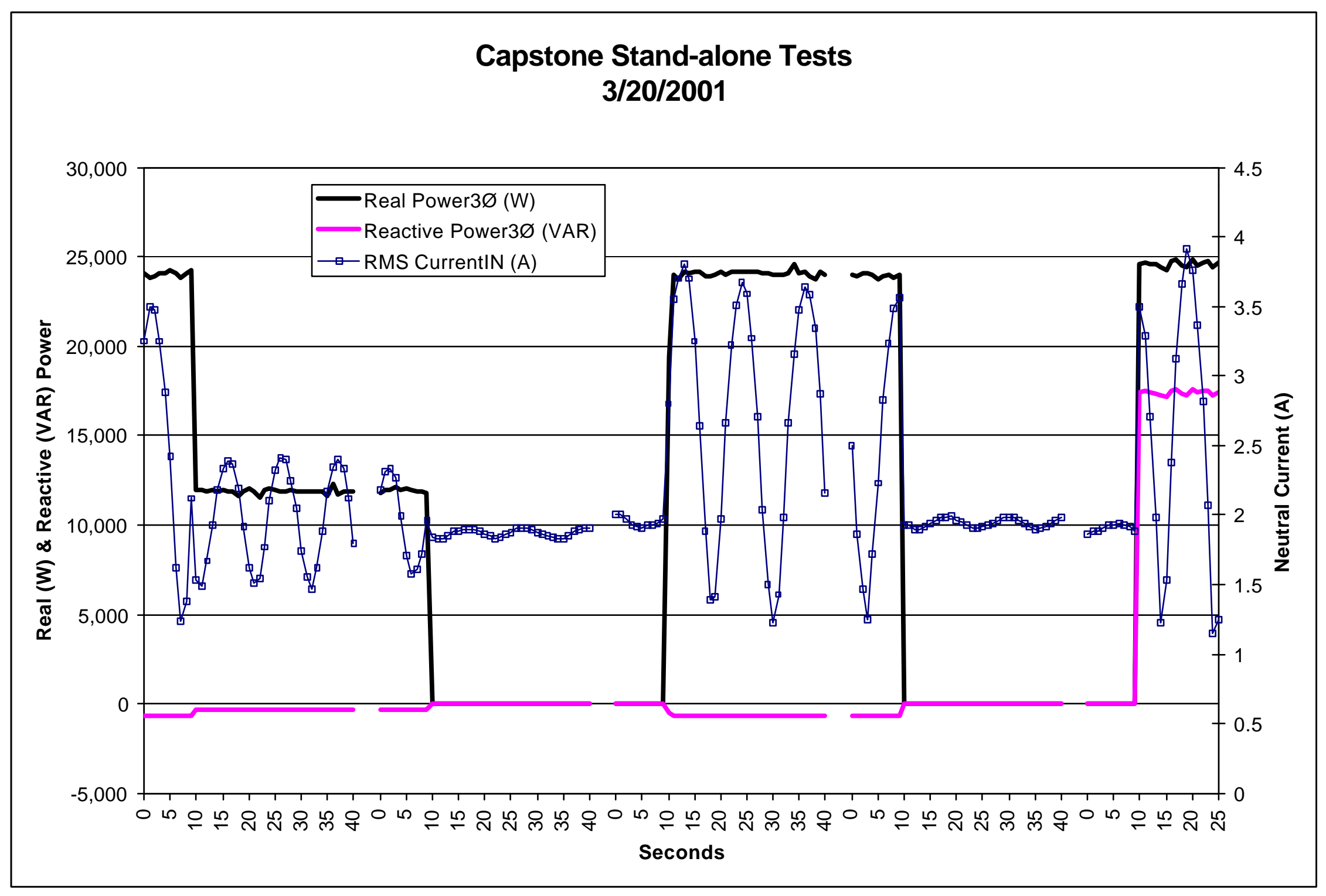

Figure D-24: Ramp Tests - Power and Neutral Current - 12/24 kW and 18 kVAR Power Steps 


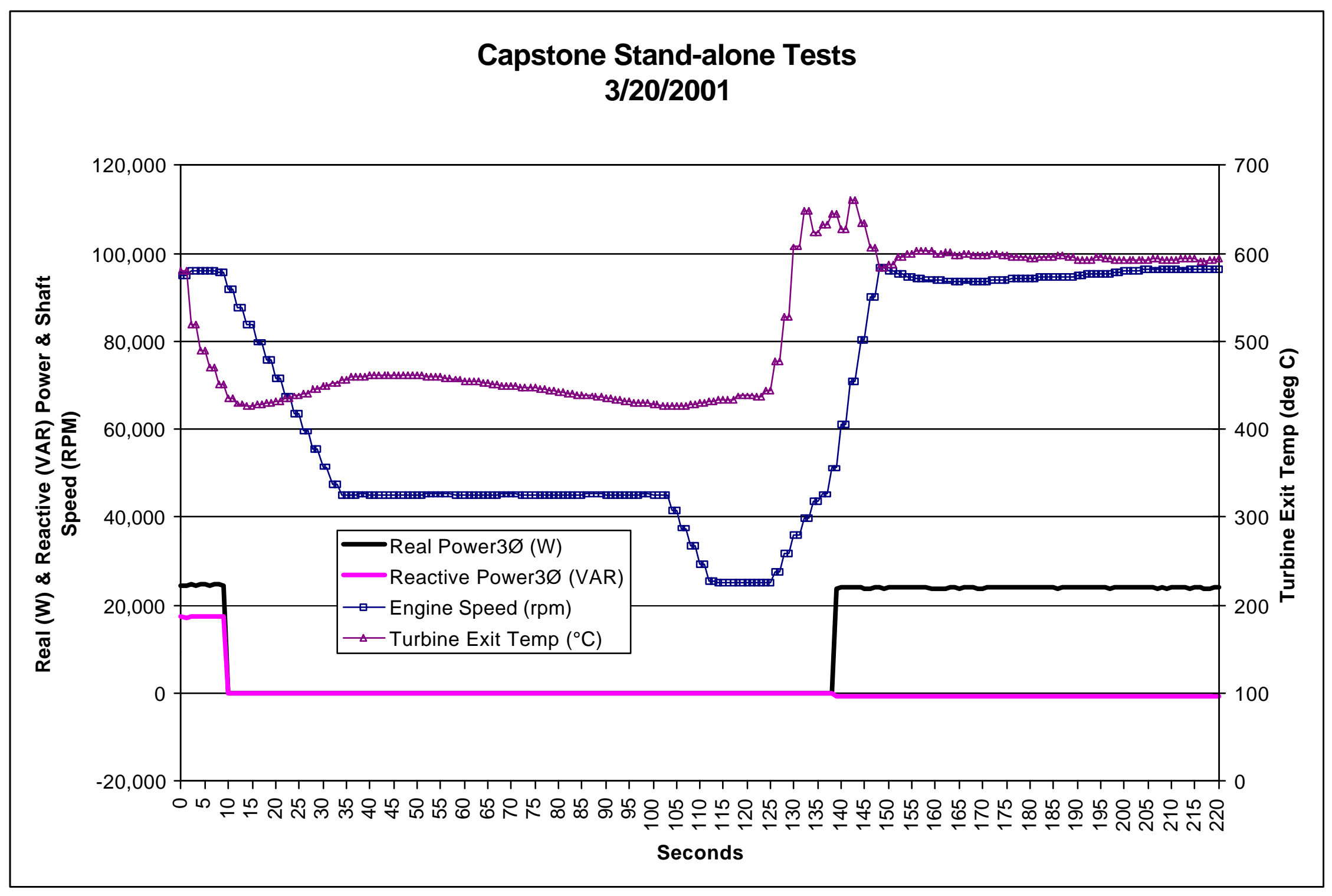

Figure D-25: Power, Shaft Speed and Turbine Exit Temperature During MTG Shutdown and Start 


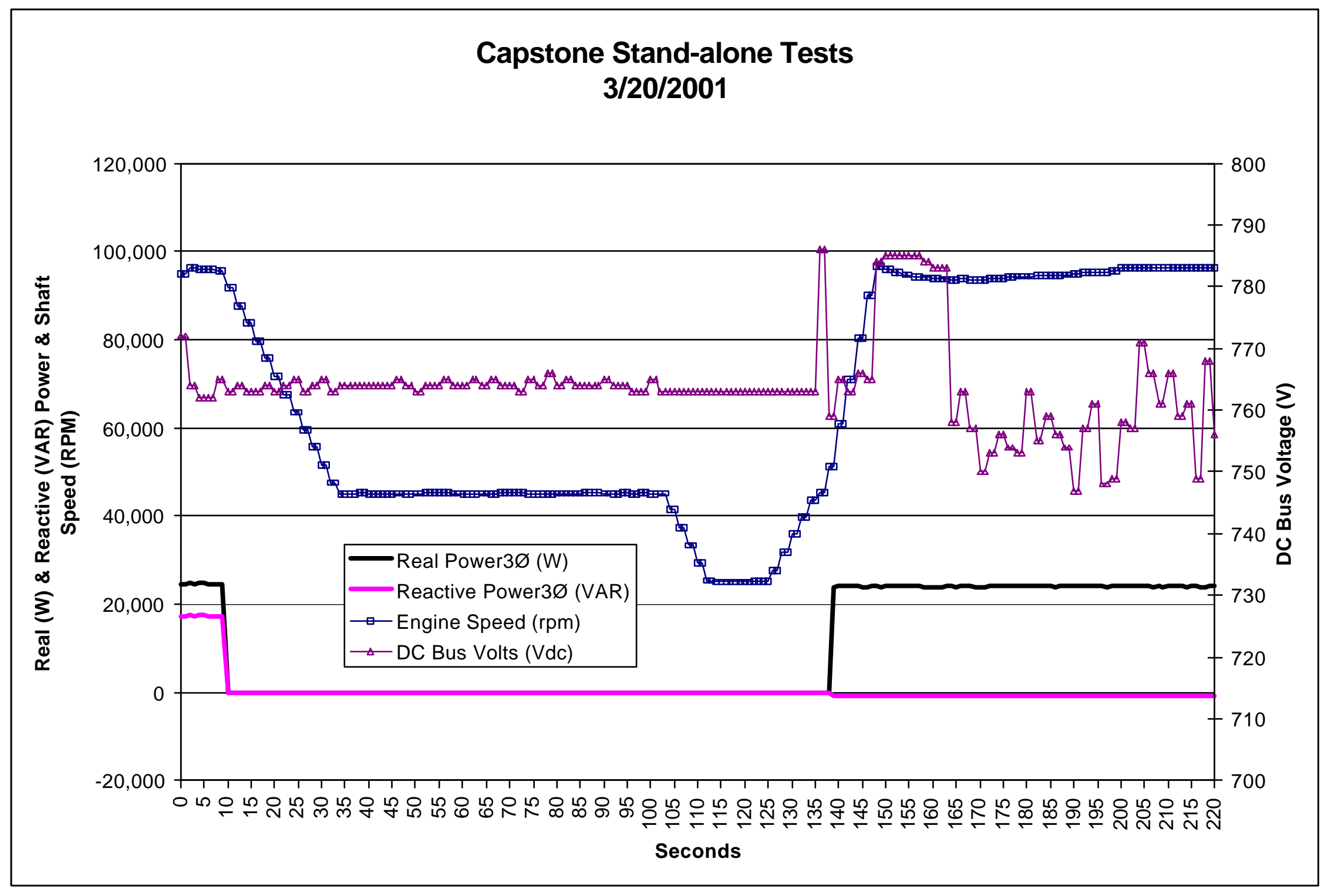

Figure D-26: Power, Shaft Speed and DC Bus Voltage During MTG Shutdown and Start 


\section{Appendix E}

\section{Honeywell Parallon Stand-alone Tests}

$5 / 2 / 2001$ 


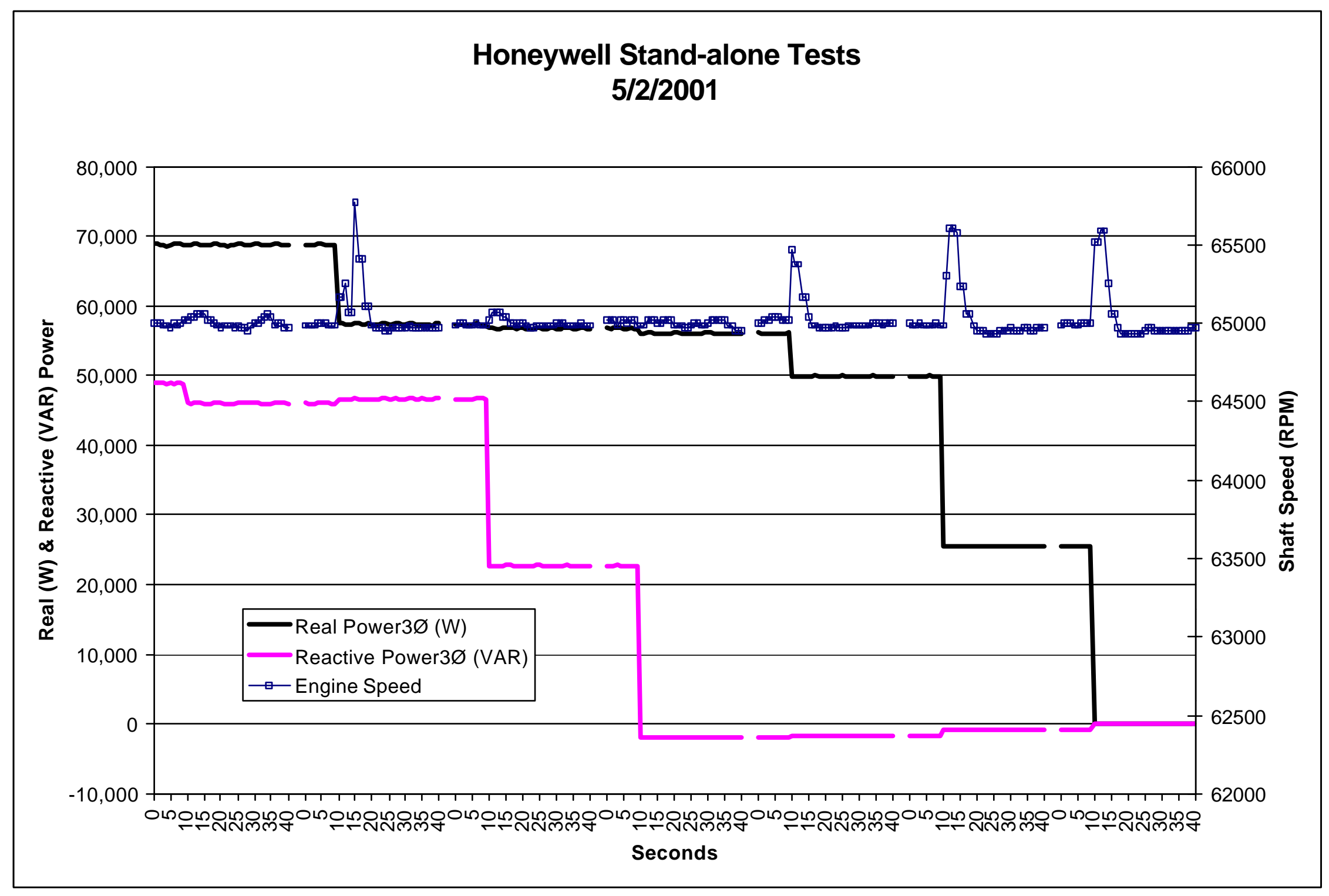

Figure E-1: Ramp Down Tests - Power and Shaft Speed - kW and kVAR Steps 


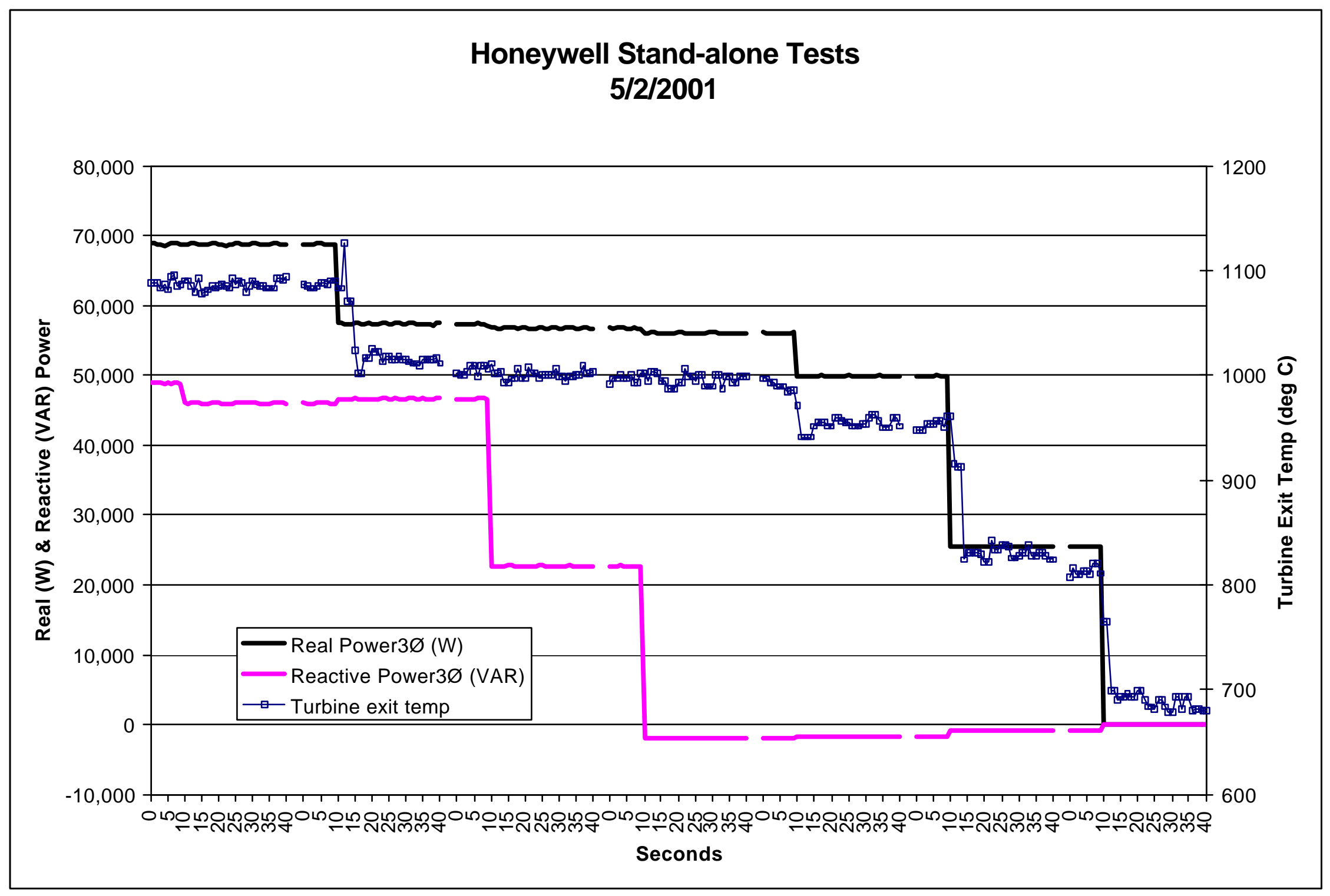

Figure E-2: Ramp Down Tests - Power and Turbine Exit Temperature - kW and kVAR Steps 


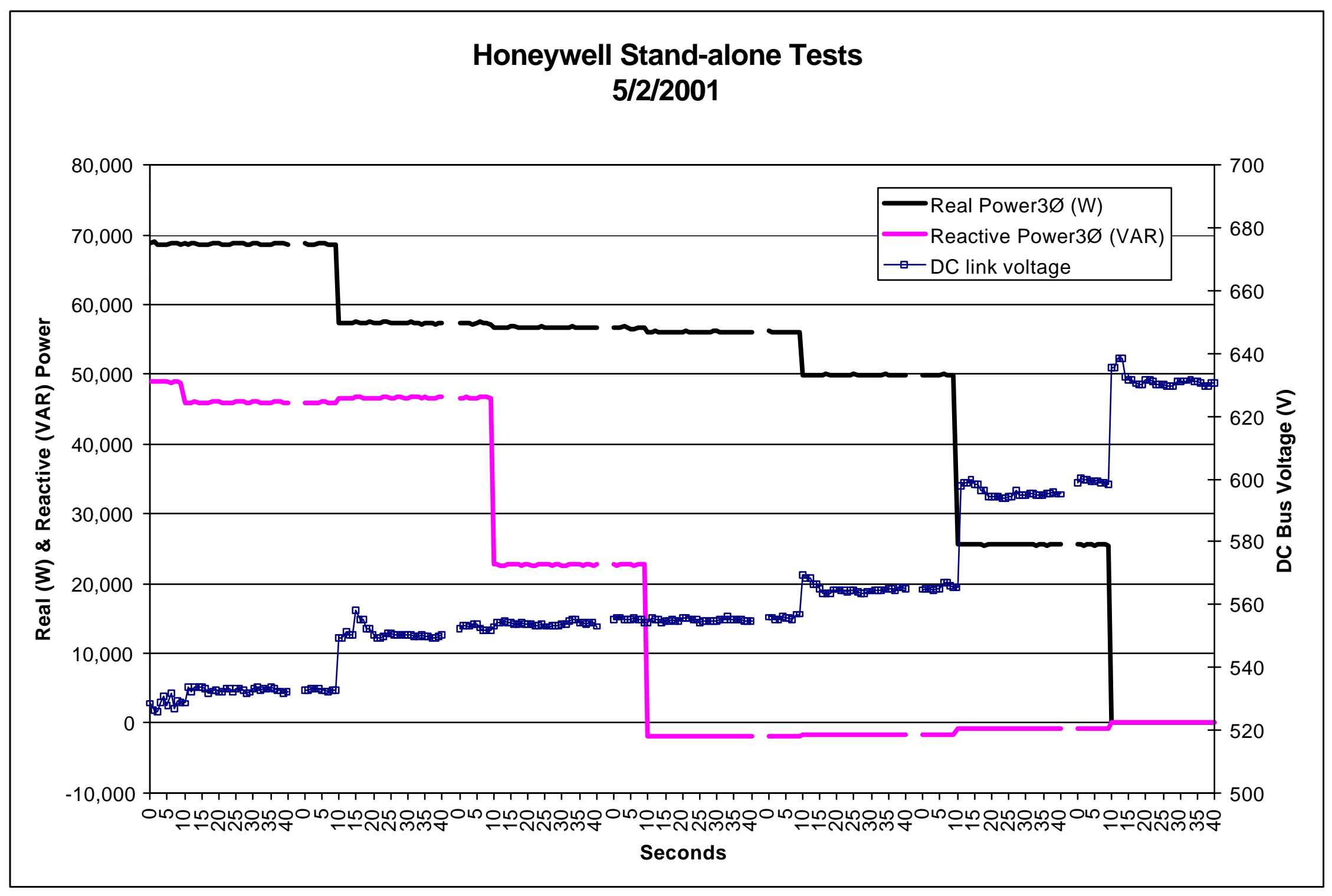

Figure E-3: Ramp Down Tests - Power and DC Bus Voltage - kW and kVAR Steps 


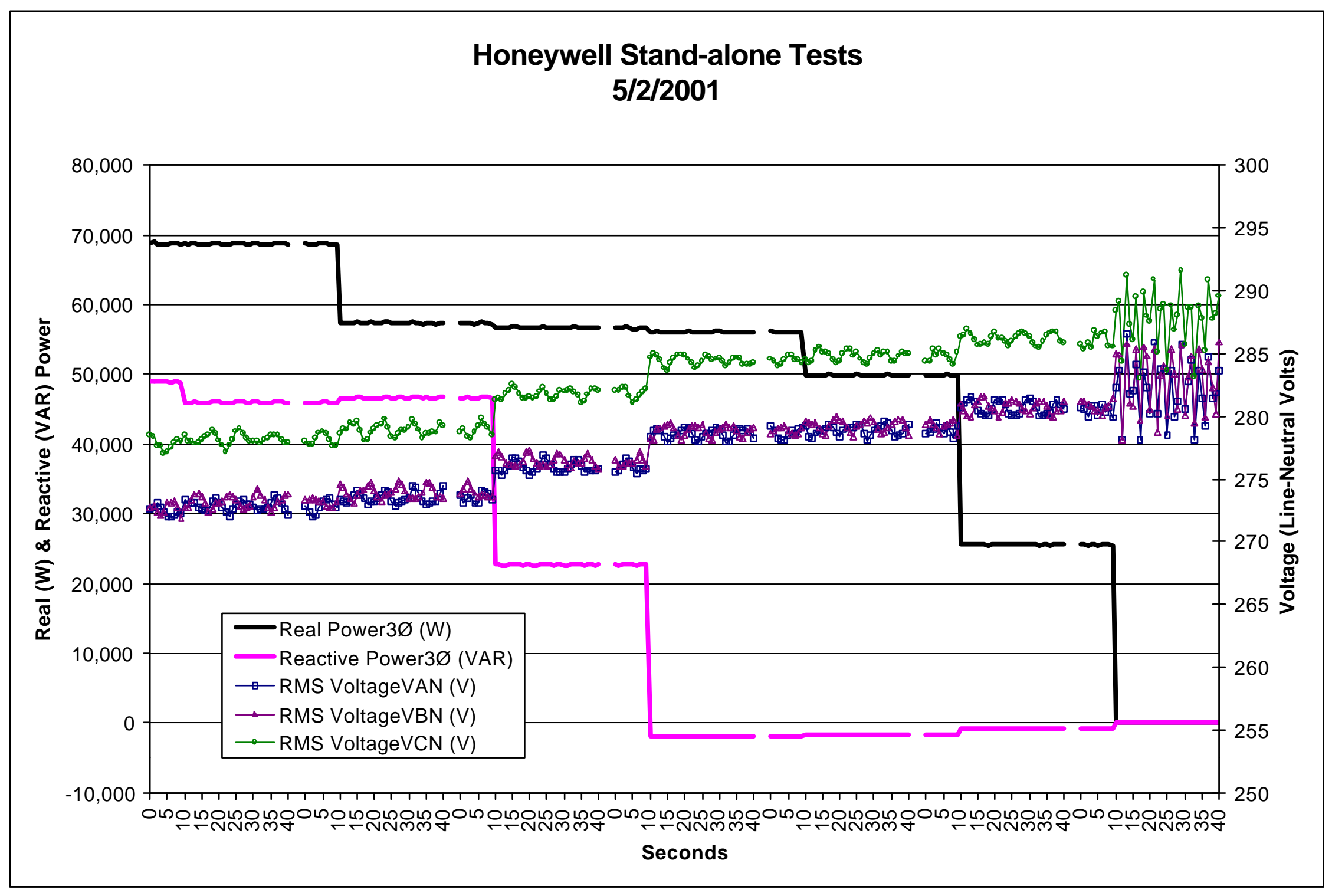

Figure E-4: Ramp Down Tests - Power and Line-Neutral Voltage - kW and kVAR Steps 


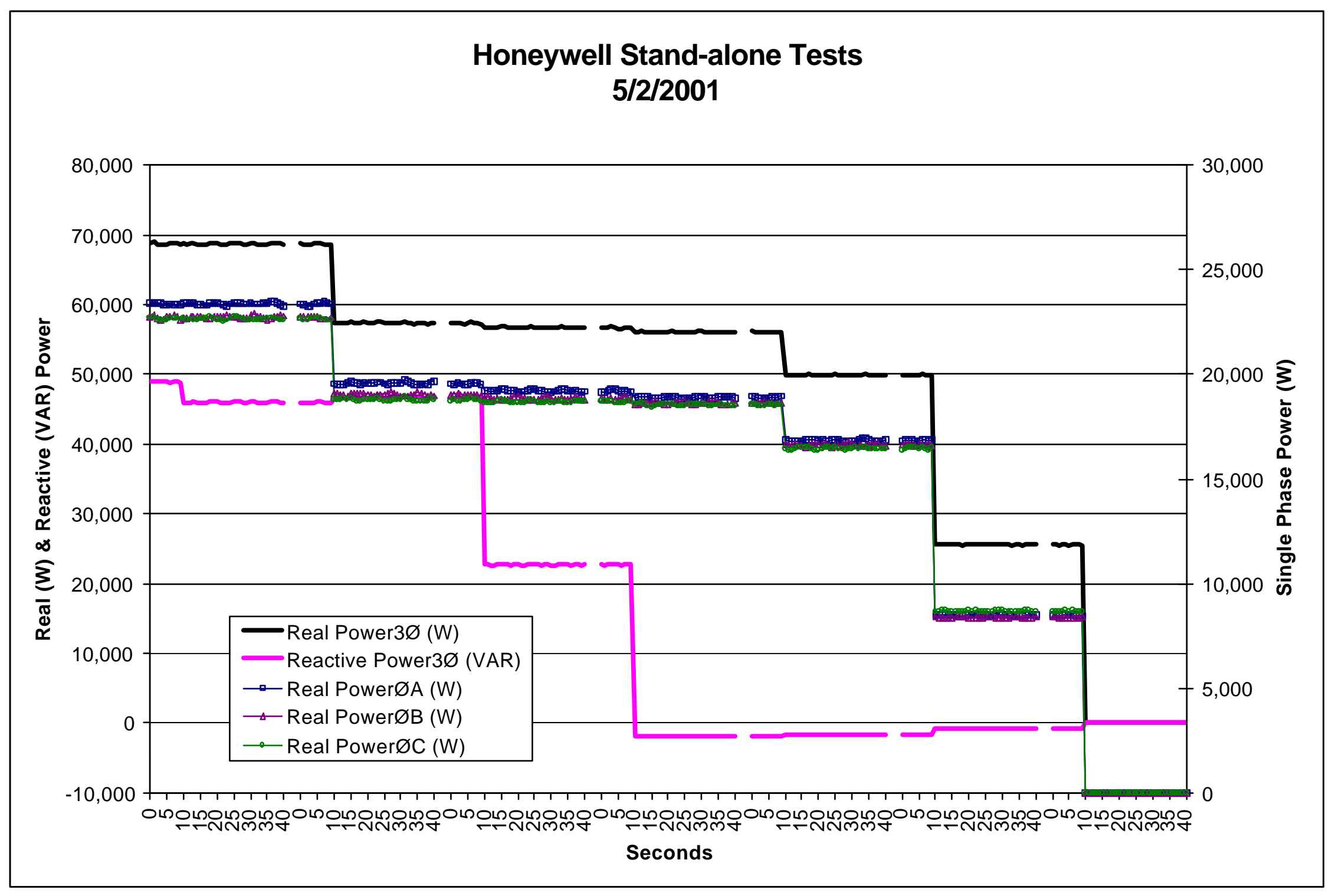

Figure E-5: Ramp Down Tests - Power and Single Phase Power - kW and kVAR Steps 


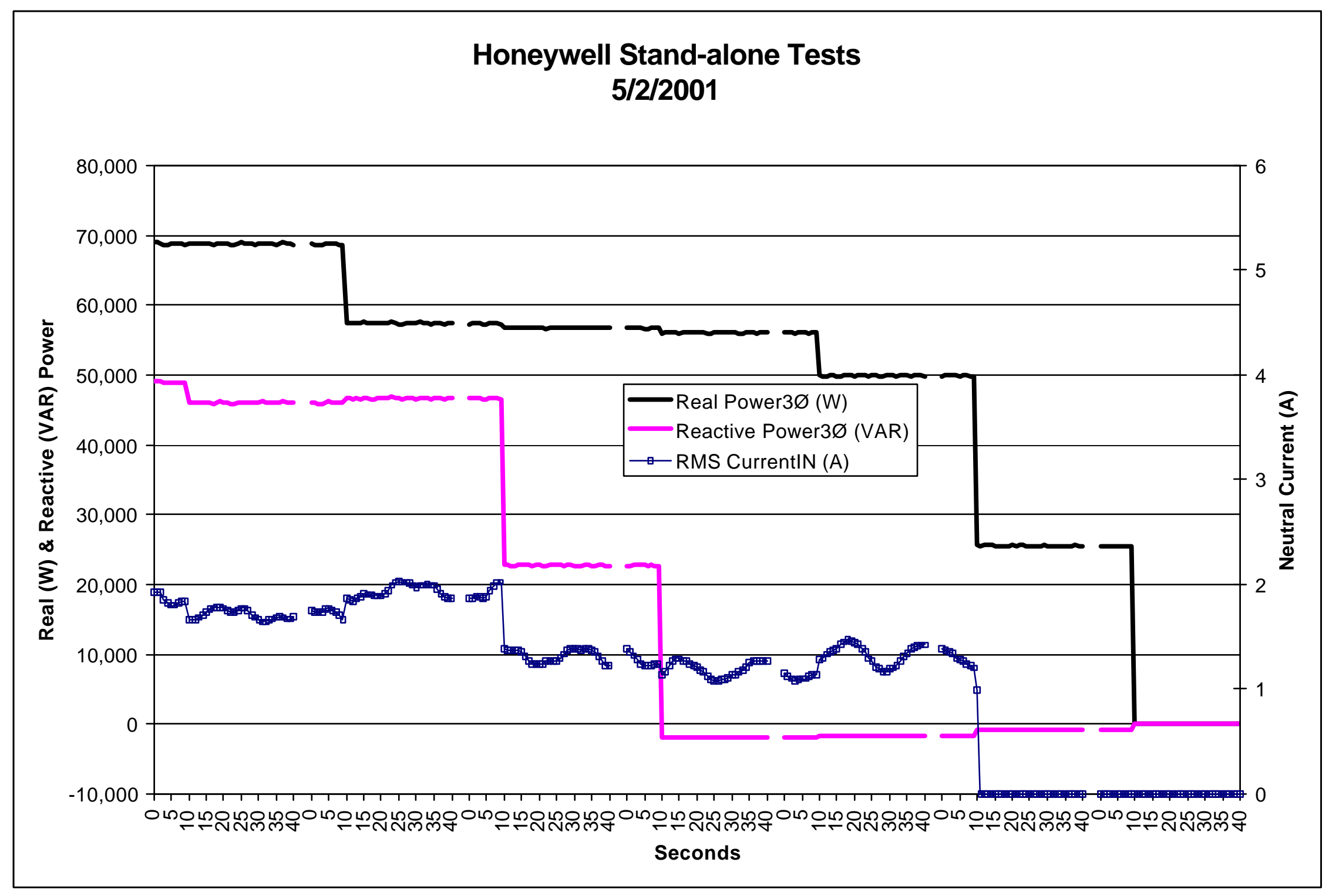

Figure E-6: Ramp Down Tests - Power and Neutral Current - kW and kVAR Steps 


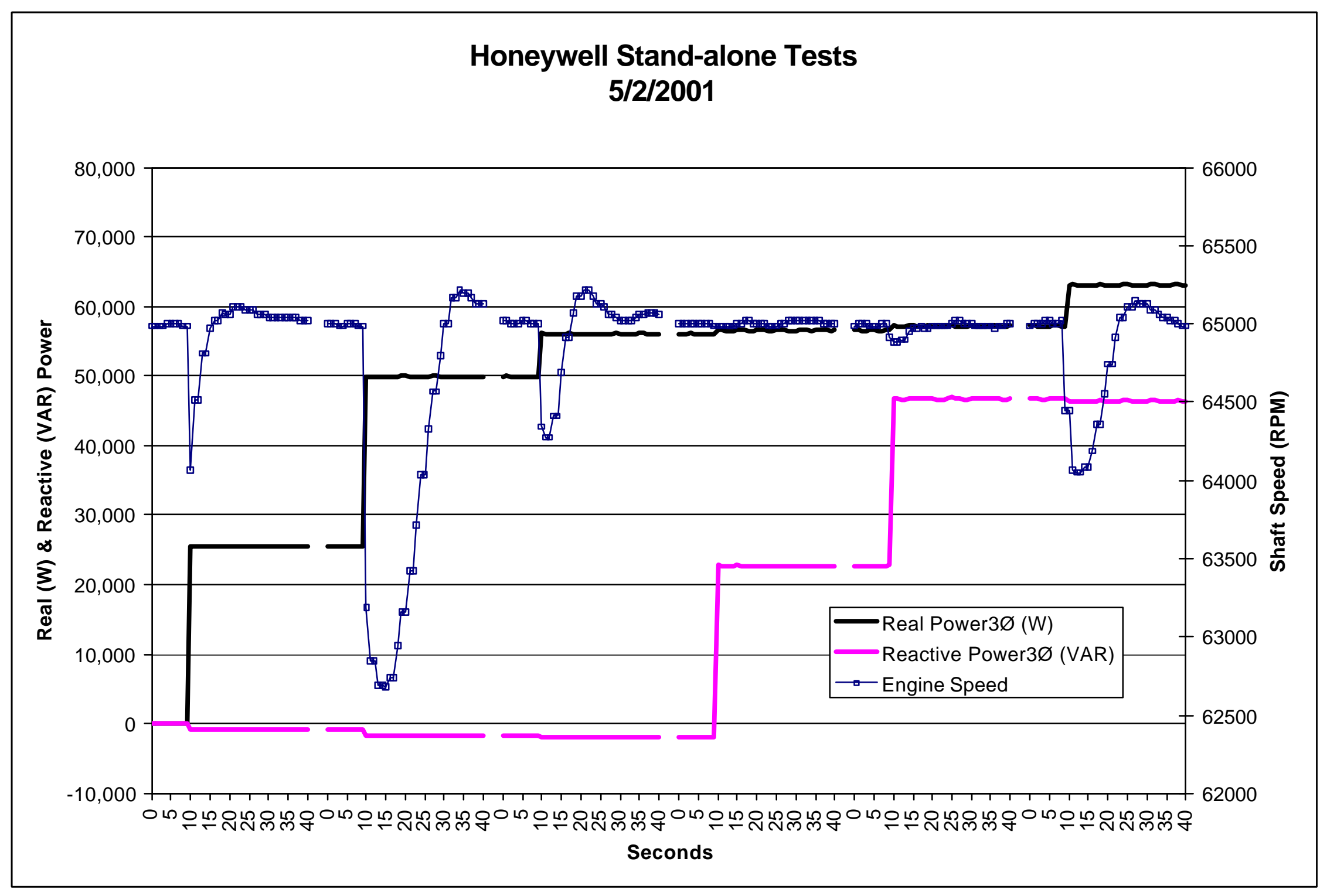

Figure E-7: Ramp Up Tests - Power and Shaft Speed - kW and kVAR Steps 


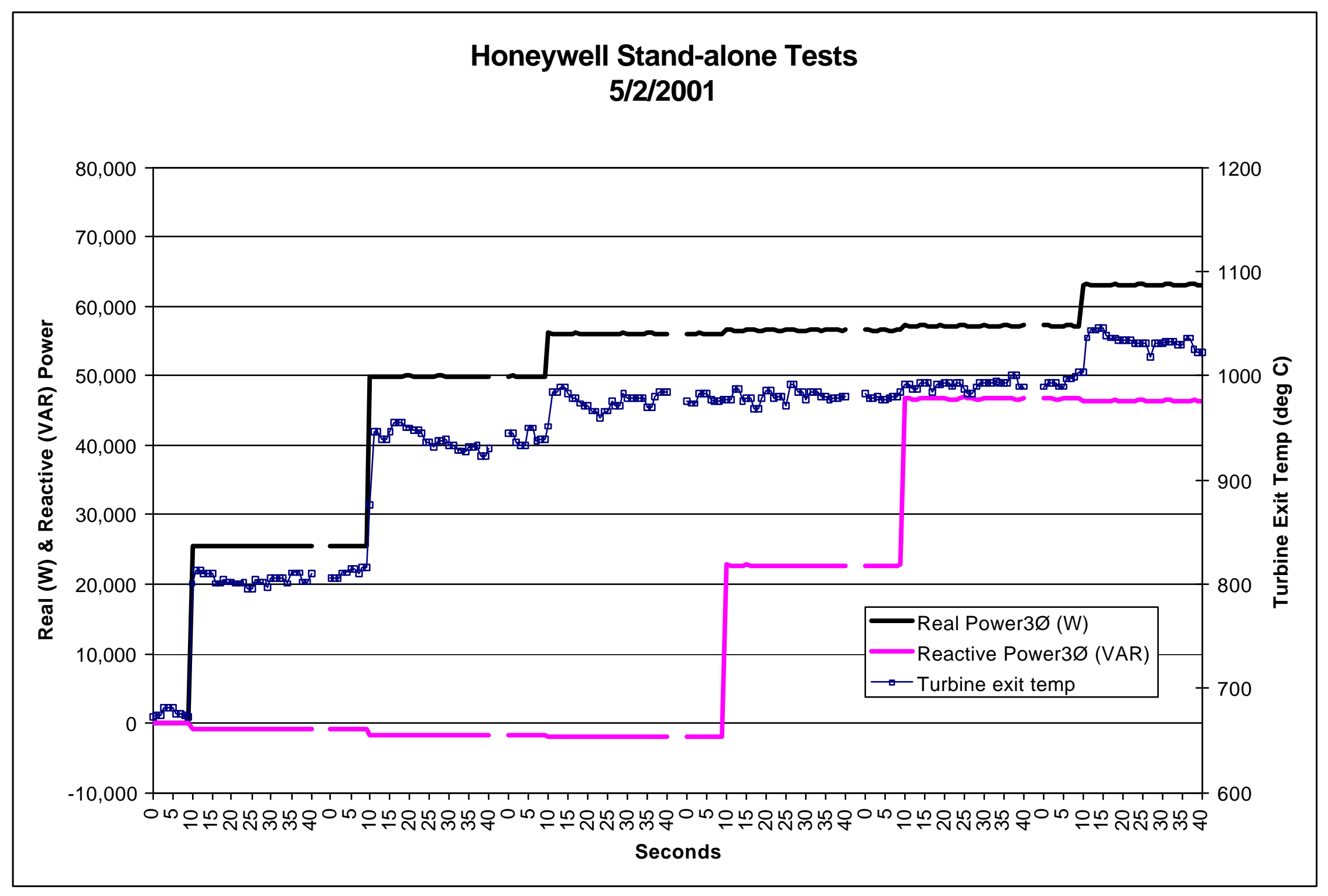

Figure E-8: Ramp Up Tests - Power and Turbine Exit Temperature - kW and kVAR Steps 


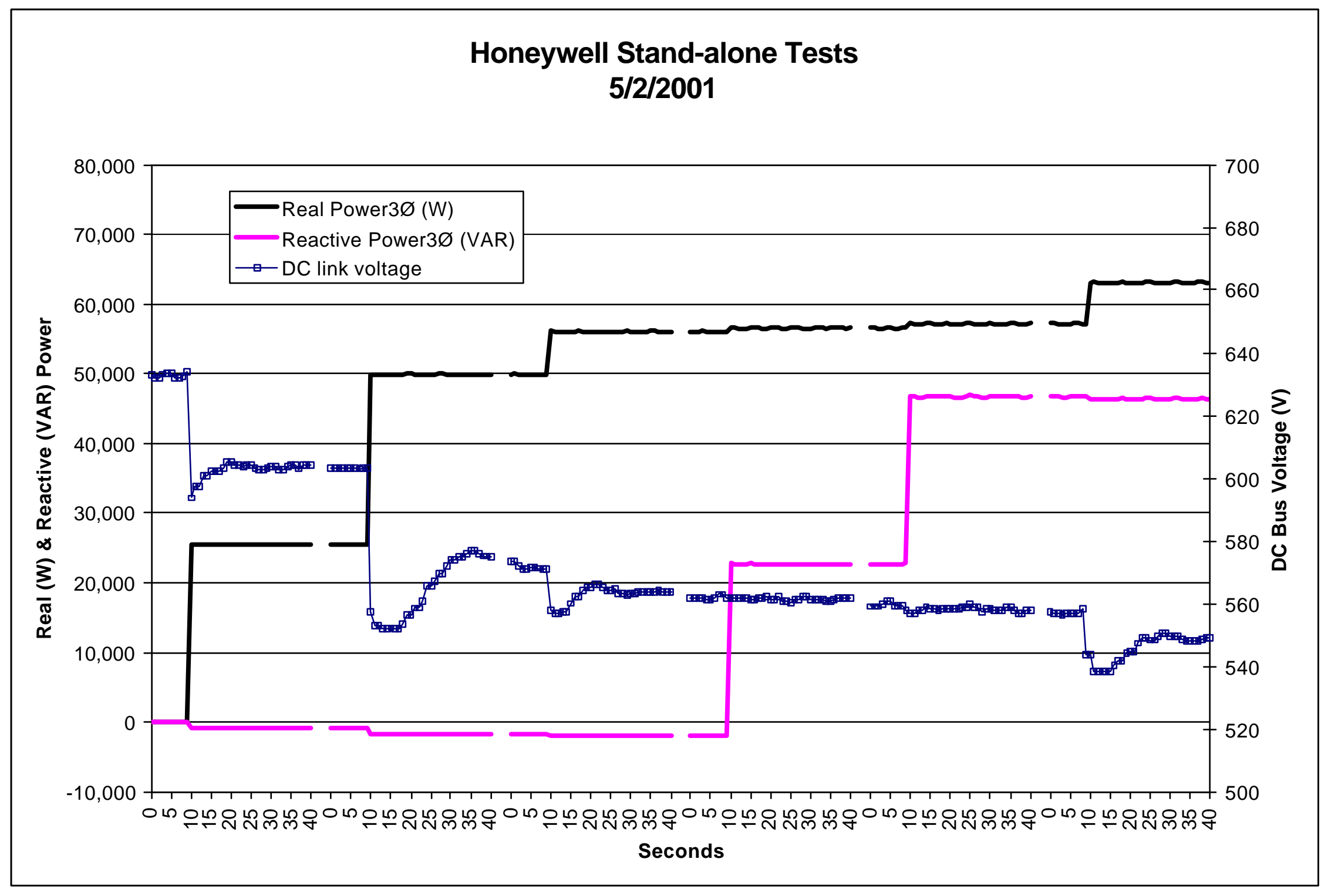

Figure E-9: Ramp Up Tests - Power and DC Bus Voltage - kW and kVAR Steps 


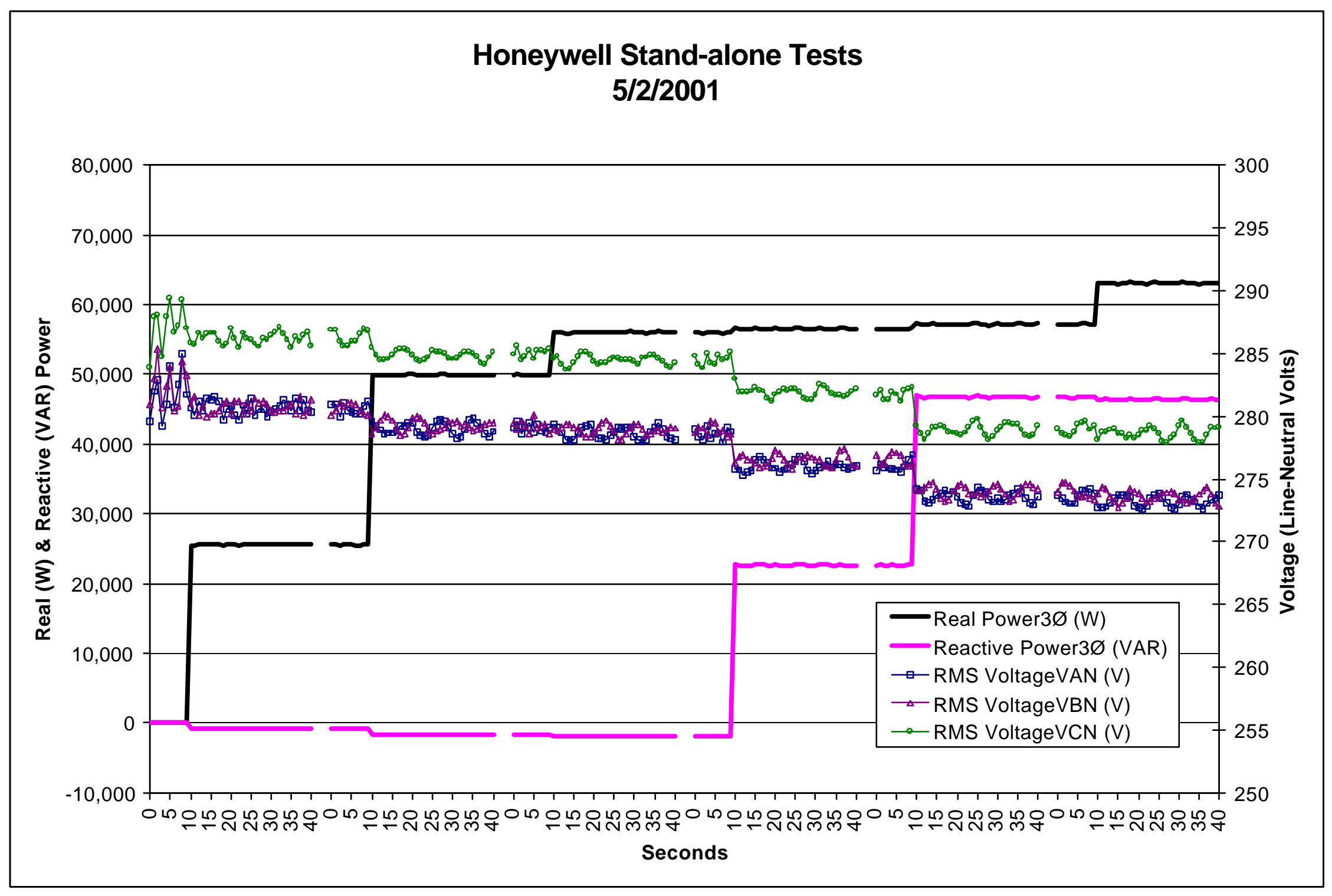

Figure E-10: Ramp Up Tests - Power and Line-Neutral Voltage - kW and kVAR Steps 


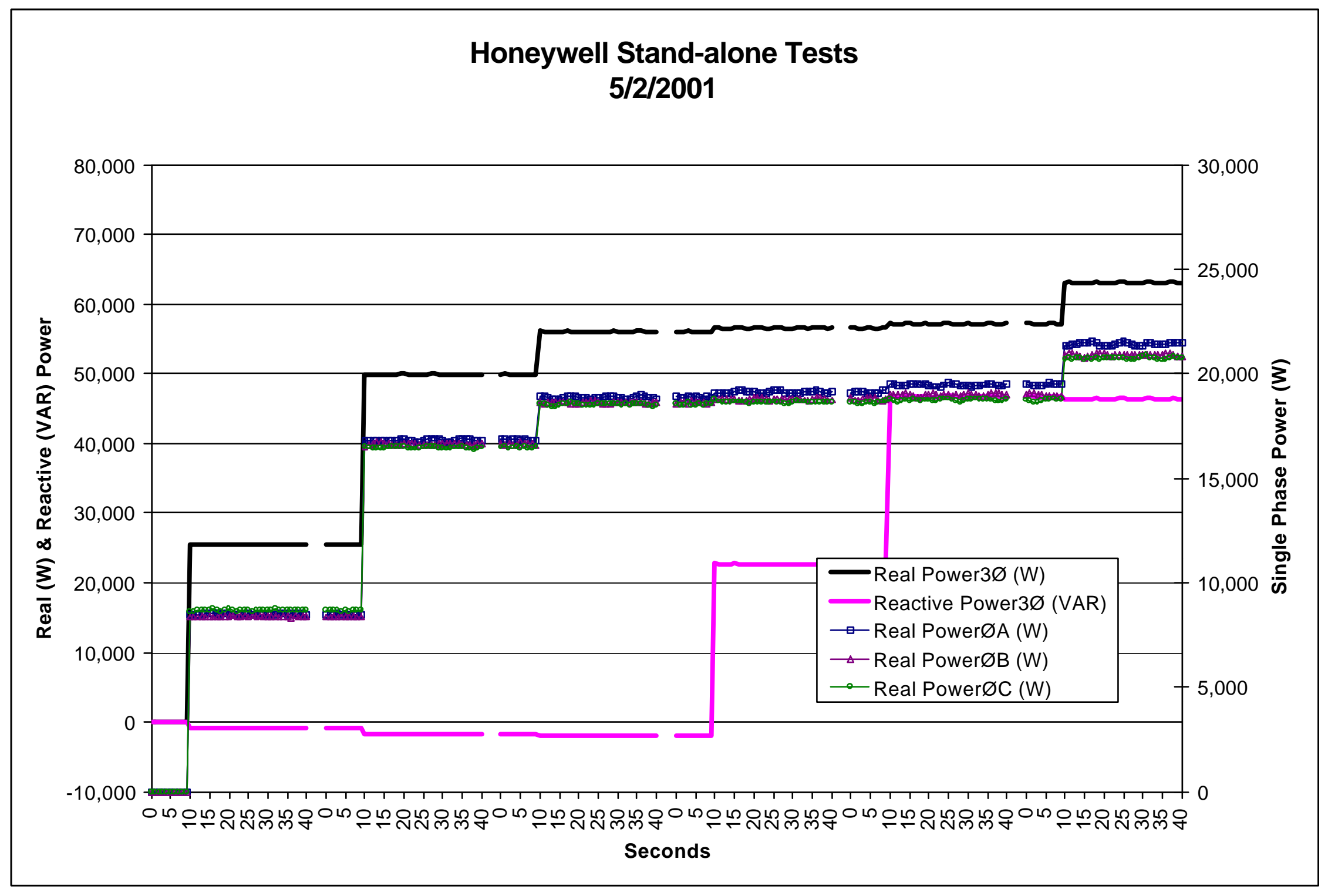

Figure E-11: Ramp Up Tests - Power and Single Phase Power - kW and kVAR Steps 


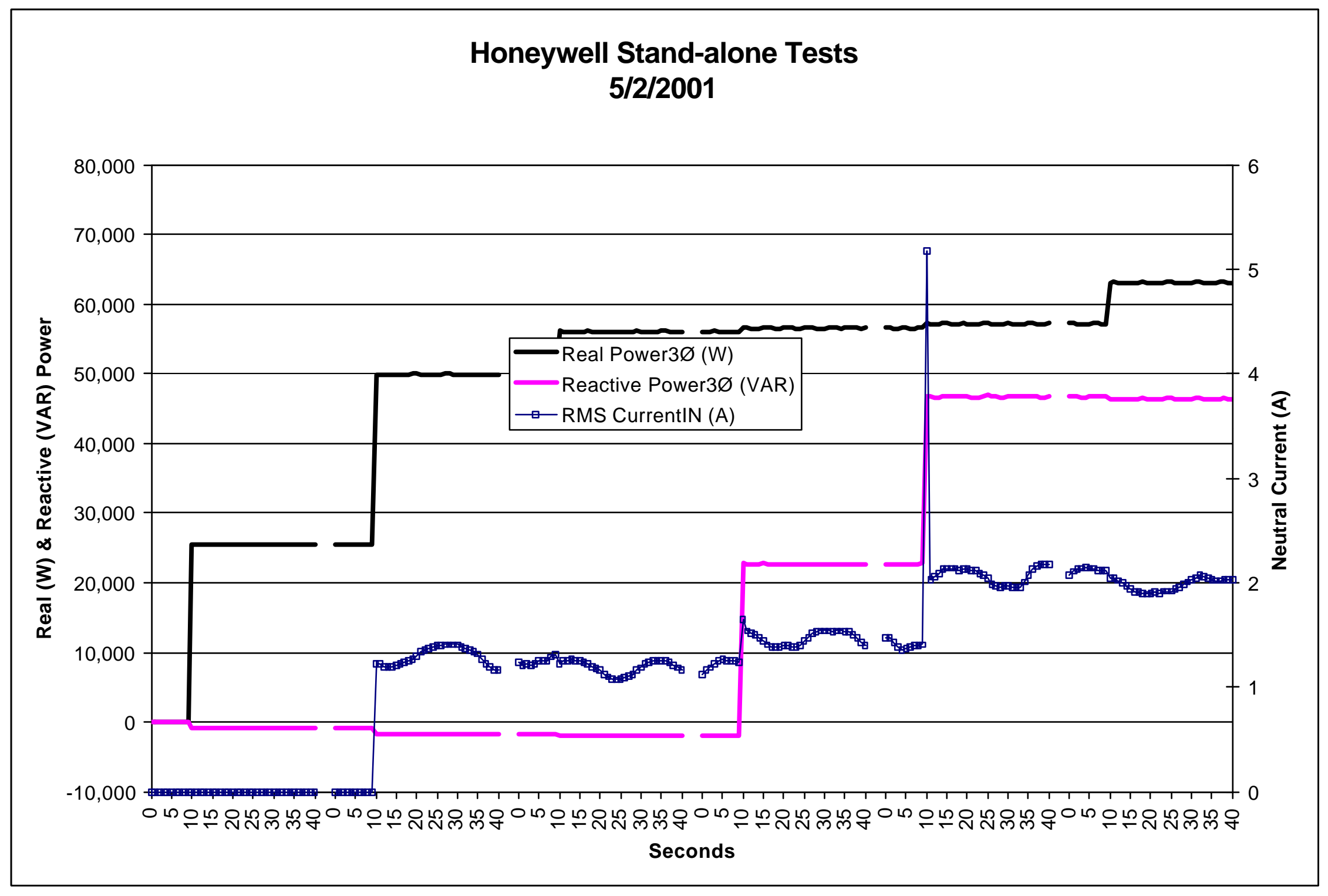

Figure E-12: Ramp Up Tests - Power and Neutral Current - kW and kVAR Steps 


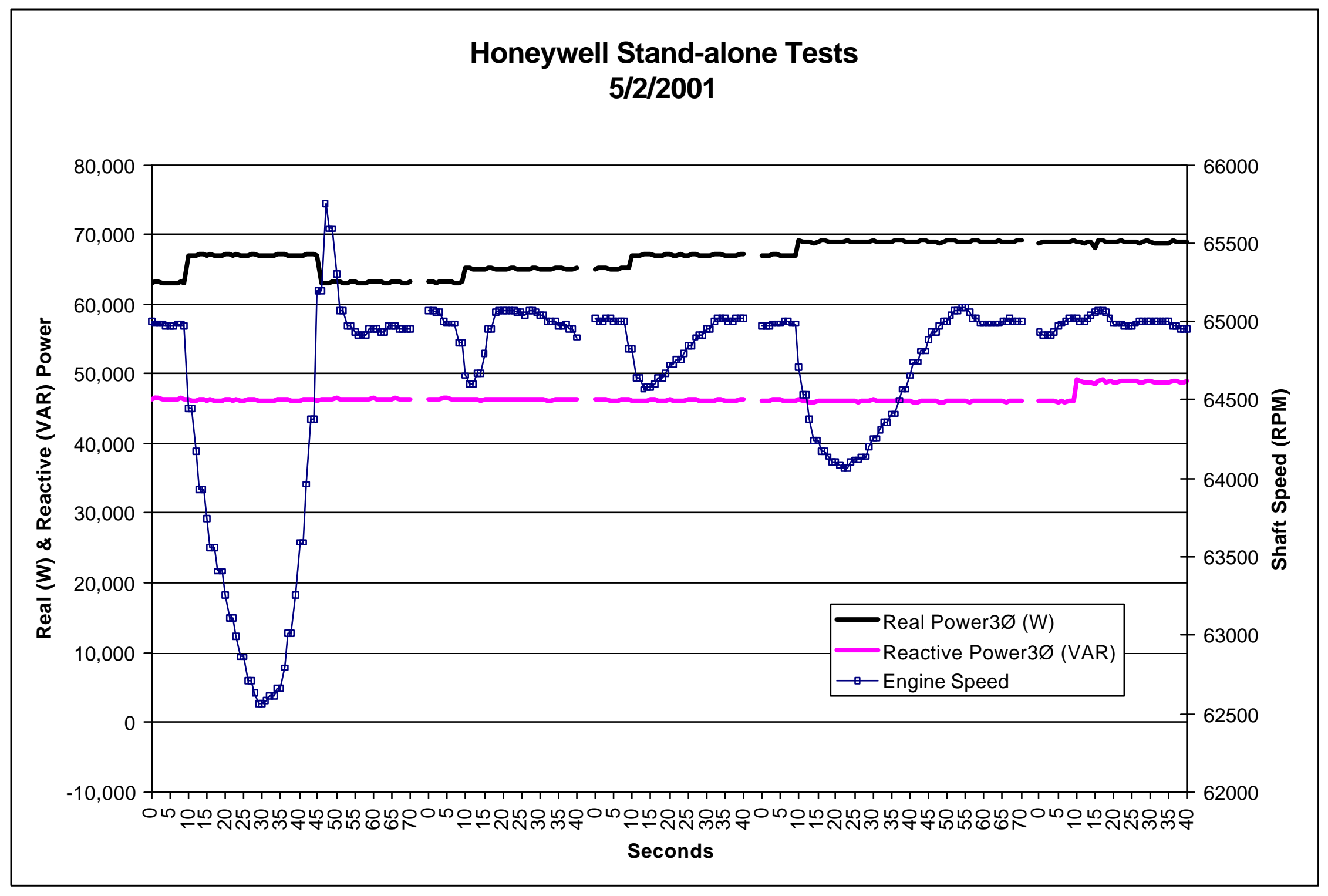

Figure E-13: Ramp Up Tests - Power and Shaft Speed - kW and kVAR Steps 


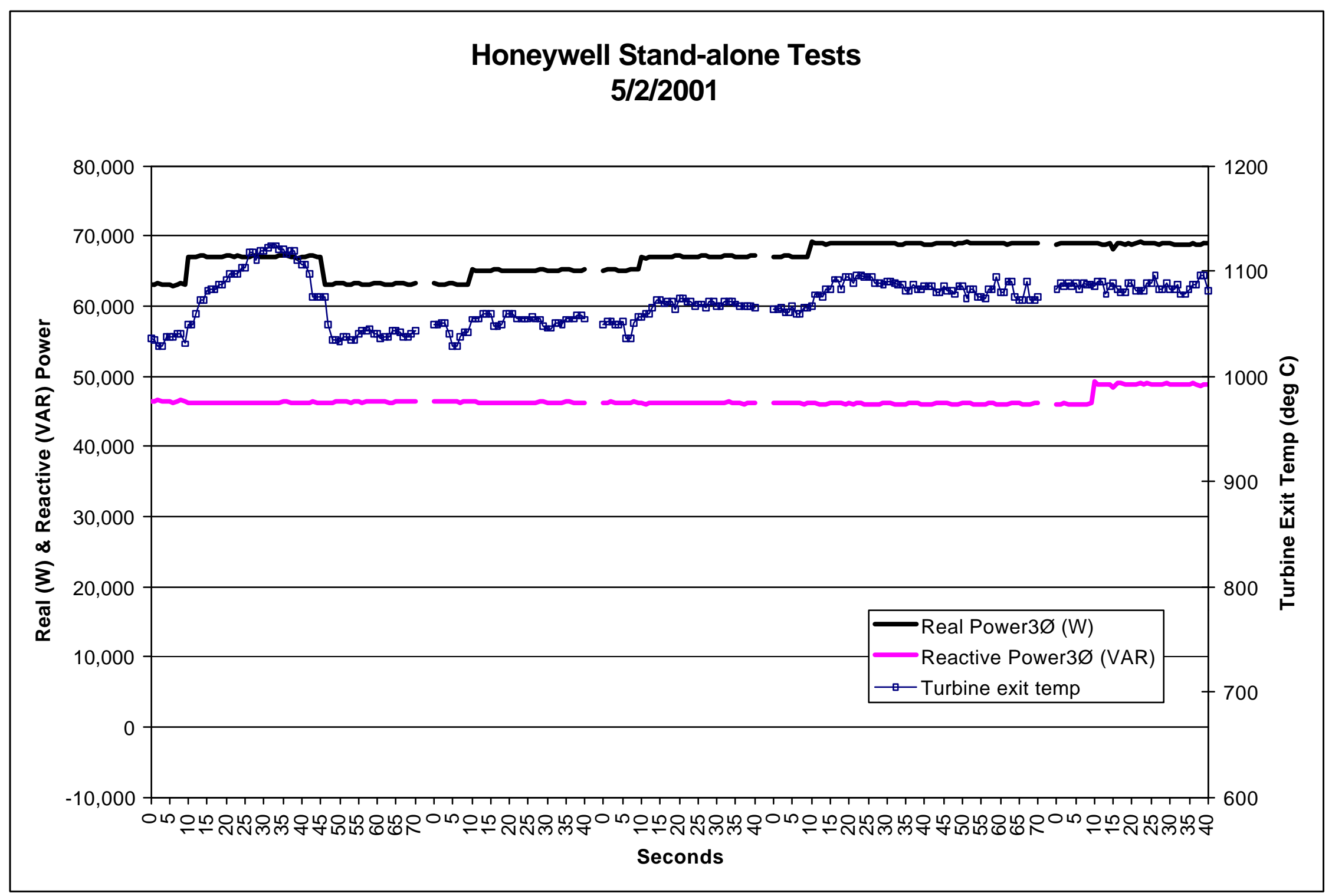

Figure E-14: Ramp Up Tests - Power and Turbine Exit Temperature - kW and kVAR Steps 


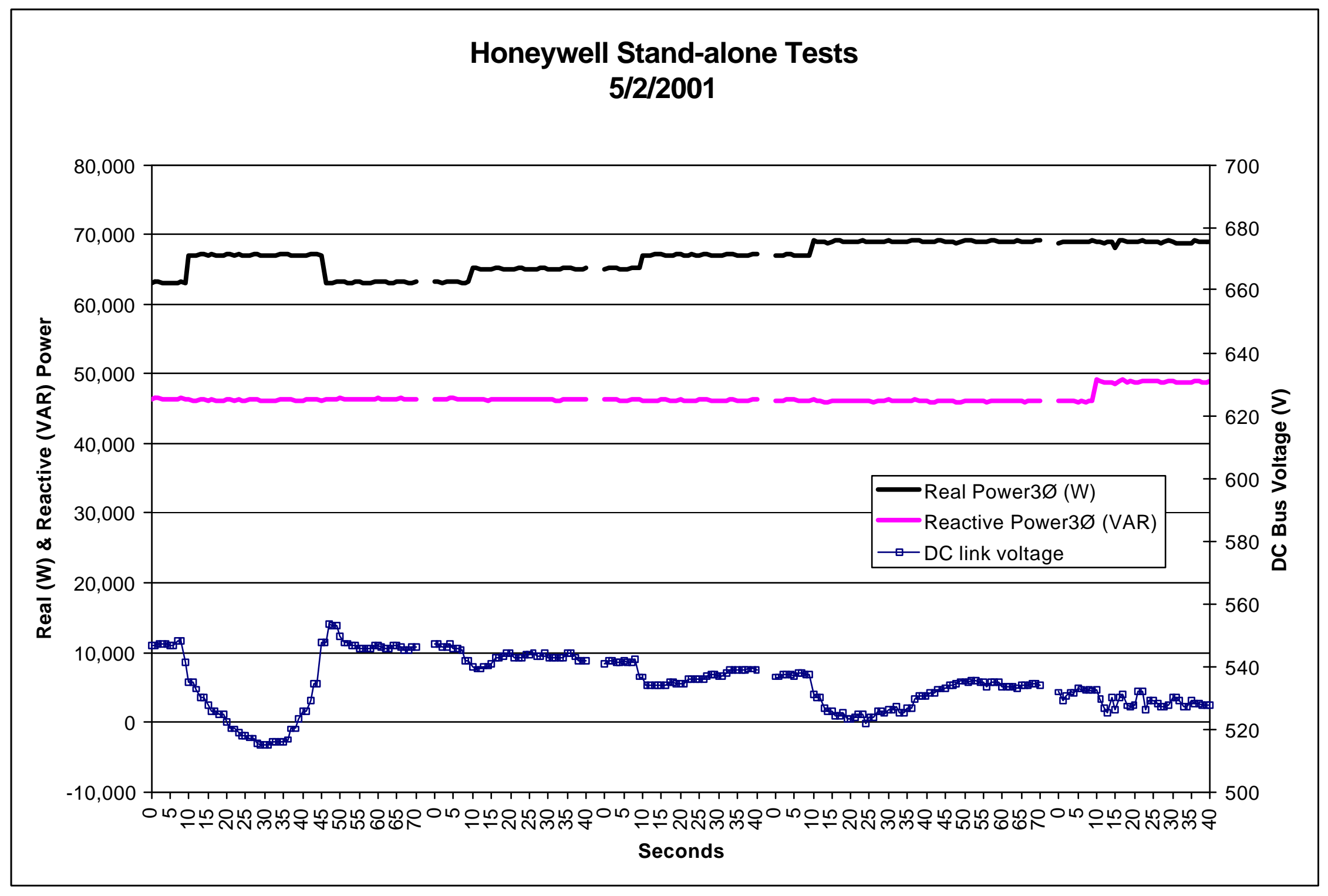

Figure E-15: Ramp Up Tests - Power and DC Bus Voltage - kW and kVAR Steps 


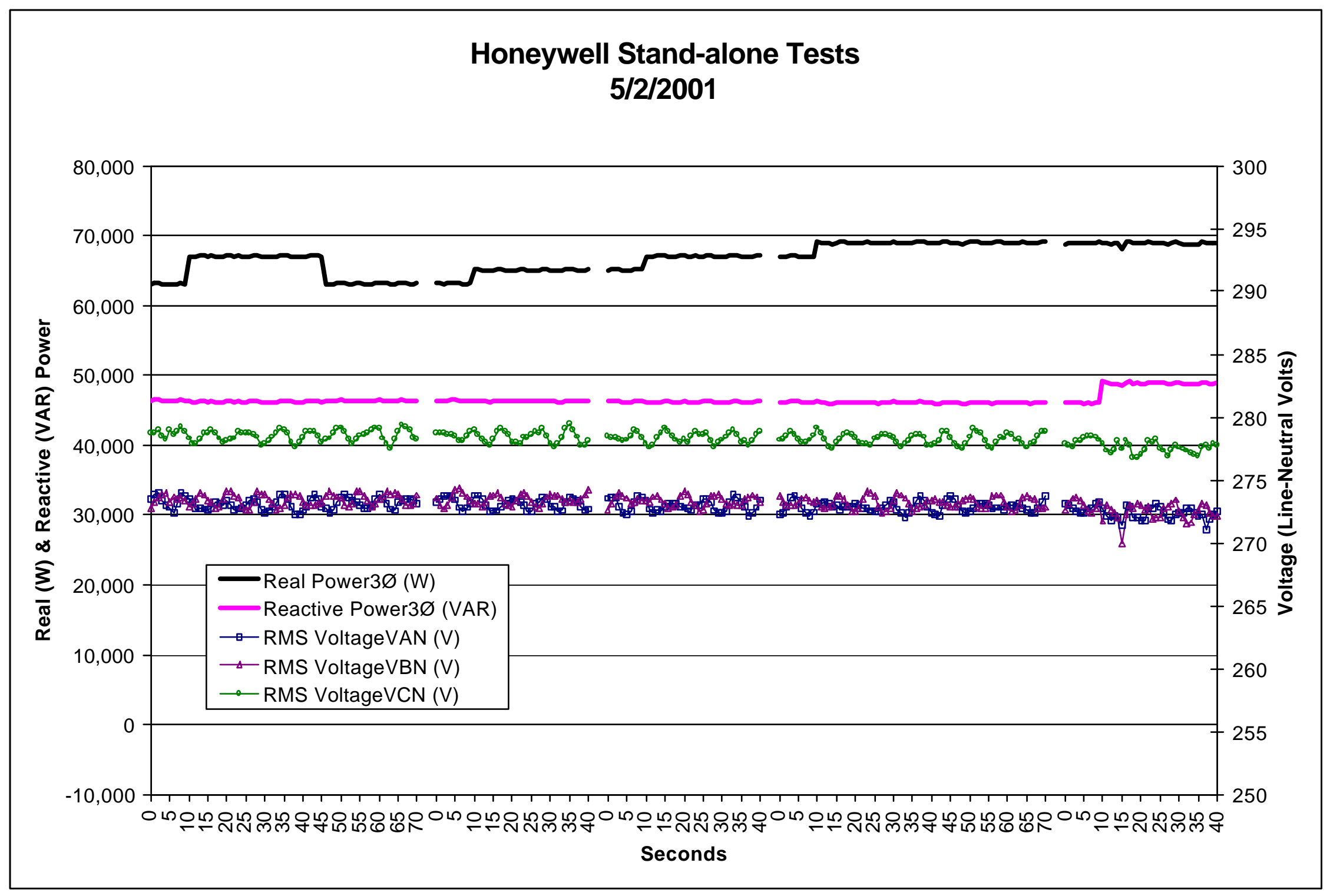

Figure E-16: Ramp Up Tests - Power and Line-Neutral Voltage - kW and kVAR Steps 


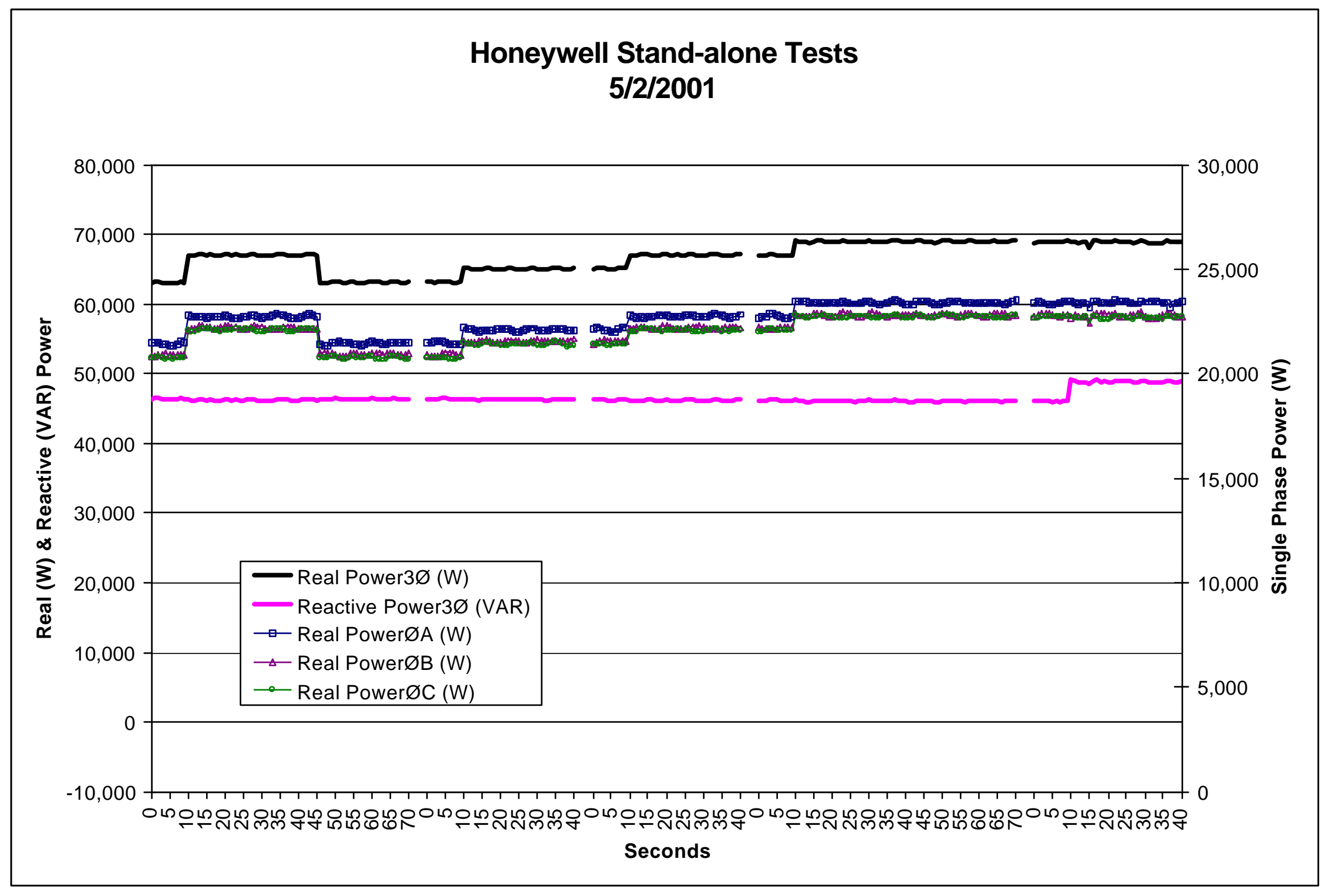

Figure E-17: Ramp Up Tests - Power and Single Phase Power - kW and kVAR Steps 


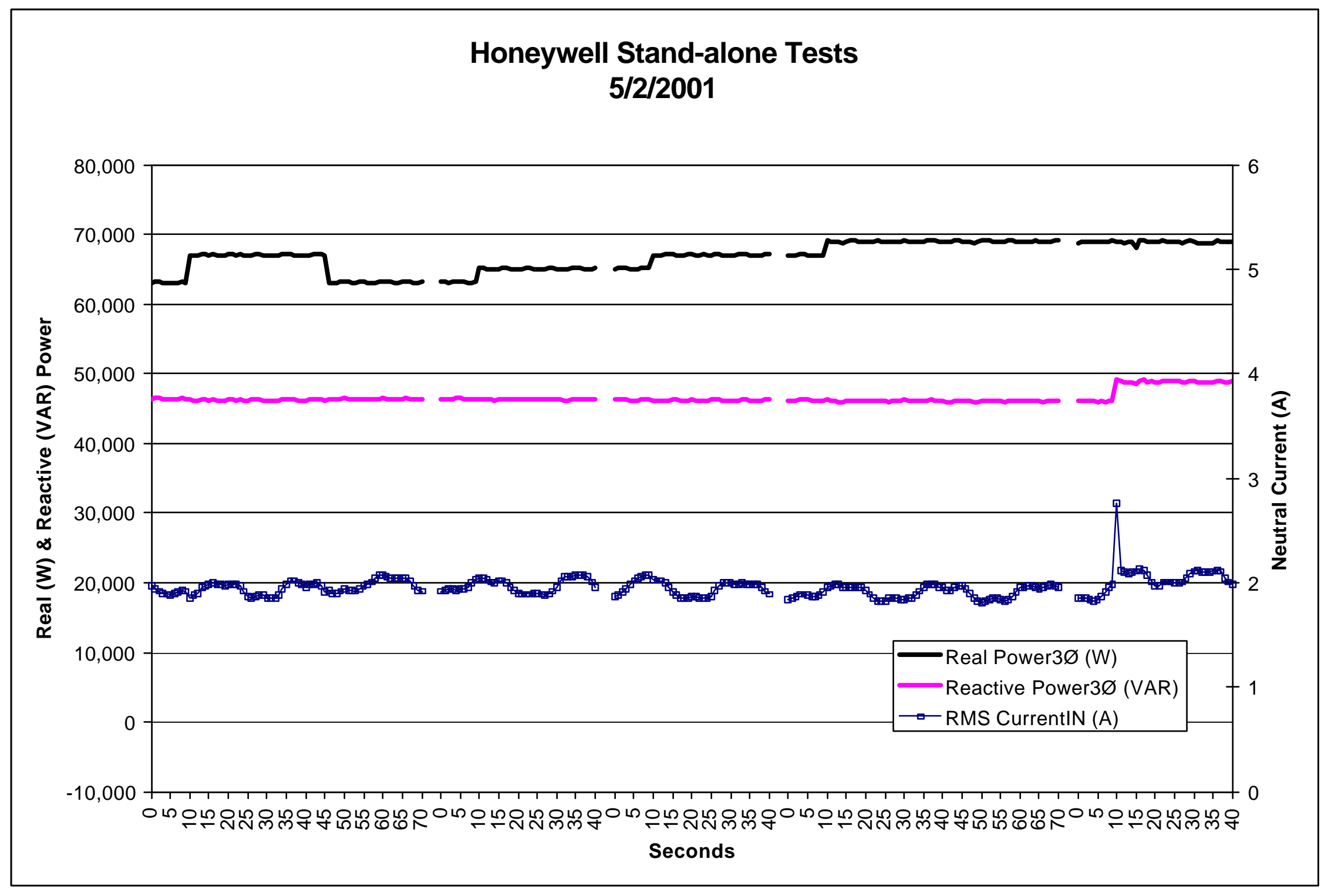

Figure E-18: Ramp Up Tests - Power and Neutral Current - kW and kVAR Steps 


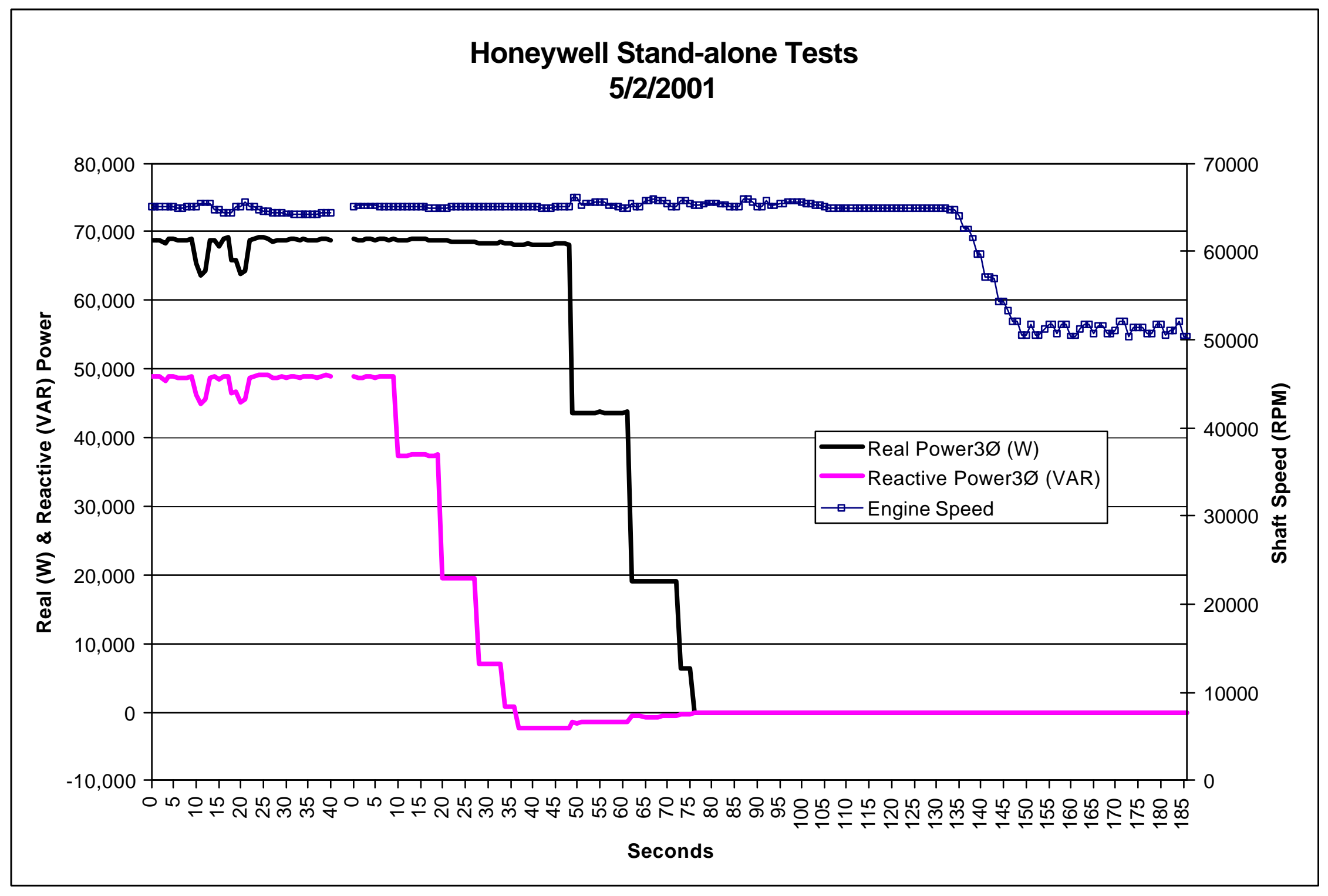

Figure E-19: Ramp Down and MTG Shutdown - Power and Shaft Speed 


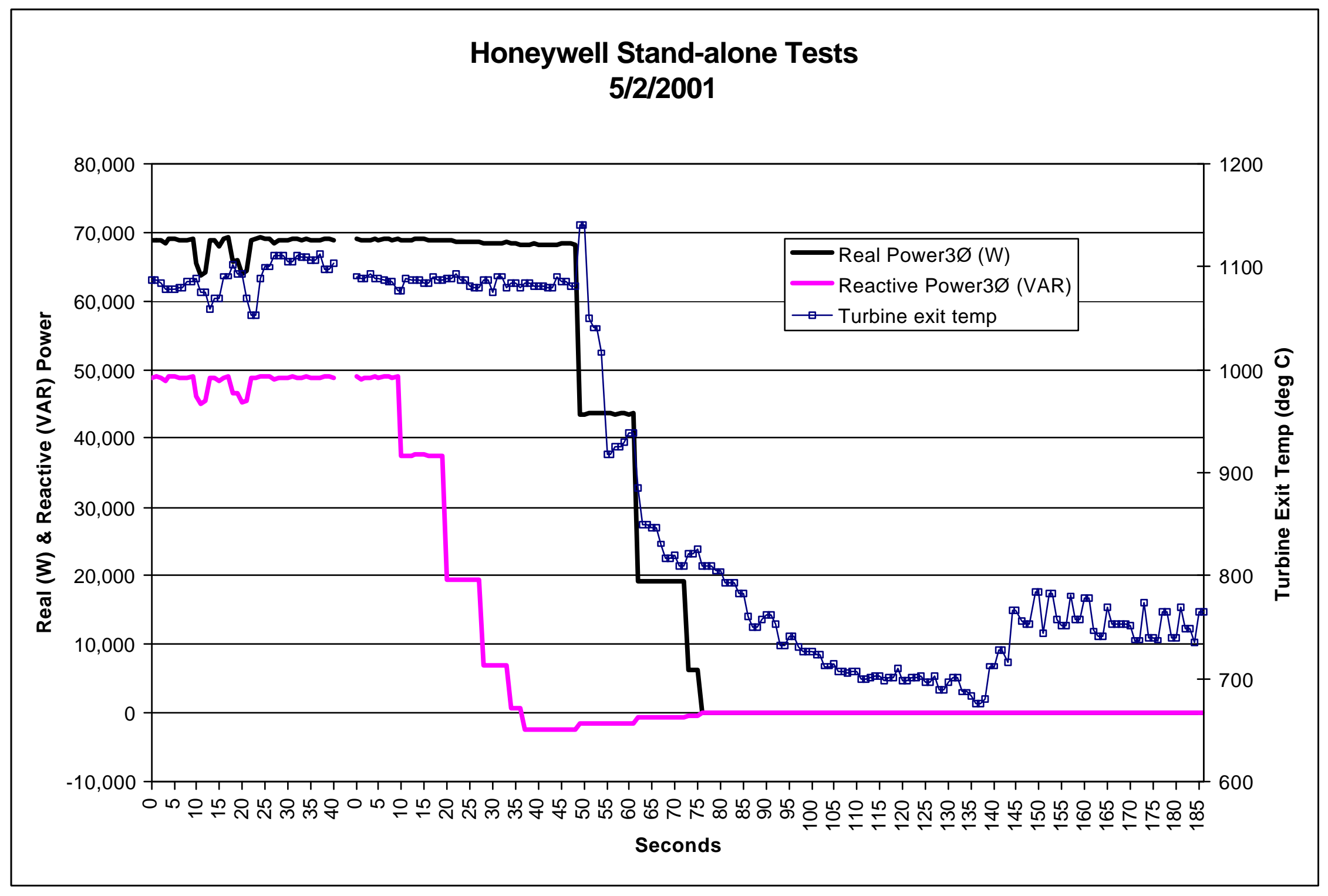

Figure E-20: Ramp Down and MTG Shutdown - Power and Turbine Exit Temperature 


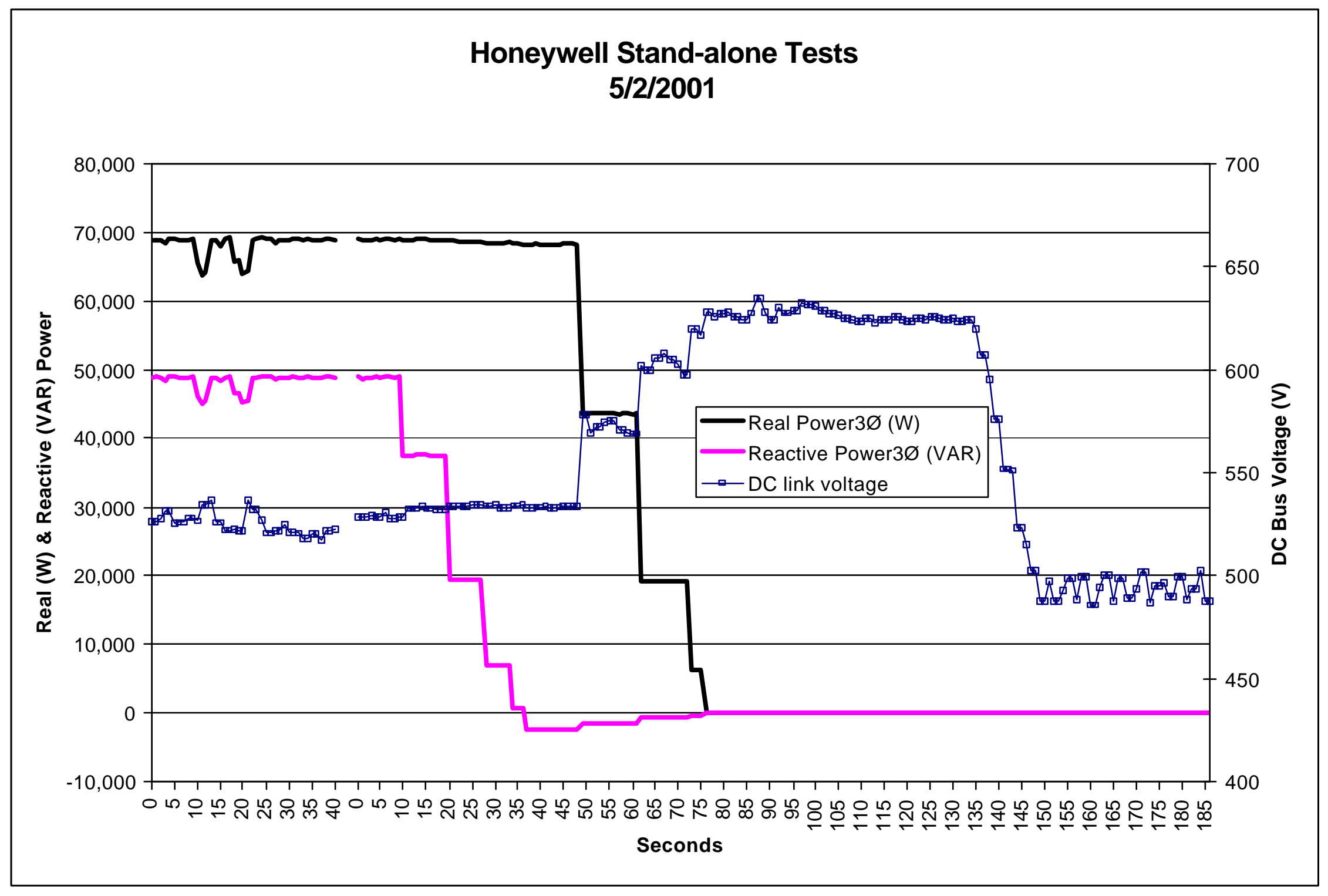

Figure E-21: Ramp Down and MTG Shutdown - Power and DC Bus Voltage 


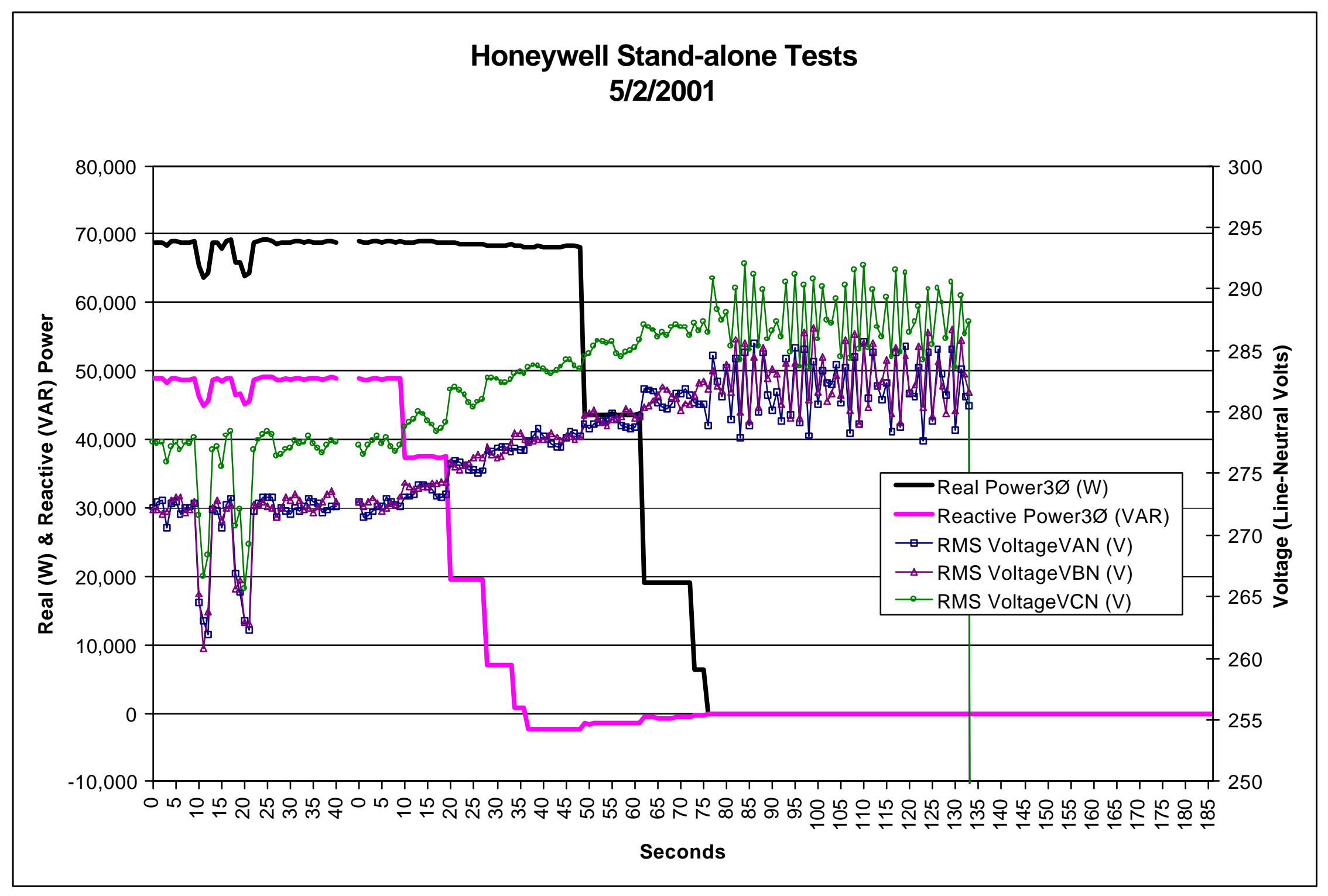

Figure E-22: Ramp Down and MTG Shutdown - Power and Line-Neutral Voltage 


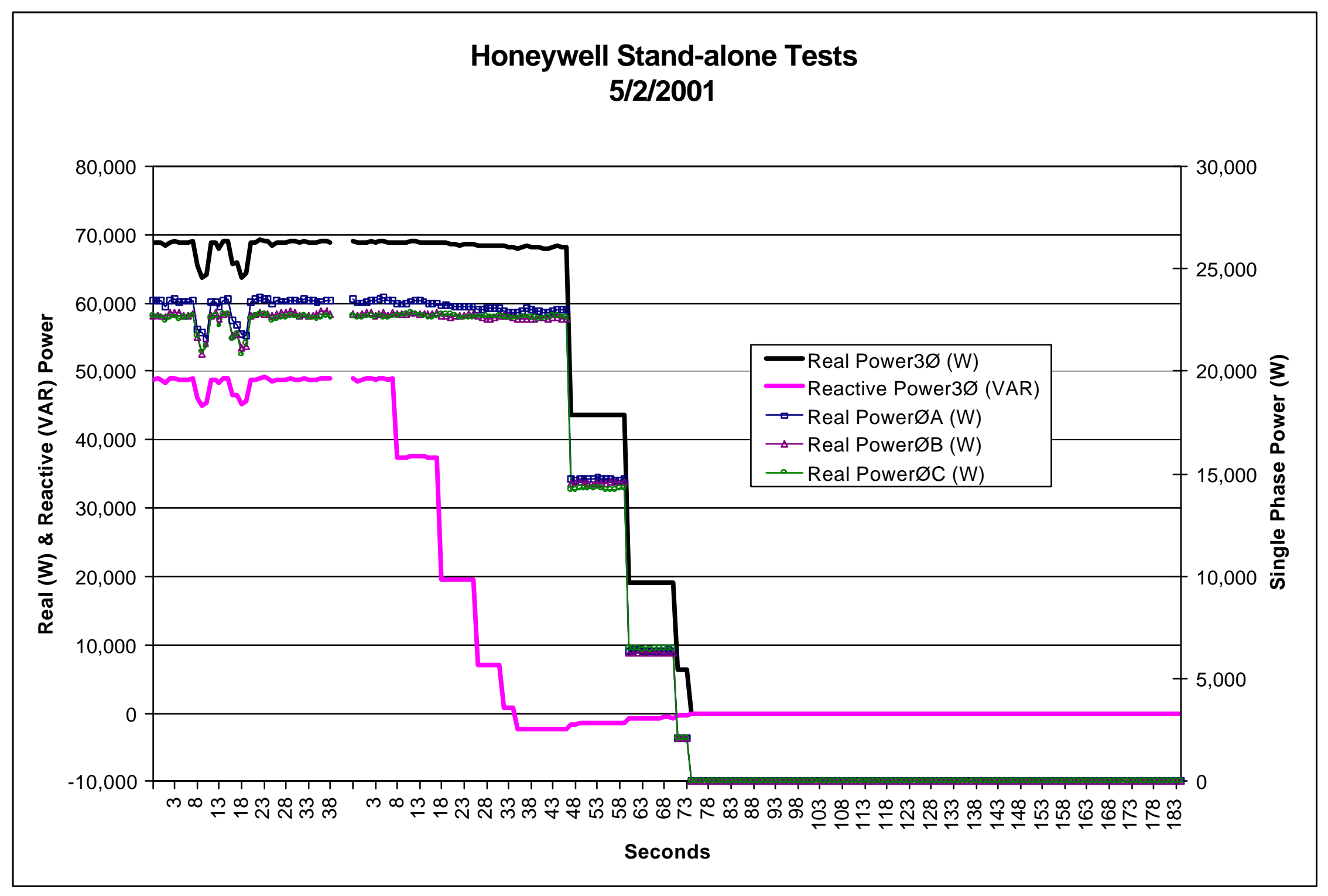

Figure E-23: Ramp Down and MTG Shutdown - Power and Single Phase Power 


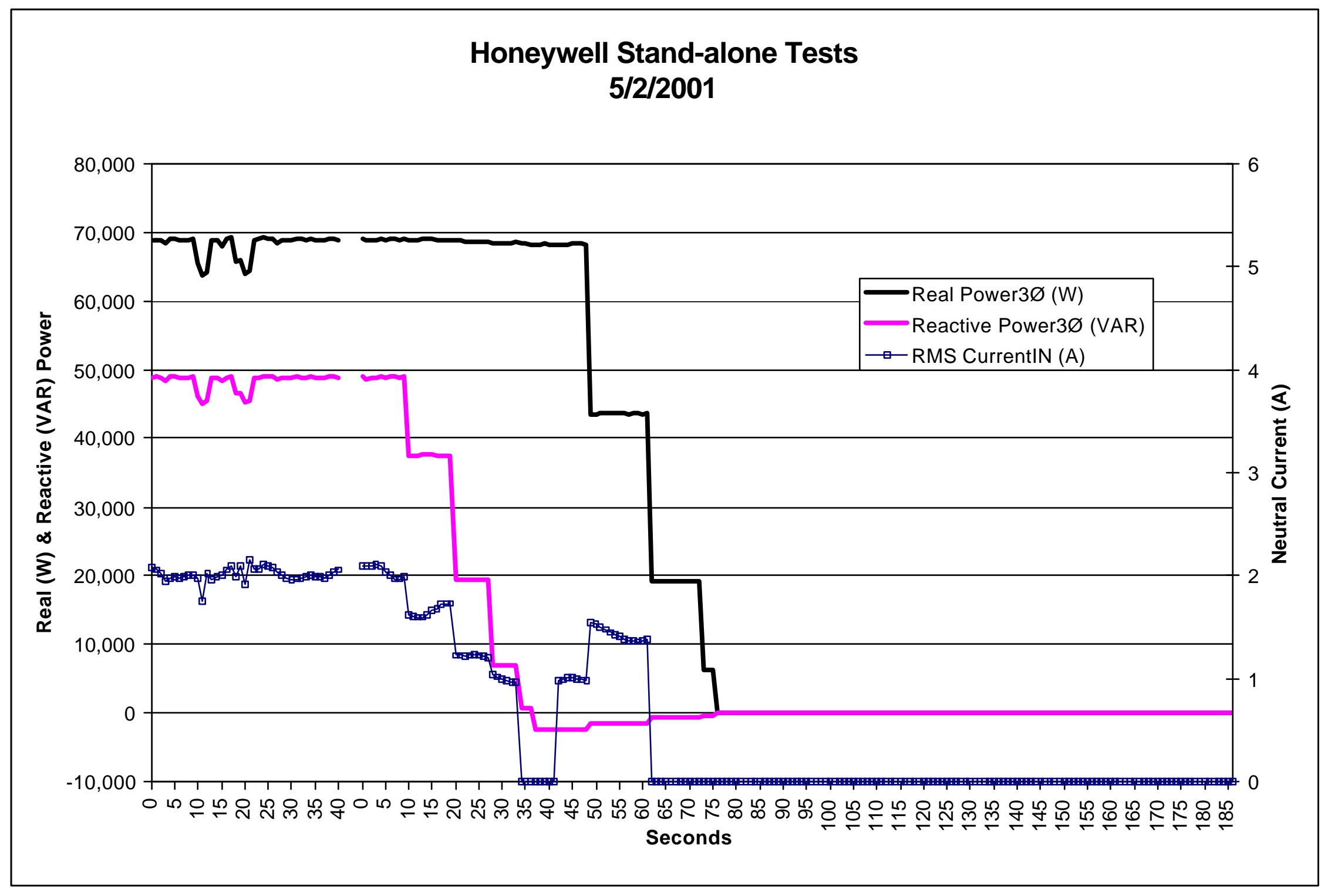

Figure E-24: Ramp Down and MTG Shutdown - Power and Neutral Current 


\section{Appendix F}

Honeywell Parallon Delta Measurement Stand-alone Tests

$6 / 20 / 2001$ 


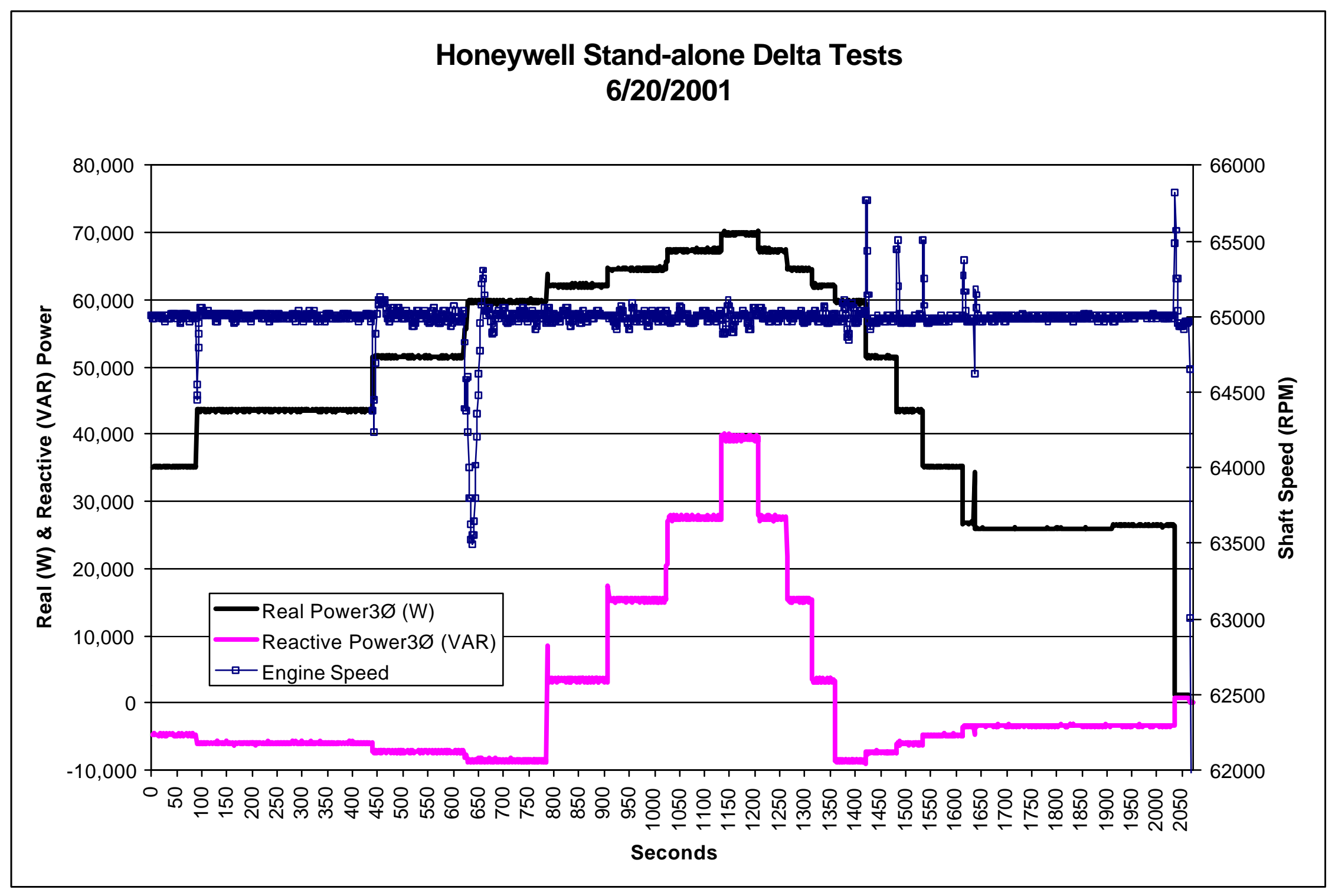

Figure F-1: Ramp Tests - Power and Shaft Speed - Delta Measurements 


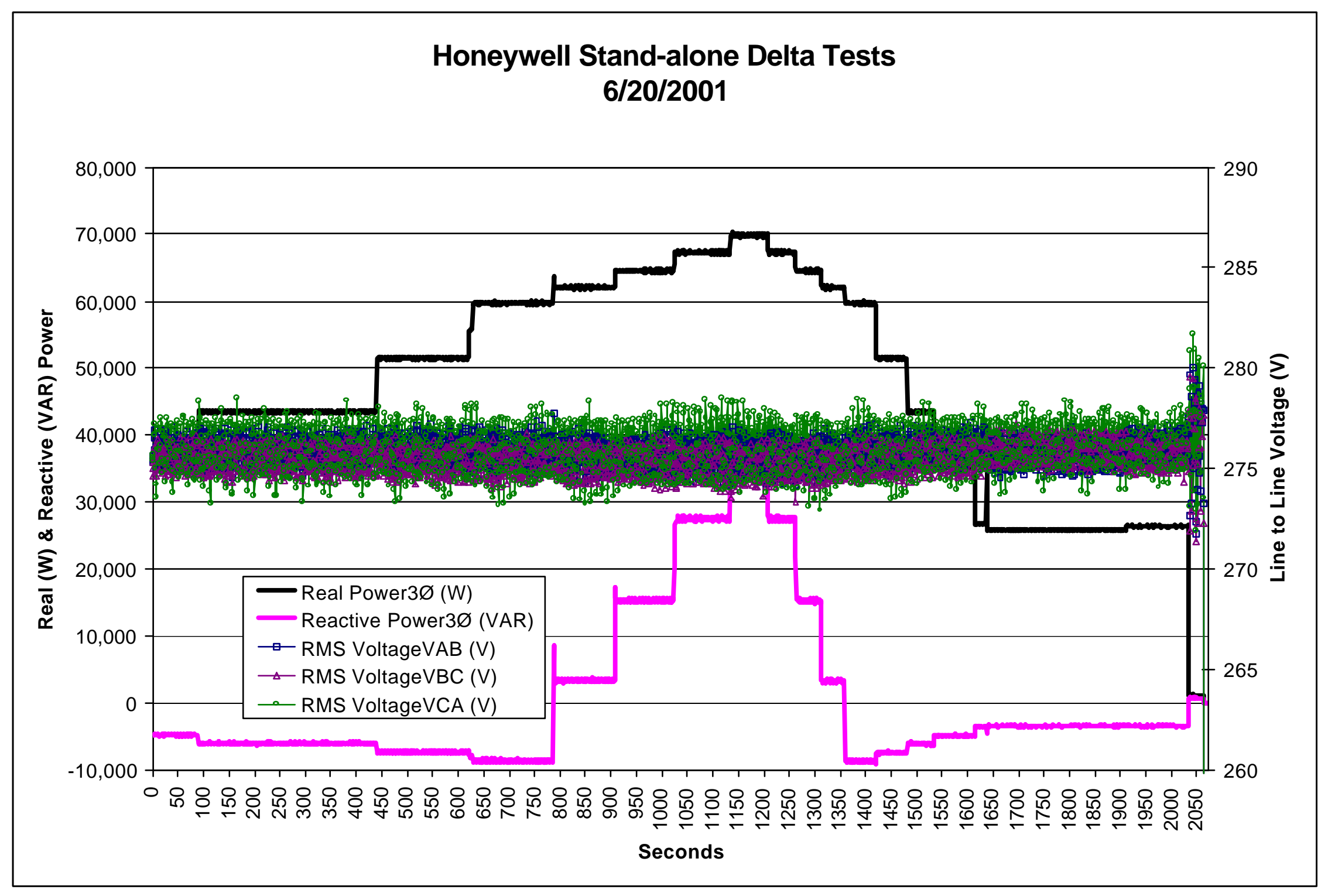

Figure A-2: Ramp Tests - Power and Line-to-Line Voltages - Delta Measurements 


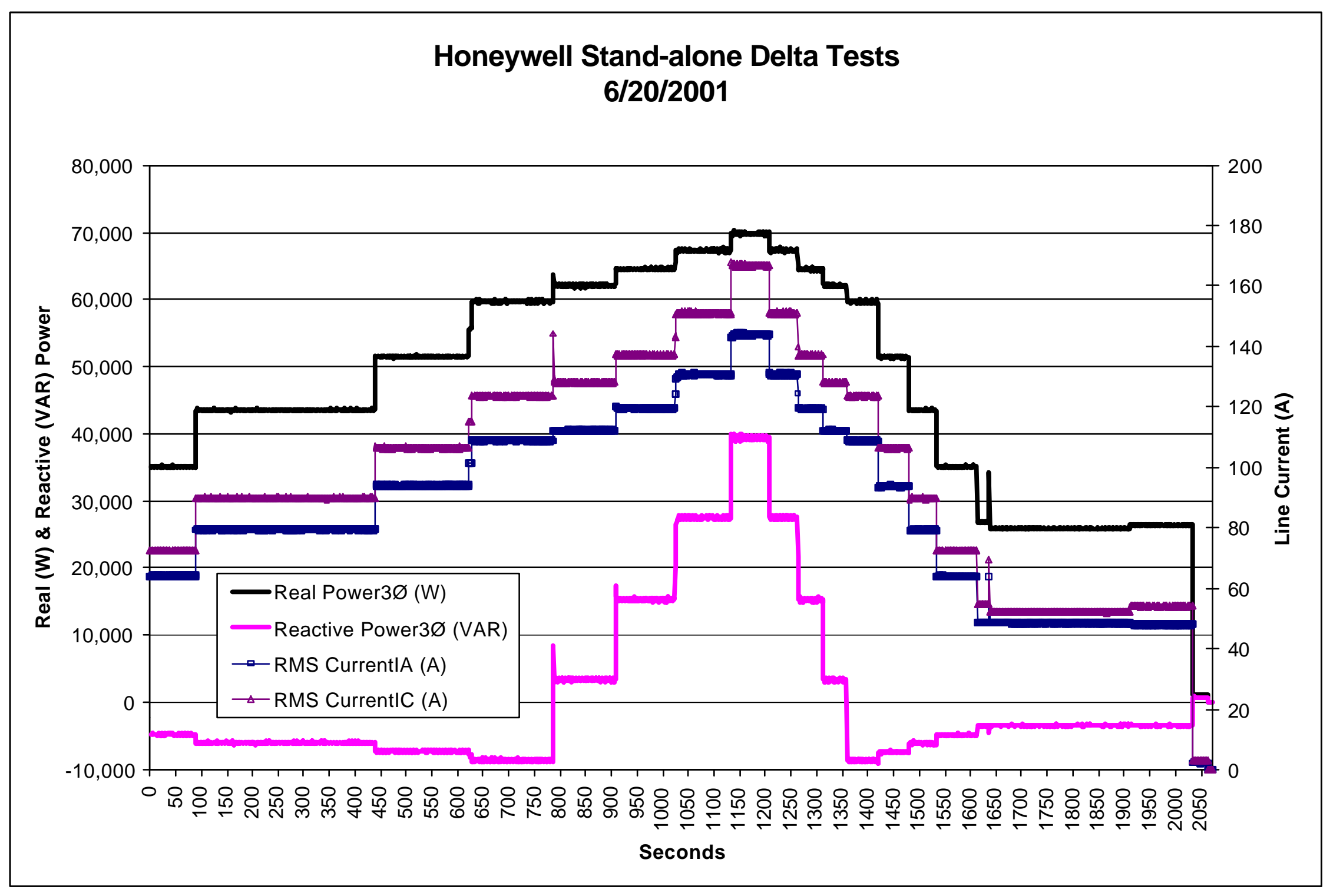

Figure A-3: Ramp Tests - Power and Line Current - Delta Measurements 


\section{Appendix G}

Capstone/Capstone Parallel Stand-alone Tests 4/17/2001 


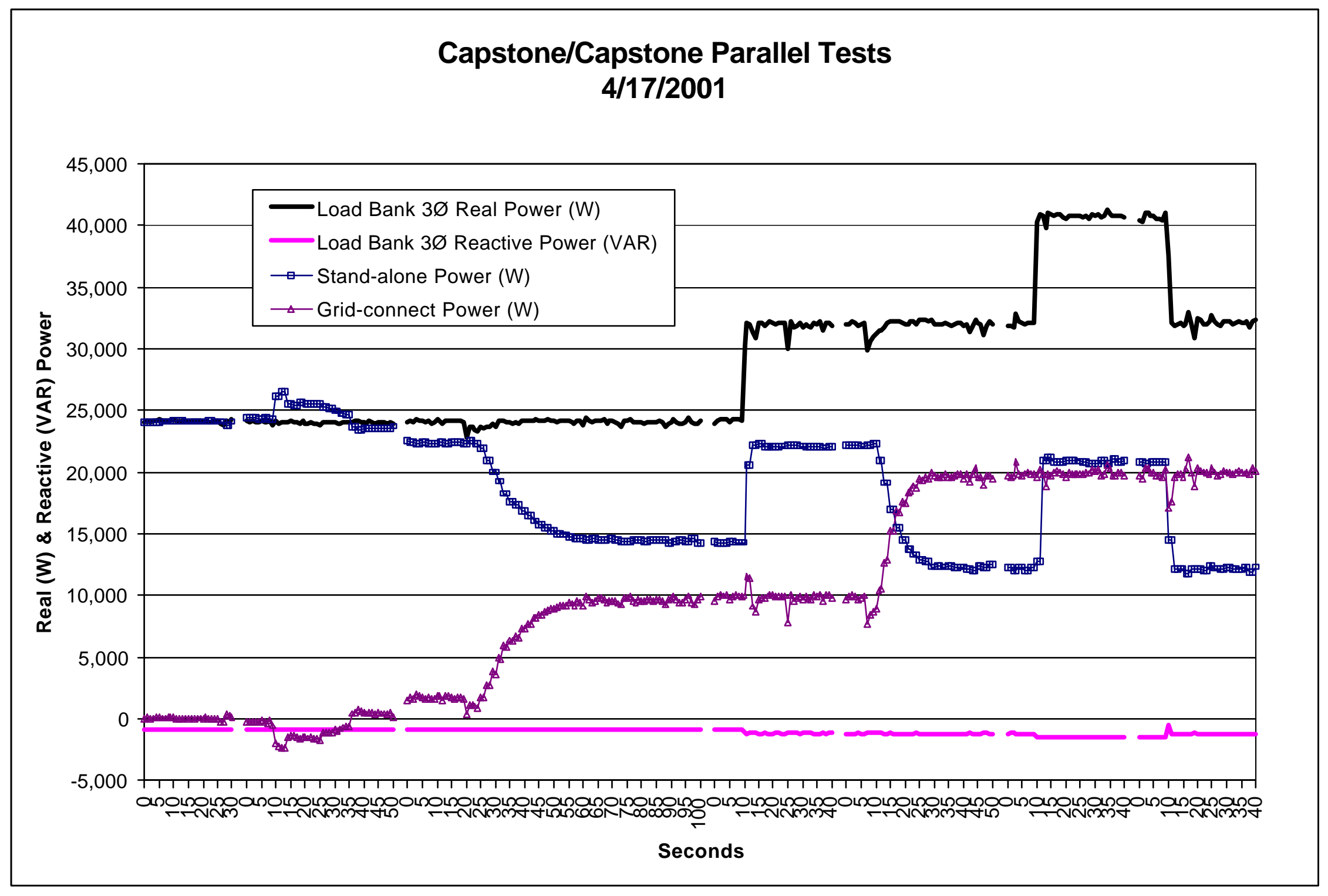

Figure G-1: Start Grid-connect MTG and Ramp MTG and Load Bank Power 


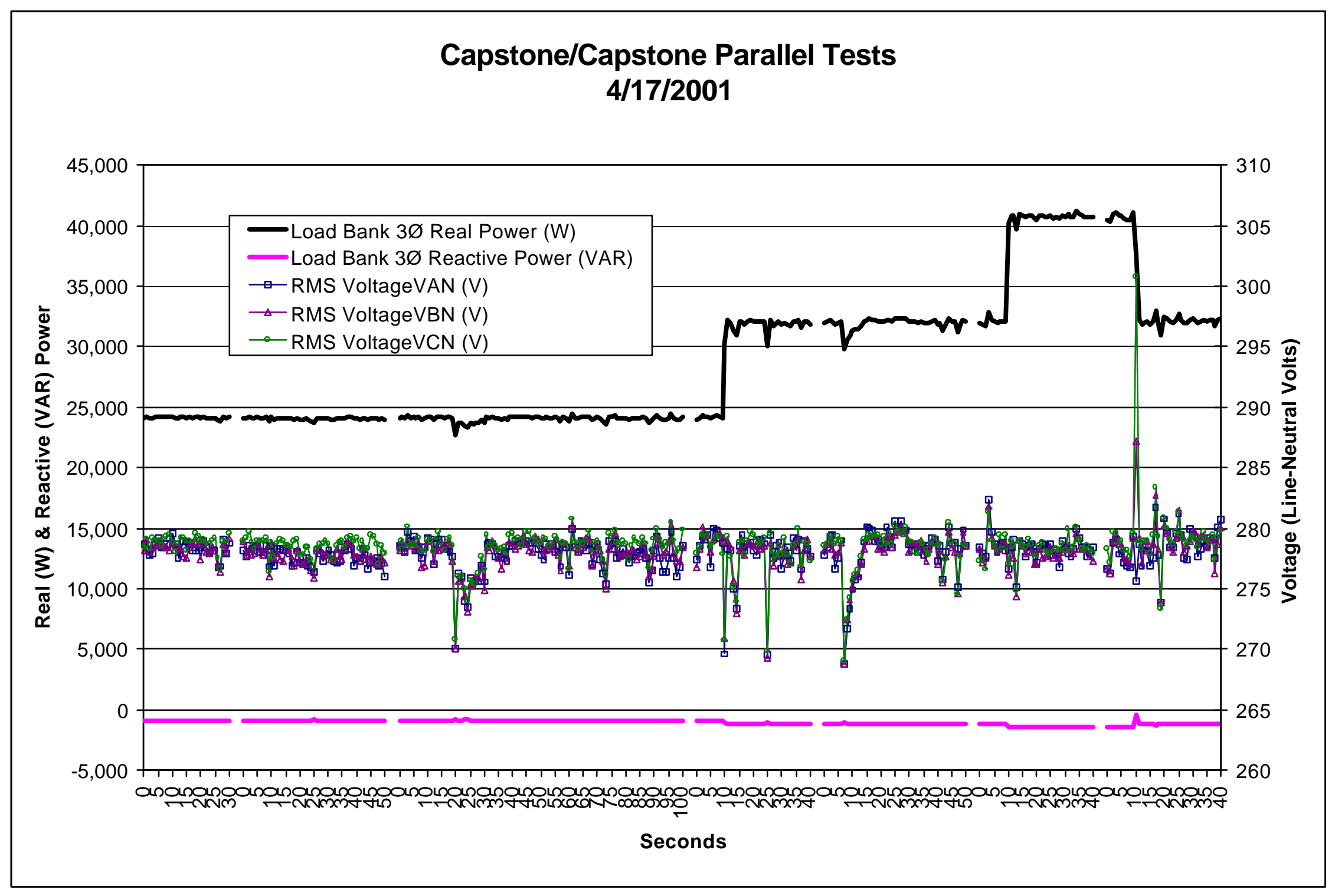

Figure G-2: Start Grid-connect MTG and Ramp MTG and Load Bank Power - Power and Line-to-Neutral Voltage 


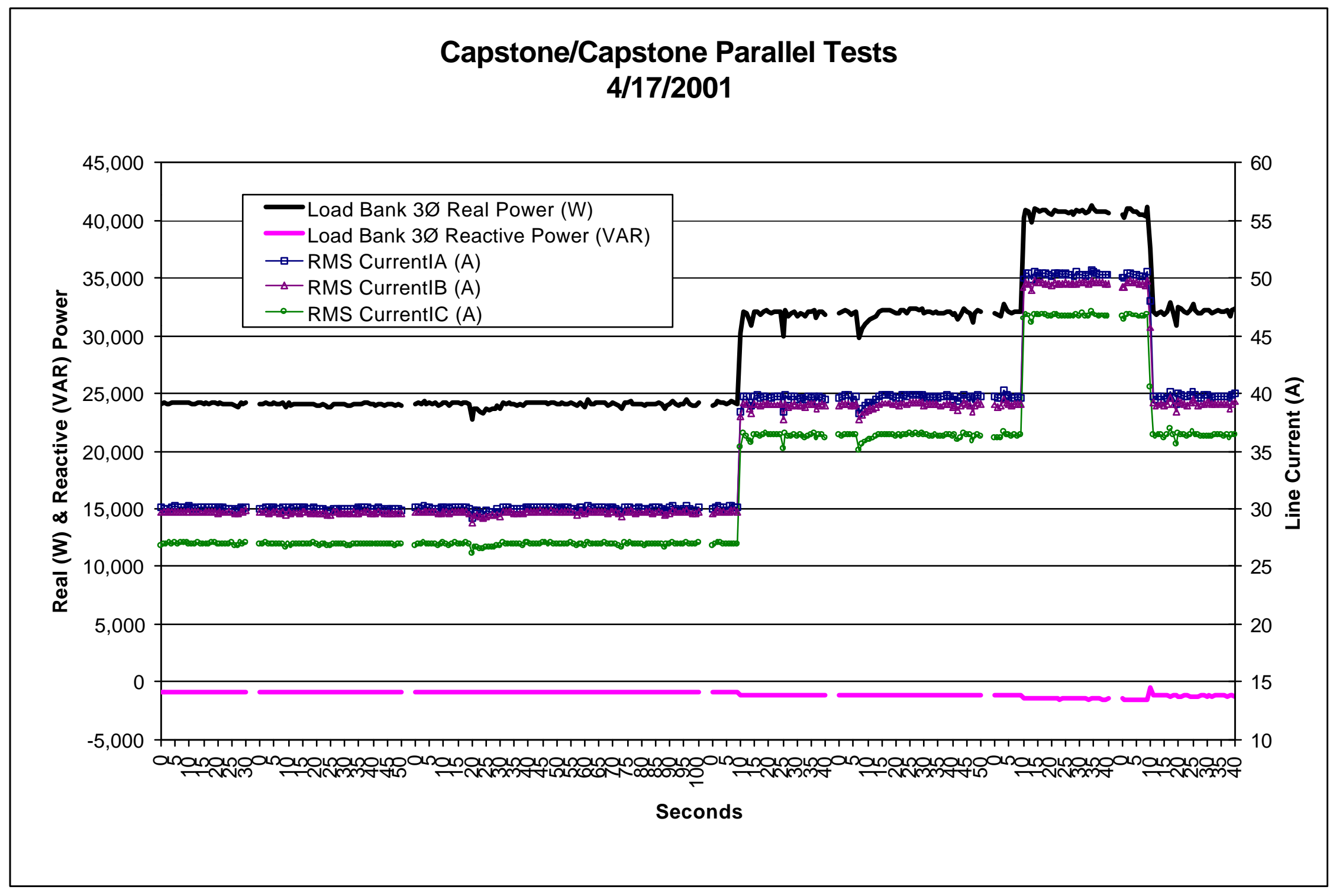

Figure G-3: Start Grid-connect MTG and Ramp MTG and Load Bank Power - Power and Line Current 


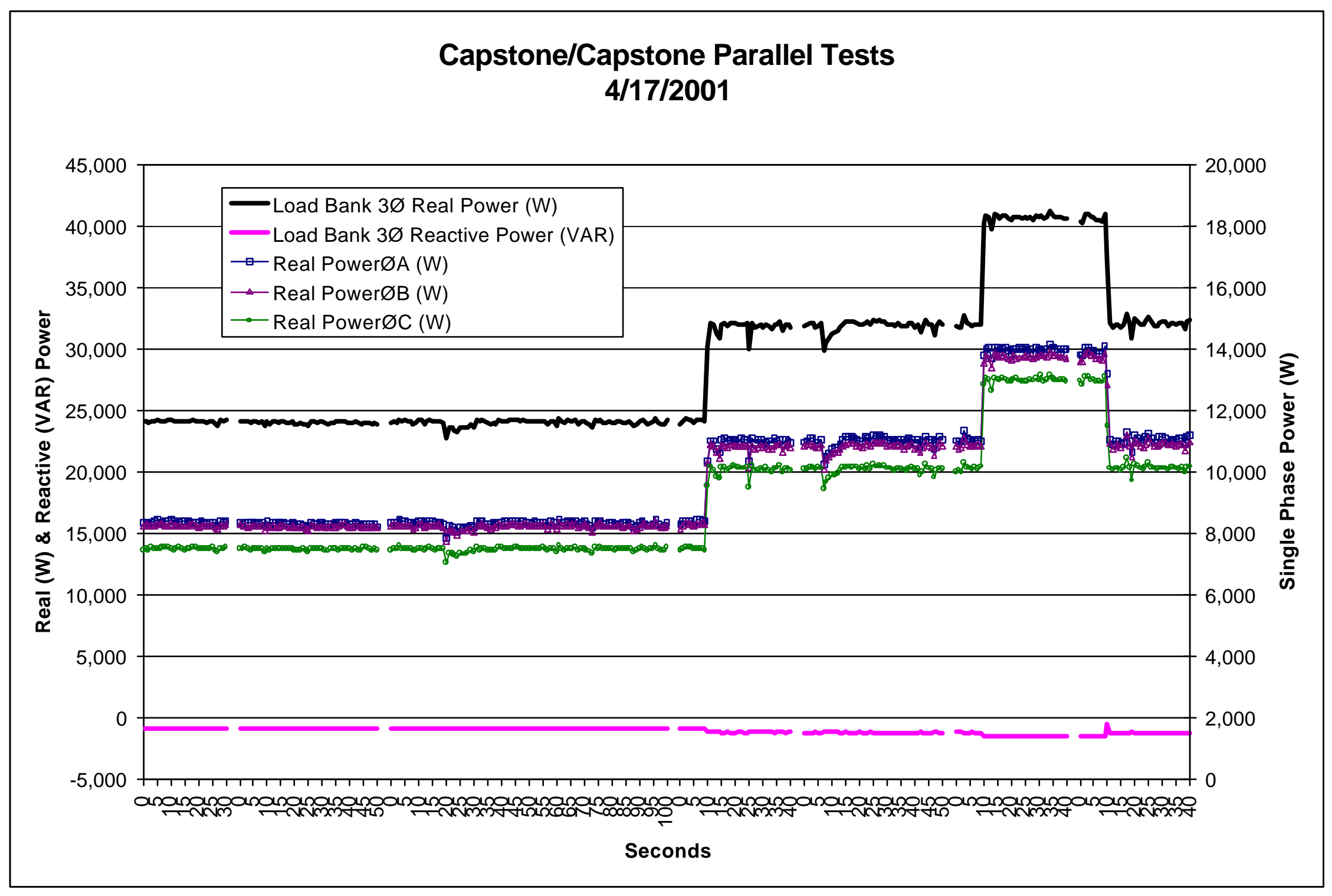

Figure G-4: Start Grid-connect MTG and Ramp MTG and Load Bank Power - Power and Single Phase Power 


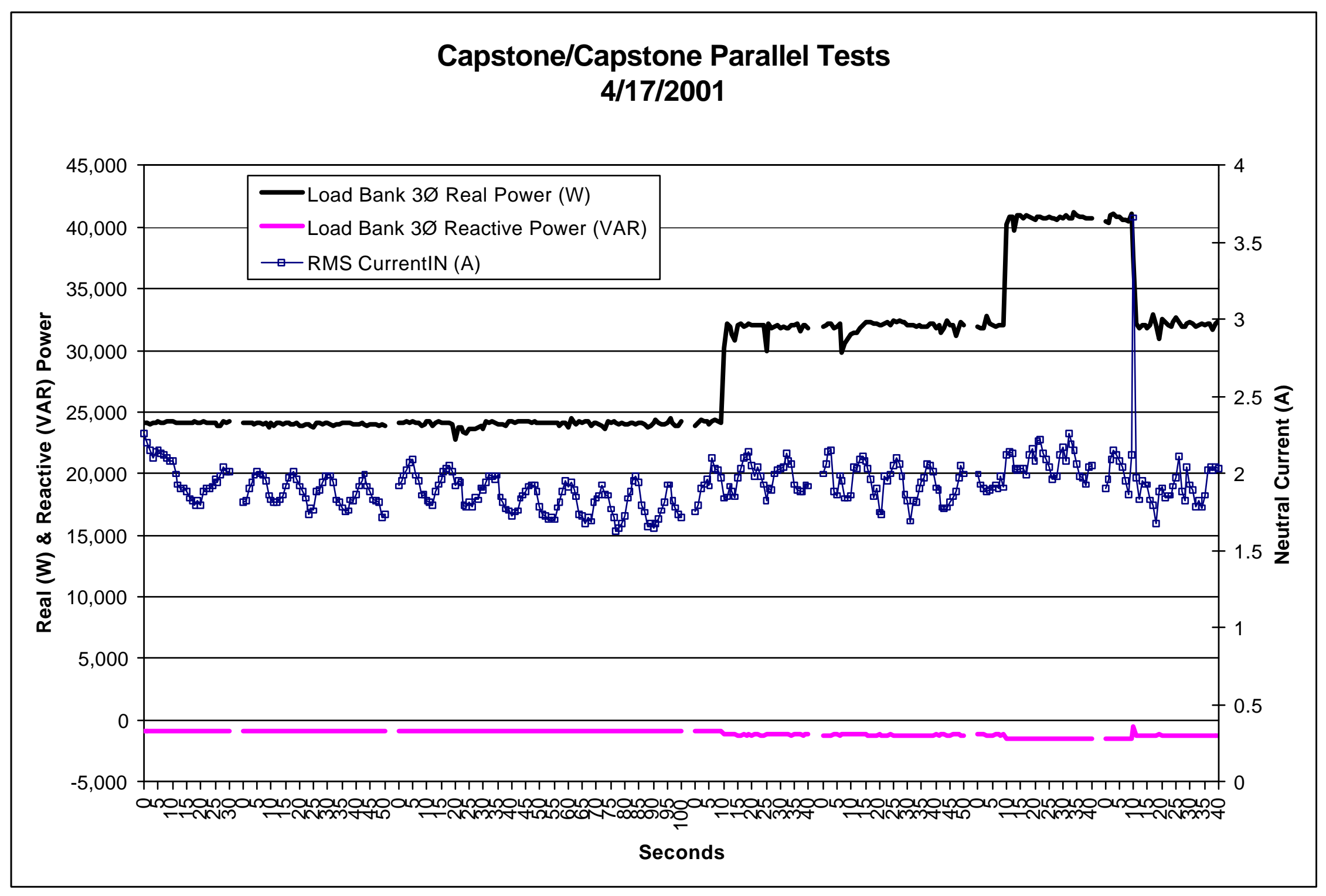

Figure G-5: Start Grid-connect MTG and Ramp MTG and Load Bank Power - Power and Neutral Current 


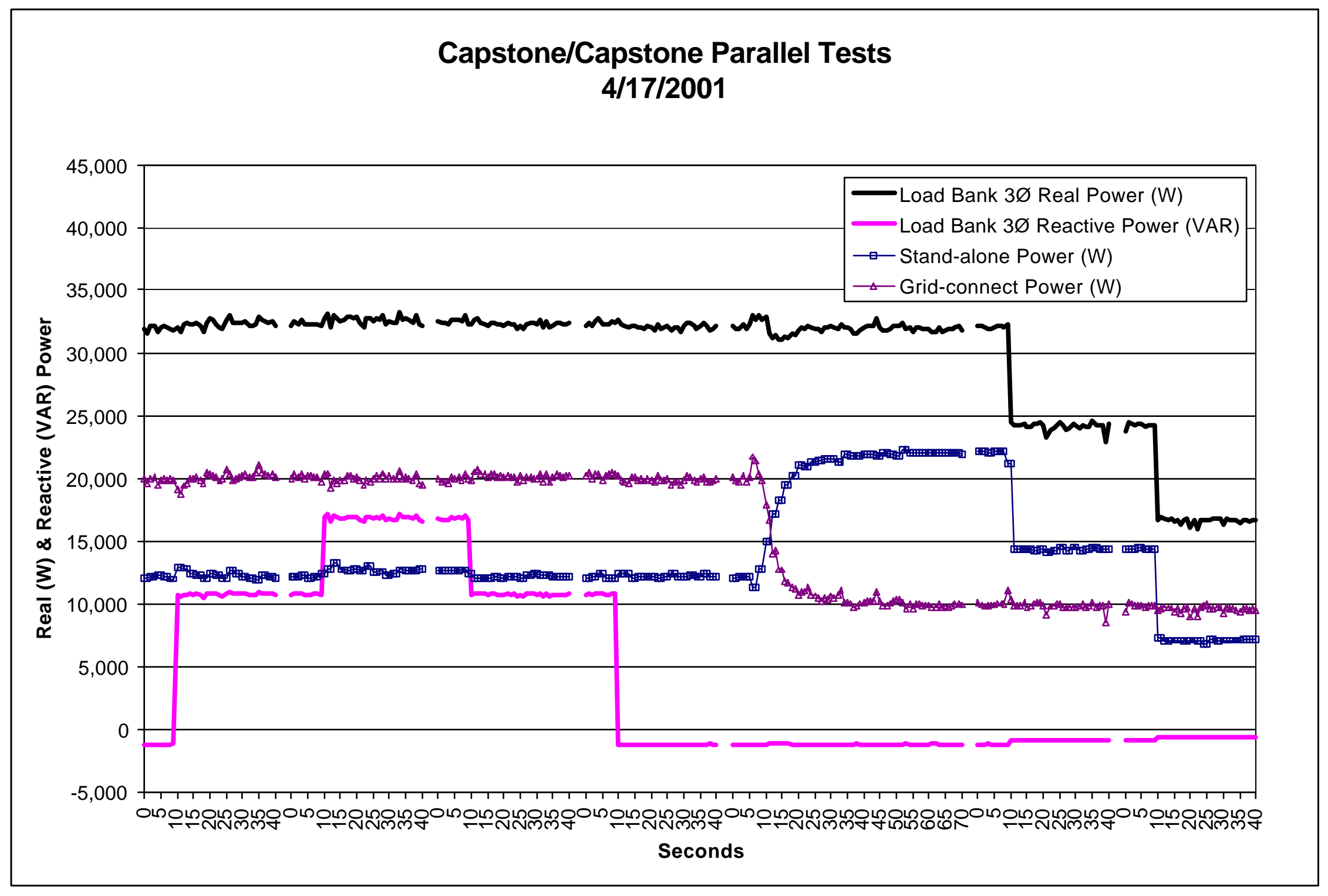

Figure G-6: Ramp Reactive Power and Reduce Power on Grid-connect MTG and Load Banks 


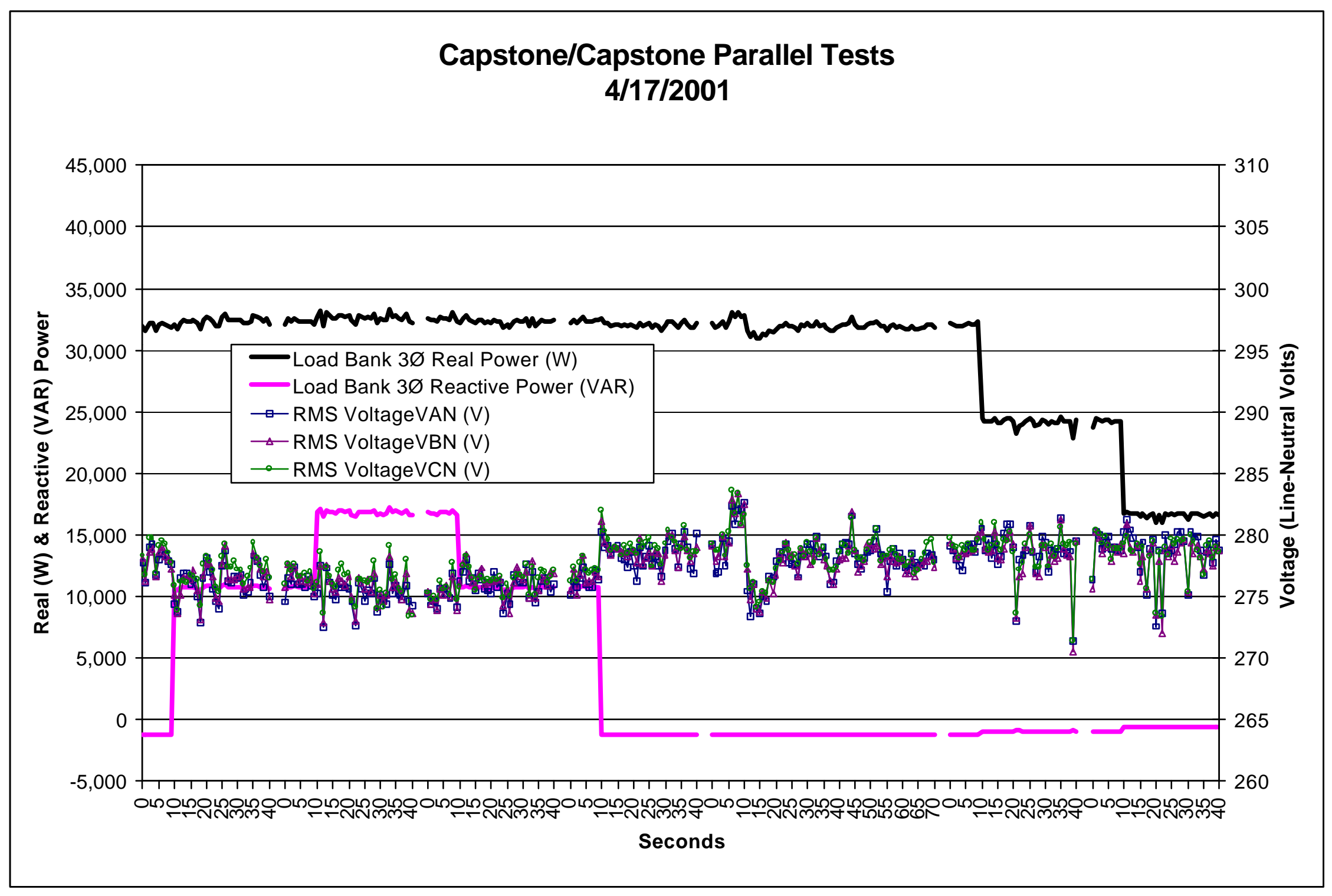

Figure G-7: Ramp Reactive Power and Reduce Power on Grid-connect MTG and Load Banks - Power and Line-Neutral Voltage 


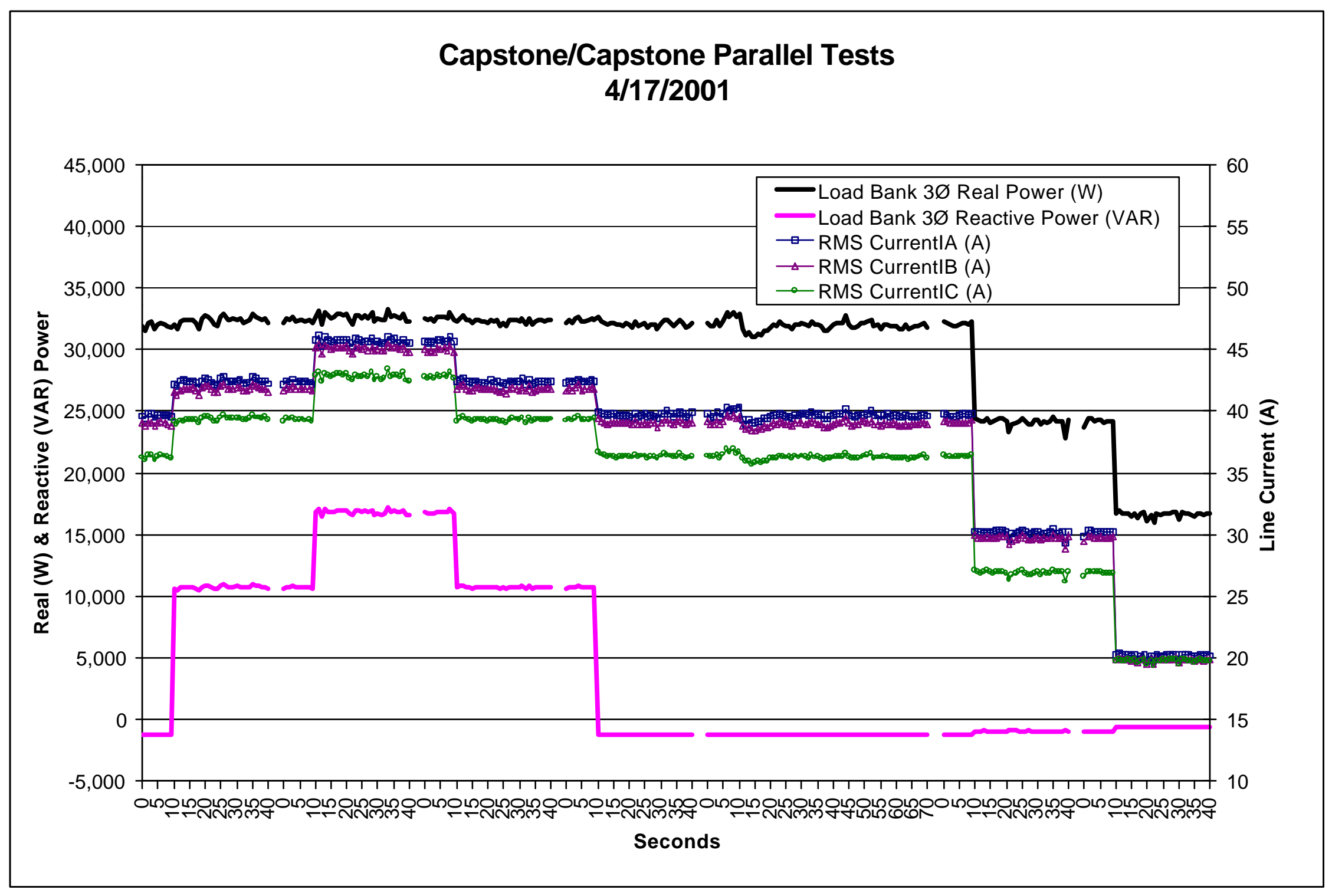

Figure G-8: Ramp Reactive Power and Reduce Power on Grid-connect MTG and Load Banks - Power and Line Current 


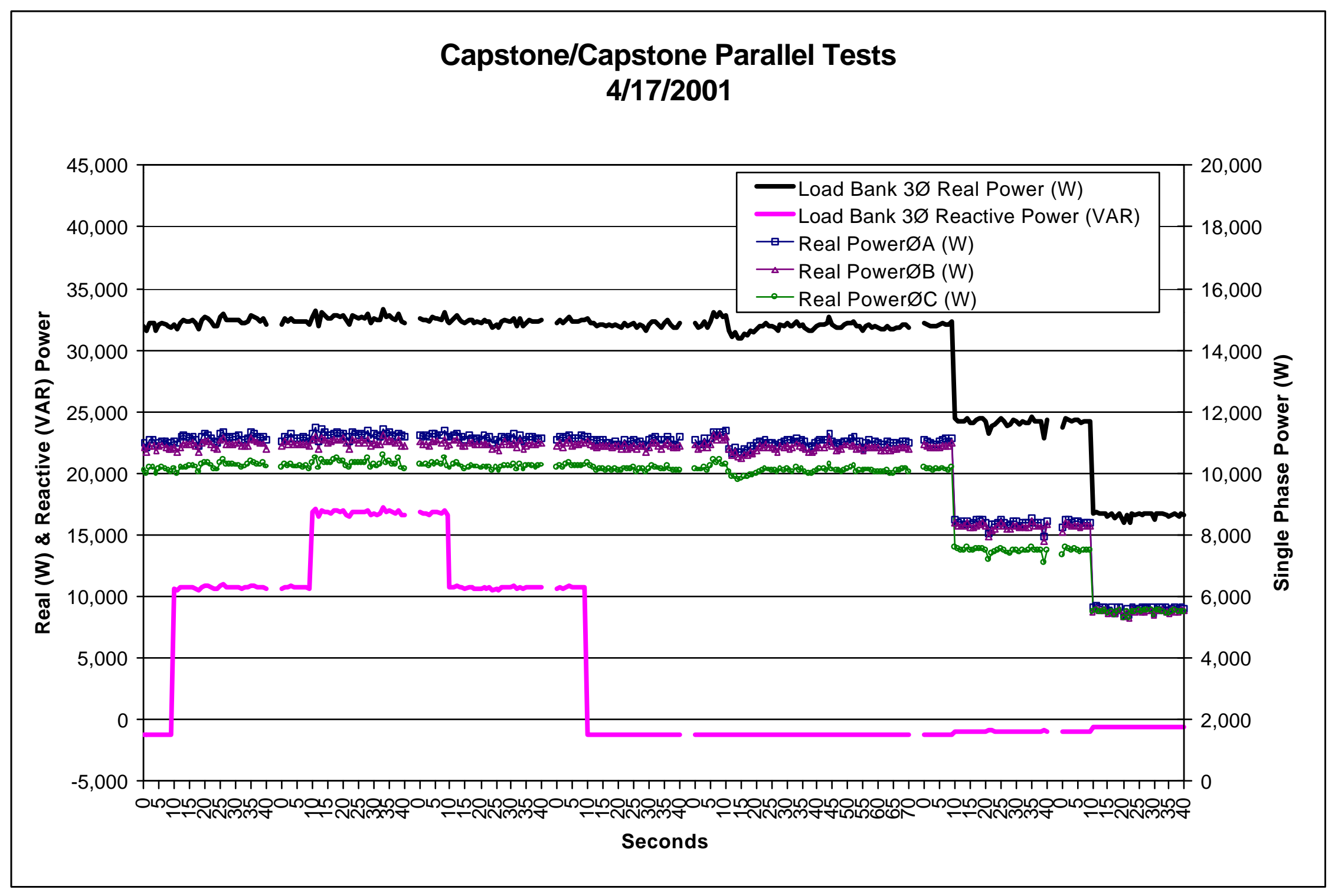

Figure G-9: Ramp Reactive Power and Reduce Power on Grid-connect MTG and Load Banks - Power and Single Phase Power 


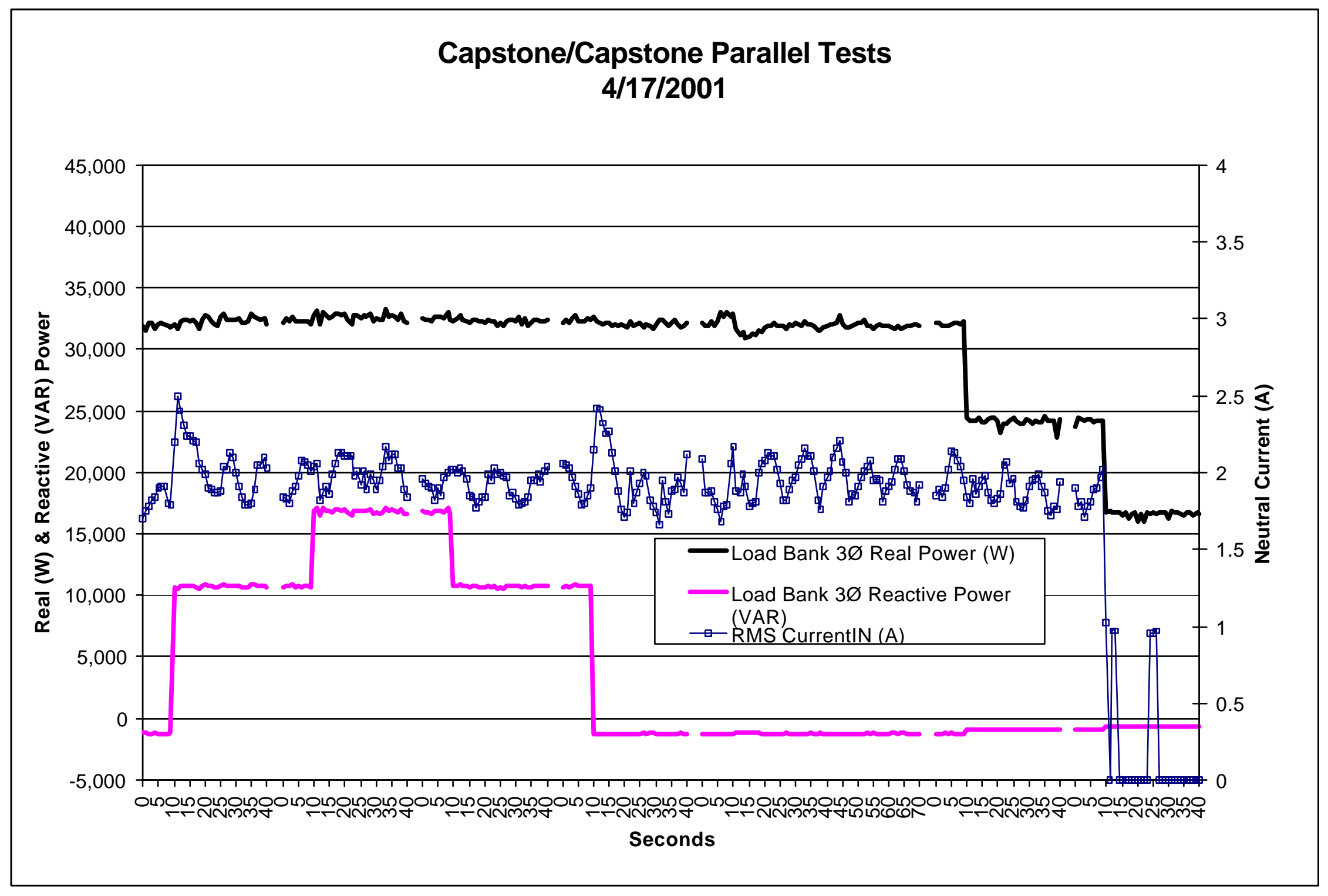

Figure G-10: Ramp Reactive Power and Reduce Power on Grid-connect MTG and Load Banks - Power and Neutral Current 


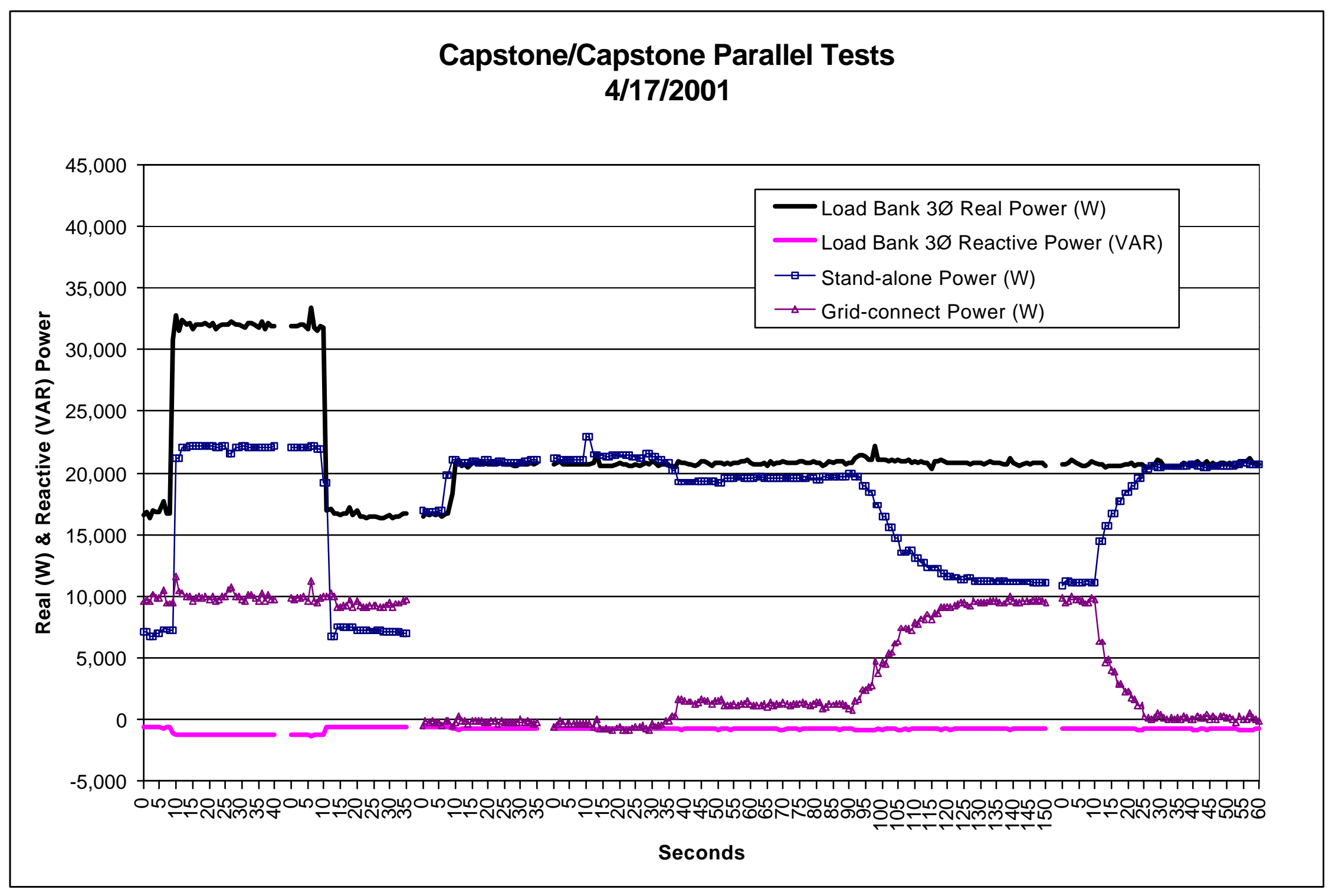

Figure G-11: Reduce Load Bank Power, Start and Shutdown of Grid-connect MTG 


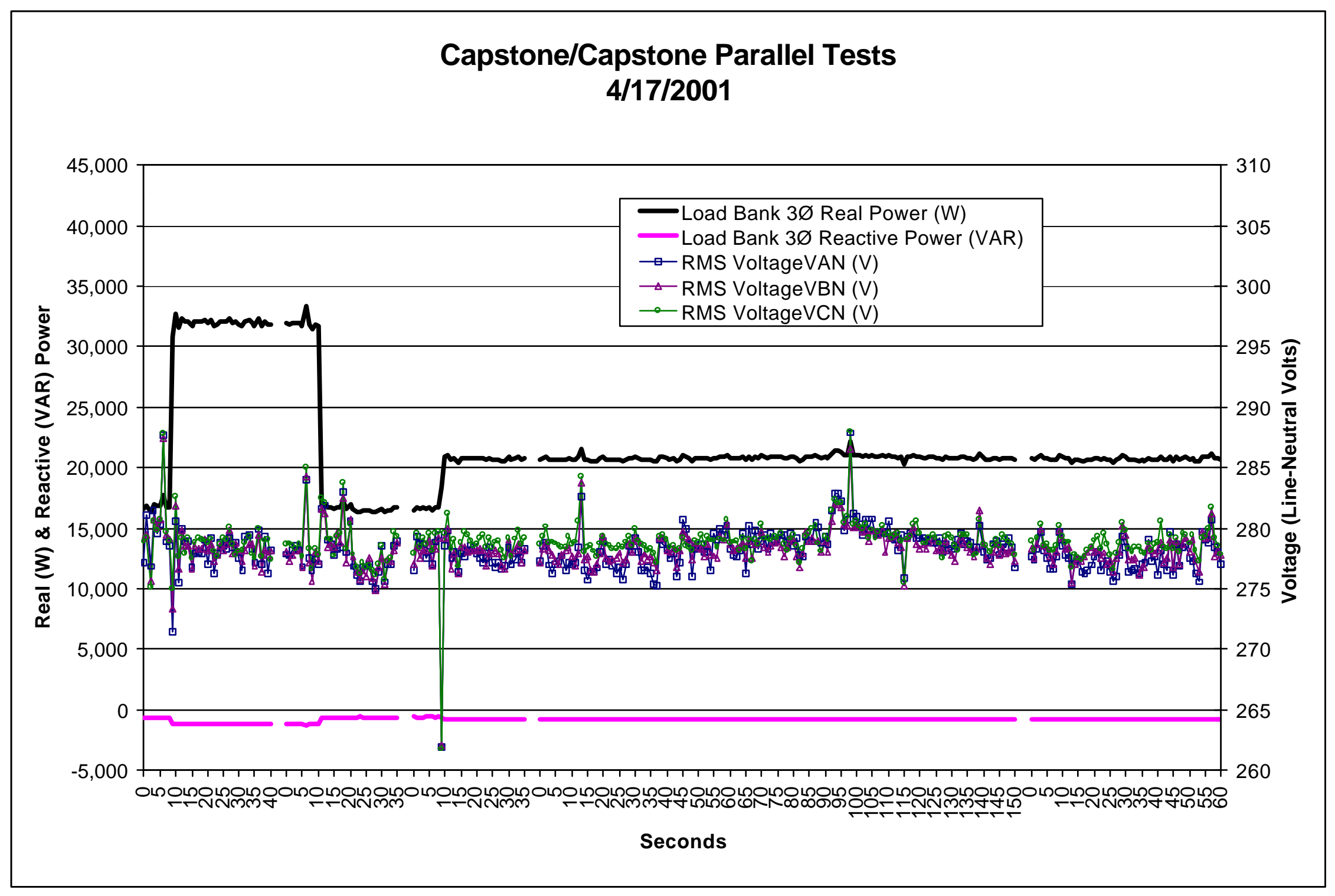

Figure G-12: Reduce Load Bank Power, Start and Shutdown of Grid-connect MTG - Power and Line-Neutral Voltage 


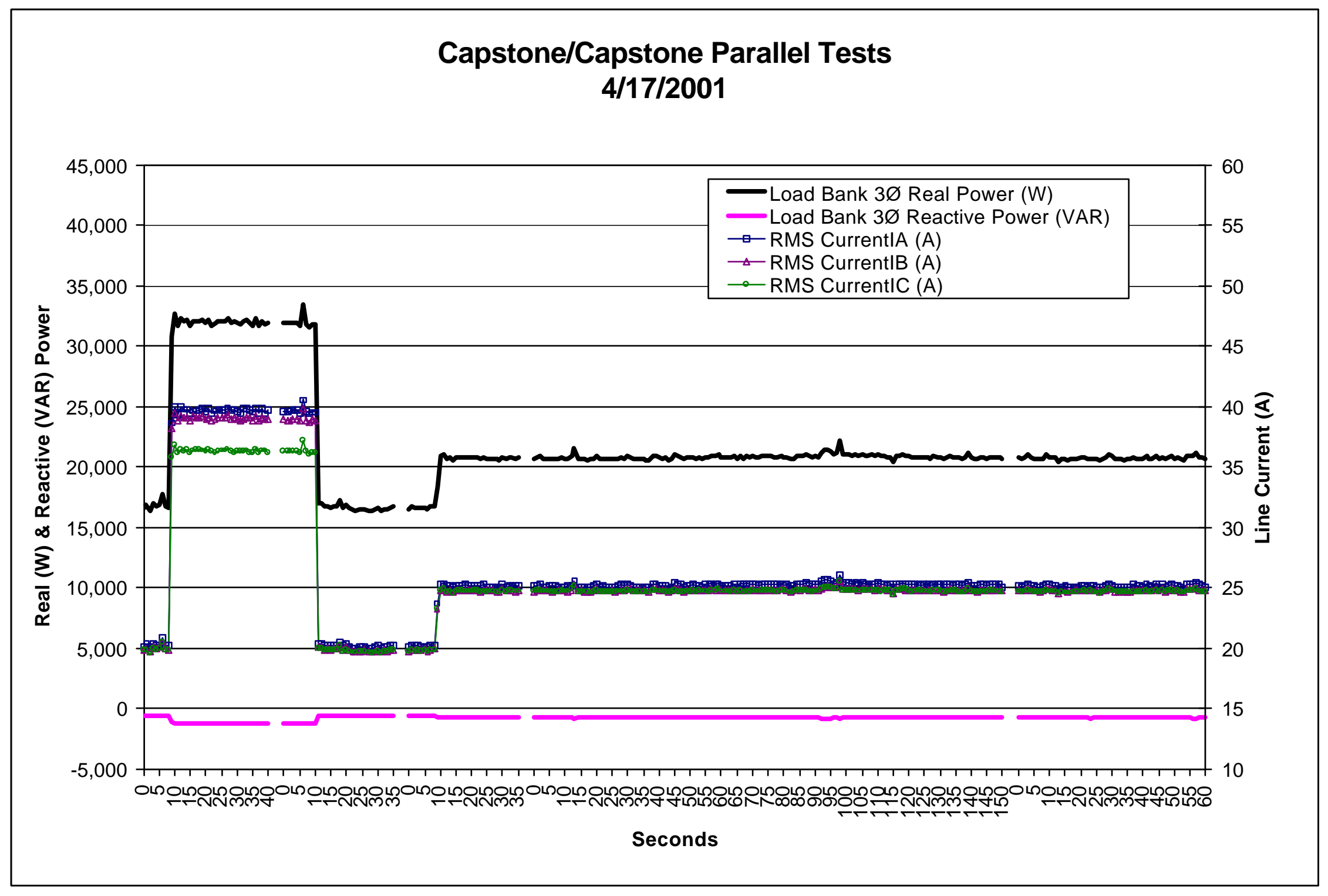

Figure G-13: Reduce Load Bank Power, Start and Shutdown of Grid-connect MTG - Power and Line Current 


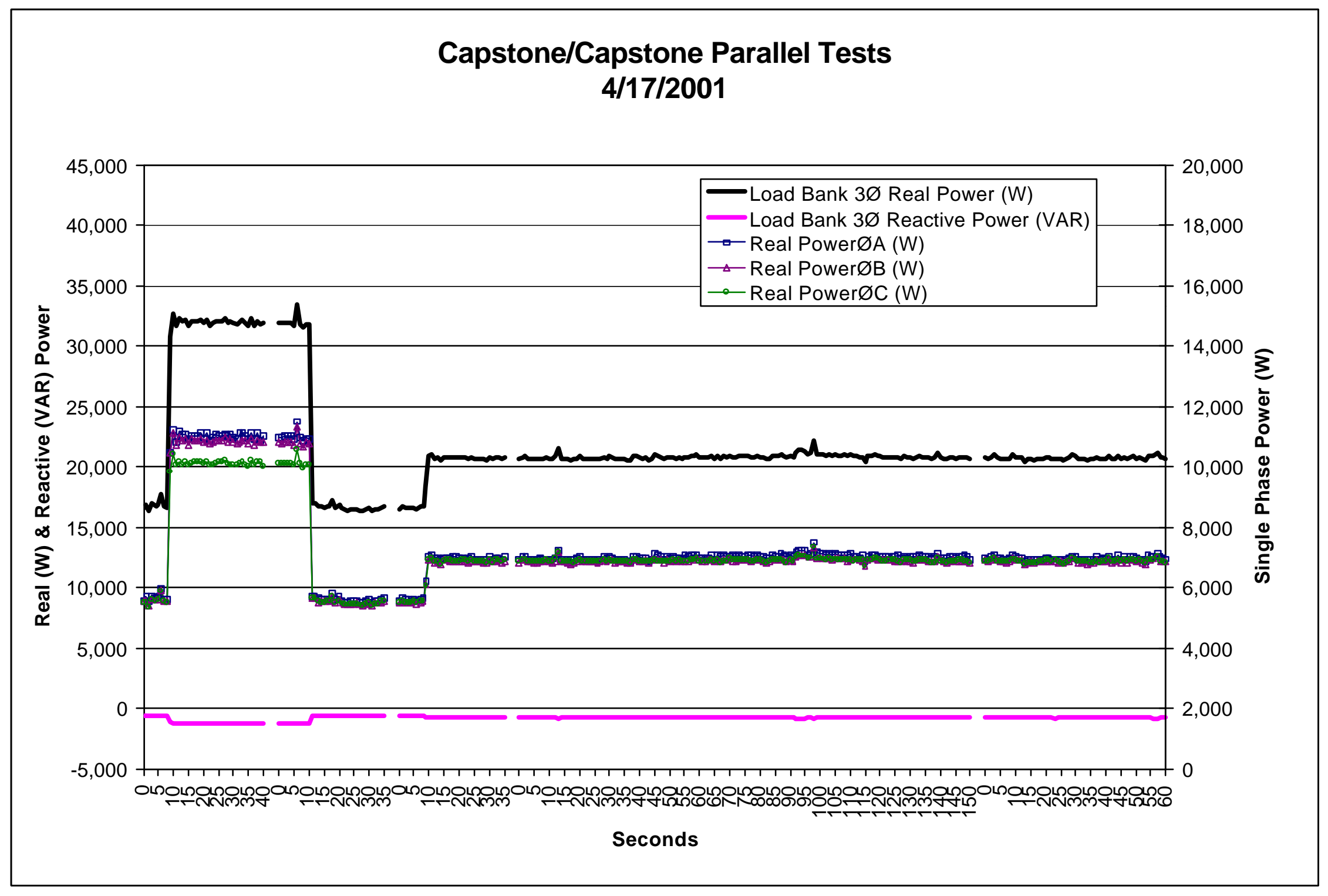

Figure G-14: Reduce Load Bank Power, Start and Shutdown of Grid-connect MTG - Power and Single Phase Power 


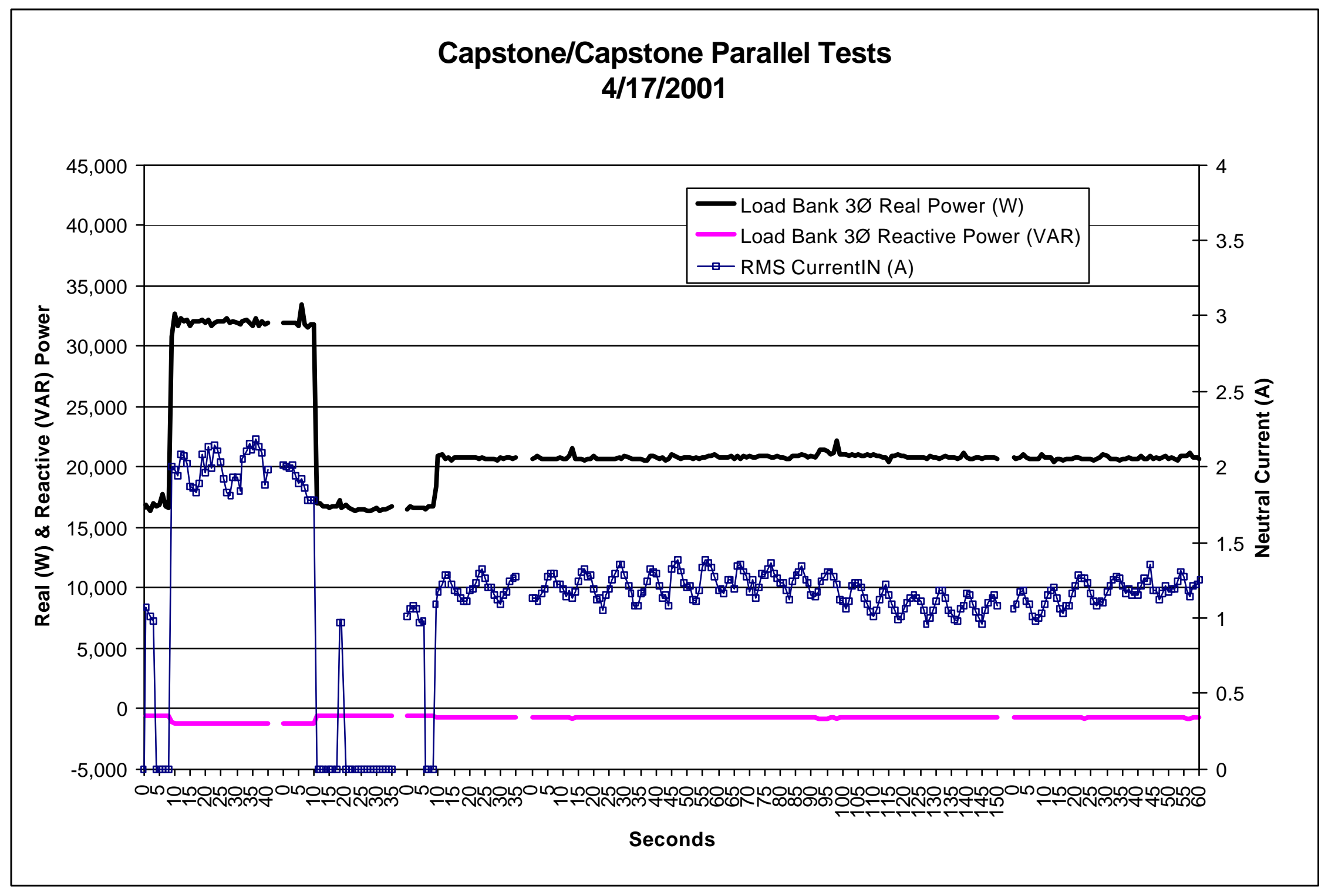

Figure G-15: Reduce Load Bank Power, Start and Shutdown of Grid-connect MTG - Power and Neutral Current 


\section{Appendix H}

Honeywell/Capstone Parallel Stand-alone Tests

6/20/2001 


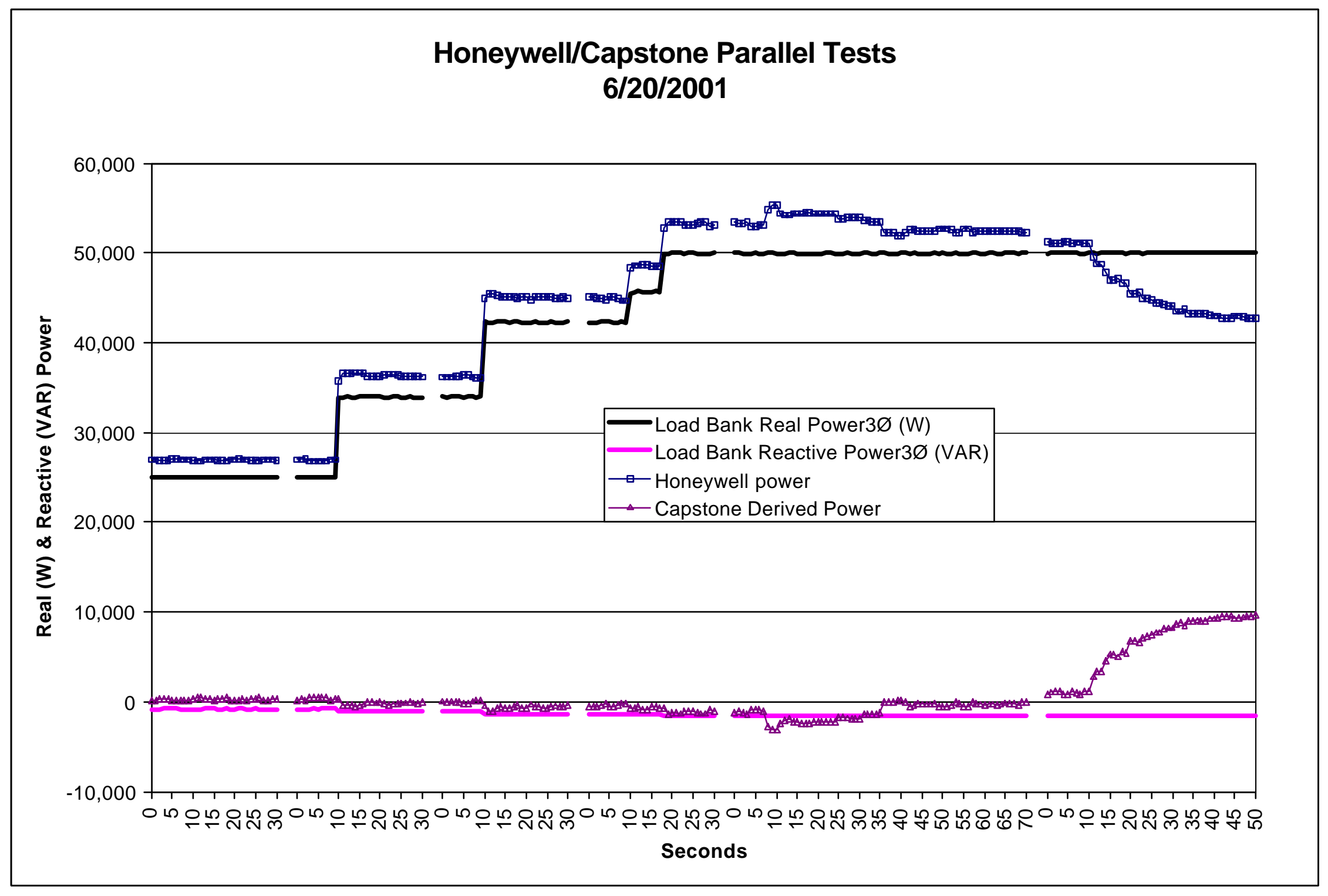

Figure H-1: Ramp Up Load Bank Power and Start Grid-connect MTG 


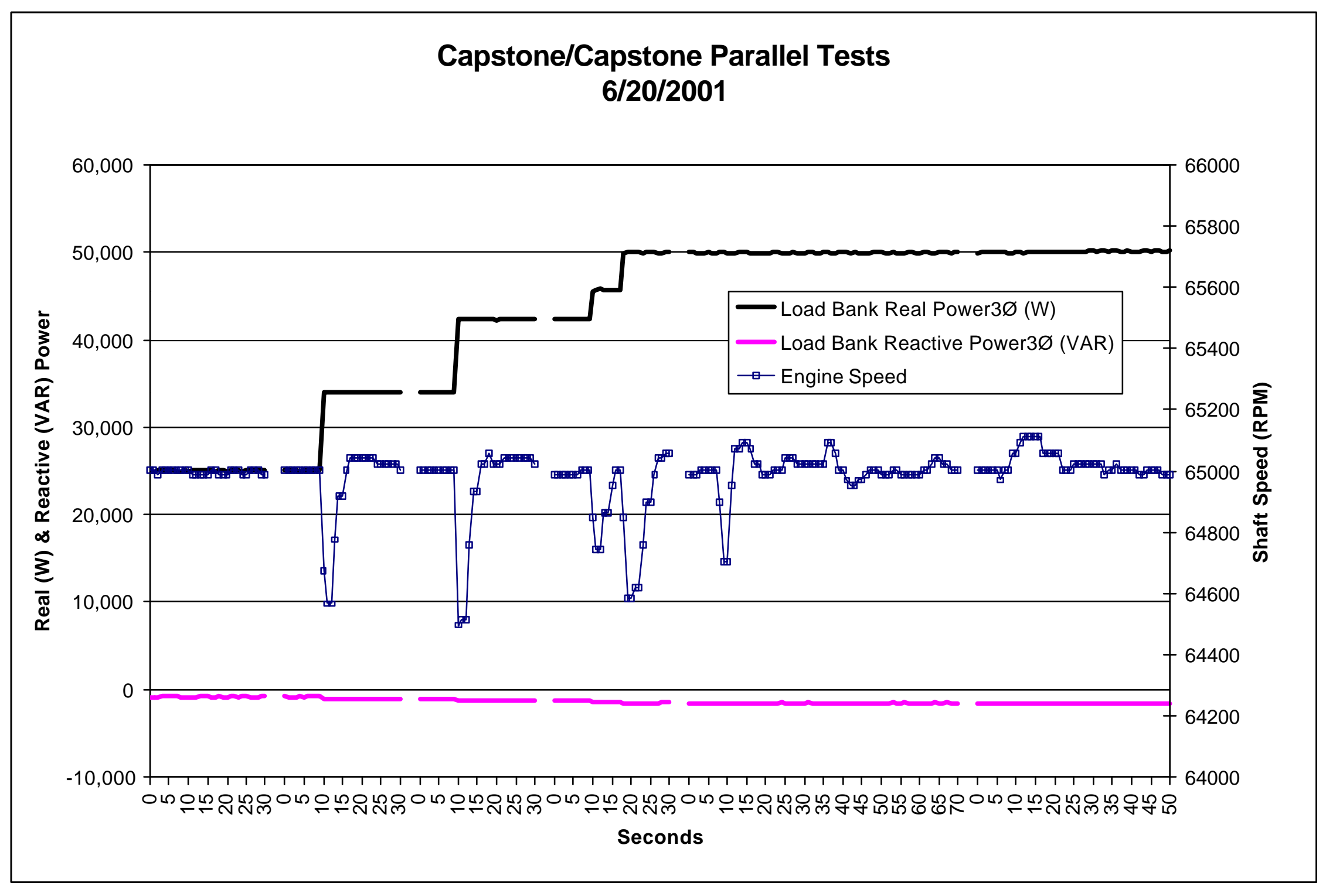

Figure H-2: Ramp Up Load Bank Power and Start Grid-connect MTG - Power and Shaft Speed 


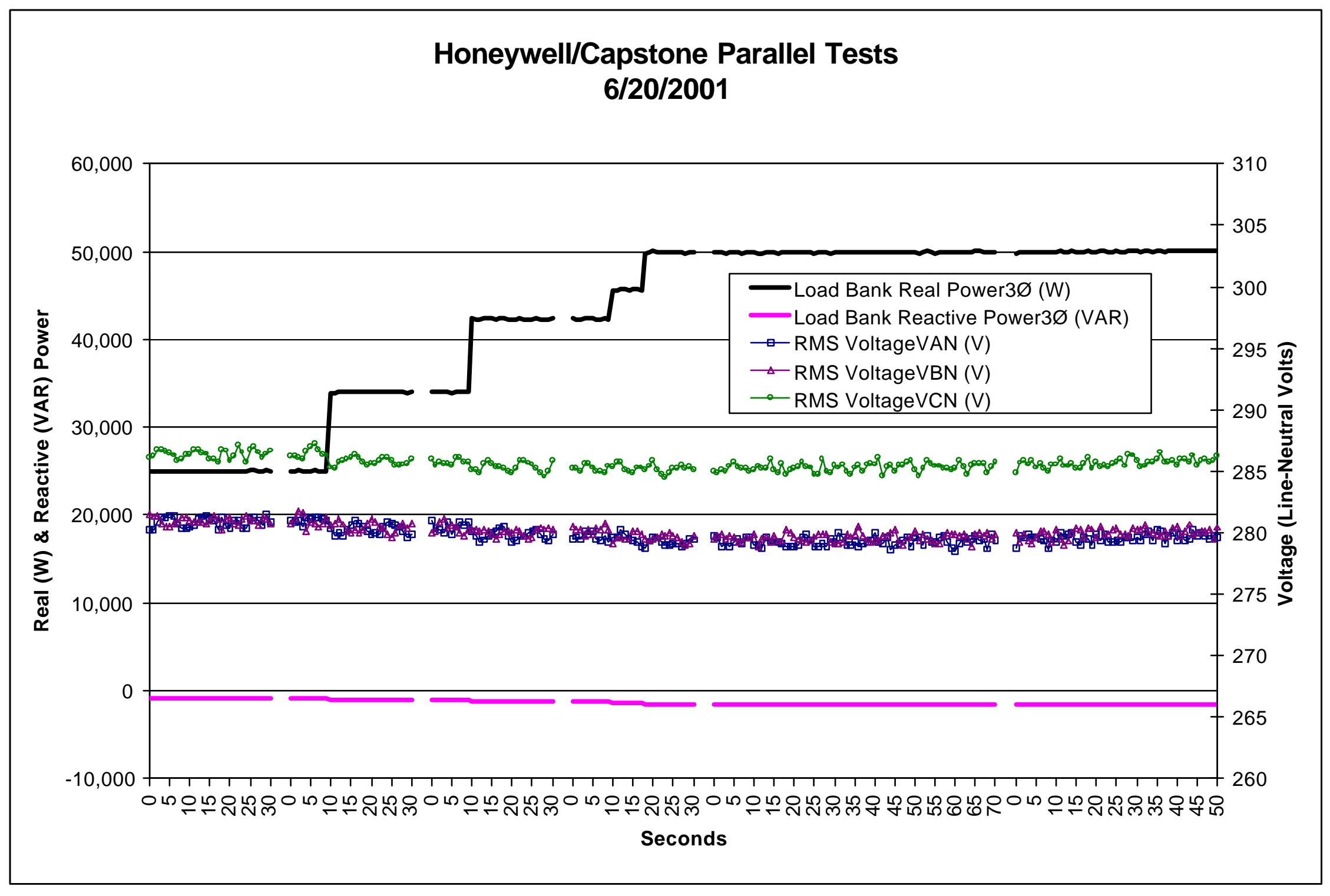

Figure H-3: Ramp Up Load Bank Power and Start Grid-connect MTG - Power and Line-Neutral Voltage 


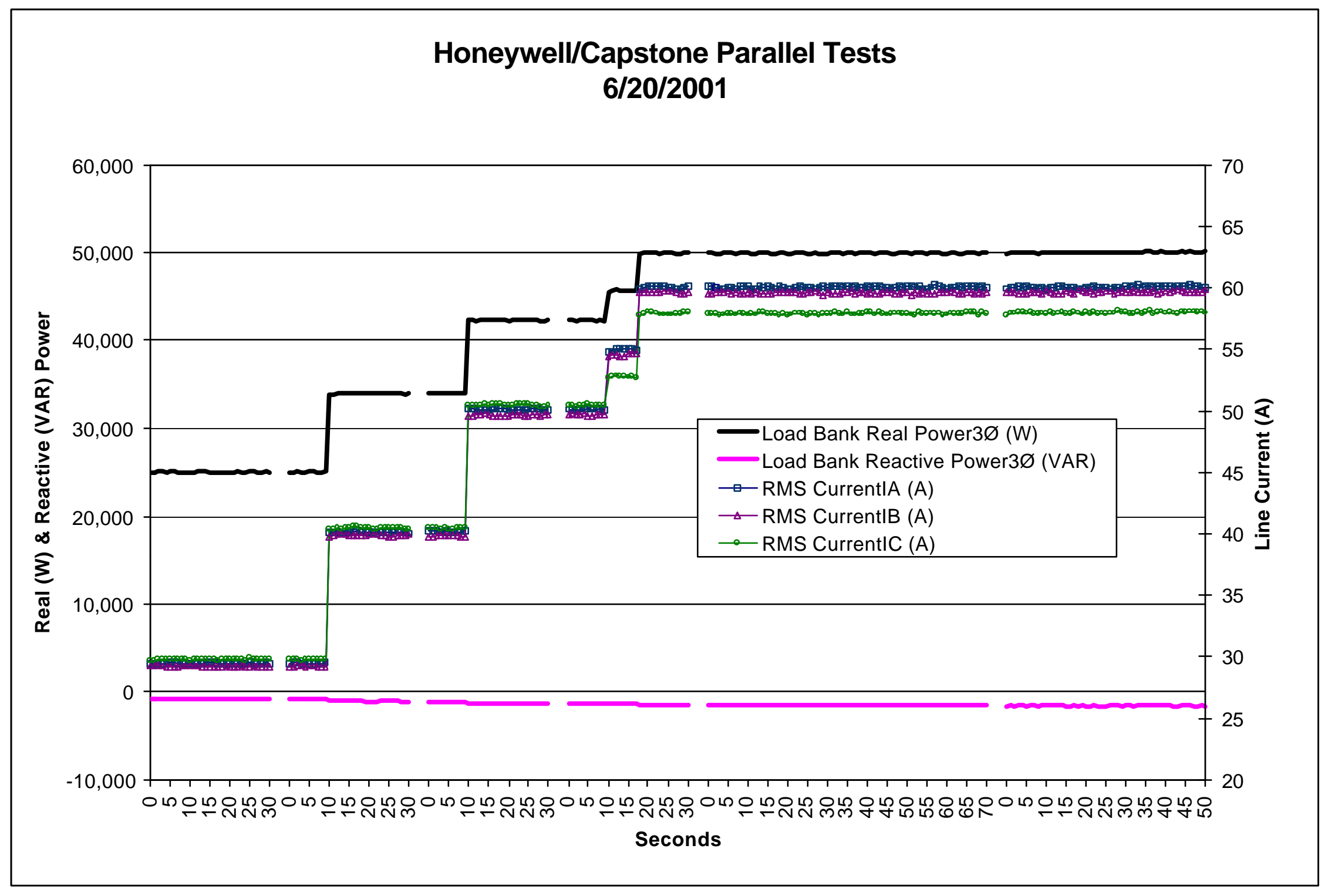

Figure H-4: Ramp Up Load Bank Power and Start Grid-connect MTG - Power and Line Current 


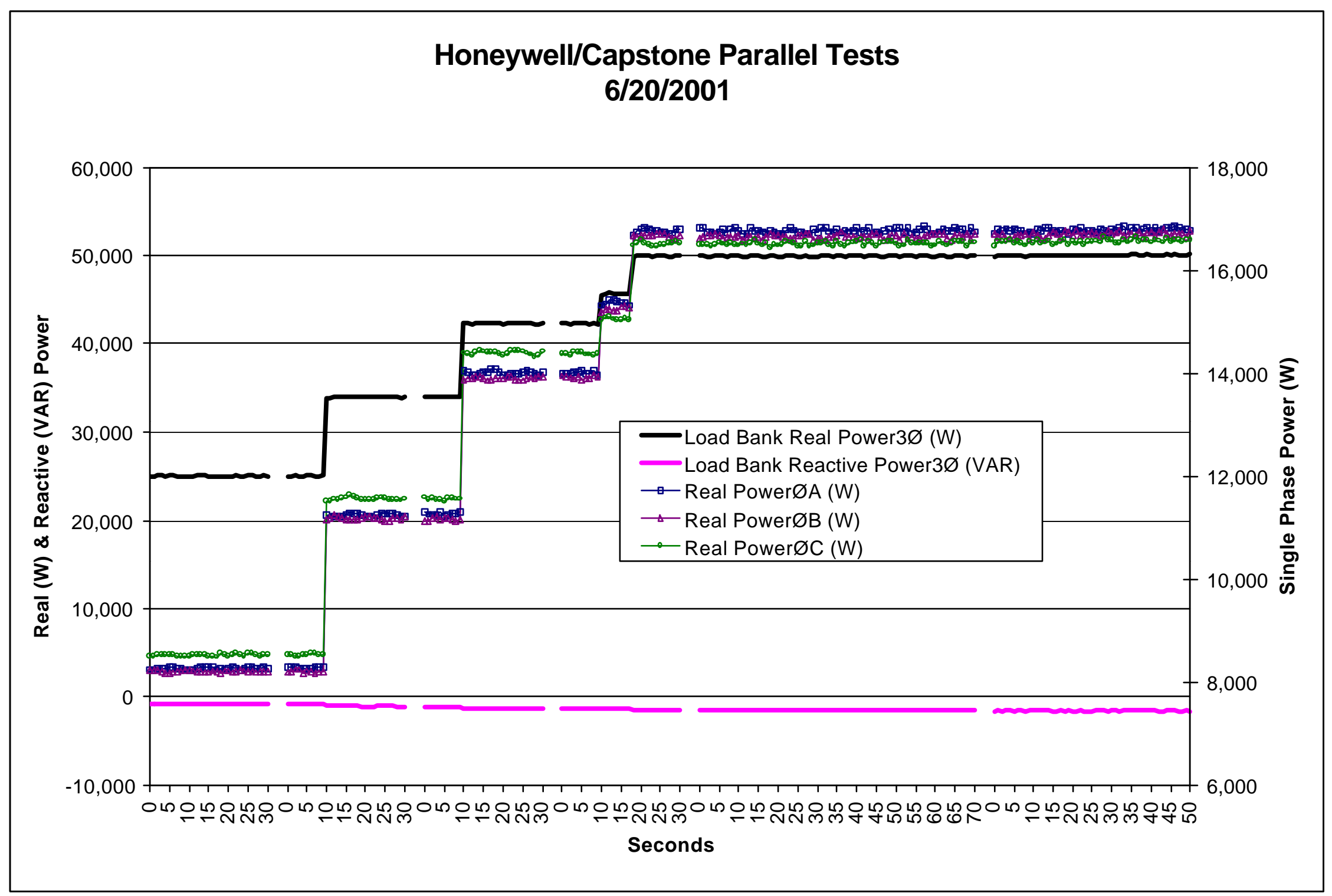

Figure H-5: Ramp Up Load Bank Power and Start Grid-connect MTG - Power and Single Phase Power 


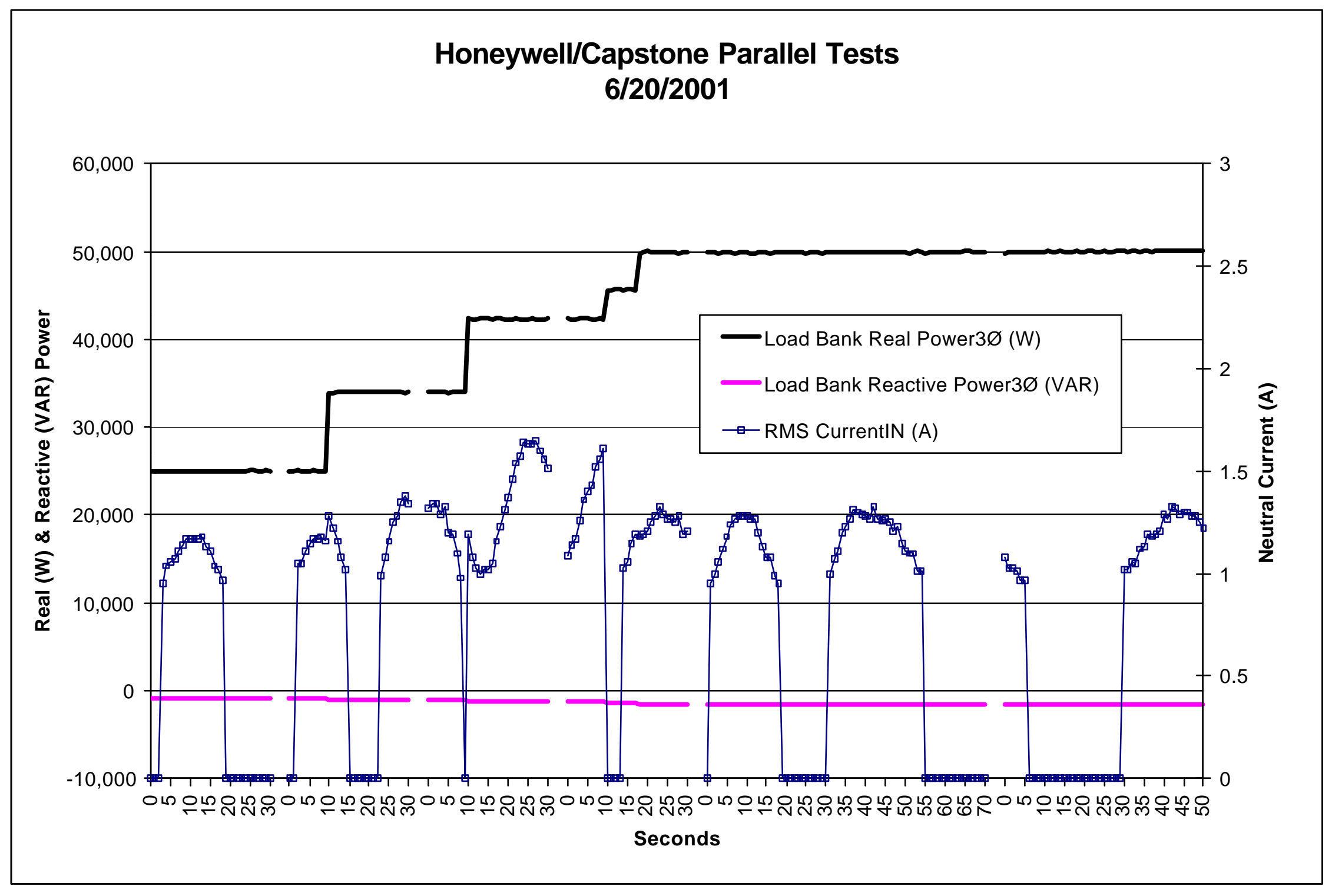

Figure H-6: Ramp Up Load Bank Power and Start Grid-connect MTG - Power and Neutral Current 


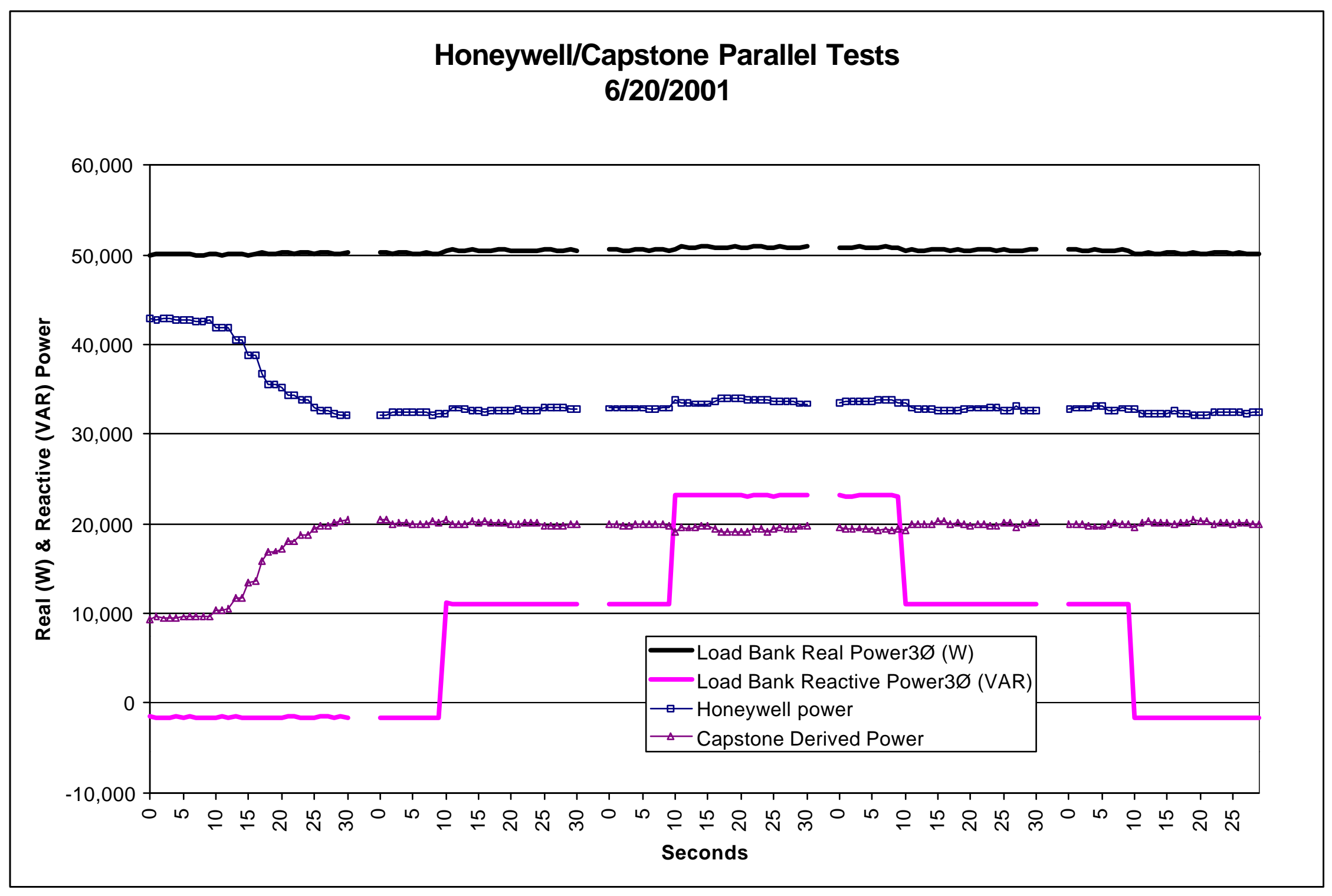

Figure H-7: Increase Grid-connect Generation and Ramp Reactive Power 


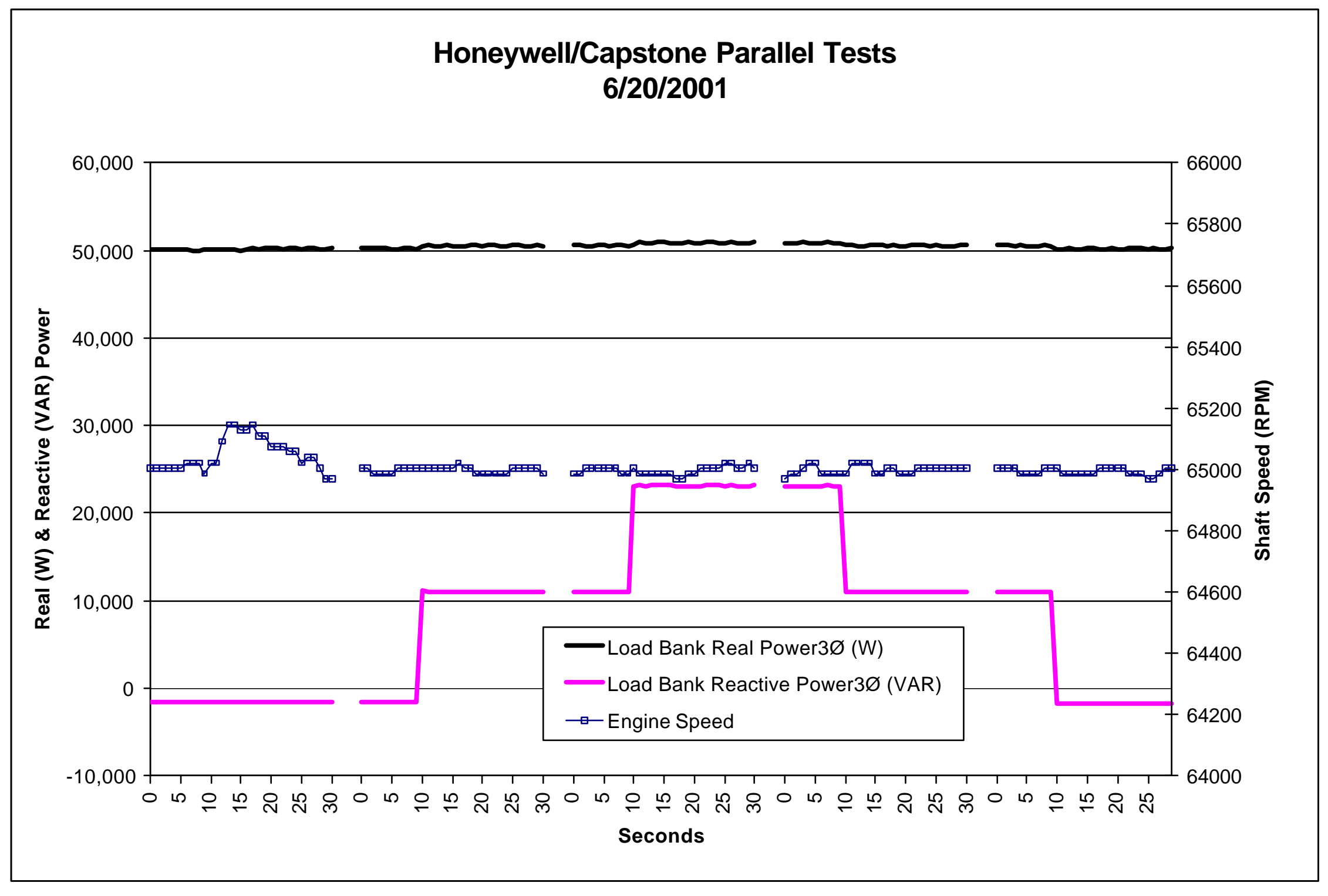

Figure H-8: Increase Grid-connect Generation and Ramp Reactive Power - Power and Shaft Speed 


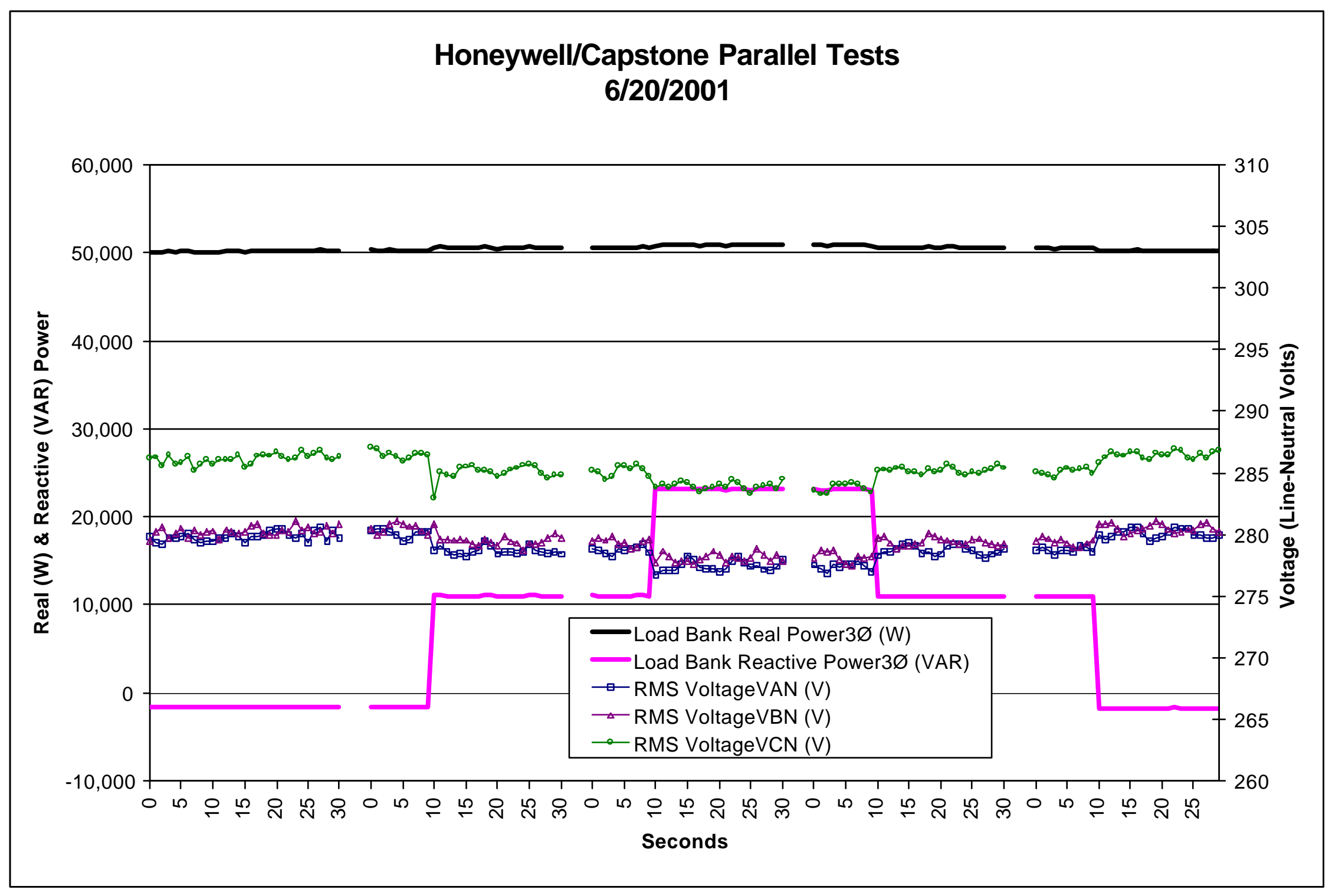

Figure H-9: Increase Grid-connect Generation and Ramp Reactive Power - Power and Line-Neutral Voltage 


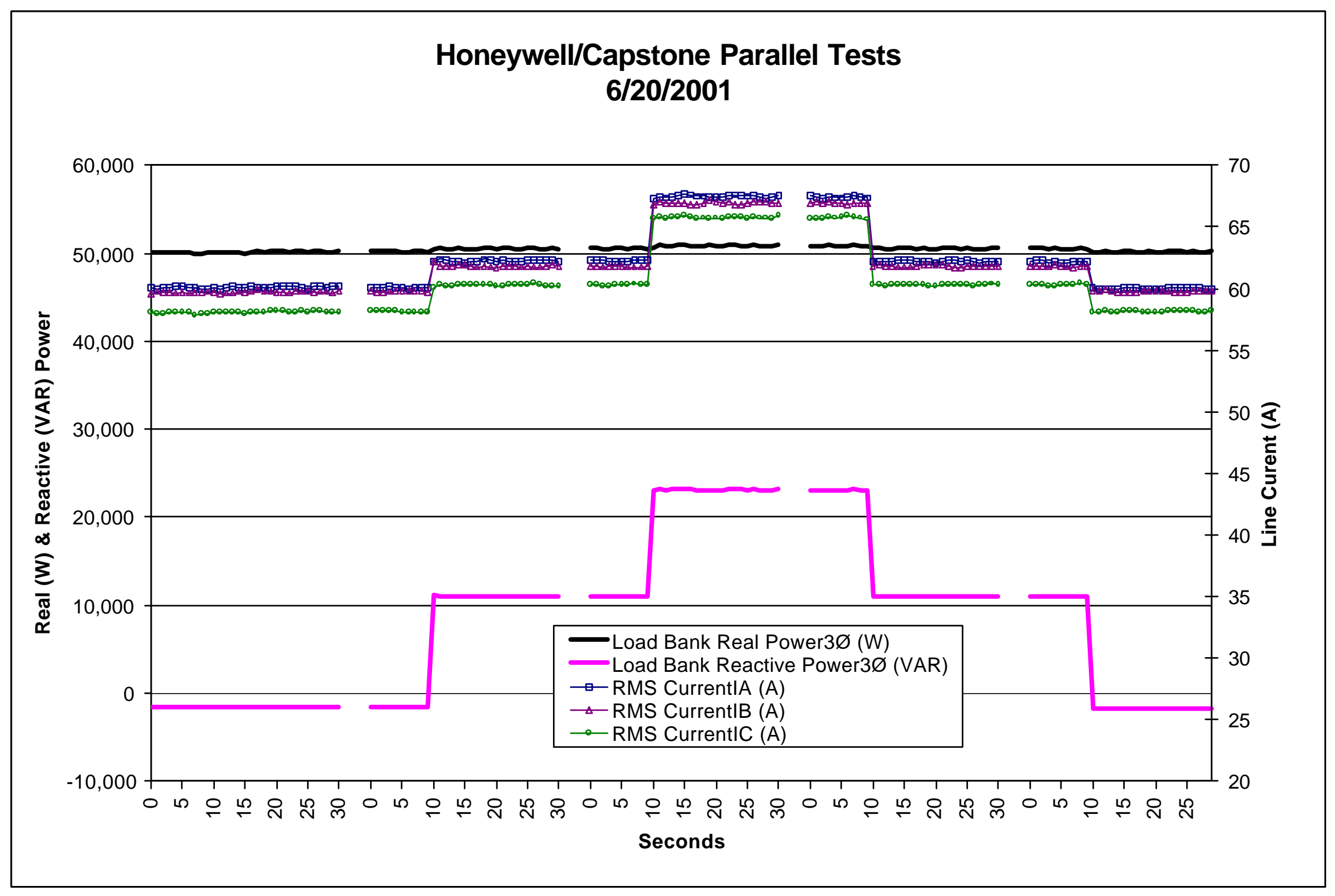

Figure H-10: Increase Grid-connect Generation and Ramp Reactive Power - Power and Line Current 


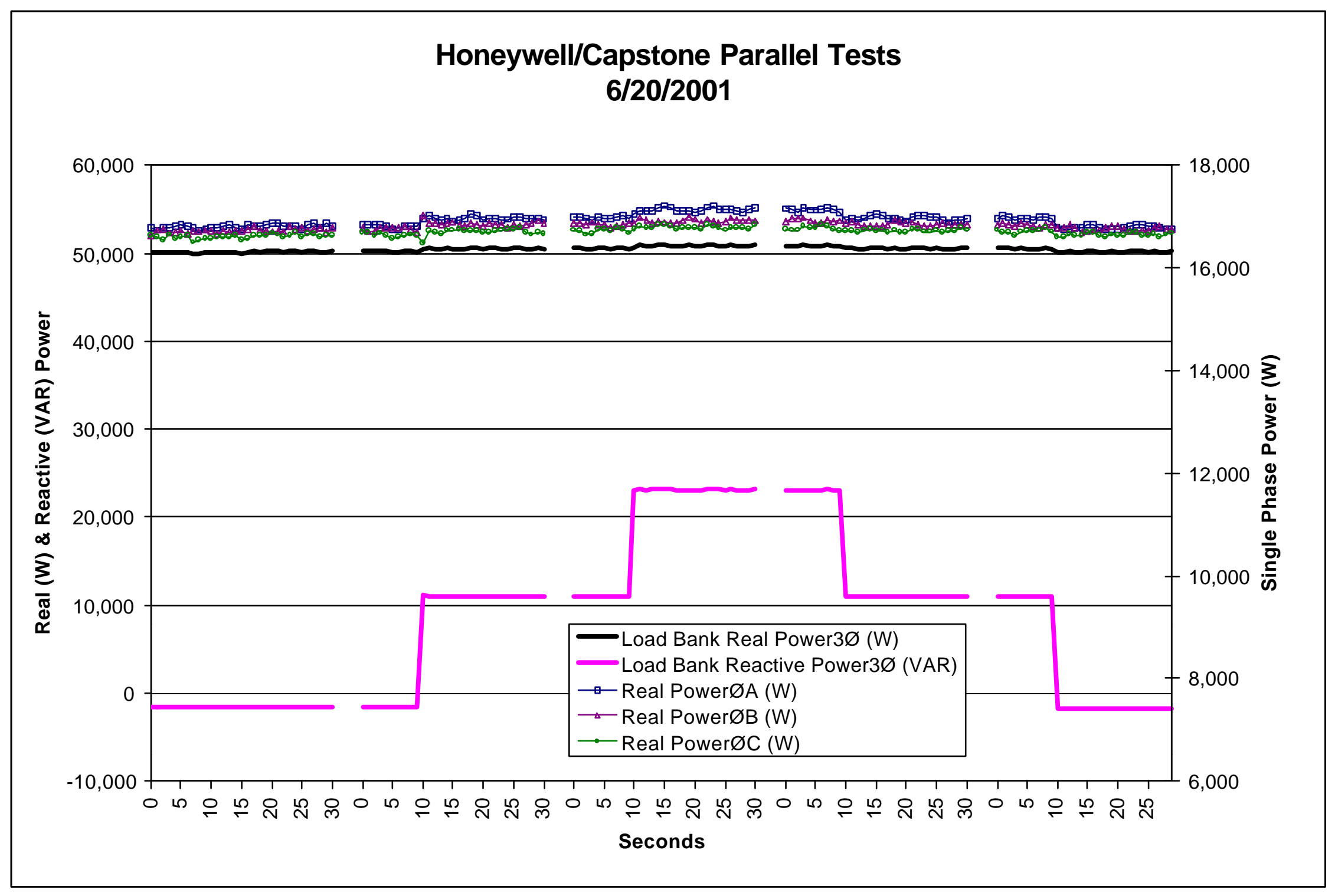

Figure H-11: Increase Grid-connect Generation and Ramp Reactive Power - Power and Single Phase Power 


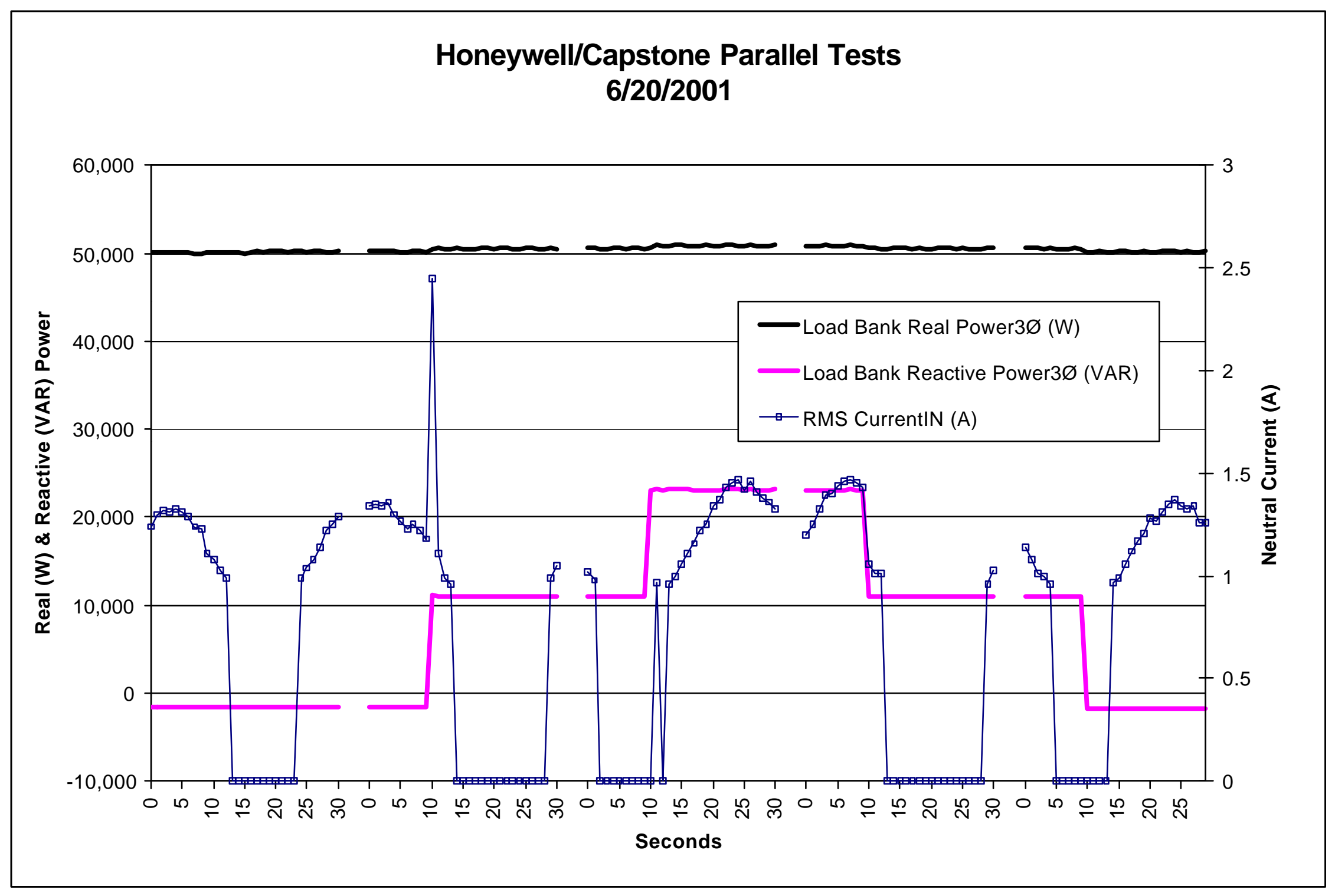

Figure H-12: Increase Grid-connect Generation and Ramp Reactive Power - Power and Neutral Current 


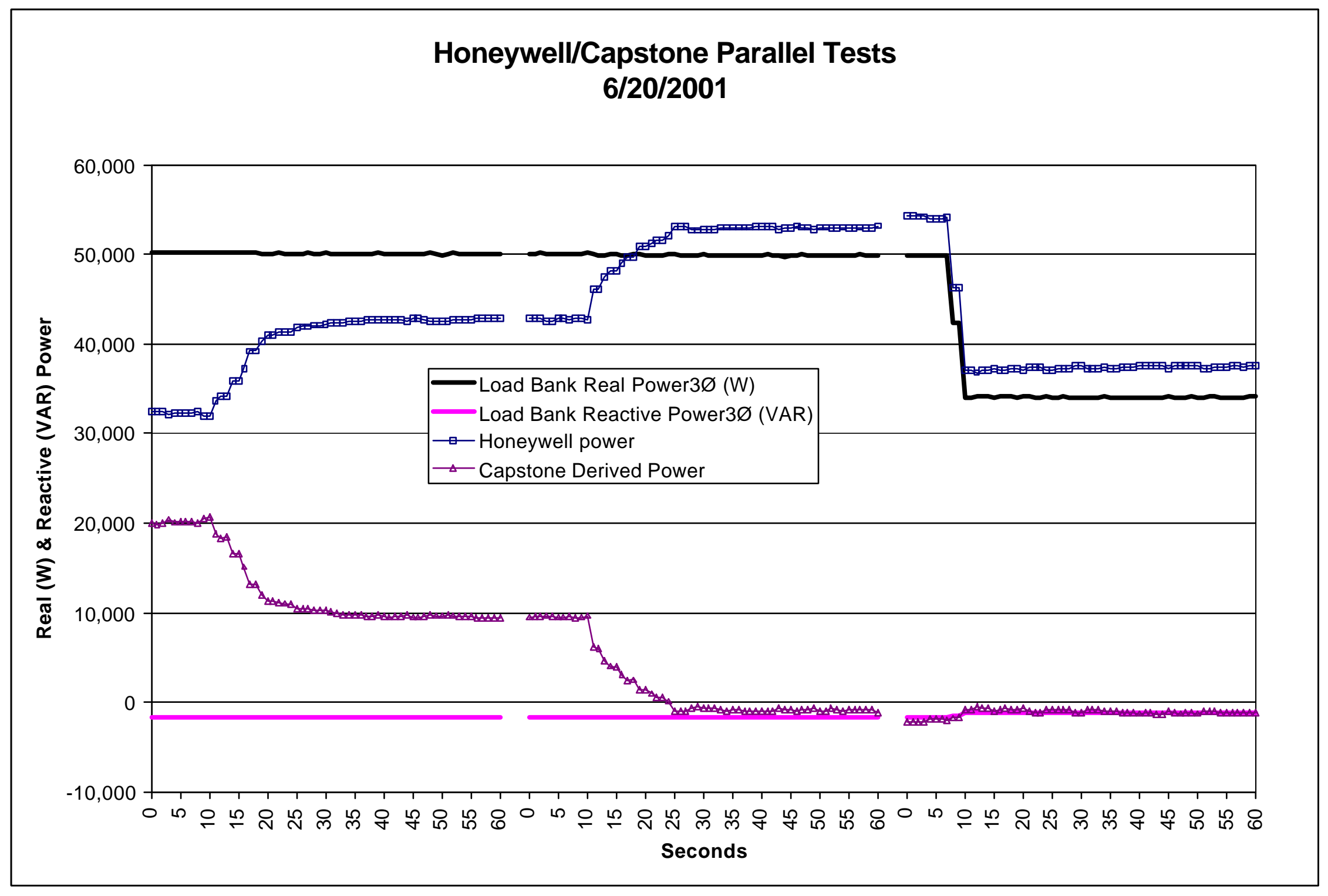

Figure H-13: Reduce Grid-connect Generation and Reduce Load Bank Power 


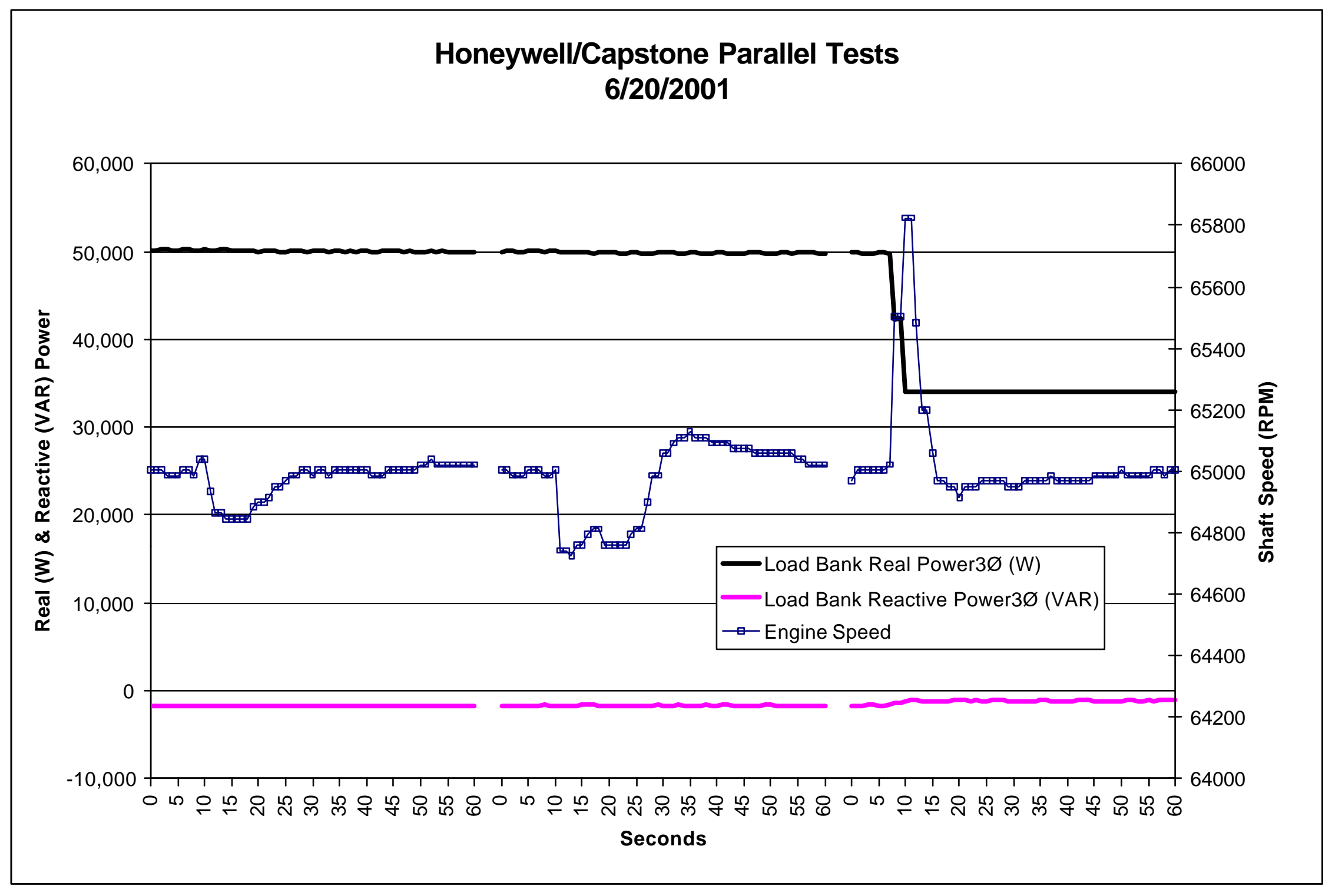

Figure H-14: Reduce Grid-connect Generation and Reduce Load Bank Power - Power and Shaft Speed 


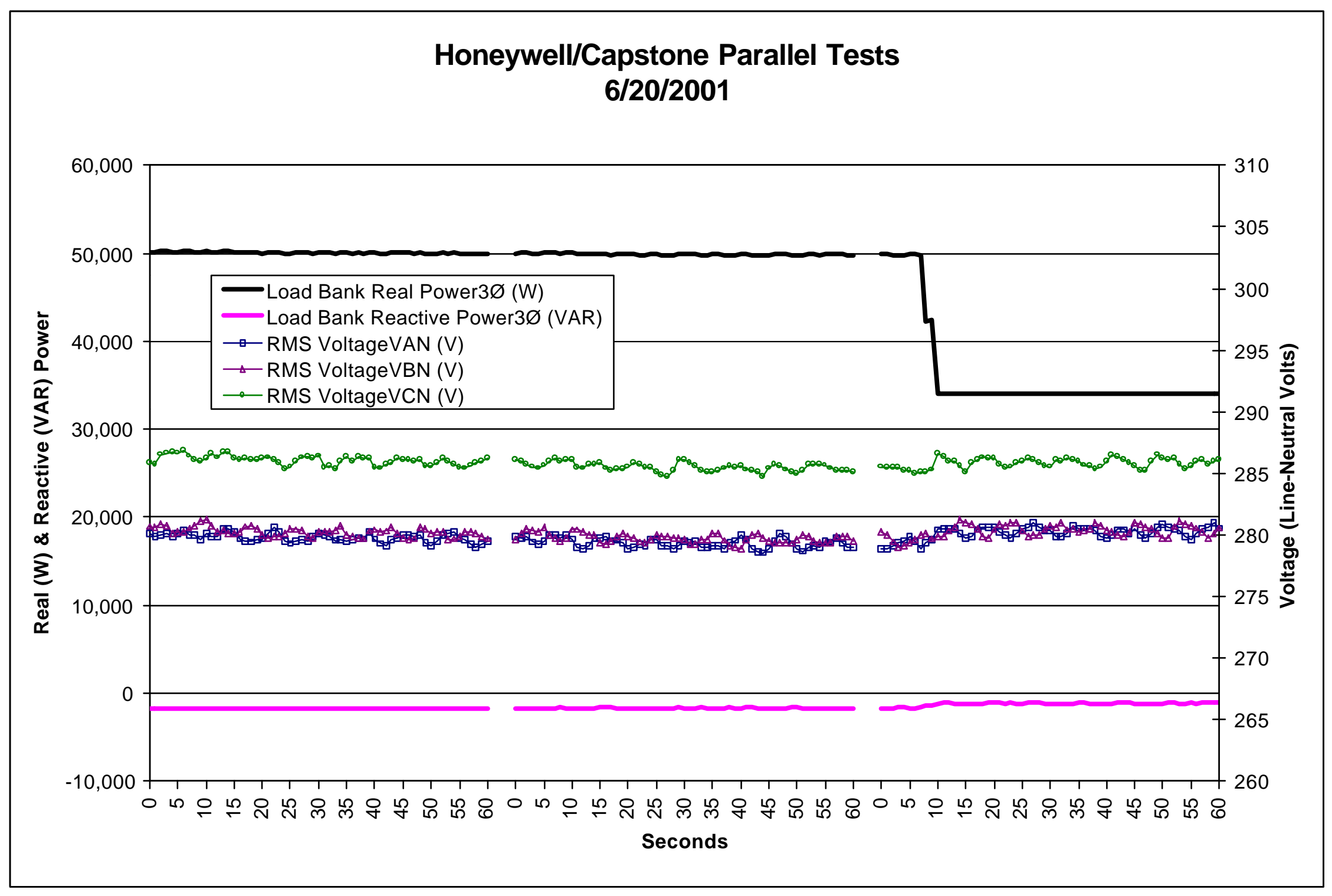

Figure H-15: Reduce Grid-connect Generation and Reduce Load Bank Power - Power and Line-Neutral Voltage 


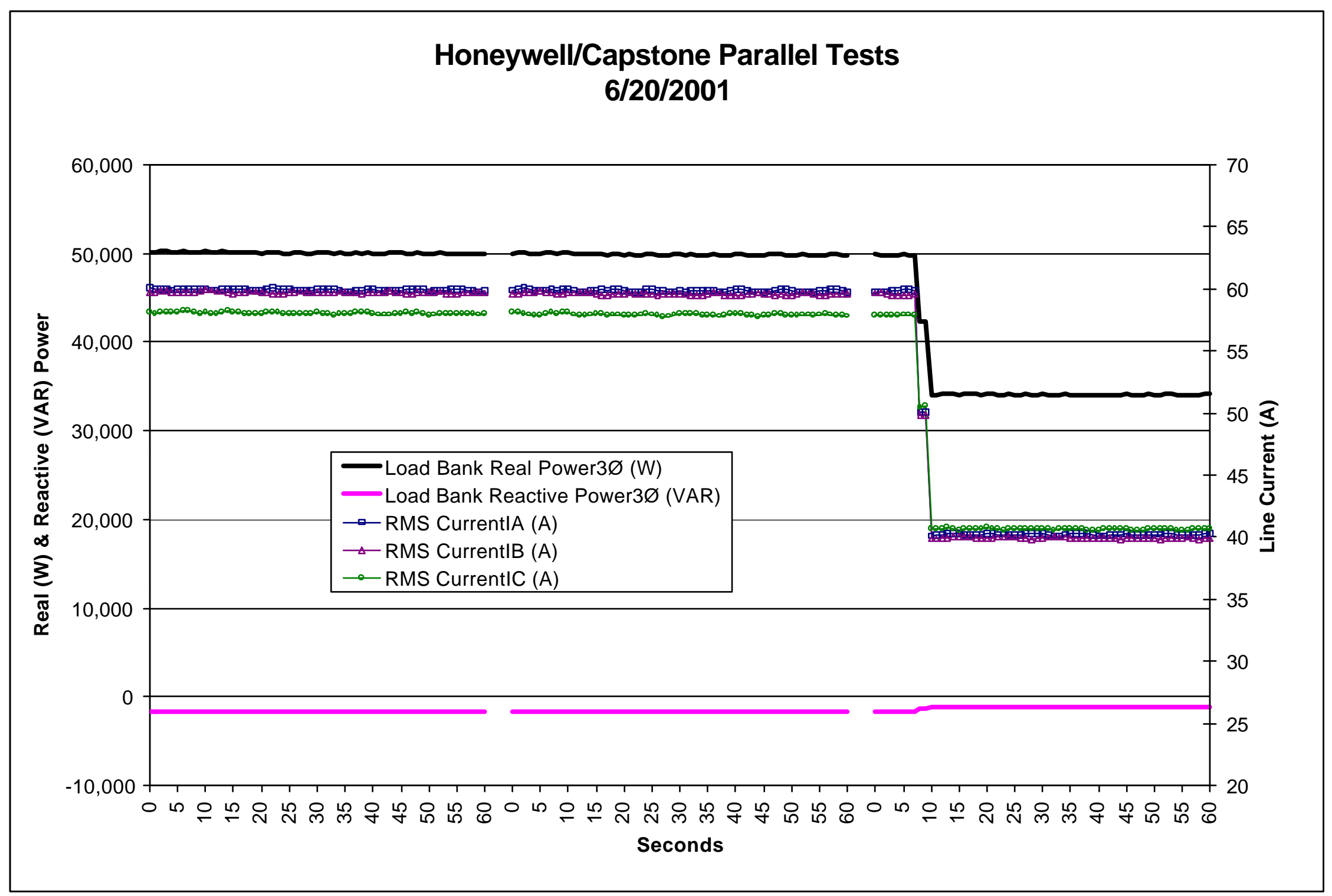

Figure H-16: Reduce Grid-connect Generation and Reduce Load Bank Power - Power and Line Current 


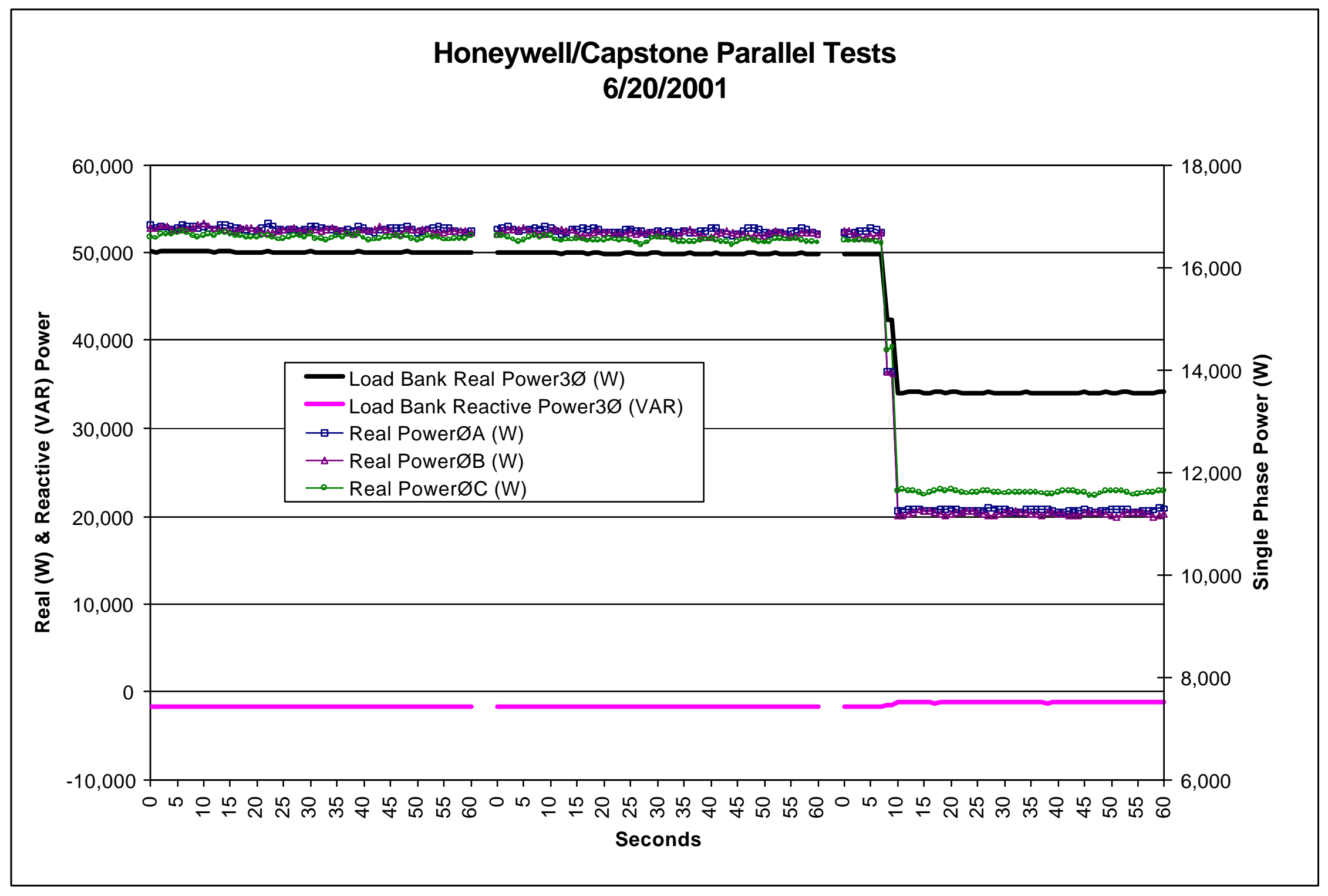

Figure H-17: Reduce Grid-connect Generation and Reduce Load Bank Power - Power and Single Phase Power 


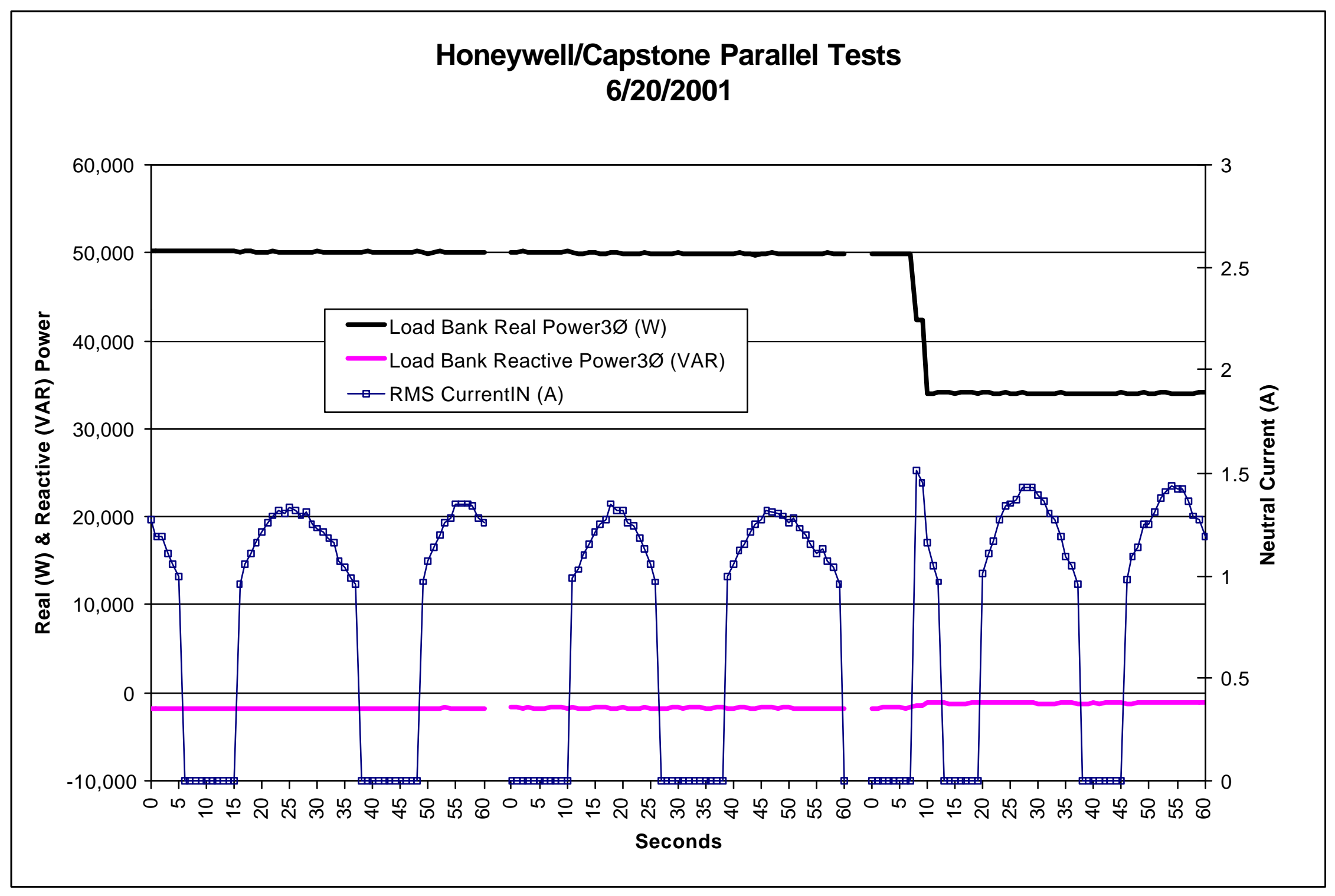

Figure H-18: Reduce Grid-connect Generation and Reduce Load Bank Power - Power and Neutral Current 